INSTITUTO DE ARQUITETURA E URBANISMO UNIVERSIDADE DE SÃO PAULO

IAU - USP

\title{
AUTOMAÇÃO DE PROCESSOS DE PROJETO E PROGRAMAÇÃO EM BIM: DYNAMO, PYTHON E C\#
}

11011011011100101011011101101110101001010110111010100101011011011011011 0110110110110101001010110111010100101011011101011011101101101101

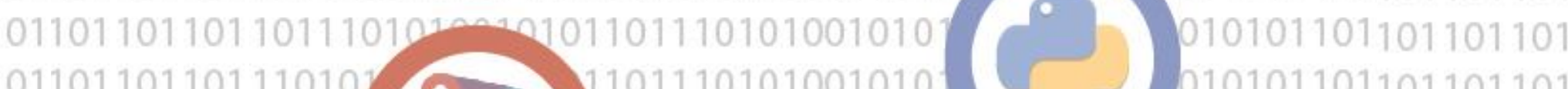
011011011011101010110111010100101010010101101101101101

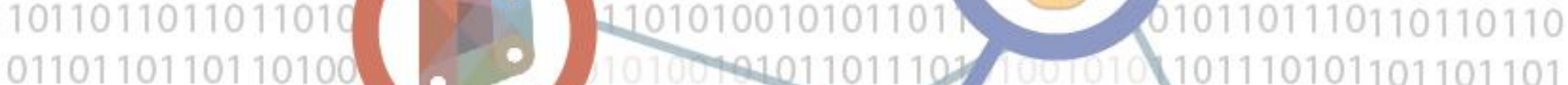
0110110110110100 • \& 01001001001001010 _ 10101001001001001 $10010010010010110111 / 1010 / 0101101 / 01010 / 0107+01101 / 01010010010010$ $10110110110110111010 / 001010 / 10101001 / 1011011101070110110110$ 01101101101111010100 /

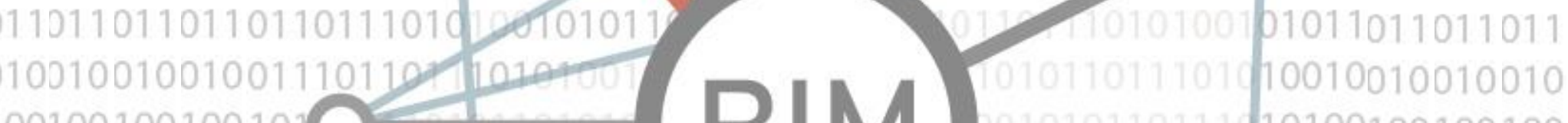
100100100100101 011011011011010110 . 0100100100100110111018

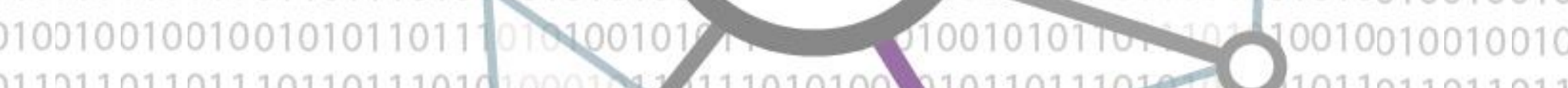

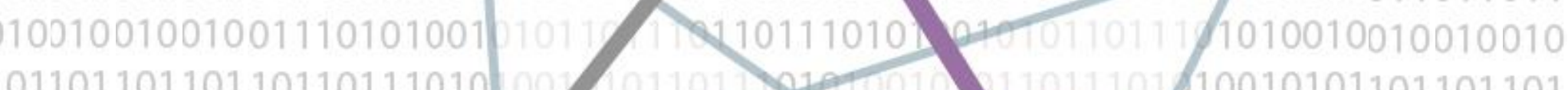

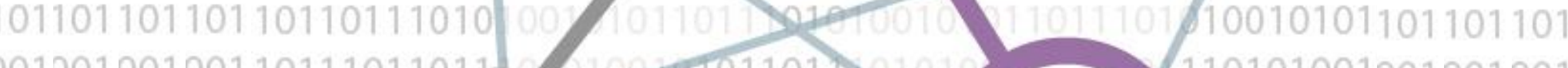
01001001001001011011101010010101101110 100100100100101011011 1010010101101110101 101110101101101101 010010010010010101101110101001010110111010100 1110101001001001001 01101101101010110111010100010110111010100101011011101010010101101101101

PAULO CÉZAR PEIXOTO DE SENA

SÃO CARLOS - SP 2019 

PAULO CÉZAR PEIXOTO DE SENA

\section{AUTOMAÇÃO DE PROCESSOS DE PROJETO E PROGRAMAÇÃO EM BIM: DYNAMO, PYTHON E C\#}

\section{Versão Corrigida}

Dissertação apresentada ao Programa de PósGraduação do Instituto de Arquitetura e Urbanismo da Universidade de São Paulo, como parte dos requisitos para obtenção do título de Mestre em Arquitetura e Urbanismo.

Área de concentração: Arquitetura, Urbanismo e Tecnologia

Orientador: Prof. Dra. Anja Pratschke

SÃO CARLOS - SP

2019 


\section{AUTORIZO A REPRODUÇÃO TOTAL OU PARCIAL DESTE TRABALHO, POR QUALQUER MEIO CONVENCIONAL OU ELETRÔNICO, PARA FINS DE ESTUDO E PESQUISA, DESDE QUE CITADA A FONTE}

Ficha catalográfica elaborada pela Biblioteca do Instituto de Arquitetura e Urbanismo com os dados fornecidos pelo(a) autor(a)

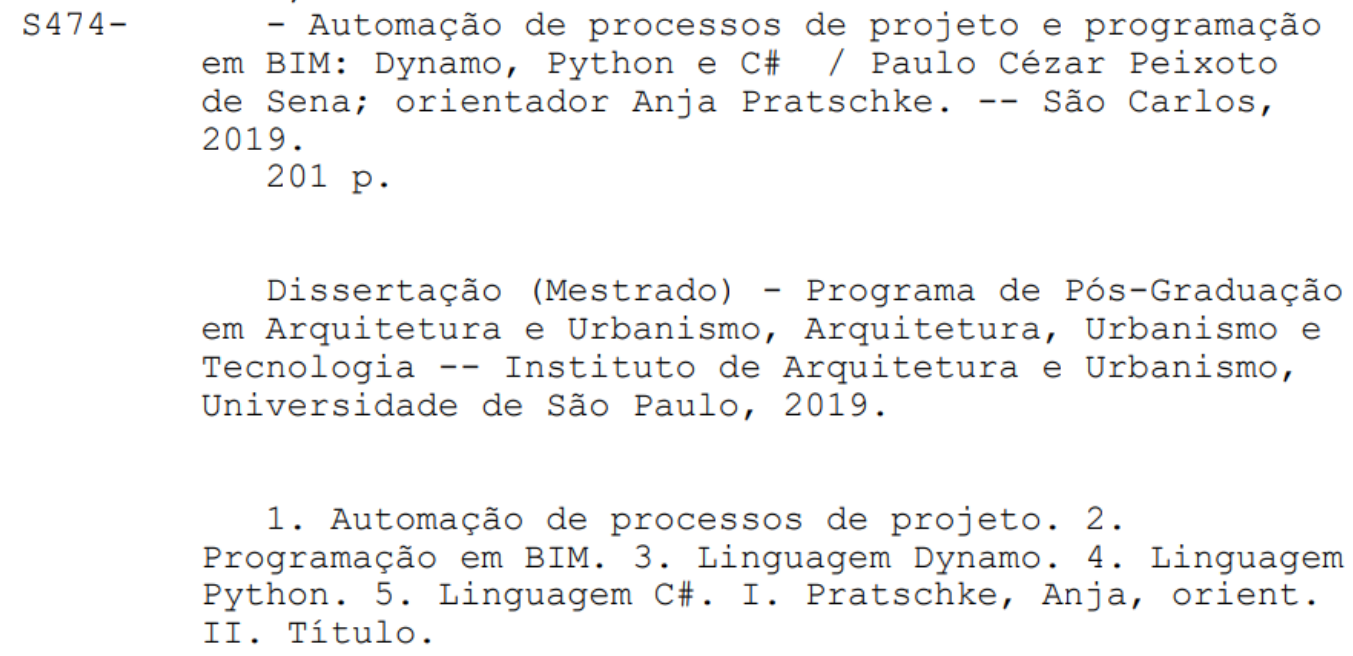

Bibliotecária responsável pela estrutura de catalogação da publicação de acordo com a AACR2:

Brianda de Oliveira Ordonho Sígolo - CRB - 8/8229 
SENA, P. C. P. 2019 - Automação de processos de projeto e programação em BIM: Dynamo, Python e C\# dissertação (Mestrado em Arquitetura e Urbanismo) Instituto de Arquitetura e Urbanismo, Universidade de São Paulo, São Carlos, 2019

\section{FOLHA DE JULGAMENTO}

Candidato(a): Paulo Cézar Peixoto de Sena

Título da dissertação: "Automação de processos de projeto e programação em BIM: Dynamo. Python e C\#"

Data da defesa: 29/11/2019

Orientadora: Profa. Dra. Anja Pratschke

Comissão Julgadora:

Resultado:

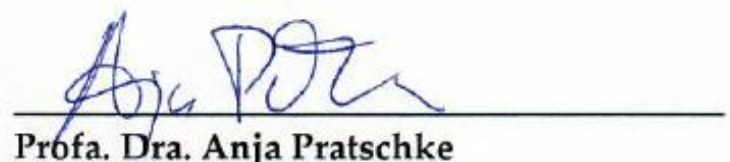

(IAU/USP)

Não votante

Prof. Dr. Marcio Minto Fabricio

(IAU/USP)

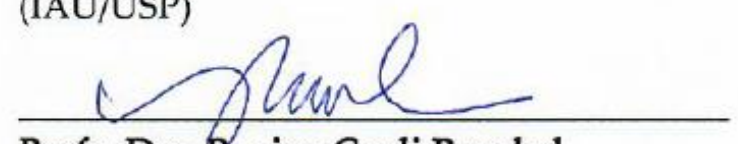

Profa. Dra. Regina Coeli Ruschel

(UNICAMP)

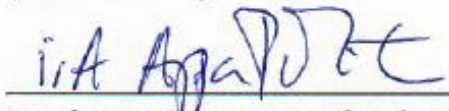

Prof. Dr. Jarryer Andrade De Martino

APROVAPO

(UFES)

Coordenador e Presidente da Comissão de Pós-Graduação do Programa de PósGraduação em Arquitetura e Urbanismo: Prof. Dr. Tomás Antonio Moreira. 



\section{AGRADECIMENTOS}

O período de minha passagem pelo curso de Pós-graduação em Arquitetura e Urbanismo desta instituição foi muito gratificante. Entregar o produto final desta rica experiência e ter tido a oportunidade de lidar com pessoas tão generosas me traz um sentido de gratidão à toda instituição. No entanto, não poderia deixar de citar nominalmente aqueles que estiveram mais próximos dessa jornada, primeiramente a minha orientadora, Profa. Dra. Anja Pratschke, sem a qual essa jornada simplesmente não teria acontecido. Meus sinceros agradecimentos pelos seus ensinamentos, orientações e apoio que fizeram com que eu chegasse até aqui. Também gostaria de agradecer a todos os professores do IAU que colaboraram no aprofundamento dos meus conhecimentos sobre BIM, dando a oportunidade para a discussão do tema com outros colegas.

Em nome de Flavia, Mara e Brianda, gostaria de deixar os meus agradecimentos pela forma simpática, atenciosa e prestativa pela qual sempre fui atendido por todos os colaboradores do IAU - USP. Quero deixar também minhas estimas aos amigos profissionais que fiz durante esse tempo, e ao colega Dr. Lucas Melchiori Pereira, que muito colaborou com as discussões sobre o tema aqui proposto. Não posso deixar de agradecer também ao time da Sena Arquitetura, que sempre agarrou os desafios do escritório enquanto tive que me dedicar ao mestrado.

Finalmente, relembrar com gratidão que eu nunca estou sozinho nos meus projetos pois minha família sempre está ali para me apoiar: Tininha, Paulinha, Anete, Leda, Lula, Jonga, Matheus, Lívia e Tavinho.

Por último, deixei para falar de uma pessoa que não merece apenas meu agradecimento, mas minhas honras: meu filho mestrando Tito Ceci de Sena. Além de meu colega de mestrado, é meu sócio, meu amigo e parceiro de todas as horas. Tito foi uma fonte inspiradora para essa dissertação e nossas discussões sobre o BIM são intermináveis. Ele me faz crescer como profissional, sempre mesclando a força da juventude com a vivência dos anos passados. Muito obrigado, filho! 

"Não é o mais forte que sobrevive, nem o mais inteligente, mas o que melhor se adapta às mudanças". 



\section{RESUMO}

SENA, P. C. P. 2019 - Automação de processos de projeto e programação em

BIM: Dynamo, Python e C\# dissertação (Mestrado em Arquitetura e Urbanismo) Instituto de Arquitetura e Urbanismo, Universidade de São Paulo, São Carlos, 2019.

O momento histórico que vivemos é o reflexo das demandas geradas pela sociedade e seus atores. Demandas que nem sempre podem ser atendidas de forma imediata, mas apontam os caminhos a serem trilhados no sentido de atendê-las. A sociedade sempre buscou a automação para a melhoria de seus processos produtivos e hoje temas como Indústria 4.0 e Inteligência Artificial fazem parte do nosso cotidiano. $\mathrm{Na}$ arquitetura, a modelagem paramétrica já é uma realidade e o BIM tem sido um dos principais propulsores da mudança de paradigmas que acontece atualmente com relação aos processos projetuais. Dentro deste contexto, se faz necessário um melhor entendimento das ferramentas computacionais que podem ser inseridas no processo do projeto arquitetônico. Esta pesquisa discute a automação de processos de projeto através da programação e são destinados três capítulos distintos, que discorrem sobre as linguagens Dynamo, Python e C\# usando o Revit e sua Application Programming Interface (API). Em cada capítulo três seções são apresentadas: a primeira discute referências sobre a linguagem; a segunda apresenta dois plugins de terceiros abordando suas estruturas de criação e/ou sua usabilidade e um plugin experimental, desenvolvido pelo pesquisador, para melhor entendimento da linguagem; a terceira seção faz uma breve avaliação sobre a linguagem de programação utilizada. Essa estrutura permitiu que uma análise sobre o uso de cada linguagem fosse feita através de um quadro comparativo, que evidencia o nível de conhecimento necessário que o projetista deve adquirir sobre uso de ferramentas para programação e 0 aprofundamento que deve obter em ciência da computação. Por fim, a contribuição mais significante que a pesquisa apresenta é mostrar caminhos a serem trilhados para aqueles que pretendem automatizar processos de projeto por meio de plugins usando tanto linguagens de programação mais simples, como o Dynamo, quanto mais sofisticadas, como o Python ou o C\#. Estes plugins podem variar desde rotinas básicas de automação até aplicativos mais robustos.

Palavras-chave: Automação, BIM, Processo de projetos, Programação, Linguagens Dynamo Python C\#. 



\section{ABSTRACT}

SENA, P. C. P. Design process automation and programming using BIM: Dynamo, Python and C\#. dissertation (Architecture and Urban Planning Masters Degree) - Instituto de Arquitetura e Urbanismo, Universidade de São Paulo, São Carlos, 2019.

The historical moment we are living is a reflection of the various demands generated by society. These demands cannot always be achieved immediately, but act as drivers of change, providing goals to be met through research and development on various subjects. Society has always strived for automation to improve its production processes and nowadays subjects like Industry 4.0 and artificial intelligence are more present than ever in our day to day lives. Parametric modelling is already a reality in architecture and BIM is one of the main forces driving the current paradigm shift in design processes. Within this context, a better understanding of the computational tools that can be used in the architectural design process is vital. This research discusses design automation through programming it was dedicated three specific distinct chapters, using Dynamo, Python, and C\# languages combined with Revit and its Application Programming Interface (API). Each chapter is divided in three sections: the first one discusses references regarding each language; the second discusses the usability and creation frameworks of two third-party plugins and presents an experimental plugin developed by the researcher to provide a more in-depth study of the language; in the third section a brief assessment of the programming language used is presented. This structure allowed the analysis of each language through a comparative basis, which shows the level of programming knowledge required from the designer in each language. The most significant contribution of this research is to show paths that may guide any user that desires to automate design processes through plugins using both simpler programming languages like Dynamo or more sophisticated ones like Python or $\mathrm{C \#}$. These plugins can range from basic automation routines to more robust applications.

Keywords: Automation, BIM, Design process, Programming, Dynamo Python C\#. 



\section{LISTA DE FIGURAS}

Figura 1 - A informação gera o modelo de construção ..................................................... 25

Figura 2 - Representação de projeto de climatização em 2D ........................................... 27

Figura 3 - Representação de projeto de climatização em 3D ........................................... 27

Figura 4 - Vistas e planilhas geradas automaticamente por um software BIM .................... 28

Figura 5 - Clash Detection feito no Navisworks, onde podemos observar as interferências entre hidráulica e estrutura ....................................................... 29

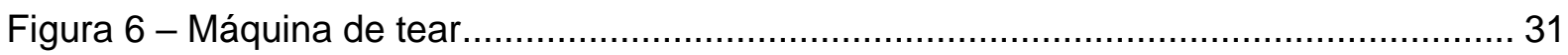

Figura 7 - Evolução histórica da Automação Industrial..................................................... 33

Figura 8 - Estrutura de banco de dados BIM com interface externa e interna ..................... 35

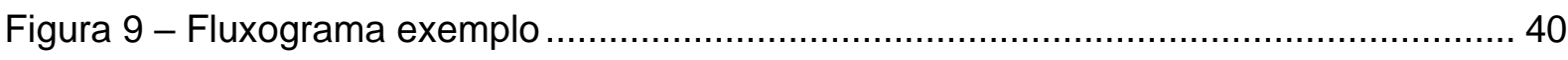

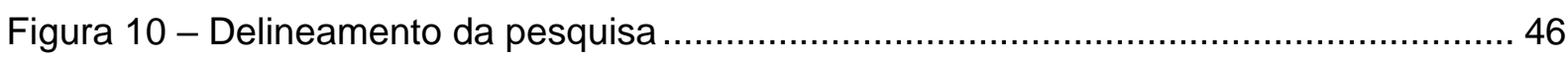

Figura 11 - Código escrito em VPL e seu similar em código escrito .................................. 53

Figura 12 - Fluxo de comunicação Dynamo x Revit ........................................................ 54

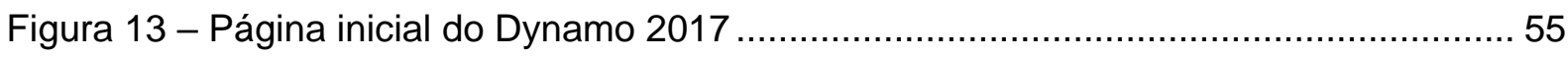

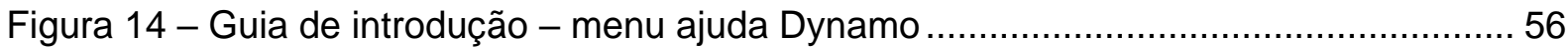

Figura 15 - Exemplo de rotina para alterar um parâmetro de peitoril do elemento

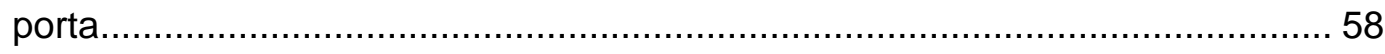

Figura 16 - Nós para a comunicação do banco de dados do Revit com softwares

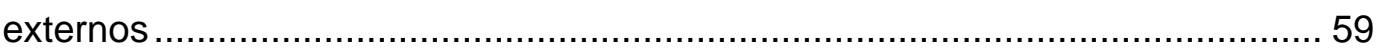

Figura 17 - Nó para escrever dados em planilha Excel ................................................ 59

Figura 18 - Ajuste de topografia automática por meio da leitura de planilha Excel .............61

Figura 19 - Rotina para experimentar o número de tesouras em telhado ............................ 62

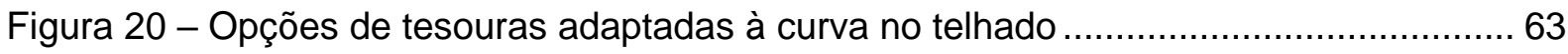

Figura 21 - Algoritmo escrito em uma VPL e a mesma codificação feita em Python ........... 64

Figura 22 - Nó em Python para input de parâmetros em todos os elementos de uma

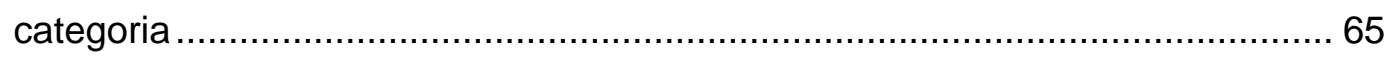

Figura 23 - Utiliza Design Script para criar um objeto a partir de pontos: Bezier e

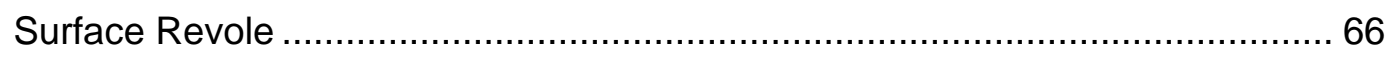

Figura 24 - Nó do Dynamo usando a linguagem DesignScript........................................ 67

Figura 25 - Code Block nó para a escrita de código Design Script .................................... 67

Figura 26 - Descrição de como criar um nó personalizado no Dynamo ................................. 68

Figura 27 - Nó customizado pacote do Lunchbox .......................................................... 70 
Figura 28 - Pacote para o Dynamo LunchBox - Linguagem de Máquina ............................. 70

Figura 29 - Estrutura e acesso aos dados de uma lista .................................................. 71

Figura 30 - Estrutura usada para extração de parâmetros de elementos no Revit............... 72

Figura 31 - Uso de nó de Dicionário - Dictionary. ValueAtKey ........................................... 73

Figura 32 - Parâmetros de Tipo - elemento janela Autodesk Revit ..................................... 75

Figura 33 - Mudança de uma instância do tipo Janela PAC_JAN_Correr 1.2×1.2m Vidro Liso 76

Figura 34 - Exemplo de modelagem de revestimento de parede com Nó WallFinishesByRoom.... 78

Figura 35 - Diagrama de fluxo de desenvolvimento da pesquisa 80

Figura 36 - Novos parâmetros criados no Revit para associá-los às informações provindas do bando de dados em Excel.

Figura 37 - Rotina para inserção de dados LCA nos elementos paredes. Impacto sobre Ocupação de Terras Agricultáveis.

Figura 38 - Rotina de exportação de totais de LCA para o modelo em função do índice de Ocupação de Terras Agrícolas.

Figura 39 - Planilha Excel com informações compiladas de um modelo BIM com relação aos indicadores de LCA

Figura 40 - Planta para análise do código de obras Ribeirão Preto 89

Figura 41 - Fluxograma da rotina de isolamento e ventilação

Figura 42 - Famílias criadas para alerta aos projetistas sobre o não atendimento ao código de obras

Figura 43 - Exemplo de resultado de uma pesquisa on line sobre loop na linguagem Python

Figura 44 - Cinco aspectos comuns a diversas linguagens de computação 106

Figura 45 - Python Shell 110

Figura 46 - Console Python Shell - Linhas de comandos executados. 112

Figura 47 - Janela do RPS importação de classes carregamento dos elementos parede na variável cl. 113

Figura 48 - Script para determinar volume das paredes inseridas 114

Figura 49 - Ribbon do pyRevit com novos comandos para o Revit. 115

Figura 50 - PyRevit botões para adição, subtração e limpeza de elementos selecionados em memória. 116

Figura 51 - Código em Python do comando MRead .118

Figura 52 - Árvore do diretório para criação de nova aba no Revit 121

Figura 53 - Script de rotina em Python - Código de Obras 122 
Figura 54 - Apresentação dos resultados da rotina experimental em Python 124

Figura 55 - Python Shell prompt de comandos - teste de sintaxe da escrita do

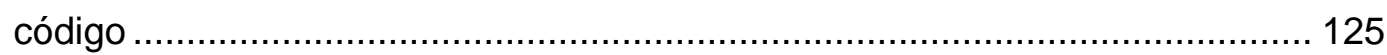

Figura 56 - Estrutura .Net para gerenciamento de diferentes tipos de linguagem ............ 133

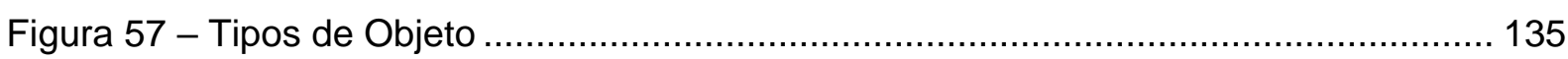

Figura 58 - Exemplo da criação de uma classe tijolos................................................... 136

Figura 59 - Propriedades de instância de uma parede e do Revit.................................... 137

Figura 60 - Microsoft Visual Studio - Projeto_exem_classe ........................................... 137

Figura 61 - Diagrama da estrutura tecnológica da criação de um Plugin ........................... 141

Figura 62 - Esquema de árvore de como buscar informações na API do Revit ................. 142

Figura 63 - Pasta de exemplos disponíveis dentro do SDK do Revit ............................... 143

Figura 64 - Esquema de janelas e busca de informações do elemento através do

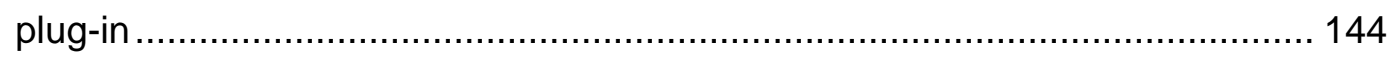

Figura 65 - Interface do usuário IDE Visual Studio ....................................................... 145

Figura 66 - Diagrama do Plugin para verificação de performance do modelo.................... 148

Figura 67 - Código de implementação dos eventos relacionados ao Ribbon do Revit ...... 150

Figura 68 - Plugin com eventos e saídas que são gravadas no arquivo texto. ................... 151

Figura 69 - Modelo para teste de performance de modelagem ........................................ 152

Figura 70 - Janela de configuração do Classification Manager ........................................ 157

Figura 71 - Tabela Excel com Classificação Customizada .............................................. 158

Figura 72 - Classificação de elementos pelo Classification Manager................................. 159

Figura 73 - Parâmetro de classificação aplicado ao elemento ........................................ 160

Figura 74 - Configurações para exportação das planilhas COBie ................................... 161

Figura 75 - Configuração de projeto no COBie Extension .............................................. 161

Figura 76 - Configuração de contatos no COBie Extension ........................................... 162

Figura 77 - Parâmetros gerados no Revit para exportação dados COBie ........................ 163

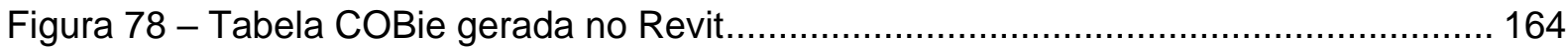

Figura 79 - Planilha Excel exportada conforme padrão COBie ........................................ 164

Figura 80 - Fluxo de informações entre API do Revit e linguagens de programação ......... 167

Figura 81 - Rotina de inserção de círculo de área mínima em função das regras municipais de Ribeirão Preto .................................................................... 169

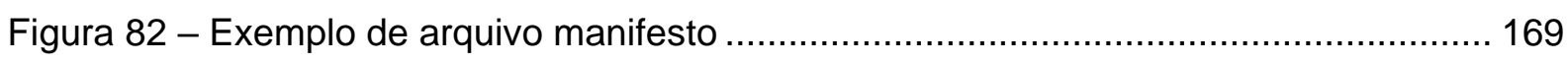

Figura 83 - Janelas capturadas da IDE do Visual Studio enquanto um código está sendo depurado

Figura 84 - Rotina que desenha um círculo na planta com diâmetro mínimo do código permitido pela legislação. 
Figura 85 - Projeto criado no Visual Studio contendo várias classes 173

Figura 86 - Rotina para coletar numa variável todos dados dos ambientes do projeto ...... 174

Figura 87 - Base de dados SQL - Janela de entrada de dados. 175 


\section{LISTA DE QUADROS}

Quadro 1 - Diferenças entre níveis de linguagem de programação ................................... 38

Quadro 2 - Exemplo de Pseudocódigo ...................................................................... 39

Quadro 3 - Conceitos de programação Woodbury .......................................................... 107

Quadro 4 - Resumo dos conceitos de programação estruturada a objeto ........................ 138

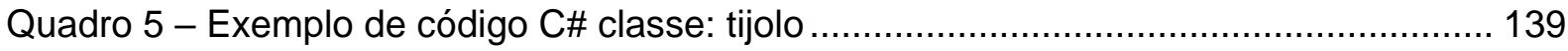

Quadro 6 - Exemplo de adição de método à classe: volume do tijolo .............................. 140

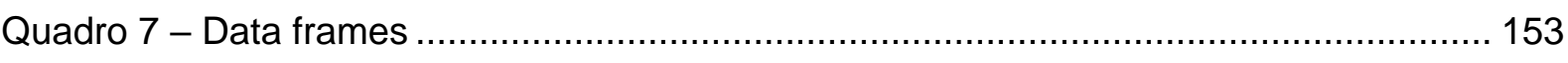

Quadro 8 - Resumo de ações coletadas pelo plugin por modelador ................................ 154

Quadro 9 - Resumo de conceitos atribuídos aos painéis do plugin.................................. 156

Quadro 10 - Comparação entre características das linguagens de programação analisadas. 182

Quadro 11 - Comparação entre as características das linguagens de programação com relação ao usuário.

\section{LISTA DE TABELAS}

Tabela 1 - As dimensões mínimas dos compartimentos em edificações residenciais 88

Tabela 2 - Planilha Excel com código de obras e dados retirados do modelo BIM. 93 



\title{
LISTA DE ABREVIATURAS E SIGLAS
}

\author{
ABNT - $\quad$ Associação Brasileira de Normas Técnicas \\ AEC - Arquitetura Engenharia, Construção \\ AECO - $\quad$ Arquitetura Engenharia, Construção e Operação \\ API - Application Programming Interface \\ BIM - Building Information Modelling \\ CLR - Common Language Runtime \\ CVS - Command Separated Values \\ CWI - National Institute for Mathematics and Computer Science in \\ Amsterdam \\ GSA - United States General Services Administration \\ ICC - International Code Council \\ IDE - Integrated Development Environment \\ IFC - Industry Foundation Classes \\ LCA - Life Cycle Assessment \\ NBR - Norma Brasileira \\ OPP - Object oriented program \\ RPS - Revit Python Shell \\ SDK - Software Development Kit \\ TXT - Formato texto \\ VB - Visual Basic \\ VPL - Visual Programming Language
}




\section{SUMÁRIO}

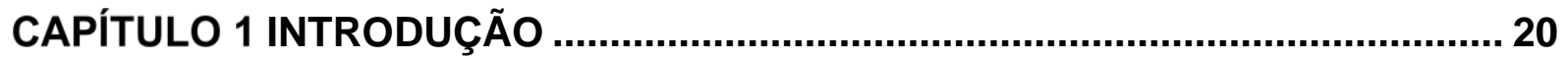

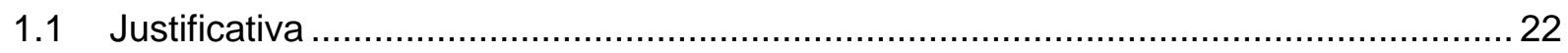

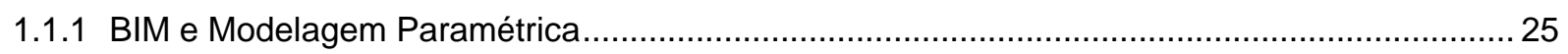

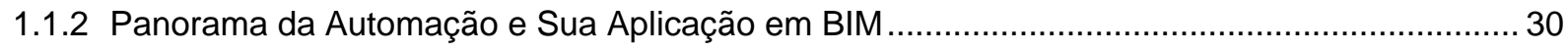

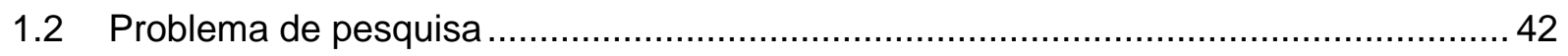

CAPÍTULO 2 OBJETIVO E MÉTODO .................................................................... 44

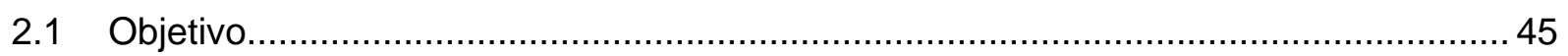

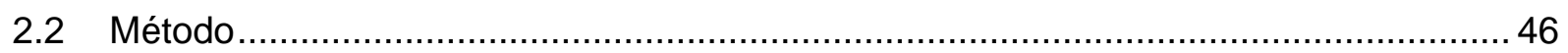

CAPÍTULO 3 AUTOMAÇÃO COM O DYNAMO ....................................................50

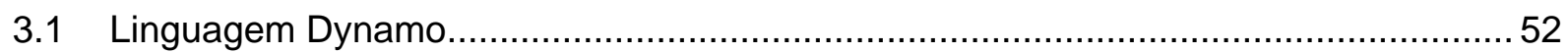

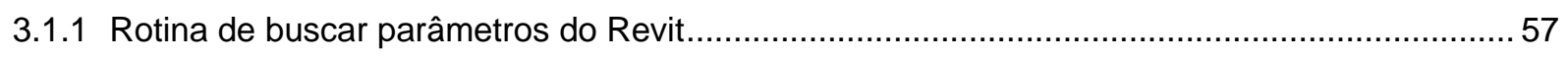

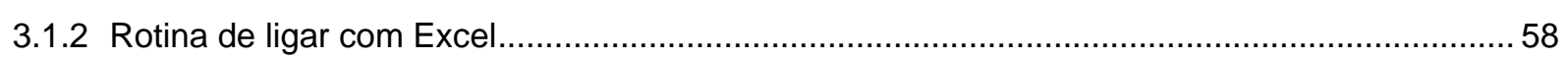

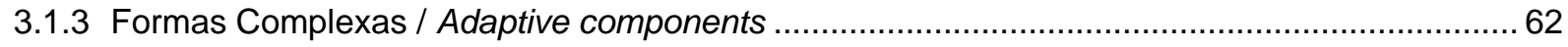

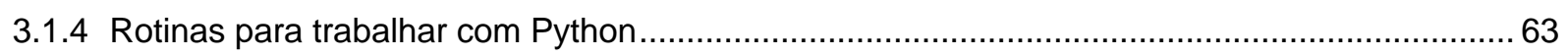

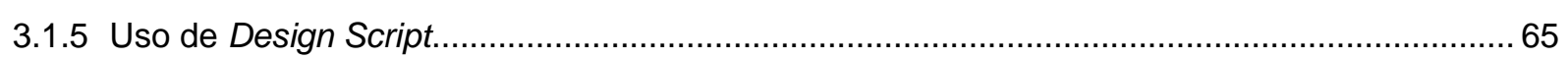

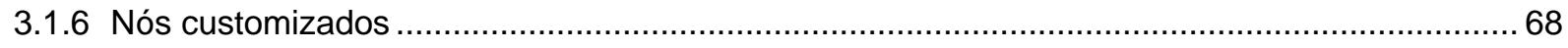

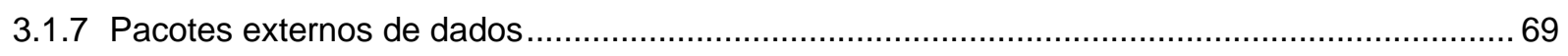

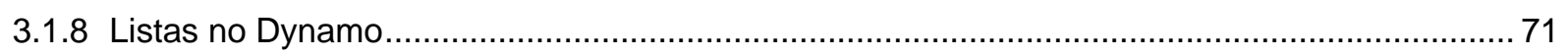

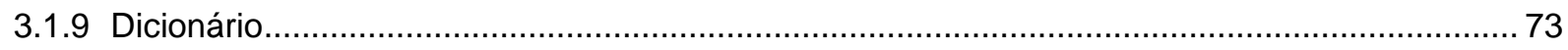

3.2 Estudos exploratórios e rotina experimental em dynamo ........................................... 74

3.2.1 Criação automática de paredes a partir do elemento ambiente ................................................. 74

3.2.2 Automação da análise do ciclo de vida do edifício ............................................................. 78

3.2.3 Estudo experimental - Checagem de código de obras - Rotina em Dynamo .............................. 85

3.3 Considerações sobre o uso de DYNAMO para automação ........................................ 94

CAPÍTULO 4 AUTOMAÇÃO COM O PYTHON .................................................. 97

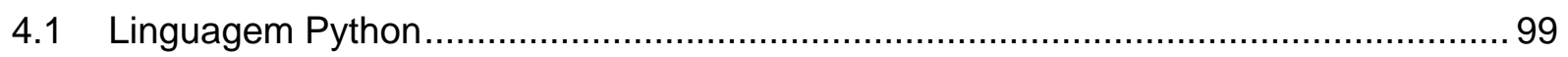

4.1.1 Modelos paramétricos e a automatização dos processos projeto ……….............................. 101

4.1.2 Habilidades para projetar usando programação + BIM …….............................................. 103

4.2 Estudos EXPLORATÓRIOS E rotina experimental em PYTHON .............................. 109

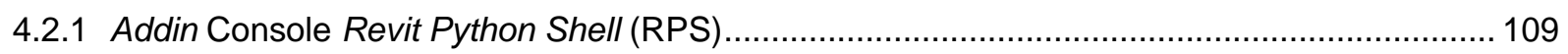

4.2.2 Addin PyRevit - Comandos acrescentados no Ribbon do Revit ............................................ 114

4.2.3 Experimento - Checagem de código de obras - Rotina em IronPython .................................. 119

4.2.4 Considerações sobre o uso do PYTHON para automação ................................................... 126 


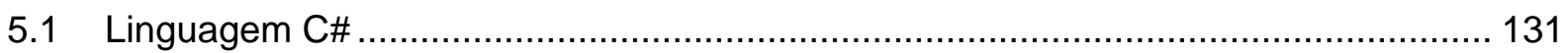

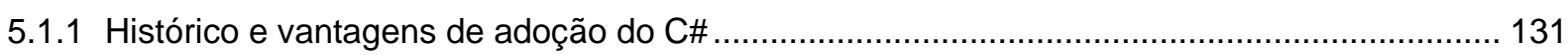

5.1.2 Linguagem orientada a objetos, classes, métodos............................................................. 134

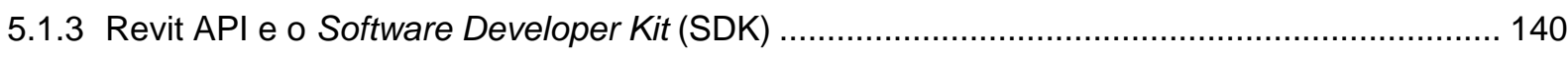

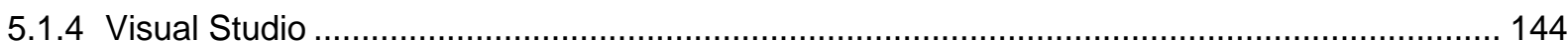

5.2 Estudos exploratórios e rotina experimental em c\#................................................ 146

5.2.1 Monitoramento de modelagem 3D através de API do Revit................................................. 146

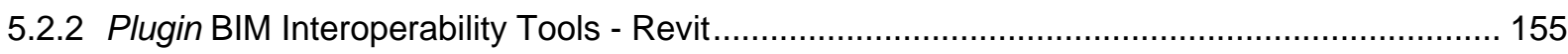

5.2.3 Experimento - Checagem de código de obras - Rotina C\# .................................................. 165

5.3 Considerações sobre o uso do C\# para automação .............................................. 176

CAPÍTULO 6 CONCLUSÃO ...........................................................................179

6.1 Considerações sobre a análise comparativa entre as linguagens de programação .. 181

6.2 Considerações sobre a análise comparativa sobre as habilidades de

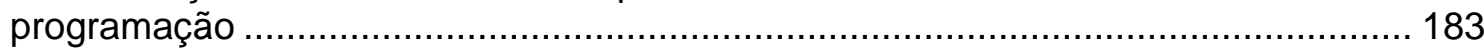

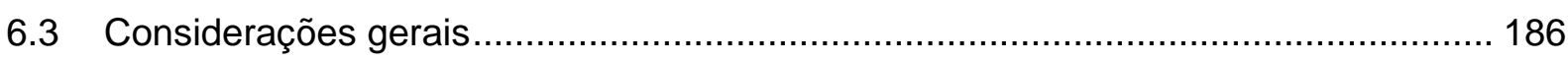

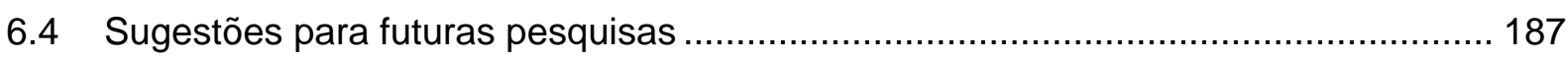

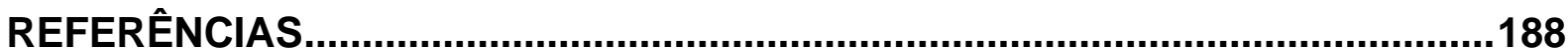






\section{PREFÁCIO}

Ao entregar minha dissertação aos 61 anos de idade, sinto-me renovado e agradecido pela rica experiência de participar da academia e estar concluindo o meu mestrado pelo IAU São Carlos. Depois de 30 anos, volto para onde tudo começou, meu interesse pelo uso do computador aplicado ao desenvolvimento de projetos em arquitetura sempre norteou meus passos. Uma pergunta clássica recorrente que me vinha a cabeça era: "Como posso melhorar este processo?" Sempre achei muito trabalhoso o ato de desenhar; nanquim, normógrafo, copiar para vegetal... Em 1982, ainda na escola de arquitetura, tive meu primeiro contato com o CAD. Comecei a trabalhar com a versão 1.8 do Autocad e, em 1985, tinha um escritório fazendo projetos totalmente em CAD. Em seguida, para automatizar processos, fiz pósgraduação em Análise de Sistemas, que hoje seria um curso de ciência da computação. Comecei a desenvolver aplicativos para mesas digitalizadoras em linguagem Lisp e desde então trabalhei na área voltada ao uso do computador auxiliando projetos.

Minha jornada com o BIM começou em 2010 quando tornei-me um entusiasta do processo e tecnologia. Como não poderia deixar de ser, logo que comecei a dominar o uso do software Revit, a busca por maneiras de automatizar processos dentro da plataforma foi natural. A incursão em busca do mestrado foi uma forma de trocar informações com novas pessoas, especialistas no assunto e estar em contato com as informações mais atuais deste processo, abrindo a possibilidade de criar uma ponte entre o uso prático do BIM no escritório e os aprendizados trazidos pela academia. Nesse sentido, todas as expectativas foram superadas, aliando os conhecimentos adquiridos ao longo de minha vida profissional às aplicações práticas no escritório e ao grande embasamento teórico que a academia proporcionou. Isso me fez decidir por escrever um misto de teoria, a partir do conhecimento já adquirido, e das aplicações práticas sobre programação e automação na arquitetura, usando as três linguagens de programação mais comuns para interagir com a API do Revit. Este caminho me levou à investigação e pesquisa do uso destas soluções e serviu como base para a elaboração desta dissertação, que tem como objetivo indicar um trajeto a ser seguido com referências e com os principais conceitos que devem ser adquiridos por aqueles que pretendem trilhar o mesmo caminho. 



\section{CAPÍTULO 1 INTRODUÇÃO}

"Uma ferramenta nada mais é do que a extensão da mão do homem, e uma máquina nada mais é do que uma ferramenta complexa. Aquele que inventa uma máquina aumenta o poder do homem e o bem-estar da humanidade." Henry Ward Beecher (1813-1887) 
A indústria de Arquitetura Engenharia, Construção e Operação (AECO) tem apresentado nas últimas décadas significativas mudanças em tecnologia e processos de projeto. Entre essas iniciativas destaca-se o paradigma da modelagem da informação da construção, ou Building Information Modelling (BIM), em função da expressiva influência acadêmica e mercadológica de seus conceitos, termos, tecnologia, processos e competências, que abrangem todo o ciclo de vida do edifício, da concepção e viabilidade até o gerenciamento de operação, uso e manutenção.

O BIM pode ser compreendido como parte de um movimento mais abrangente de informatização, de integração das informações e de gerenciamento do conhecimento de sistemas produtivos, possíveis somente a partir do aumento do poder computacional. Entre as possibilidades de aplicação dos recursos computacionais, destaca-se a capacidade de automatizar processos, de forma a reduzir trabalho e evitar erros humanos e desperdícios de recursos naturais (EASTMAN et al., 2012, p. 21) ${ }^{1}$.

Dentre as formas mais sofisticadas de novas tecnologias de informática, o desenvolvimento de inteligência artificial já é observado em alguns setores produtivos como automobilístico, aeroespacial, farmacêutico, todos relacionados ao gerenciamento de trânsito, urbanismo, logística e outros. De forma menos radical, porém bastante consolidada, também se observam significativos avanços de integração informacional no setor AECO, promovidos graças a uma ação coordenada de promoção do BIM por parte de representações setoriais, agentes públicos, desenvolvedores de software e academia, para viabilizar a obtenção de benefícios de novas ferramentas computacionais da automação, que auxiliam os processos que envolvem a construção civil.

\footnotetext{
${ }^{1}$ Charles M. Eastman é professor nas Faculdades de Design e Ciência da Computação do Georgia Institute of Technology. Especialista nas áreas de modelagem de informações de construção, modelagem sólida e paramétrica, bancos de dados de engenharia e modelos de produtos e interoperabilidade.
} 


\subsection{JUSTIFICATIVA}

A execução de um projeto é uma tarefa difícil que envolve a resolução de vários problemas e um contexto ambíguo e social complexo pois, além dos aspectos estéticos e formais, faz-se necessário promover a colaboração entre várias disciplinas para resolver interfaces (KLEINSMANN; VALKENBURG, 2008; PEREIRA; HIROTA; FABRICIO, 2017; VALKENBURG, 2000)².

Além disso, no caso de projetos arquitetônicos, deve se respeitar um conjunto de regras construtivas impostas por meio de normas, códigos, leis, dentre outras formas de regulamentações:

O projeto arquitetônico é complexo, pois envolve soluções técnicas e artísticas, resultado da manipulação criativa de diferentes elementos como funções, volume, espaço, textura, luz, materiais, componentes técnicos e custos, desempenho e tecnologia construtiva. Não há um método único para resolver os problemas, pois cada caso é único e precisa de soluções específicas. Diferentes métodos, ferramentas, técnicas e formas de representação são necessários para lidar com diversas variáveis: sociais, culturais, legais, funcionais, estéticas, econômicas, psicológicas, tecnológicas, de conforto ambiental; e com n diferentes escalas: regionais, urbanas, do edifício e do objeto. Por isso, a equipe de projetos tornou-se multidisciplinar e conta com a participação de especialistas de diferentes áreas (KOWALTOWSKI et al., 2011, p. 21) ${ }^{3}$.

Diante de tais características, estudos que visam reduzir erros inerentes à complexidade do ato de projetar e viabilizam maior qualidade do resultado final são cada vez mais recorrentes no setor de AECO (MORAIS; GRANJA; RUSCHEL, 2015; PEREIRA et al., 2015) ${ }^{4}$. Uma das correntes de ação neste sentido é promovida por profissionais pesquisadores, desenvolvedores e operadores de BIM.

\footnotetext{
${ }^{2}$ Dra. Maaike Kleinsmann é professora em design da faculdade IDE (EUA). Tem mais de quinze anos de experiência na pesquisa de projetos de design colaborativo e em design para inovação. Sua pesquisa atual é sobre o Design Thinking na inovação digital na área da saúde e atualmente é a líder do Laboratório de Cardiologia da Faculdade de Design Industrial e Engenharia. Tem ampla experiência na organização e coordenação de consórcios público-privados.

${ }^{3}$ Doris Catharine Cornelie Knatz Kowaltowski foi Professora Titular pela Universidade Estadual de Campinas, UNICAMP; É Mestre em Arquitetura pela Universidade da Califórnia em Berkeley e obteve o Doutorado (PhD) em Arquitetura pela mesma Universidade. Formou-se em Arquitetura pela Universidade de Melbourne (Austrália) com o diploma revalidado no Brasil. Atua como professora aposentada colaboradora no Departamento de Arquitetura e Construção da Faculdade de Engenharia Civil, Arquitetura e Urbanismo (FEC) da UNICAMP.

${ }^{4}$ Regina Ruschel é Engenheira Civil, Mestre em Mecânica dos Solos, Doutora em Engenharia Elétrica e da Computação e Livredocente em Projeto Auxiliado pela Universidade Estadual de Campinas. Foi professora da UNICAMP de 1986 a 2016 . É bolsista de Produtividade do CNPq. Desenvolve pesquisa em Modelagem da Informação da Construção.
} 
Apontada por autores que abordam o BIM como uma caracterização pertinente a esse tipo de abordagem (LI, 2017, p. 202), podemos também citar o BIM como descrito segundo os seguintes termos:

[...] Como uma tecnologia de Modelagem e um conjunto associado de processos para produzir, comunicar e analisar modelos de construção. Modelos de construção são caracterizados por:

Componentes de construção, que são representados com representações digitais inteligentes (objetos) que "sabem" o que eles são, e que podem ser associados com atributos (gráficos e de dados) computáveis e regras paramétricas.

Componentes que incluem dados que descrevem como eles se comportam, conforme são necessários para análises e processos de trabalho, por exemplo, quantificação, especificação e análise energética.

Dados consistentes e não redundantes de forma que as modificações nos dados dos componentes sejam representadas em todas as visualizações dos componentes.

Dados coordenados de forma que todas as visualizações de um modelo sejam representadas de maneira coordenada. [...] . (EASTMAN et al., 2014, p. 13)

A definição apresentada acima reforça o entendimento em torno da característica paramétrica da estrutura do banco de dados de um sistema BIM. Uma segunda definição sobre BIM é apresentada pela GSA - United States General Services Administration (2007, p. 3), que define Building Information Modeling como 0 desenvolvimento de um software multifacetado de dados em um modelo capaz de não somente documentar o projeto de um edifício, mas também de simular a construção e a operação de um novo edifício ou sua reconstrução.

O resultado, assim, é um banco de dados inteligente e parametrizado, orientado a objetos que representam elementos da construção, de onde diferentes usuários podem analisar e extrair informações do modelo, contribuindo com feedback de diferentes óticas, capaz de introduzir melhorias ao projeto (GSA, 2007, p. 3). Essa definição aborda uma questão muito importante, que está ligada ao banco de dados de modelos em BIM, o qual apoia-se em uma programação voltada a objetos. Isto permite a realização de uma série de análises de projeto com base nos elementos construtivos que compõem este banco de dados. 
Conforme apontam Solihin e Eastman (2015, p.69) ${ }^{5}$, a adoção de processos de projetos envolvendo os conceitos BIM tem aumentado em todo mundo. Depois de uma curva inicial de aprendizagem, usuários tem percebido as potencialidades que a modelagem embasada em plataformas BIM podem trazer em termos de benefícios para a melhoria e qualidade do projeto. Os modelos estão mais sofisticados e ricos em detalhes, chegando a um nível de complexidade em que inspeções apenas visuais não são mais suficientes para assegurar a consistência do modelo e o atendimento às especificações e requerimentos associados ao processo de projeto (SOLIHIN; EASTMAN, 2015, p. 69). Ao mesmo tempo que os projetos feitos em BIM facilitam a visualização do modelo, a falta de verificação das informações nele contidas pode trazer prejuízo para a execução dos mesmos, já que os elementos podem estar modelados de forma errada (PEREIRA et al., 2015) ${ }^{6}$. Neste sentido, faz-se necessária uma verificação mais precisa dos modelos, dentre outras ações, para a mitigação de erros de projetos feitos em BIM.

Pesquisas recentes indicam duas vertentes que vem se destacando: a ação de mitigação de erros por meio da compatibilização entre modelos e a checagem de regulamentações aplicadas a projetos na área de AECO. As peças gráficas bidimensionais demandam um entendimento das normas e um rigor para evitar falhas e omissões durante a análise do projeto. Conforme apontam Ferreira e Santos (2007, p. 42) ${ }^{7}$, a representação exclusivamente em 2D pode também contribuir para a falha na compreensão do projeto e detecção de falhas de compatibilização, uma vez que o "coordenador de projeto ou qualquer outro colaborador no processo de projeto precisa recriar mentalmente, com muito cuidado, o espaço com as informações omissas ou simplificadas." (FERREIRA; SANTOS, 2007, p. 44). Neste contexto, a

\footnotetext{
${ }^{5}$ Wavan Solihin é Phd em Design Computing pelo Georgia Institute of Technology, Mestre pela National University of Singapore, Graduado em Engenharia pelo Institut Teknologi Bandung. É Vice-Presidente da novaCITYNETS e atua há 22 anos em desenvolvimento de softwares inovadores, gerente de produto e de projetos em diferentes países e continentes.

${ }^{6}$ Lucas Melchiori Pereira é Doutor em Arquitetura e Urbanismo do Instituto de Arquitetura e Urbanismos da Universidade de São Paulo, Mestre pela Universidade Estadual de Londrina e graduado em Arquitetura e Urbanismo pela UEL. A atuação acadêmica e profissional abrange os temas: Organização do processo de projeto, com enfoque no atendimento de requisitos de projeto, requisitos de clientes, gestão de valor, desempenho e qualidade nas edificações. Gestão e Coordenação de projetos, coordenação, execução e acompanhamento da construção de edificações. Projetos de Empreendimentos Imobiliários, Planejamento Urbano, Desenho Urbano, Arquitetura de Edificações Permanentes, Instalações e Paisagismo.

${ }^{7}$ Rita Cristina Ferreira é Doutoranda em Arquitetura no Instituto de Arquitetura e Urbanismo da USP de São Carlos. Mestrado em Engenharia Civil pela Escola Politécnica da USP. Graduação em Arquitetura e Urbanismo pela Faculdade de Arquitetura e Urbanismo da USP. Tem experiência na área de Construção de Edifícios, com ênfase em Tecnologia da Informação aplicada a projeto e construção, Coordenação Técnica de Projetos para construção, desenvolvimento de Projetos de Produção, Gestão de Projetos de inovação.
} 
modelagem do projeto e avaliação dos espaços de maneira tridimensional podem representar um ganho significativo em relação ao meio tradicional.

\subsubsection{BIM e Modelagem Paramétrica}

O conceito BIM amplia os horizontes da qualidade dos projetos no sentido de ser uma construção virtual repleta de informações em seus elementos, com grande capacidade de gerar quantos documentos forem necessários para o bom entendimento do edifício na sua fase executiva.

Figura 1 - A informação gera o modelo de construção

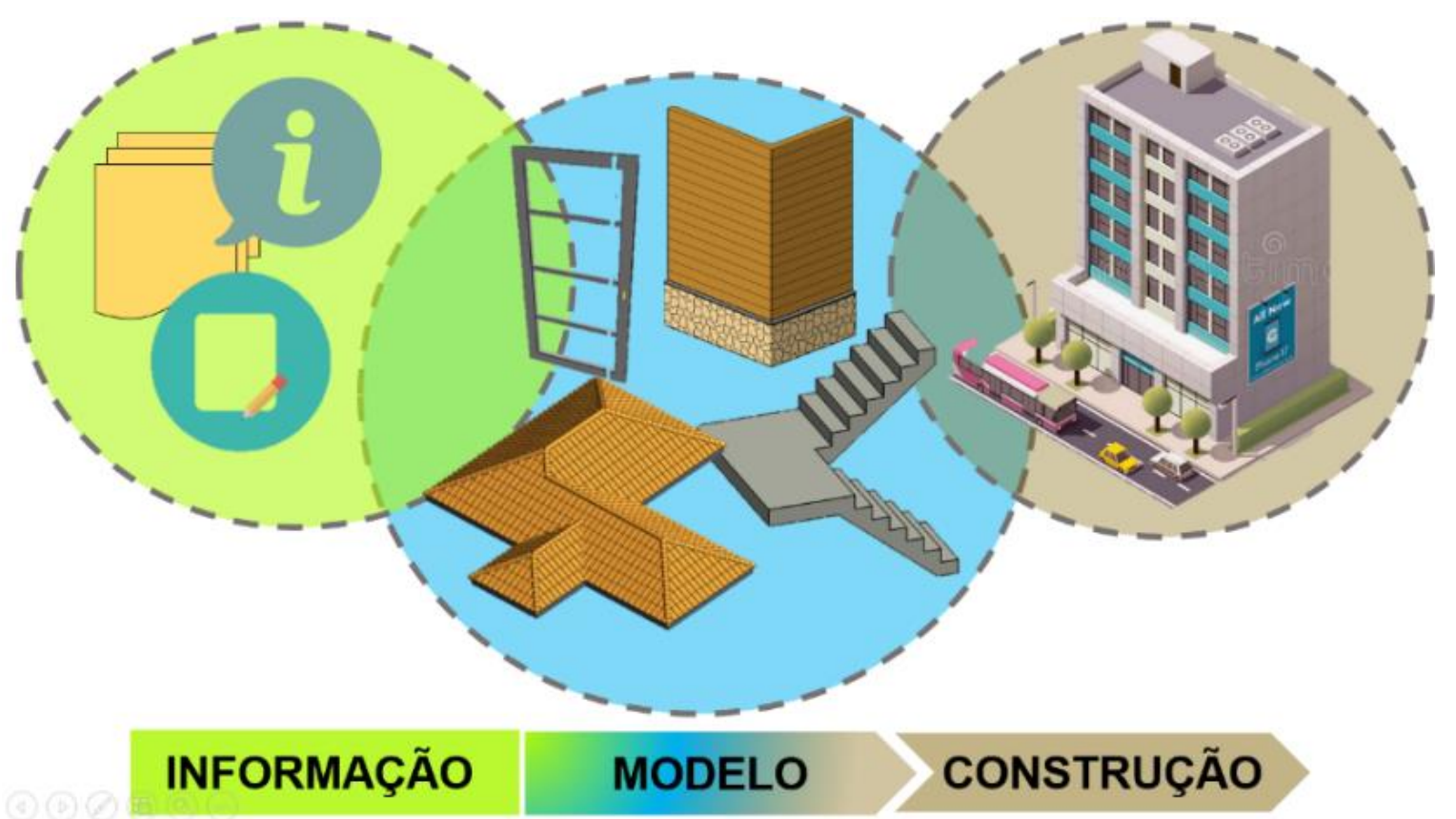

Fonte: autor, baseado em Succar (2015, p. 1-15)

Succar (2015, p. 1-15) ${ }^{8}$ sugere uma interpretação para a sigla BIM que considere as palavras Building (construção) Information (informação) Modeling (modelagem) em uma ordem diferente de relações, indicadas por Information (a Informação), Model (o Modelo) e Building (que Constrói), como mostra a Figura 1. Succar coloca a Informação como a base do projeto geradora do modelo e, consequentemente, da construção.

\footnotetext{
${ }^{8}$ Bilal Succar é graduado em administração de empresas, design de interiores e artes plásticas. Pós-graduado em comportamento organizacional e gestão de recursos humanos. Doutorado pela Universidade de Newcastle com foco em estruturas de conhecimento BIM e ferramentas de melhoria de desempenho. E um dos autores mais citados no mundo no que se refere ao BIM.
} 
As informações sobre a construção são inseridas nas plataformas BIM por meio dos elementos construtivos nativos, tais como portas, janelas, paredes, entre outros. Estes elementos são dotados de propriedades físicas predeterminadas pelo programa, de forma que os objetos inseridos no modelo possam simular virtualmente determinadas condições físicas dos elementos de uma edificação real, conforme estabelecidos por diversos parâmetros materiais, espaciais, construtivos, internos e de interface. Assim, os elementos do modelo são definidos por uma série de relações e regras que podem ser usadas para controle dos parâmetros e sofrer alterações em função do contexto de sua inserção e da manipulação pelo usuário (EASTMAN et al., 2014, p. 29). Conforme Kowaltowski et al. (2011, p. 422):

Sob o enfoque mais tecnológico, o BIM pode ser considerado uma tecnologia para desenvolvimento e uso da informação do edifício baseado num modelo de banco de dados, visando à documentação do projeto, simulação da construção e operação do edifício.

A visualização tridimensional do projeto, possível em um sistema BIM, faz com que sua compreensão seja mais clara e explícita, apoiando a consolidação do entendimento compartilhado acerca da intenção e especificidades técnicas do projeto. A Figura 2 - Representação de projeto de climatização em 2D e a Figura 3 exemplificam a diferença de visualização entre projeto em 2D e 3D no que se refere à legibilidade dos elementos constituintes do projeto de climatização. No processo de modelagem 3D, é possível relacionar o arranjo formal e funcional do projeto da edificação, permitindo verificar a conformidade com a realidade executada e alterar o modelo com facilidade. 
Figura 2 - Representação de projeto de climatização em 2D

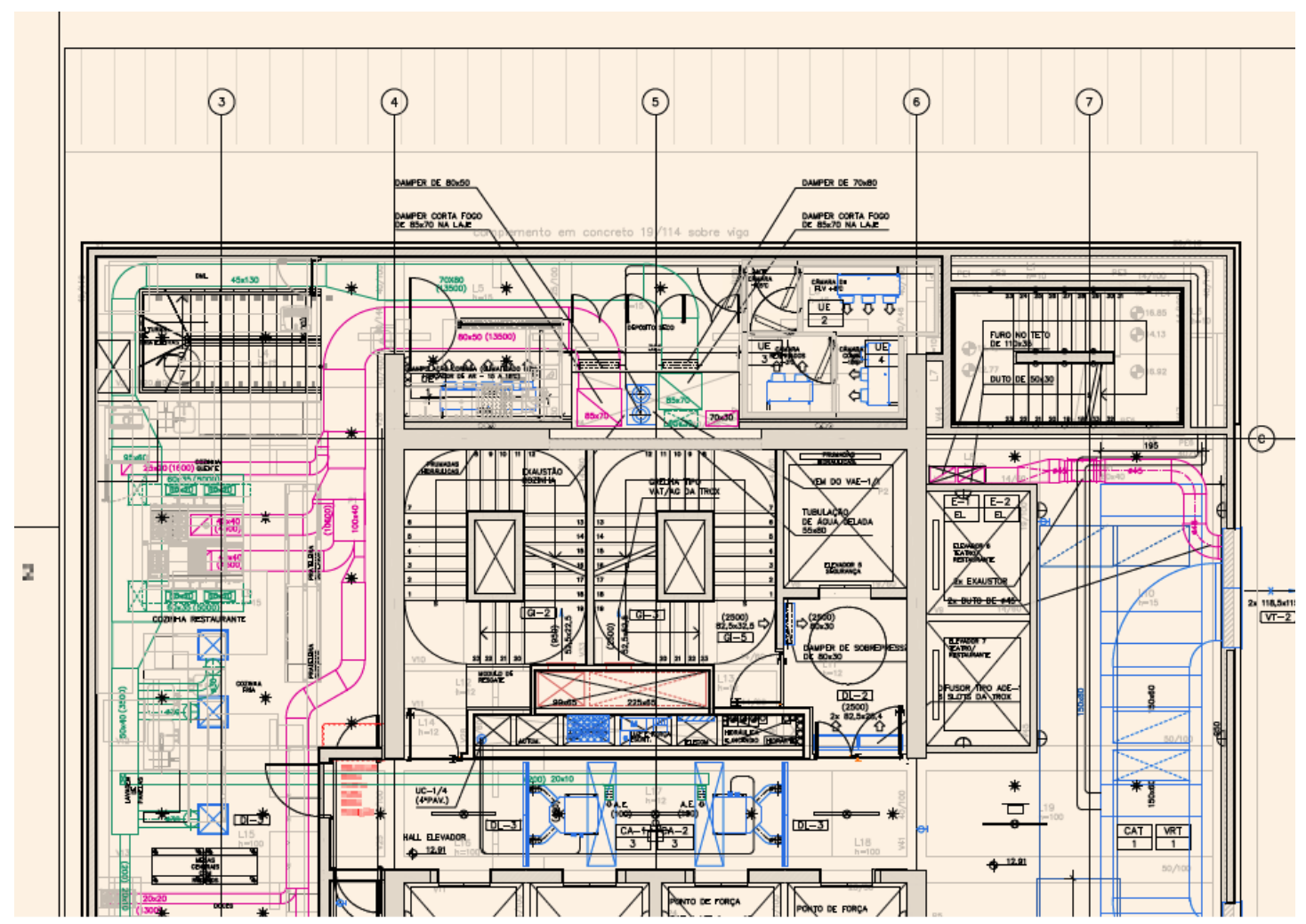

Fonte: Catelani (2016, p. 28)

Figura 3 - Representação de projeto de climatização em 3D

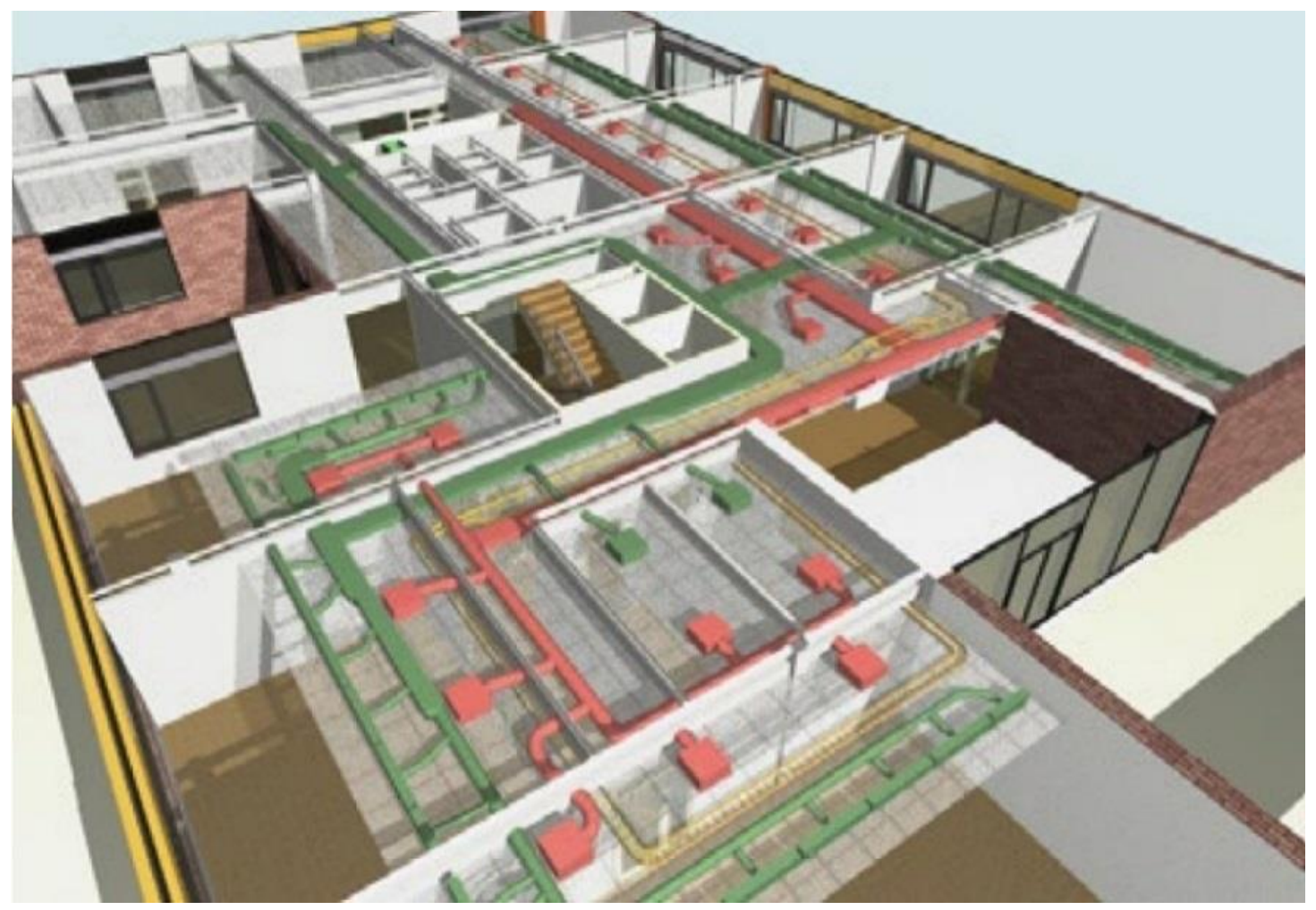

Fonte: Catelani (2016, p. 29) 
A geração do 3D é automática, isto é, "[...] o modelo 3D gerado pelo software BIM é projetado diretamente em vez de ser gerado a partir de múltiplas vistas 2D [...]" (EASTMAN et al., 2014, p. 21).

Em relação ao processo criativo, a qualidade do produto é ampliada com a facilidade de se observar tridimensionalmente as experimentações geométricas, associada a maior rapidez de modelagem, o que gera uma produtividade significativamente mais alta se comparada aos processos baseados em CAD 2D. Todas as informações estão correlacionadas através de um banco de dados paramétrico capaz de fornecer informações sobre todos os elementos inseridos no modelo (Figura 4).

Figura 4 - Vistas e planilhas geradas automaticamente por um software BIM

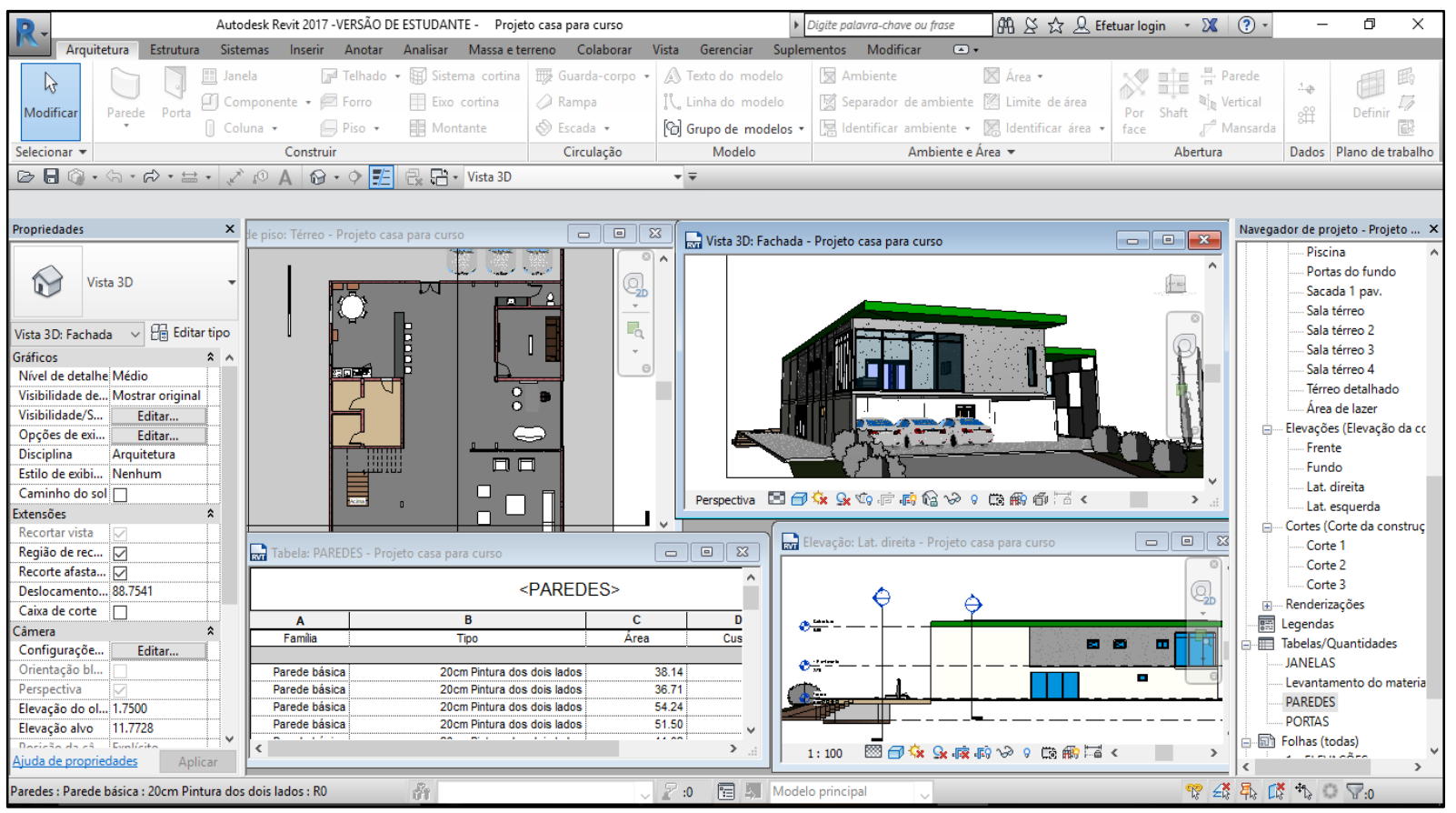

Fonte: Elaborado pelo autor

O uso de recursos de sistemas BIM para a compatibilização entre as diversas disciplinas e subsistemas de um projeto de edifício, como ilustra a Figura 5, também contribui para a rapidez no desenvolvimento e ganho da qualidade do produto final por mitigar erros, com possibilidade de verificação automática de incompatibilidades: "A detecção automática de interferências é um excelente método para identificação de erros de projeto [...]" (EASTMAN et al., 2014, p. 214). 
A possibilidade de ajustes e eventuais alterações na arquitetura para mitigar incompatibilidades identificadas com antecedência, ainda na fase de projeto, evita retrabalho, atrasos e custos adicionais na fase de execução da obra (PEREIRA et al., 2015).

Figura 5 - Clash Detection feito no Navisworks, onde podemos observar as interferências entre hidráulica e estrutura

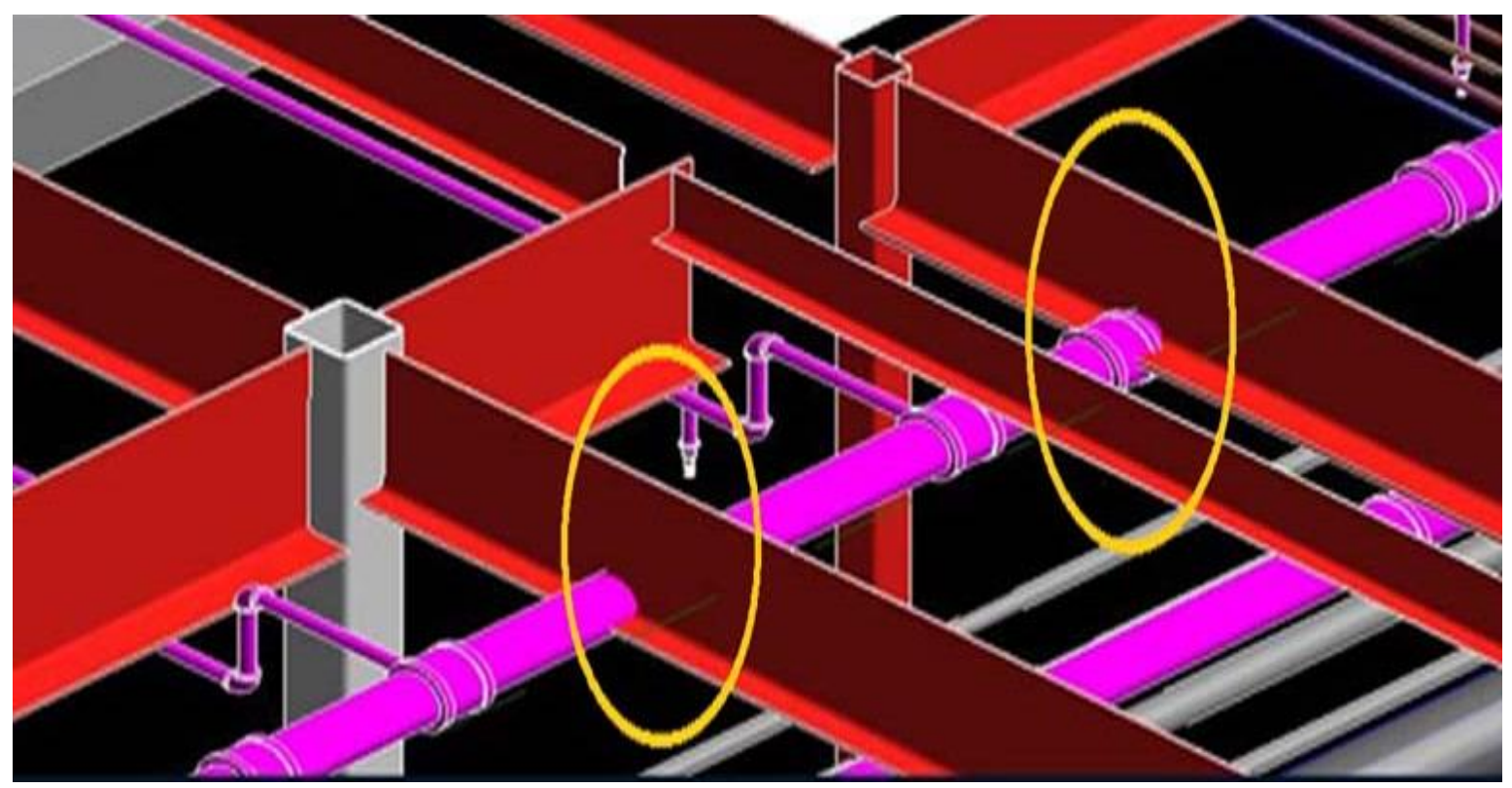

Fonte: (BIM SERVICES INDIA, [s.d.])

As plataformas BIM de modelagem de projeto de AECO foram desenvolvidas a partir de experiências da indústria mecânica, onde os parâmetros já eram atribuídos a objetos. Esses são criados em função de parâmetros envolvendo distâncias, ângulos e regras como "vinculado a", "distante de", entre outras. Os autores citam que "[...] estas relações permitem que cada instância de um elemento varie de acordo com os valores de seus parâmetros e suas relações contextuais [...]." (EASTMAN et al., 2014, p. 29), o que permite criar regras relacionais que condicionem o comportamento de cada um destes elementos.

Como os exemplos sugerem, o uso da modelagem da informação da construção é adequado para conceber soluções de projeto, gerar documentação e para a análise do processo construtivo ( RISKUS, 2007, apud FURNEAUX; KIVVITS, 
2008, p 3) $)^{9}$. "BIM apresenta considerável potencial para melhorar a eficiência e a eficácia da indústria de AECO, pois amplia a funcionalidade e a aplicação de tecnologias de projeto auxiliado por computador CAD existentes" (FURNEAUX; KIVVITS., 2008, p. 4) (tradução nossa) ${ }^{10}$.

Um dos aspectos principais, relevantes para a pesquisa, está no fato de que todos os elementos do edifício representados em um modelo 3D parametrizado estão ligados por meio de regras e propriedades registradas em um banco de dados relacional. Assim, regras parametrizadas sobre os elementos podem ser definidas e transmitidas junto com as demais informações para outros projetistas e demais profissionais envolvidos com o ciclo de vida do edifício projetado, como construtores e gerentes de operação, uso e manutenção.

Este novo paradigma de concepção e gestão de projetos por meio de elementos e dados permite ampliar as perspectivas de automatização de diversos processos ligados ao ciclo de vida de um projeto na indústria de AECO, possibilitando aumentar a eficiência do setor da construção, processo semelhante ao ocorrido em outras indústrias ao longo do tempo.

\subsubsection{Panorama da Automação e Sua Aplicação em BIM}

A perspectiva de que grandes transformações sociais, especialmente relacionadas ao trabalho, são ocasionadas por mudanças tecnológicas tem suporte em exemplos que remetem à constituição de ferramentas e ao aprimoramento de procedimentos de trabalho que influenciam diretamente os aspectos da vida e da cultura humana (CHALINE, 2014, p. 6) ${ }^{11}$. Com o desenvolvimento computacional e de tecnologias de informação e de comunicação mais recentes, tais mudanças têm assumido proporções e velocidade inauditas. Enquanto sistemas como Uber, Netflix,

\footnotetext{
${ }_{9}^{9}$ Riskus, J, 2007, Which Architecture Firms Are Using BIM? Why? The American Institute of Architects.

Dr Craig Furneaux é conferencista e coordenador do Australian Centre for Philanthropy and Nonprofit Studies, Queensland University of Technology na Australia. Tem mais de 20 anos de experiência no gerenciamento e pesquisas com organizações sem fins lucrativos, com foco principalmente na capacidade de gerenciamento de construções com viés social.

${ }^{10}$ Original: BIM has considerable potential for enhancing the efficiency and effectiveness of the Architectural/Engineering/Construction/Facilities Management (AEC/FM) Industry as it extends the functionality and application of existing Computer-aided-design (CAD) technologies.

${ }^{11}$ Eric Chaline é jornalista e escritor especializado em história, filosofia e religião. Graduou-se em Cambridge e é autor de diversos livros. Realiza pesquisas de doutorado em Sociologia na South Bank University, de Londres.
} 
WhatsApp, Dropbox, Google Drive e OneDrive ocupam o cotidiano da população e remodelam o trabalho em empresas dos mais diversos setores, outras tecnologias são direcionadas a um determinado segmento produtivo, como o BIM é para AECO.

Como característica comum de diversas destas tecnologias, está a possibilidade de integrar informações necessárias para a colaboração e automatização de procedimentos de rotina, antes realizados manualmente por pessoas. Logo, entende-se que a automação tem como objetivo melhorar processos, aumentar a eficiência e reduzir custos. No campo da manufatura, as máquinas gradativamente dependem menos de operadores até a completa automação. De uma realidade de rotinas exaustivas de trabalho repetitivo, que substituiu os antigos artesãos no final do século XVII, à atualidade em que diferentes graus de inteligência são aplicados à informatização da informação, a busca por automação é uma constante presente nas Revoluções Industriais (COELHO, 2016, p. 14) $)^{12}$.

A primeira Revolução Industrial se deu na Inglaterra entre 1760 e 1840 e foi marcada pela criação de máquinas a vapor, uso do carvão como fonte energética e a substituição do processo manual de produção para o automatizado por meio de máquinas e ferramentas diversas (COELHO, 2016, p. 14). A invenção de Joseph Marie Jacquard em 1804, que foi um aperfeiçoamento de seu próprio invento, o Tear de Jacquard, é descrita por Chaline (2014, p. 9) como sendo a primeira vez que o conceito de automação foi usado com sucesso. O tear usava cartões perfurados metálicos para criar um sistema mecânico de operações automáticas repetitivas (Figura 6).

Figura 6 - Máquina de tear

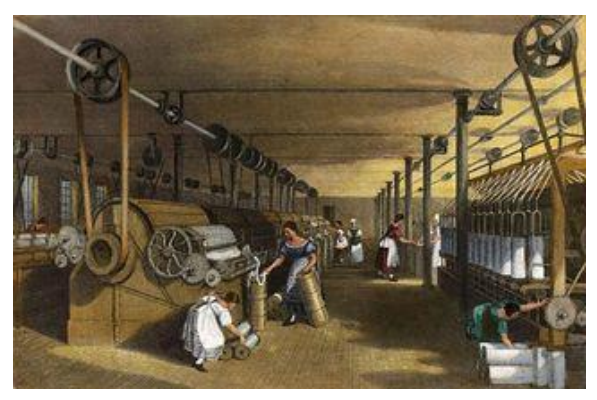

Fonte: (SÓ HISTÓRIA, [s.d.])

${ }^{12}$ Pedro Miguel Nogueira Coelho é graduado em Engenharia Mecânica e Mestre pela Faculdade de Coimbra. 
A seguir, de meados do século XVIII até o final da Segunda Guerra, vimos outras transformações significativas marcadas pela invenção do motor a combustão, do uso da energia elétrica, da criação do telefone, que aumentaram de forma significativa a capacidade de mobilidade e comunicação da sociedade. Este período foi tido como a segunda fase da Revolução Industrial, como se pode observar o aumento da produção em massa, ressaltando, neste aspecto, a linha de montagem estabelecida por Henry Ford (RODRIGUES; JESUS; SCHÜTZER, 2016, p. 35) ${ }^{13}$.

A terceira Revolução Industrial, que se iniciou em 1960, foi caracterizada pelo uso de semicondutores. Ademais, essa época também foi marcada pela substituição de sistemas analógicos por digitais, no início com o uso de mainframes. De 1970 a 1980, o computador pessoal ganhou força e logo depois, na década de 90, tivemos como fato marcante o advento da internet (SCHWAB, 2016, p. 11)..$^{14}$

Os novos desafios que se apresentam para os dias de hoje têm suas origens no surgimento dos conceitos da Indústria 4.0, concebidos pelo movimento alemão Industrie 4.0 conforme destacado a seguir:

A iniciativa Industrie 4.0 surgiu na Alemanha em resposta à competitividade global. Hermann, Pentek e Otto (2015) reportam que o governo federal alemão apoiou a ideia, anunciando que o programa Industrie 4.0 será uma parte integrante da sua estratégia de alta tecnologia para a Alemanha 2020, iniciativa que visa à liderança da inovação tecnológica (RODRIGUES; JESUS; SCHÜTZER, 2016, p. 35).

O surgimento desta nova revolução na indústria parte dos preceitos de que a comunicação entre máquinas e componentes inteligentes se dará sem a intervenção humana (RODRIGUES; JESUS; SCHÜTZER, 2016, p. 36) (Figura 7).

\footnotetext{
${ }^{13}$ Leticia Francischini Rodrigues possui graduação em Engenharia de Produção pela Universidade Federal de Ouro Preto (2015) e mestrado em Engenharia de Produção na área de Indústria 4.0 pela Universidade Metodista de Piracicaba (2018) com período sanduíche na Technische Universität Darmstadt, Alemanha.

${ }^{14}$ Klaus Schwab é graduado em Engenharia e Economia. Doutor em Economia pela Universidade de Friburgo e em Engenharia pelo Instituto Federal de Tecnologia de Zurique (ETH Zurich).
} 


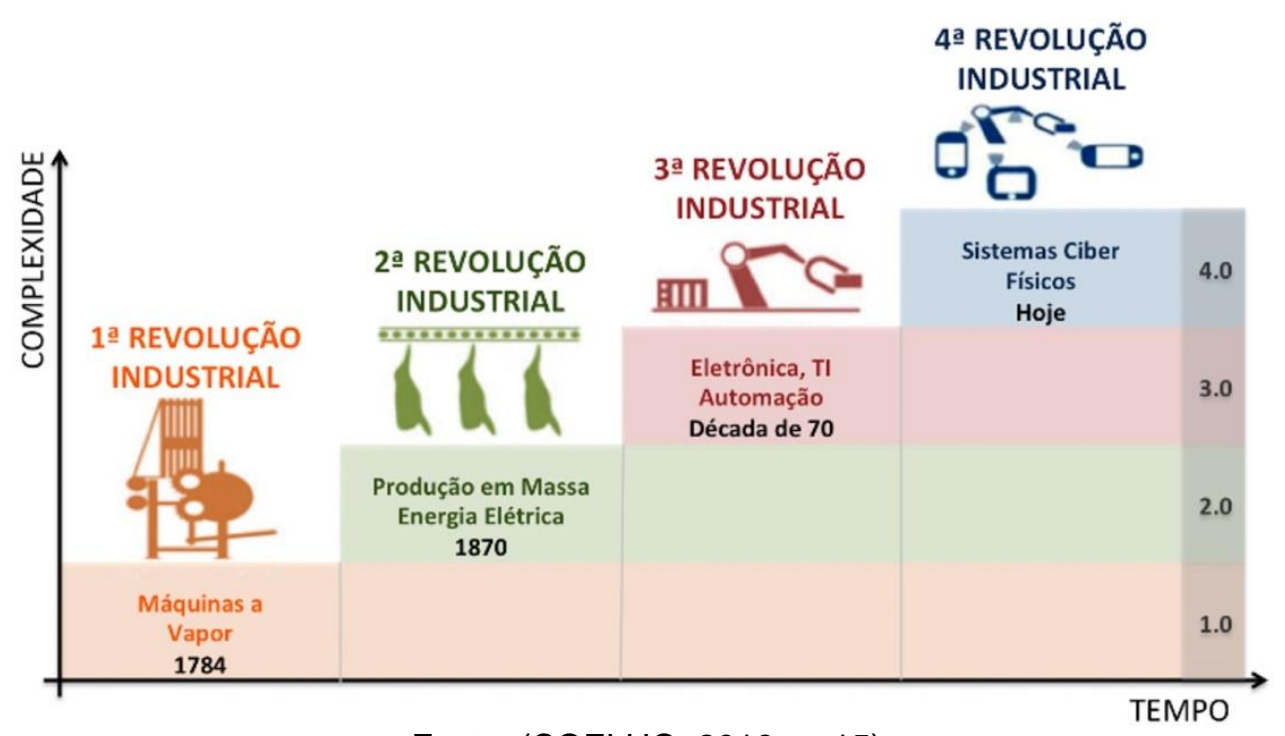

Fonte: (COELHO, 2016, p. 15)

É neste contexto de grande competitividade e de adoção de estratégias de alta tecnologia que se observa o desenvolvimento de tecnologias de suporte ao projeto baseadas em BIM, em que soluções de colaboração e automação são combinadas visando integrar informacionalmente processos dispersos em um longo ciclo de vida e aumentar a eficiência destes processos, orientando-os à criação de valor (PEREIRA et al., 2018).

O processo do projeto responde não apenas a cuidados inerentes à funcionalidade e estética da edificação, mas também deve atender a aspectos relacionados à consistência interdisciplinar entre arquitetura e estrutura, conforto térmico, sustentabilidade, meio ambiente, bem-estar do usuário, espaços mínimos a serem respeitados, adequação de materiais, implantação adequada em função da topografia, viabilidade construtiva, dentre outros. No que diz respeito ao aspecto legal, o projeto arquitetônico tem que atender a normas projetuais, sejam elas de âmbito municipal ou federal, como é o caso dos códigos de obras das cidades e das normas de acessibilidade (ABNT, 2015), da Norma de Desempenho (ABNT, 2013), para citar algumas. Dessa forma, adequar o projeto arquitetônico a um processo de qualidade sistêmico seria uma tarefa de alta complexidade. 
Tradicionalmente, $\mathrm{o}$ ato de desenvolvimento de um projeto arquitetônico passa por várias fases: estudo preliminar, anteprojeto, projeto legal e executivo (ABNT; 1995, p. 3). Ao longo deste processo, o respeito às normas deve ser rigoroso, obedecendo aos parâmetros restritivos que estas impõem, muitos dos quais estão ligados às necessidades mínimas de atendimento das atividades humanas dentro de um padrão aceitável. Várias tarefas se repetem ao longo deste percurso, especialmente quando se trata da representação gráfica exigível para a boa compreensão do projeto arquitetônico (ABNT, 1994). Tem-se, portanto, pelo menos dois aspectos tangíveis neste processo: as regras de representação gráfica e os parâmetros de restrição.

O uso do conceito BIM vem tomando grande espaço na área de projetos devido a ganhos significativos que o mesmo apresenta quando comparado ao uso de ferramentas tradicionais . Enquanto BIM oferece recursos robustos de automatização de validação de parâmetros legais e tecnológicos, ferramentas como AutoCAD estão restritas a parâmetros básicos associados a desenhos vetorizados por meio de comandos de linhas, arcos, círculos, utilizados principalmente para representação 2D de projeto ou geometrias $3 \mathrm{D}$ simples, sem atributos materiais e paramétricos (EASTMAN et al., 2014; OLOFSSON; LEE; EASTMAN, 2008).

No BIM, os elementos inseridos no projeto correspondem virtualmente aos próprios elementos construtivos como porta, janelas, paredes, dentre outros, em que todas as relações materiais, físicas e espaciais dos elementos e como estes interferem nos outros são estabelecidas por meio de parâmetros controláveis por uma série de relações e regras associadas ao contexto de sua inserção (EASTMAN et al., 2014, p. 26-35).

As informações paramétricas dos elementos do projeto ficam registradas em um banco de dados do modelo, podendo ser acessadas e manipuladas por meio de linguagens de programação, de forma a criar algoritmos capazes de otimizar tarefas, criar arranjos espaciais e volumétricos, alterar parâmetros, checar inconsistências, ou inserir elementos. Segundo Ignatova, Zotkin e Zotkina $(2018, \text { p. } 3)^{15}$ temos duas

\footnotetext{
${ }^{15}$ Elena V. Ignatova - Moscow State University of Civil Engineering (National Research University).
} 
formas de acessar as informações contidas no banco de dados de um projeto feito em um sistema BIM para obter novas funcionalidades processando estas informações: por meio de aplicativos externos ou criando aplicativos dentro dos softwares de BIM.

Figura 8 - Estrutura de banco de dados BIM com interface externa e interna

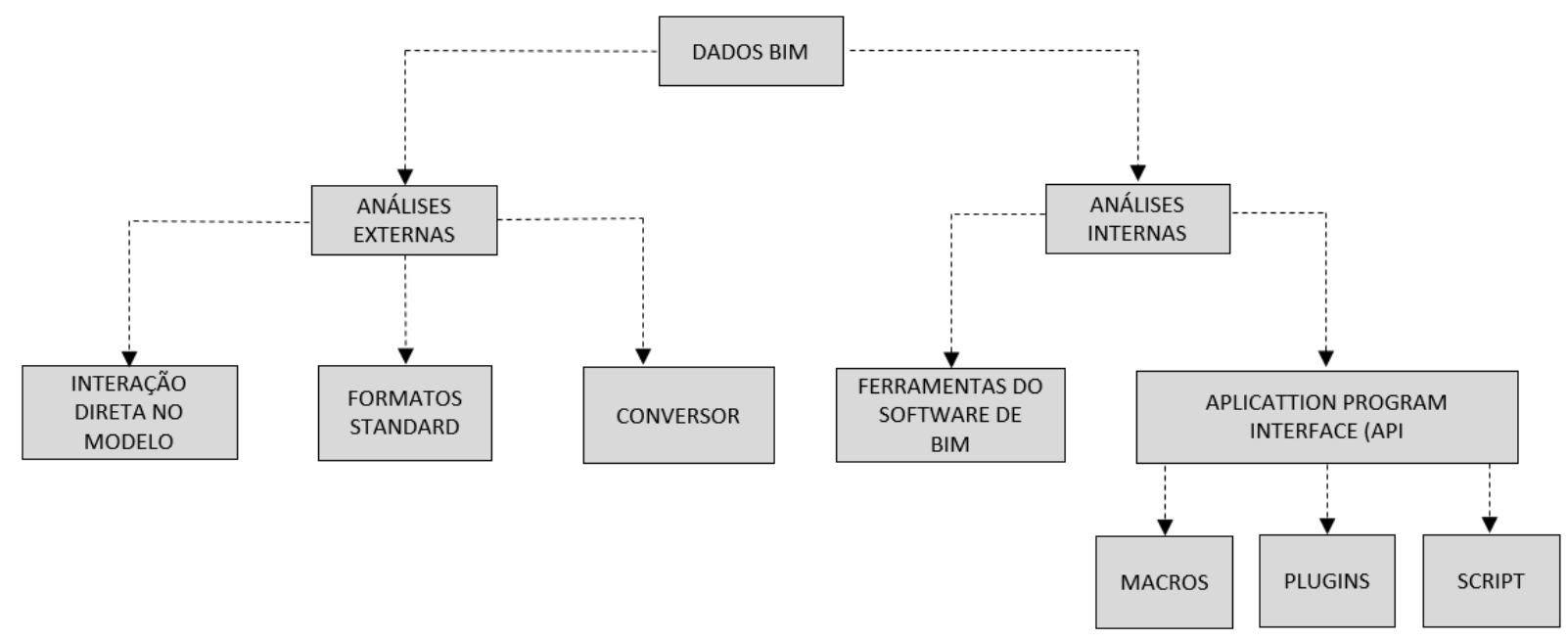

Fonte: (IGNATOVA; ZOTKIN; ZOTKINA, 2018, p. 3)

Além disso, os aplicativos que processam modelos BIM externamente geralmente recebem os dados de forma fechada. Por conta disso, faz-se possível uma interação mais completa quando pré-configurações de formatação de dados são definidas entre o aplicativo de BIM e o aplicativo externo, normalmente sem uma possível interação imediata com o modelo (Figura 8). Assim, os dados de um modelo BIM também podem ser enviados para análise em outro aplicativo em seus formatos nativos ou através do uso de um formato standard da indústria. Normalmente, todos os softwares de BIM têm a possibilidade de exportar e importar dados através do Industry Foundation Classes (IFC), esquema de dados que permite o intercâmbio de dados entre modelos BIM. O IFC permite a visualização dos dados do modelo através do código ASCIl que, entretanto, por ter uma estrutura orientada a objetos, não permite um fácil acesso a parâmetros dos elementos do modelo (IGNATOVA; ZOTKIN; ZOTKINA, 2018, p. 2), além de não ser uma interface de dados que possibilita a ordenação e dependência entre os objetos do modelo. 
Outrossim, a análise dos modelos, realizada internamente aos sistemas de modelagem correspondente, pode ser realizada por novas funções (comandos) que analisam e processam dados do projeto BIM e o resultado deste processamento permanece dentro do sistema. Ao se usar a programação, o acesso aos modelos pelo sistema de modelagem com todas as informações paramétricas dos elementos está disponível para a análise dos dados e processamento das informações, usando as capacidades nativas do software. A criação de macros, plugins, e scripts se torna possível através Application Programming Interface (API).

Outro ponto a ser levantado é que o acesso ao banco de dados do projeto permite buscar informações sobre os elementos nele inseridos, bem como as informações paramétricas sobre cada elemento. O manuseio de informações através de bancos de dados remete a uma das funções clássicas de programação. Os dados estão disponíveis para um processamento, ou seja, sua análise, interpretação e modificação.

A análise de um banco de dados BIM se adequa perfeitamente aos processos inerentes à programação; sua estrutura facilita a criação de algoritmos para a indústria AECO pois já conta com diversos parâmetros que podem ser manipulados. Os conceitos computacionais para manipulação de dados BIM dão aos usuários destes sistemas uma possibilidade a mais de tornar seus processos produtivos mais eficientes usando recursos de automação.

As civilizações sempre procuraram criar máquinas ou ferramentas que auxiliassem os processos produtivos. O principal intuito foi o de eliminar as tarefas repetitivas, ganhando tempo e diminuindo esforços. Neste cenário, o computador se adequa muito bem. Embora não seja útil caso não receba orientações ou instruções para executar alguma tarefa, esse meio tecnológico é capaz de processar um grande número de informações muito mais rapidamente que o ser humano (ASCENCIO; CAMPOS, 2006, p. 1) ${ }^{16}$. O computador recebe, processa, manipula e armazena

\footnotetext{
${ }^{16}$ Ana Fernanda Gomes Ascencio possui graduação em Ciência da Computação pela Pontifícia Universidade Católica de São Paulo (1992) e mestrado em Computação pela Universidade Federal do Rio Grande do Sul (2000). Tem experiência na área de Ciência da Computação, com ênfase em Linguagens de Programação, atuando principalmente nos seguintes temas: informática na educação, software educacional, educação matemática, engenharia de software e sistema de informação.
} 
dados. Sua função é a de processar os dados que lhe são imputados através de entradas de informações que podem ser transmitidas com o uso de teclados, mouses, scanners e outros equipamentos semelhantes. Uma vez recebidos, os dados são processados e devolvidos ao usuário através de dispositivos de saída como, por exemplo, monitores, impressoras dentre outros (ASCENCIO; CAMPOS, 2006, p. 1).

Os computadores processam dados através de uma série de instruções, chamadas de programas de computador (softwares). Esse é um conjunto de instruções que devem ser executadas pela máquina, bem como suas instruções são escritas a partir da criação de códigos inteligíveis. Existem muitas formas diferentes de transmitir a um computador o que deve ser executado e são as linguagens de programação que determinam como será feita esta comunicação (PUGA; RISSETI, 2004, p. 29-30) ${ }^{17}$.

Embora existam várias linguagens de programação, podemos dizer que elas são separadas em três categorias: linguagem de máquina; linguagem assembly e linguagem de alto nível. A linguagem de máquina é chamada também de linguagem de baixo nível, pois tem comunicação direta com o computador (hardware) através de códigos numéricos. Esta linguagem é, em última análise, um conjunto de códigos binários ( 0 's ou 1's), exclusiva para um determinado tipo de computador. A linguagem assembly foi criada para aproximar a comunicação entre homem e máquina, tornando mais fácil escrever um código neste tipo de ambiente. No entanto, o objeto tecnológico só poderá executar as instruções recebidas depois que transformar a linguagem assembly em linguagem de máquina e isso é feito através da compilação do programa ou algoritmo.

Seguindo a tendência de melhorar a forma com que as linguagem de programação se comunicam com o computador através de códigos, foram criadas as

\footnotetext{
17 Sandra Puga é doutora em Engenharia Elétrica - pesquisa na área de Engenharia de Software - Poli-USP. Mestre em Comunicação e Semiótica - área de Tecnologia da Informação - PUC (SP). Autora de diversos livros na área de Algoritmos e Estrutura de Dados e Banco de Dados e diversas publicações na área de Engenharia de Software e Interfaces com o usuário.
} 
linguagens de alto nível, dentre as quais podemos citar como mais populares hoje em dia: C, C++, C\#, Java Visual Basic, Pearl e Python (DEITEL et al., 2003a, p. 7) ${ }^{18}$.

O Quadro 1 exemplifica a diferença entre as linguagens de programação. Nele podemos verificar que as linguagens de mais baixo nível são mais próximas dos computadores, porém, as mais difíceis de serem manipuladas estando suscetíveis a erros por parte dos programadores e mais tediosas para serem escritas. As linguagens de alto nível são mais próximas de uma frase entendida pelo ser humano, portanto mais acessíveis e intuitivas.

Quadro 1 - Diferenças entre níveis de linguagem de programação

\begin{tabular}{||l|l||}
\hline \multicolumn{2}{||c||}{ Programa para somar remuneração bruta (remunBruta = remuneração } \\
básica + horas extras
\end{tabular}

Fonte: Elaborado pelo autor

Um código de programa normalmente é criado levando-se em conta o seu algoritmo, que nada mais é do que uma sequência lógica de instruções para o computador. Esses códigos são amplamente usados em outras áreas de conhecimento e no dia a dia das pessoas sem que estas se deem conta que estão fazendo uma série de tarefas sequenciadas. Como exemplo tem-se uma dona de casa quando faz um bolo, segue uma receita, que é o conjunto de passos necessários para que o bolo seja feito. Da mesma maneira os algoritmos são importantes aliados na construção de programas de computadores e podemos destacar dois tipos principais: pseudocódigos e fluxogramas (PUGA; RISSETI, 2004, p. 9).

\footnotetext{
${ }^{18}$ Paul Deitel, presidente e diretor técnico da Deitel \& Associates, Inc.é graduado pelo MIT Sloan School of Management no curso de Tecnologia da Informação. Certificado e premiado em linguagem Java, é considerado um dos maiores especialistas em Microsoft C\#.
} 
Pseudocódigos configuram-se por serem sistemas que organizam as ideias através de um misto de linguagem apropriada para a programação e a escrita humana. Um exemplo de pseudocódigo é dado por Puga e Risseti (2004, p. 11), conforme apresentado no Quadro 2.

\section{Quadro 2 - Exemplo de Pseudocódigo}

Pseudocódigo para ler o nome, a idade, o cargo e o salário de 50 pessoas e verificar quantas possuem idade inferior a 30 anos e um salário superior a $R \$ 3.000 .00$.

\section{Identificação do algoritmo \\ Algoritmo Exemplo.2.1}

Declaração de variáveis das variáveis:

Var nome, cargo: literal

Idade, n_pessoas, tot_pessoas: inteiro

salario: real

\section{Corpo do algoritmo}

Início

N_pessoas $<-1$

Tot_pessoas $<-0$

Enquanto (n_pessoas <= 50) Faça

Ler (nome, idade, cargo, salário)

Se (idade $<=30)$ e (salario $>=3000,00)$ Então

tot_pessoas $<-$ tot_pessoas +1

Fim-Se

n_pessoas $<-$ n_pessoas +1

Fim-Enquanto

Mostrar ("o total de pessoas que atendem a condição é", tot_pessoas)

Fim.

Fonte: (PUGA E RISSETI, 2004, p. 11)

Como demonstrado no Quadro 2, normalmente um algoritmo se inicia com a declaração de suas variáveis, ou seja, valores que serão alterados durante a programação. Pode também ter início por valores que não se alteram, chamados de constantes. O corpo do algoritmo é a área onde a solução para o problema é descrita. Exemplos das principais estruturas de um algoritmo: local para entrada de dados; operações de atribuições, lógicas e aritméticas; abertura e fechamento de arquivos; laços de repetição; exibição dos dados. 
Fluxogramas são símbolos gráficos inseridos em uma determinada regra para que programas possam ser descritos inicialmente com esta ferramenta de base para depois passar para uma linguagem de programação. Existem vantagens e desvantagens decorrentes do uso dos fluxogramas: são de mais fácil entendimento por utilizarem elementos gráficos, porém a simbologia e a função de cada um destes elementos gráficos tem que ser conhecidas e compreendidas pelo usuário (ASCENCIO; CAMPOS, 2006, p. 6). A Figura 9 - Fluxograma exemplo

Figura 9 - Fluxograma exemplo

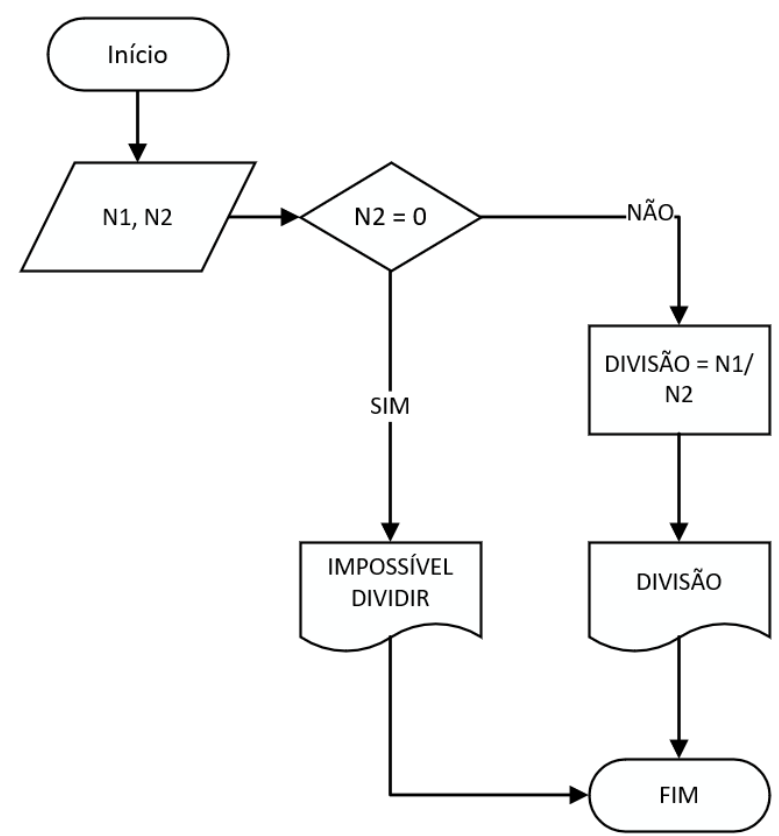

Fonte: (ASCENCIO; CAMPOS, 2006, p. 6)

Segundo Puga e Rissetti (2004, p. 32-40) as formas de estruturação dos códigos de programação que mais se destacam são a programação procedural , programação estruturada e programação orientada a objetos:

Programação procedural - este tipo de programação é usado de forma sequencial, onde cada linha de programação segue os passos linha a linha tendo início e fim específicos. Abordagem era muito usada na programação em Basic: cada linha tinha número e código; caso tivesse que fazer um desvio, o comando apontava para o número da linha desejada. 
Programação estruturada - a designação mais adequada para este tipo de programação seria o de dividir para conquistar. Ao invés do código seguir uma sequência passo a passo, blocos de códigos são escritos e chamados por um programa principal. Os blocos, chamados pelo programa principal, são geralmente denominados de funções, que executam uma determinada tarefa. Por exemplo: a soma de dois números definida pela função "soma $(\mathbf{x}, \mathbf{y})$ " retorna o valor da soma das variáveis $x+y$. Desta forma, os códigos ficam menores e mais fáceis de serem controlados, interagindo uns com os outros e podendo ou não retornar valores interagindo com o programa principal.

Programação orientada a objeto - uma das maneiras de entender a programação orientada a objetos é enxergar o mundo da programação fazendo um paralelo com o mundo real através de sistemas computacionais que estão associados a objetos que se interligam uns com os outros. Desta forma, os objetos que são definidos através de códigos têm condutas próprias que são delineadas através de seus atributos e operações.

Além destas, interessa a pesquisa acrescentar uma quarta forma de programação a estas apontadas por Puga e Rissetti. A linguagem de programação visual, oferece uma interface mais intuitiva para a criação de códigos, a partir de nós de programação predeterminados, que se conectam a outros por meio de entradas e saídas de dados específicos à função que se destina. Entre os programas baseados em linguagem de programação visual voltados para a área de arquitetura, podemos destacar o Dynamo e o Grasshoper.

Na prática, é possível que uma mesma linguagem use mais de uma estrutura de programação. O Python, por exemplo, usa tanto a linguagem estruturada como a orientada a objetos. Já o C\# é mais voltado a orientação para objeto. 


\subsection{PROBLEMA DE PESQUISA}

Por compreender a relevância e o tamanho do desafio apresentado pelo contexto explanado, o presente trabalho se insere entre as iniciativas mais recentes para compreender as condições de automação usando diferentes linguagens de programação para a plataforma BIM. Para tanto, todavia, foi preciso determinar alguns limites e orientações para os estudos empíricos que subsidiaram as análises da pesquisa.

A investigação de um fenômeno tão complexo como automação por meio de programação impõe a definição dos limites de operacionalização dos estudos empíricos. Como o foco é compreender o potencial da programação, entendeu-se que era preciso reduzir variáveis relacionadas ao software BIM. Assim, esta pesquisa adotou o uso do Revit, software da Autodesk, como plataforma sobre a qual foram exploradas as diferentes formas de criação de automação de processos em BIM.

O Revit é um dos softwares mais utilizados no mundo na modelagem da informação do edifício na indústria de AECO por sua flexibilidade de atuar em várias disciplinas, por ser funcional e trazer consigo um dos mais fortes conceitos de BIM em sua estrutura (IGNATOVA; ZOTKIN; ZOTKINA, 2018, p. 3). Como visto anteriormente, a automação pode ser usada para a manipulação de dados computacionais. Através de informações contidas num banco de dados, cuja entrada é dada pelo usuário, um processamento é executado segundo as instruções fornecidas pela programação para obtenção de um resultado.

A Autodesk permite que isto seja feito usando a interface de programação do Revit, a Application Programming Interface (API). Esta interface de programação usa o NET Framework da Microsoft que, em última instância, é uma base de códigos que pode ser usada a partir de linguagens de programação como $\mathrm{C \# ,}+++$, Visual Basic, Python, JScript além de linguagens antigas como o Cobol. Usando a API do Revit, a interface de comunicação permite acesso a várias ferramentas disponíveis no aplicativo, possibilitando a manipulação e o processamento de dados gráficos e alfanuméricos (AUTODESK, [s.d.]). 
Uma grande possibilidade de automação se apresenta quando se pode acessar os dados do elemento inserido no modelo BIM, mesmo aqueles que não estão disponíveis na interface de comunicação do Revit (como é o caso das coordenadas de inserção de um objeto). Por meio da programação, pode-se ler e mudar as propriedades de um elemento. Como a interface de comunicação está disponível e tem acesso ao banco de dados do projeto e às funções e comandos do sistema de modelagem, é igualmente possível criar novos elementos diretamente do código da programação seguindo um algoritmo pré-determinado. No caso do Revit, isso pode ser feito através da criação de plugins para o software, que podem ser escritos em algumas linguagens, sendo as mais comuns a C\# e o Python. Outra forma de acessar e manipular os dados de um projeto em Revit é usar a linguagem de programação visual Dynamo.

Assim, para a aplicação da programação dentro do conceito BIM, foram utilizadas as linguagens mais comuns, apresentando exemplos e caminhos para se iniciar um aprendizado do desenvolvimento de rotinas de automação de processos projetuais, envolvendo a manipulação do banco de dados do Revit. Os detalhes de como estas aplicações foram realizadas e analisadas é apresentada a seguir, por meio da definição do objetivo e do método de pesquisa que estruturam a dissertação. 


\section{CAPÍTULO 2 OBJETIVO E MÉTODO}




\subsection{OBJETIVO}

O trabalho tem como objetivo principal:

Analisar as condições de automação dos processos de projeto BIM, realizada por meio da programação de operações que, realizadas manualmente, incorrem em grande volume de trabalho e ou riscos de erro humano.

Mais especificamente, como já foi abordado na definição do objeto de estudo, o trabalho de revisão preliminar e a prática profissional do pesquisador permitiram delimitar o estudo para a análise da programação por meio de três linguagens com grau de complexidade distintos, a saber, o Dynamo, Python e C\# aplicados a um software de BIM especifico, o Revit versão 2019 da Autodesk.

Assim, o objetivo geral se traduz nos seguintes objetivos específicos:

1. Analisar as condições de automação de operações em Revit realizadas por meio da programação em linguagem Dynamo;

2. Analisar as condições de automação de operações em Revit realizadas por meio da programação em linguagem Python;

3. Analisar as condições de automação de operações em Revit realizadas por

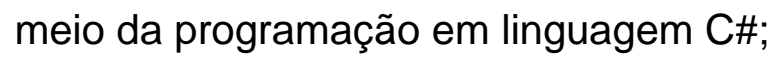

4. Comparar os resultados das análises de forma a evidenciar as condições, potencialidades e restrições de uso.

Juntos, os quatro objetivos específicos servem de direcionamento para atender ao objetivo geral, estabelecendo as bases para estruturar o trabalho como será especificado a seguir. 


\subsection{MÉTODO}

Os quatro objetivos específicos orientam a estruturação da dissertação, na medida em que os três primeiros objetivos estabelecem o desenvolvimento paralelo de estudos teóricos e práticos acerca das três linguagens de programação eleitas.

Assim, a dissertação é composta por três capítulos que abordam aspectos relacionados ao desenvolvimento de rotinas de automatização de processos de projetos arquitetônicos. Foram realizados estudos empíricos sobre três linguagens de programação aplicadas à automação em Revit: Dynamo, Python e C\# (Figura 10). Em comum, todos os estudos apresentados correspondem a códigos de programação que utilizam a Application Program Interface (API) do Revit para acessar, inserir e alterar as informações do modelo BIM, sejam estas informações geométricas ou alfanuméricas.

Figura 10 - Delineamento da pesquisa

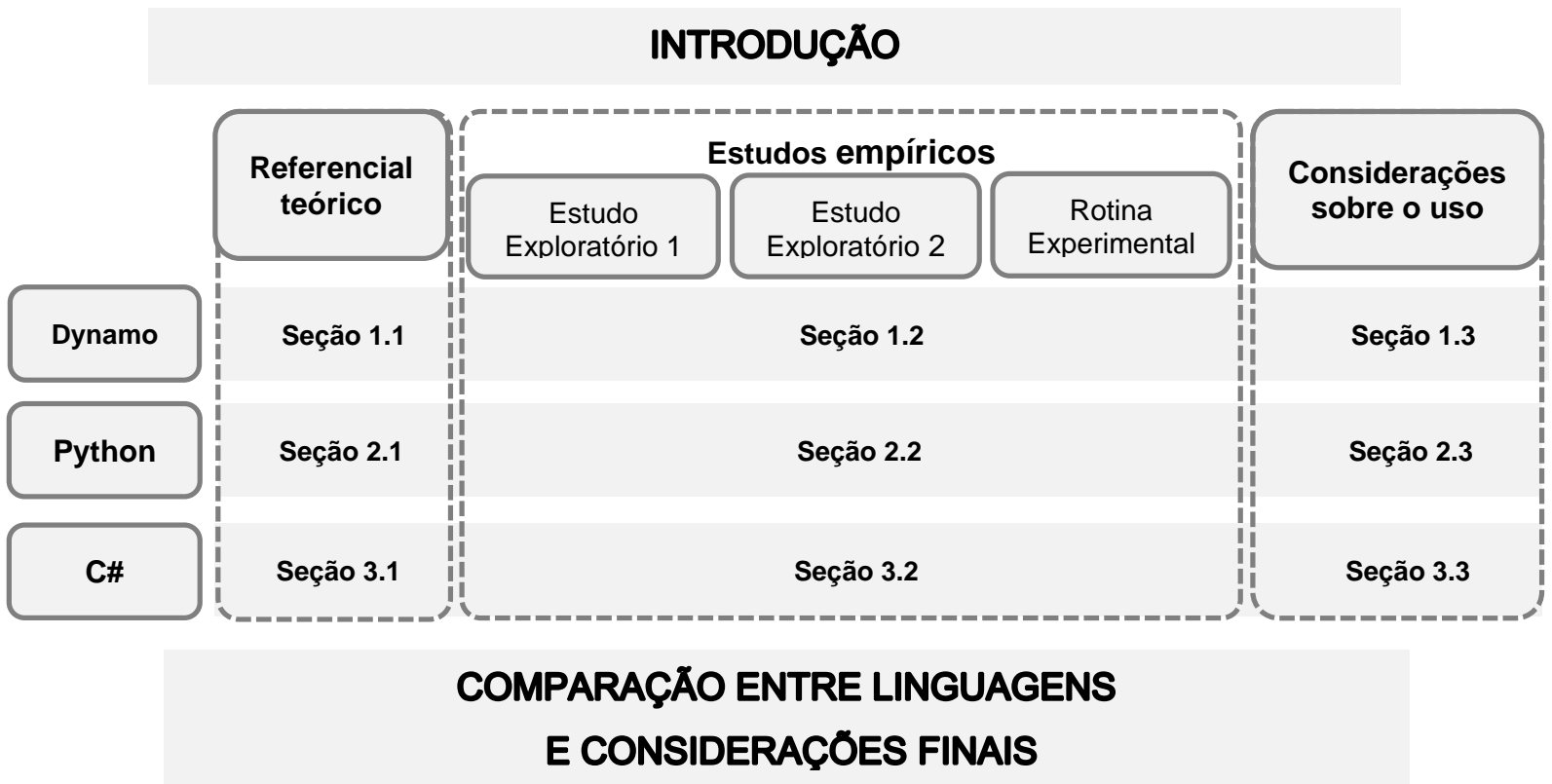

Fonte: Elaborado pelo autor

Os resultados apresentados nos três capítulos foram alcançados a partir da combinação de dois experimentos no uso de cada uma das linguagens direcionadas a automação de processos e um experimento feito pelo pesquisados abordando igualmente as três linguagens de programação selecionadas. Além das considerações sobre o uso de cada linguagem, uma comparação entre as condições de uso de cada 
uma delas é apresentada junto às considerações finais, como fechamento e síntese do conhecimento apreendido empiricamente (Figura 10).

A respeito dos três capítulos que constituem o corpo da dissertação, cabe observar que todos são compostos por uma estrutura comum, dividida em três seções.

A primeira seção de cada capítulo apresenta as considerações teóricas e técnicas a respeito da linguagem nele abordada. Em cada um dos três capítulos, o conteúdo é diverso, pois foi direcionado aos pontos considerados relevantes para subsidiar o entendimento dos estudos empíricos sobre cada uma das linguagens.

A segunda seção de cada capítulo é subdividida entre os estudos exploratórios e a rotina experimental. Os estudos exploratórios se baseiam em uma análise documental dos códigos de programação existentes, quando são disponibilizados pelos autores para uso e edição de terceiros. Cada estudo foi escolhido de forma a exemplificar um aspecto de utilização de programação como complemento às funções do Revit. Por meio do estudo de rotinas já desenvolvidas, é possível ressaltar as principais vantagens e desvantagens de cada linguagem em sua utilização para automatização de rotinas de projeto. Neste sentido, o estudo experimental permite que o pesquisador estabeleça uma compreensão mais profunda das condições de realização da programação da automação, contribuindo para o conhecimento processual, não descrito na teoria.

A terceira seção dos três capítulos, de resultados da pesquisa, apresenta uma conclusão parcial para cada estudo, baseada nas considerações de uso das linguagens Dynamo, Python e C\# analisadas individualmente a partir da experiência de programação do pesquisador.

Já a análise comparativa, que antecede as considerações finais, oferece substrato para apresentar as conclusões da pesquisa que extrapolam a observação individual possível de ser observada em cada capítulo. Assim, a síntese apresentada e considerações finais são baseadas a partir de dois quadros comparativos que compreendem as variáveis relacionadas diretamente às linguagens de programação 
e as variáveis relacionadas às habilidades necessárias para programar a automação em Revit.

As variáveis consideradas para comparar as linguagens são:

- Aderência da linguagem a grade curricular de matérias no ensino de arquitetura;

- Facilidade de uso;

- Confiabilidade;

- Simplicidade para definir tipos de variáveis;

- Uso por empresas de pequeno e médio porte;

- Uso por empresas de grande porte;

- Recursividade;

- Tipo de estrutura da linguagem é visual;

- Tipo de estrutura da linguagem é orientada a objeto;

- Manipulação de listas;

- Recursos de debugging;

- Facilidade para a manutenção do código;

- Facilidade para a documentação do código;

- Interação com a API do Revit;

- Automatizar formas complexas;

- Artigos científicos que abordam a linguagem.

Já as variáveis consideradas para comparar as habilidades de programação são:

- Usar código existente para automatizar projeto;

- Criar código para automatizar projeto;

- Disponibilizar comercialmente código para automatizar projeto;

- Raciocínio em computação;

- Compreender linguagem orientada a objeto;

- Explorar recursos de recursividade;

- Manipular as variáveis de modelos no Revit;

- Dominar manipulação de listas; 
- Entender o processo de Debugging de um código;

- Interação com a API do Revit;

- Formas complexas;

- Gerar documentação do código desenvolvido;

- Atualizar código desenvolvido.

Embora os itens se assemelhem em seu conteúdo, a repetição é necessária uma vez que as primeiras variáveis dizem respeito à linguagem e as segundas às habilidades do programador. Tal duplicidade permite situar criticamente tanto 0 potencial como as condições de operacionalização destes potenciais, o que implica em diferentes contextos adequados a implementação. $O$ apontamento de contextos adequados para adoção de cada linguagem é apresentado nas considerações finais,

Cabe observar ainda que as contribuições da dissertação para o debate acadêmico e profissional são resultado tanto das análises individuais sobre o uso de cada linguagem quanto da análise comparativa do desempenho observado entre as três linguagens. Com estas contribuições, espera-se acrescentar reflexões com bases empíricas e relacionais ao debate existente, subsidiando assim a compreensão acerca de questões maiores como curva de aprendizado, dificuldades de implementação e melhores práticas, dentre outras que circulam o campo de AECO. 


\section{CAPÍTULO 3 \\ AUTOMAÇÃO COM O DYNAMO}


A análise das condições de automação por meio da programação em Revit foi realizada a partir de três linguagens, dentre elas o Dynamo. Foi identificada uma crescente produção acadêmica e técnica relatando casos de uso da linguagem, com enfoque no processo de automação em projeto, além de tutoriais e discussões em fóruns sobre aspectos específicos do desenvolvimento de algoritmos em Dynamo. No entanto, por se tratar de uma linguagem ainda muito nova e em constante desenvolvimento, existe pouco material técnico publicado que trate em detalhes as características desta programação visual e sirva como base para consulta e aprendizado em maior profundidade nesta linguagem.

Como alternativa, podem ser consultados os manuais e tutoriais do programa ofertados pela desenvolvedora ou pela comunidade de usuários que oferece suporte à linguagem. Este material serviu como parte da base para o aprendizado sobre 0 Dynamo, o que viabilizou a criação das rotinas, a compreensão dos algoritmos escolhidos como exemplos e a discussão dos resultados.

O capítulo 3 está estruturado em três partes, definidas nas seguintes seções:

1.1 Linguagem Dynamo: aborda características gerais e os fundamentos de utilização da programação, levantados por meio da pesquisa bibliográfica que abrange tanto referências científicas acadêmicas como material técnico que permitiram consolidar o entendimento e a assimilação do processo de desenvolvimento de rotinas para automatizar processos do Revit por meio do Dynamo;

1.2 Estudos exploratórios sobre o Dynamo e rotina experimental: são apresentadas duas rotinas de automação de procedimentos realizados em Revit e desenvolvidas em linguagem Dynamo. Dois destes exemplos foram extraídos de trabalhos de terceiros, estão disponíveis na internet e contam com publicações científicas e/ou técnicas próprias. O terceiro exemplo foi desenvolvido para a dissertação pelo pesquisador, o que permite um relato da experiência de programação mais detalhado e direcionado à consolidação da discussão da pesquisa; 
1.3 Considerações sobre o uso de Dynamo para automação: relata os resultados específicos encontrados com a adoção da linguagem Dynamo para programação de automação, ressaltando os pontos entendidos como chave para execução dessa tarefa e as limitações enfrentadas.

\subsection{LINGUAGEM DYNAMO}

O Dynamo é uma linguagem de programação visual open source, orientada a objetos, desenvolvida tanto para se comunicar com a API do Revit, como para funcionar de forma independente para a criação de geometrias complexas. O software que oferece suporte para sua programação permite a interação direta com o banco de dados do Revit acessando os elementos do projeto e sua interface de comunicação com o usuário (SGAMBELLURI, 2015, p. 6) ${ }^{19}$. Entre as possibilidades de uso do Dynamo está a criação de objetos complexos, que é a mais difundida e utilizada, porém, interessa à pesquisa explorar o potencial de automatizar atividades repetitivas de modelagem, verificação e correção de modelagem com parâmetros pré-definidos que sobrecarregam o trabalho de profissionais de projeto, sujeitando o processo à ocorrência de erros humanos e atrasos.

Linguagens de programação visual, também chamadas de diagramáticas, têm como uma de suas características mais relevantes a fácil comunicação com o usuário:

Os ambientes de programação visual para modelagem paramétrica podem ser comparados às linguagens de programação visual (VPLs), também chamadas de linguagem de programação diagramáticas. As VPLs permitem que os usuários criem programas por meio da manipulação de componentes gráficos em vez do uso de linhas de código. Em outras palavras, usam uma representação analógica para os algoritmos. (CELANI; VAZ, 2011, p. 189)

Dentro do contexto AECO, a comunicação simples com o usuário facilita a escrita do seu código, possibilitando que mais usuários usufruam das possibilidades de automatizar processos. Segundo Celani e Vaz (2011, p. 127) ${ }^{20}$ a modelagem

\footnotetext{
${ }^{19}$ Marcello Sgambelluri é Diretor de BIM na John A. Martin Structural Engineers in Los Angeles, CA. É membro do Comitê ASCESEI BIM e atuante conferencista pelos EUA. Dá aulas na Autodesk University and the Revit Technology Conference, onde é um dos palestrantes mais bem avaliados.

${ }^{20}$ Gabriela Celani é arquiteta e mestre pela FAU-USP e PhD pelo MIT, onde foi orientanda e assistente de pesquisa e de ensino de William Mitchell e de Terry Knight. É também livre-docente pela Unicamp e pósdoutora pela Universidade Técnica de Lisboa, onde atuou como docente. Desde 2004 é pesquisadora e docente do curso de Arquitetura e Urbanismo da Unicamp, onde criou - Laboratório de Automação e Prototipagem para Arquitetura e Construção (LAPAC) e o grupo de pesquisas Teorias e Tecnologias Contemporâneas Aplicadas ao Projeto.
} 
paramétrica através de uma linguagem visual não é exatamente uma VPL mas tem características similares, como a de interface de programas que usa o conceito de caixas e fios (box-and-wire).

Figura 11 - Código escrito em VPL e seu similar em código escrito

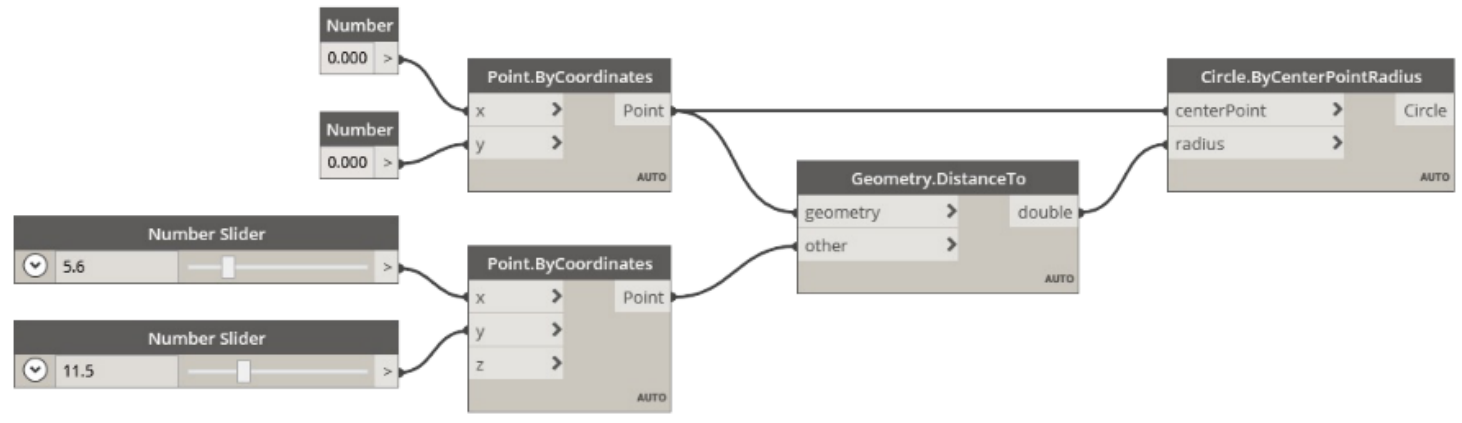

Textual Program:

myPoint $=$ Point. ByCoordinates $(\odot . \odot, \odot . \odot, \odot . \odot) ;$

$x=5.6$;

$y=11.5$

attractorPoint $=$ Point. ByCoordinates $(x, y, 0.0)$;

dist $=$ myPoint. DistanceTo $($ attractorPoint $)$;

myCircle $=$ Circle.ByCenterPointRadius (myPoint, dist) $;$

Fonte: Autodesk (2018)

No exemplo apresentado na Figura 11, o código de programa foi escrito por meio do Dynamo. Percebe-se a relação entre a sequência de tarefas realizadas visualmente pelo programador por meio dos nós e fios interconectados e a transcrição do resultado em formato de código de programação.

Segundo a desenvolvedora (DYNAMO, [s.d.]), o Dynamo é um programa que permite a manipulação de dados, a modelagem paramétrica, a comunicação entre aplicativos, a automatização de processos, explorações alternativas de formas e opções de projeto. Assim, trata-se de um software que pode ser utilizado independentemente ou integrado ao Revit como uma poderosa ferramenta para o desenvolvimento de rotinas para automatizar processos. Para Sgambelluri e John (2015, p. 6), o Dynamo cria uma geometria própria com relações paramétricas e lê e escreve em um banco de dados externo por meio de uma API (Figura 12). 
Figura 12 - Fluxo de comunicação Dynamo x Revit

\section{O que é o Dynamo?}

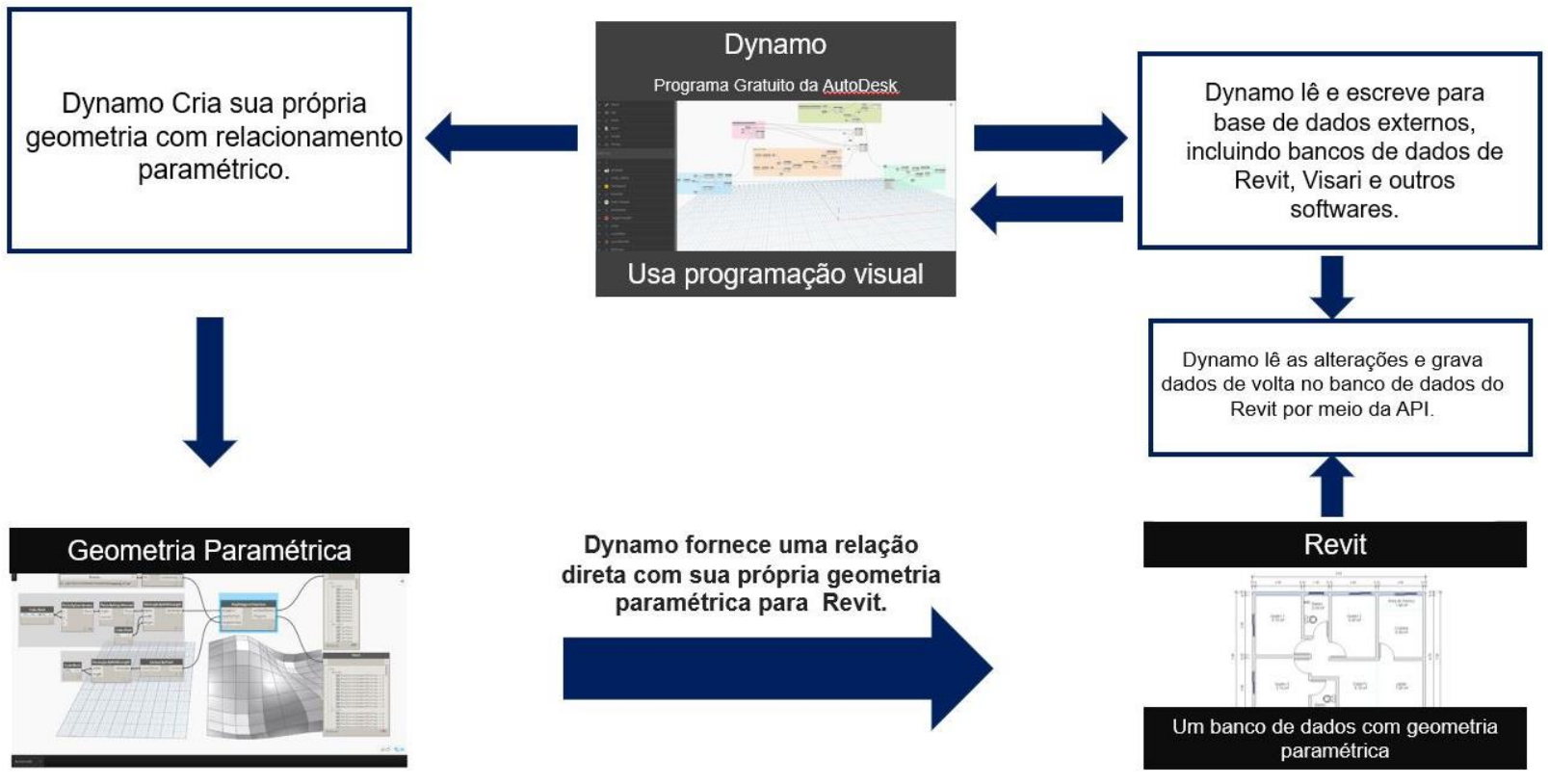

Fonte: Autodesk (2018)

A página inicial disponível quando o Dynamo é inicializado apresenta um conjunto de informações das quais são destacados três itens (Figura 13):

1. o manual Dynamo Primer, que deve ser usado por aqueles que querem fazer uso de automação de processos mais intenso;

2. outras fontes de ajuda, que permitem a consulta ao dicionário do Dynamo e

3. exemplos de rotinas, que permitem compreender o funcionamento dos principais nós de comandos por meio de exemplos, facilitando assim o entendimento dos conceitos apresentados por meio de sua aplicação 


\section{Dynamo}

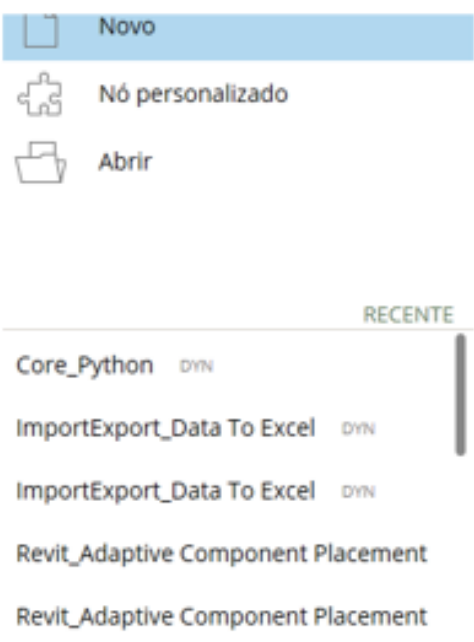

BACKUP Localização do backup

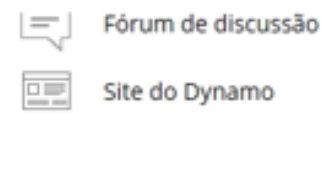

REFERÊNCIA

Iniciar

Dynamo Primer 1

Tutoriais em video 3

Dicionário do Dynamo 2

Repositório Github

Enviar perguntas

AMOSTRAS

Core_AttractorPoint.dyn

Core_CodeBlocks.dyn

Core_ListAtLevel.dyn

Core_ListLacing,dyn

Core_Math.dyn

Core_PassingFunctions.dyn

Core_Python.dyn

Core_RangeSyntax.dyn

Core_Strings.dyn

- Geometrv

Fonte: imagem retirada da interface inicial do Dynamo quando o programa é inicializado

A Figura 14 apresenta quatro telas em que são destacados os principais elementos do Dynamo sobre os quais a programação é realizada. No Quadro 1 destaca-se a aba de ajuda, em vermelho, que é acessada diretamente na interface do usuário; ela oferece as introduções básicas sobre o programa e seu funcionamento. Além disso, nos demais quadros, a numeração em destaque aponta, no [1], para os nós (box) que representam objetos e funções que serão executadas; no [2], os fios (wires) são as conexões entre as funções e o sentido do fluxo de instruções que se dão da esquerda para a direita, como indicado em [3]. Cada nó, por sua vez, funciona com dados de entrada [4] que são processados e geram uma saída com informações [5]; [6]; [7]; [8]; [9]. 
Figura 14 - Guia de introdução - menu ajuda Dynamo
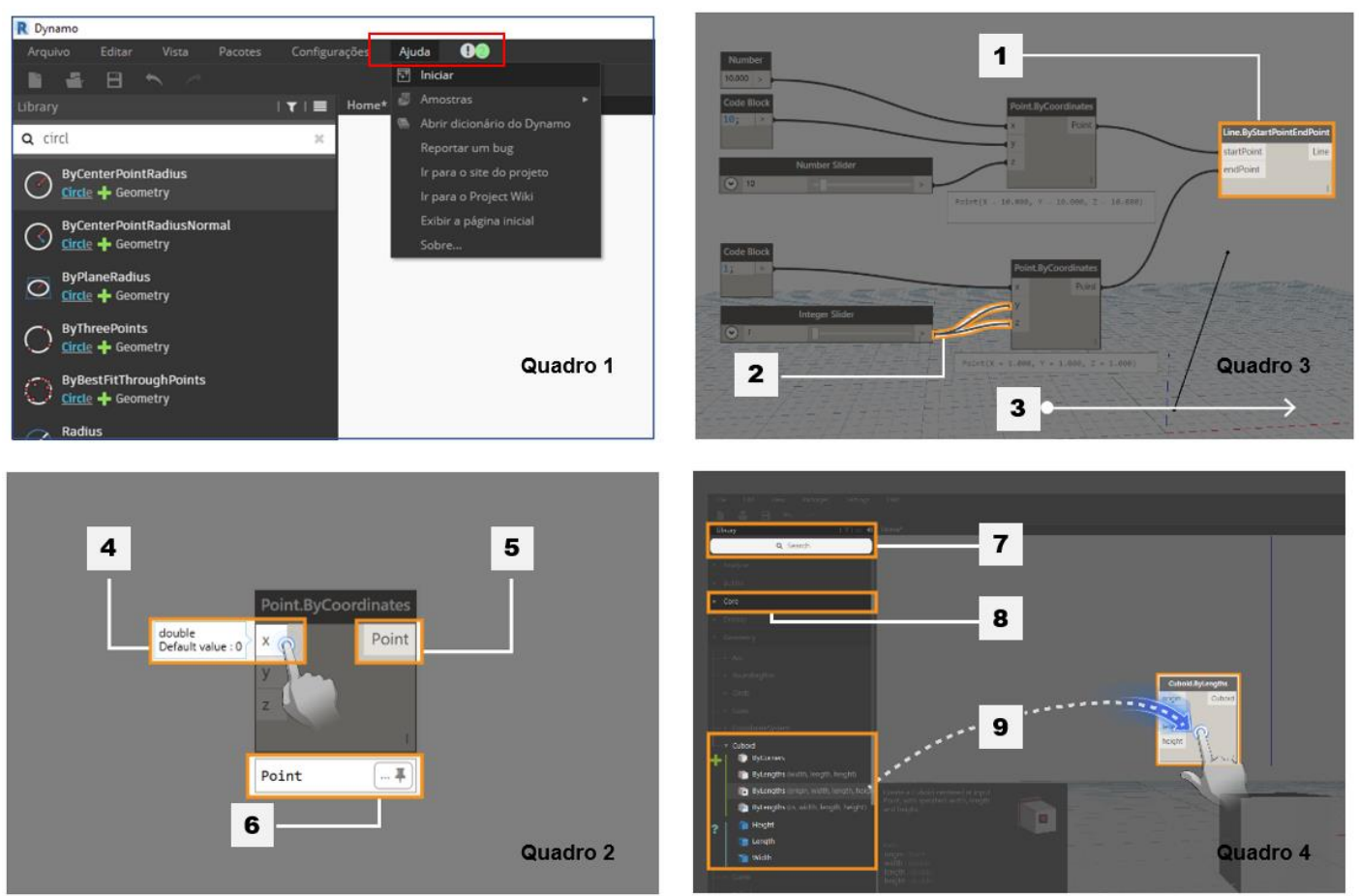

Fonte: Copyright 2017 lan Keough e copyright 2018 Autodesk, Inc, Dynamo core v2.0.2.6826 Dynamo Revit 2.0.2.6833

Por meio desta interface amigável, o usuário pode criar geometrias complexas, modelando, por exemplo, um cone e seccionando-o através de um plano. Pode-se identificar a intersecção entre os dois elementos e transformar essa intersecção em uma viga de aço. Este é um exemplo entre múltiplas possibilidades de automação de procedimentos demorados que não estão disponíveis no Revit, mas podem ser programados no Dynamo (SGAMBELLURI, 2015, p. 6).

Experiências como estas são observadas na aplicação do Dynamo para projetos, evidenciando a principal vantagem da VPL na utilização por profissionais de AECO de interface amigável, que torna a programação mais acessível do que as escritas por meio de C\#, PYTHON ou JAVA (CELANI; VAZ, 2011, p. 180-181). Para Celani e Vaz (2011, p. 181), o fato de alunos das universidades de arquitetura terem mais acesso a disciplinas ligadas a aspectos artísticos do projeto e menos a aspectos computacionais, colabora para este quadro de pouca familiaridade profissional. A predileção pela linguagem mais acessível é apontada pelos desenvolvedores do Dynamo, com destaque à grande comunidade de usuários ativos. 
Mundialmente foram identificados vários grupos de estudo de Dynamo, dentre eles um fórum hospedado pelo site da desenvolvedora do sistema (DYNAMO, [s.d.]). Além disso, uma variedade de tutoriais e manuais estão disponíveis gratuitamente. Entre estes, destaca-se o The Dynamo Primer, a principal fonte de consulta na presente pesquisa, que está acessível para download ou para ser consultado online (DYNAMO, [s.d.]). Entre os conteúdos disponíveis estão informações de instalação, informações sobre interface e exemplos de rotinas que mostram o fluxo e função de cada nó e pacotes de nós do Dynamo (STORMS, 2016, p. 7) ${ }^{21}$.

Entende-se que é importante apresentar o funcionamento e a aplicação das principais rotinas para melhor compreensão dos estudos exploratórios e discussão dos resultados. Estas explanações serão apresentadas a seguir.

\subsubsection{Rotina de buscar parâmetros do Revit}

$\mathrm{O}$ acesso ao banco de dados BIM permite o manuseio dos elementos do modelo por meio de seus parâmetros, que são relativos tanto aos metadados do projeto quanto aos dados geométricos do modelo. No Dynamo, os nós que atendem a esta demanda são Element.GetParemeterValueByName e Element.SetParemeterValueByName.

Yang, Koehl, Grussenmeyer (2018a, p. 1215) ${ }^{22}$ apresentam a perspectiva de uso do Dynamo para levantamento patrimonial histórico em BIM, apontando as seguintes vantagens: manusear elementos do Revit por meio de programação, reduzindo o processo manual de projeto; para se ter a possibilidade de criar geometrias complexas; para trabalhar com geometrias de mesh e transformá-las em elementos de família do Revit; por fim, a vantagem de conectar banco de dados externos, de bases ontológicas, com a geometria do Revit.

\footnotetext{
21 Carl Storms tem quase 20 anos de experiência em arquitetura, engenharia e construção e mais de 5 anos como professor. Através de treinamentos, conferências e consultoria, é facilitador no processo de implantação de tecnologia e processos BIM nos clientes.

22 Xiucheng Yang é mestre pela Universidade de Pequim e pós-doutorando pelo INSA Strasbourg Icube Laboratory, onde é pesquisador de Web of Science.
} 
Figura 15 - Exemplo de rotina para alterar um parâmetro de peitoril do elemento porta

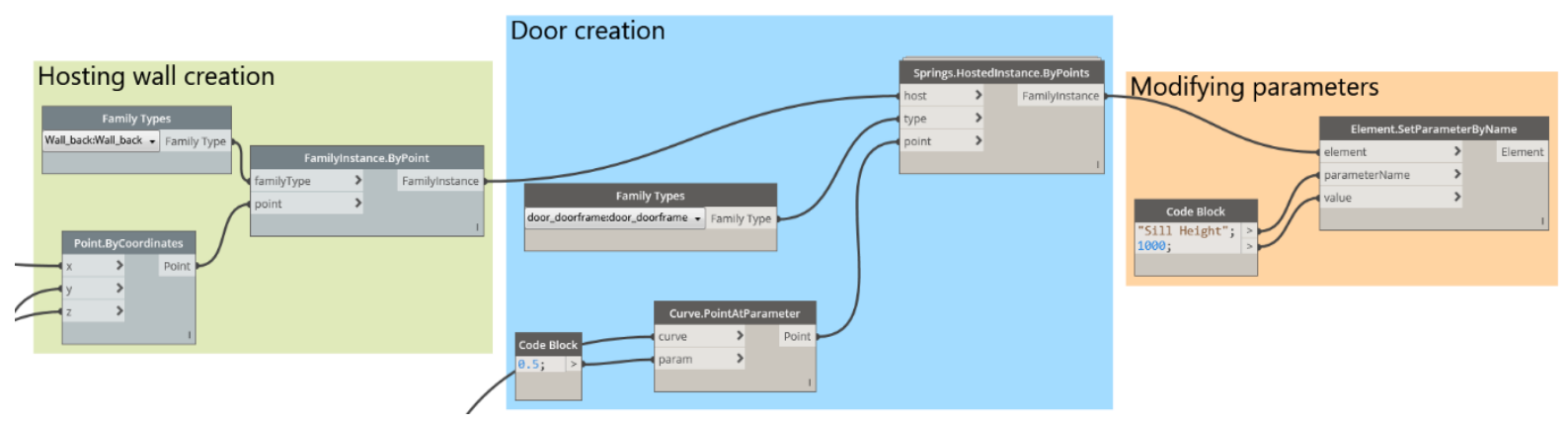

Fonte: (YANG; KOEHL; GRUSSENMEYER, 2018b, p. 1215)

Neste contexto, Yang, Koehl e Grussenmeyer (2018b, p. 1215) apontam a importância de trabalhar com nós em Dynamo, que permitem alterar parâmetros dos elementos, tornando assim possível criar novas geometrias. Um exemplo de programação apresentada na Figura 15 mostra configuração do parâmetro do peitoril da porta criada pelo nó do Dynamo. Vale ressaltar que, dentro do ambiente de programação do Revit, para que o parâmetro do elemento seja alterado ele precisa estar inserido; por isso a rotina cria a porta e, logo em seguida, altera seu parâmetro.

\subsubsection{Rotina de ligar com Excel}

Alguns nós apresentam um uso específico, ligado à comunicação do Dynamo com softwares externos. O item 1 da Figura 16 apresenta um conjunto de nós específicos para a escrita de arquivos em formato de texto. O CVS.WriteToFile exporta dados com a extensão Command Separated Values (CVS), usado em banco de dados para intercâmbio de informações entre arquivos. O File. WriteText em formato de texto e o ImageWriteToFile exporta uma imagem. Logo abaixo do item 1, é demonstrada sua utilização em uma rotina, em que o algoritmo iniciado no item 2 gera as coordenadas $X, Y, Z$, que são dados de entrada para o nó PointbyCoordinate. Então, no item 3 , os pontos são separados novamente em coordenadas $X, Y, Z$ e estas coordenadas, por sua vez, são escritas numa planilha Excel que é aberta pelo Dynamo durante a execução do programa. 
Figura 16 - Nós para a comunicação do banco de dados do Revit com softwares externos

\begin{tabular}{|c|c|c|c|c|c|c|}
\hline \multicolumn{2}{|c|}{ Image.WriteTofile } & \multicolumn{2}{|c|}{ CSV.WriteToFile } & \multicolumn{3}{|c|}{ Fille.WriteText } \\
\hline path & $>$ & filepath & $>$ & filepath & $>$ & void \\
\hline image & $>$ & data & $>$ & text & $>$ & \\
\hline
\end{tabular}

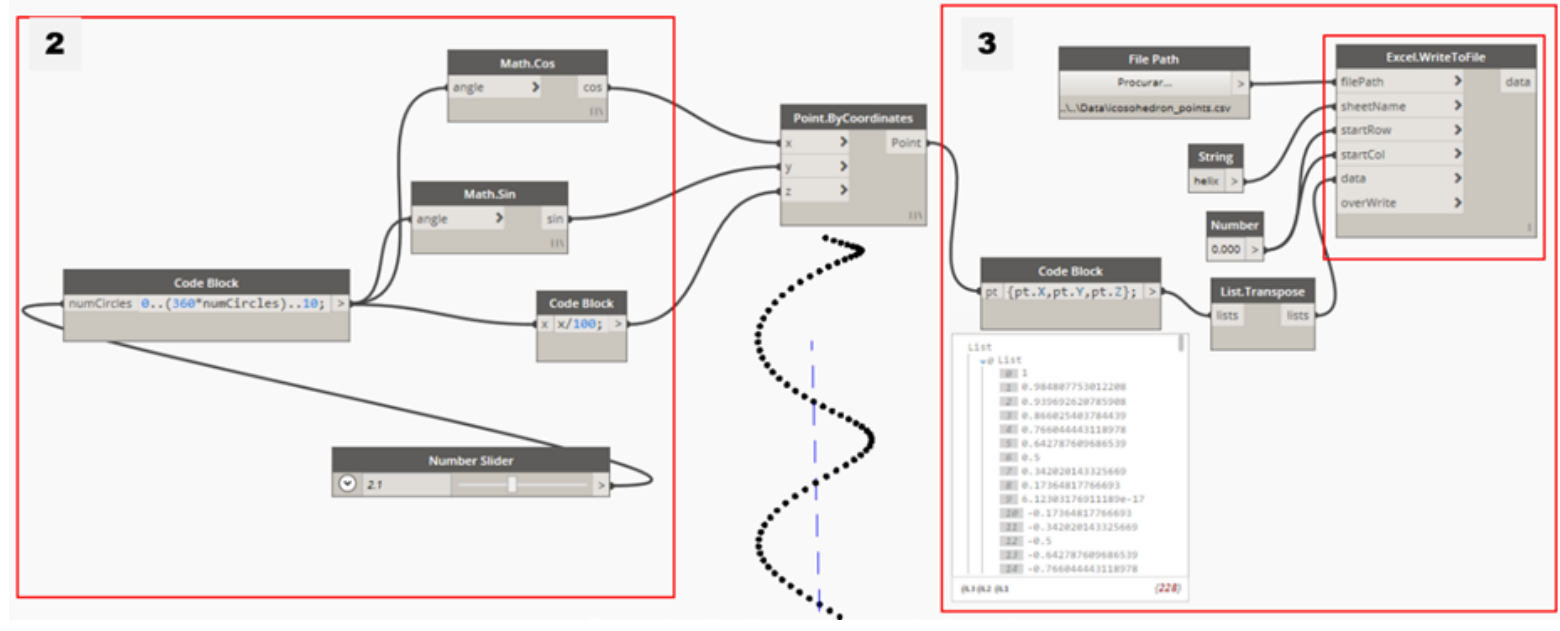

Fonte: Elaborado pelo autor

Outro nó que faz a comunicação efetiva com o Excel é detalhado na Figura 17.

Figura 17 - Nó para escrever dados em planilha Excel

1 Diretório onde está o arquivo excel

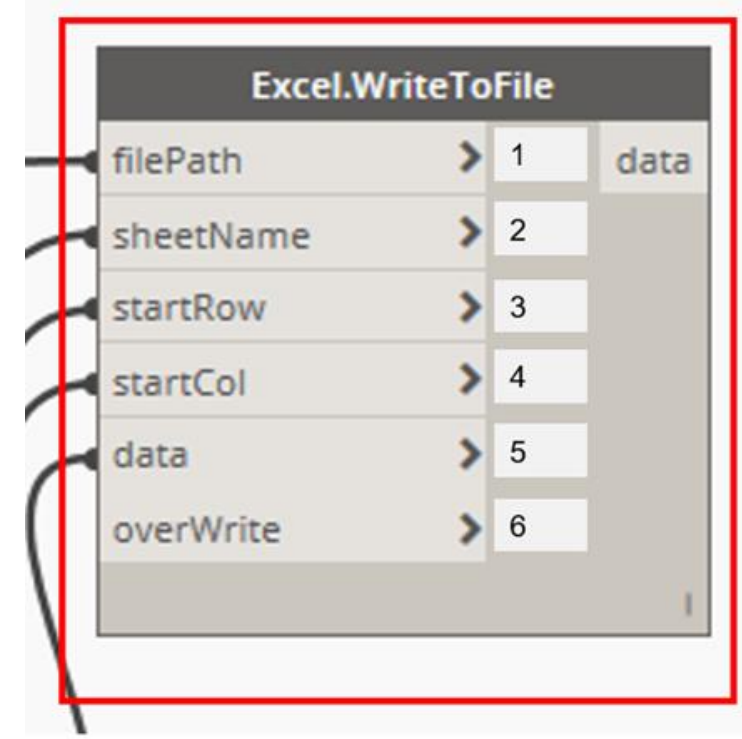

\begin{tabular}{|c|c|c|c|c|c|c|c|c|c|}
\hline Arq & vo Pági l & $\begin{array}{l}\text { Inser La } \\
\text { I }\end{array}$ & $\begin{array}{l}\text { icosohedro... } \\
\text { yo Form Dadc| }\end{array}$ & $\begin{array}{l}\text { Entrar } \\
\text { Revis Exib }\end{array}$ & $\begin{array}{l}\text { Dese } \\
\text { Des }\end{array}$ & Ajud & 8 & $\begin{array}{l}\text { ㅁ } \\
\text { Diga-me }\end{array}$ & $x$ \\
\hline Tran & $\begin{array}{l}\text { ể } \\
\text { éa de } \\
\text { feréncia }\end{array}$ & $\frac{\text { A }}{\text { Fonte }}$ & $\begin{array}{l}\bar{\equiv} \\
\text { Alinhamento }\end{array}$ & $\frac{\%}{\text { Número }}$ & $\begin{array}{l}\text { F⿸户 } \\
\text { 国F } \\
\text { 四 }\end{array}$ & $\begin{array}{l}\text { formata } \\
\text { formata } \\
\text { stilos d }\end{array}$ & $\begin{array}{l}\text { ação Co } \\
\text { ar com } \\
\text { le Célu } \\
\text { Estilos }\end{array}$ & $\begin{array}{l}\text { Condicic } \\
\text { no Tabe, } \\
\text { ula - } \\
\text { os }\end{array}$ & ^ \\
\hline A1 & - & $\vdots$ & $\checkmark \quad f_{x}$ & 1 & & & & & ^ \\
\hline 4 & & 4 & $B$ & $c$ & & D & & E & $\Delta$ \\
\hline 1 & & 1 & & 0 & 0 & & & & \\
\hline 2 & 0,9848 & 807753 & 0,173648178 & & 0,1 & 5 & & & \\
\hline 3 & 0,939 & 692621 & 0,342020143 & & 0,2 & & & & \\
\hline 4 & $0,866 \mathrm{C}$ & 025404 & 0,5 & & 0,3 & & & & \\
\hline 5 & $0,766 C$ & 044443 & 0,64278761 & & 0,4 & & & & \\
\hline 6 & 0,642 & 278761 & 0,766044443 & & 0,5 & & & & \\
\hline 7 & & 0,5 & 0,866025404 & & 0,6 & & & & \\
\hline 8 & $0,342 C$ & 020143 & 0,939692621 & & 0,7 & & & & \\
\hline 9 & 0,173 & 648178 & 0,984807753 & & 0,8 & & & & \\
\hline 10 & & $12 \mathrm{E}-17$ & 1 & 1 & 0,9 & & & & \\
\hline 11 & $-0,1736$ & 548178 & 0,984807753 & & 1 & & & & \\
\hline 12 & $-0,342$ & 20143 & 0,939692621 & & 1,1 & & & & \\
\hline 13 & & $-0,5$ & 0,866025404 & & 1,2 & & & & $\nabla$ \\
\hline & , 2 & helix & icosohec ... & .. $\oplus$ & 1 & & & & 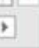 \\
\hline 웁 & & & 曲 & 巴 & - & 1 & & -+100 & $9 \%$ \\
\hline
\end{tabular}

Fonte: Elaborado pelo autor 
Os dados de entrada indicam a planilha que será aberta, seu local no diretório e qual Sheet dentro da planilha será aberto. Também é possível determinar em qual linha e coluna os dados começam a ser escritos. Esta rotina demonstra a capacidade da linguagem em obter dados do modelo Revit e também a poderosa comunicação entre o Dynamo e o Excel.

Ademais, análogo ao comando explicado na Figura 17, o nó Excel.FileRead pode ler dados de uma planilha do Excel e transferi-los para o Dynamo, que pode então repassar para parâmetros em famílias por meio de um determinado algoritmo. Além destes, existe ainda um conjunto de nós que leem outros formatos de dados, a depender do interesse do programador.

Sgambelluri e John (2014, p. 64) exemplificam a utilização de um algoritmo que permite a leitura e modificação das informações de uma planilha em Excel que contém as coordenadas para criação de topografia no Revit (Figura 18 a). Nesta rotina, a altura dos pontos da topografia que intersecciona um arrimo projetado foi corrigida automaticamente pelo Dynamo, em função de um dado de entrada do Excel (Figura 18 b). A rotina funciona da seguinte maneira: o terreno dentro do Revit pode ser modelado a partir de pontos $x, y, z$. Esses pontos estão descritos na planilha apresentada na Figura 18, onde as colunas representam os pontos e as linhas, as coordenadas de cada ponto; a célula A1 representa a coordenada $z$ do ponto $1 \mathrm{e}$ assim sucessivamente. A Figura $18 \mathrm{~b}$ apresenta na célula A8 um valor que será aplicado a todas coordenadas $z$ de todos os pontos do terreno que faceiam o muro de arrimo. 
Figura 18 - Ajuste de topografia automática por meio da leitura de planilha Excel

[a]

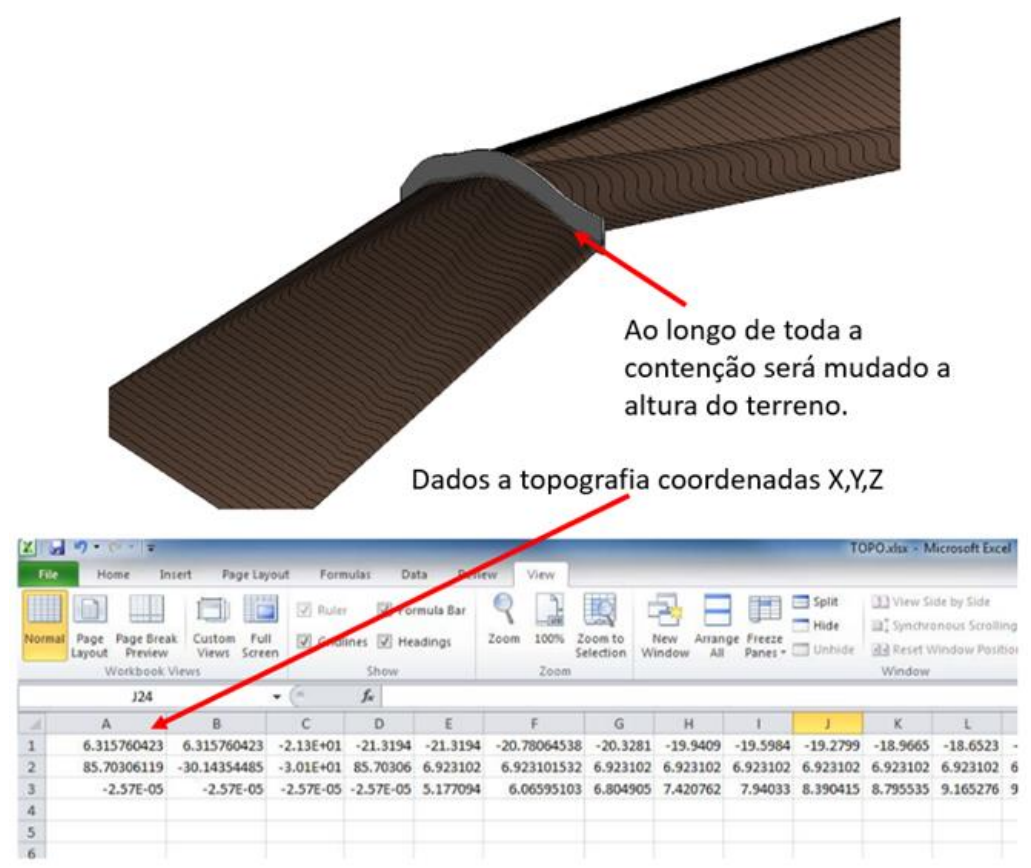

Fonte: (SGAMBELLURI, 2015, p. 63)

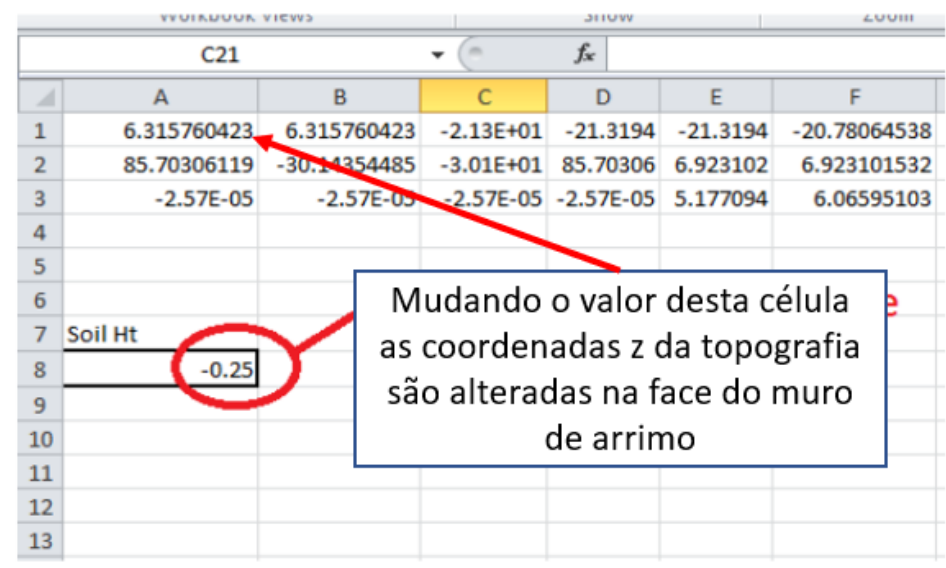

(B) A

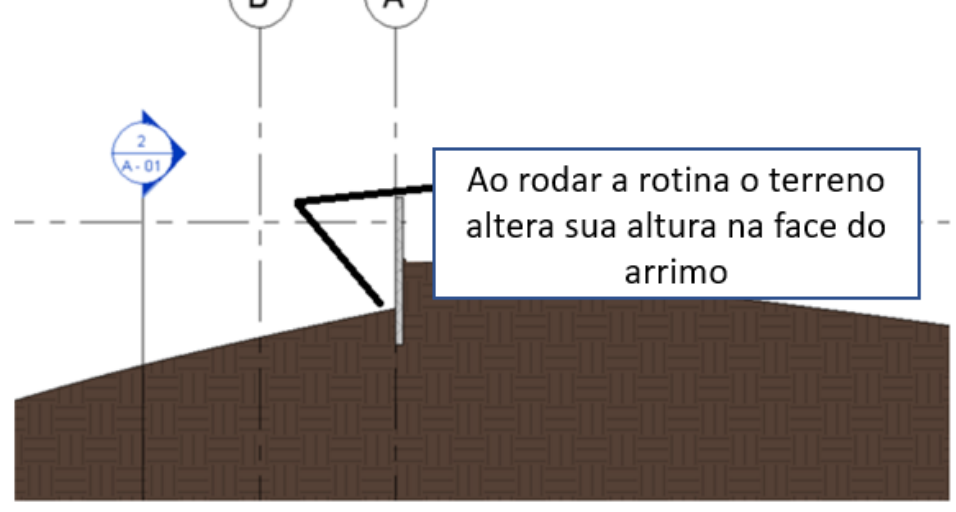

[b]

Fonte: (SGAMBELLURI, 2015, p. 65) 


\subsubsection{Formas Complexas / Adaptive components}

Adaptive components correspondem a um tipo de objetos que podem ser criados no Revit com programação por meio do Dynamo. Como característica principal, estes componentes ou objetos apresentam uma estrutura flexível capaz de se adaptar às condições ou contextos específicos. A Autodesk Knowledge Network (AUTODESK, [s.d.]) descreve os Adaptive components como uma adaptação dos painéis de paredes cortina "[...] que podem ser usados em sistemas repetitivos gerados pela ordenação de componentes múltiplos que obedecem às restrições definidas pelo usuário" (AUTODESK, [s.d.]).

Figura 19 - Rotina para experimentar o número de tesouras em telhado

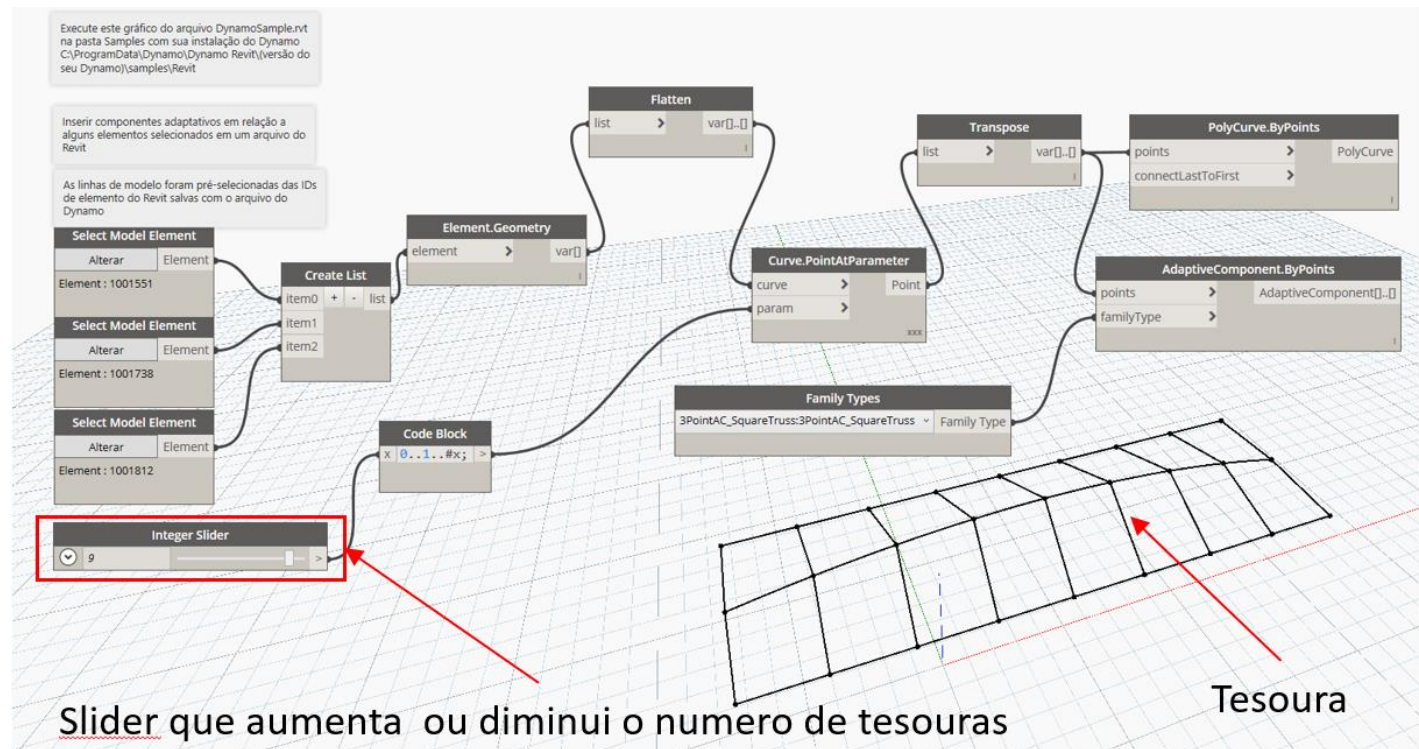

Fonte: Autodesk

Assim, o uso da programação se dá para criar várias alternativas no desenvolvimento de formas e pode gerar vários experimentos somente possíveis com a automação. A rotina descrita na Figura 19 (encontrada na pasta de exemplos instalados com o Dynamo) ${ }^{23}$, automatiza a criação de uma tesoura de telhado que diminui ou aumenta sua altura em função do número de peças criadas. Este número varia conforme o movimento do nó de slider disponível na rotina.

${ }^{23}$ C:|Program\DynamolDynamoRevit11.3\Samples|pt-BR\Revit_Adaptive ComponentPlacement.dyn 
Já a Figura 20 demonstra como a aplicação da rotina altera o modelo do projeto. Por meio desta automação, um processo de ajustes que demandaria muito tempo para ser realizado manualmente pode ser realizado em segundos. Isto permite maior eficiência na experimentação de alternativas de projeto, o que pode proporcionar uma maior velocidade e qualidade na obtenção da solução final adotada pelo projetista.

Figura 20 - Opções de tesouras adaptadas à curva no telhado

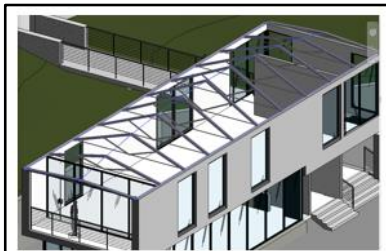

11 Tesouras

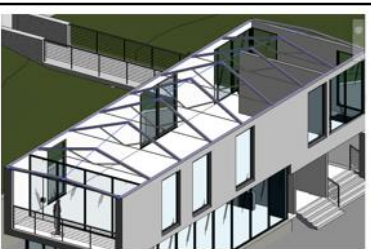

9 Tesouras

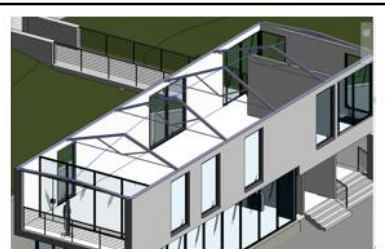

6 Tesouras

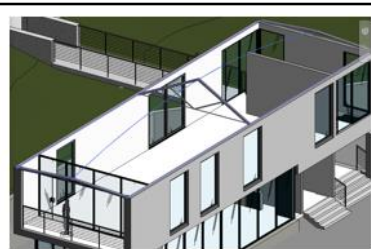

3 Tesouras

Fonte: Elaborado pelo autor

Alhadidi e Kimm $(2014 \text {, p. 3/46) })^{24}$ observam que o uso da computação nos projetos de arquitetura tem um grande impacto no resultado formal, influenciando tanto a percepção quanto a realização da solução integrada de aspectos espaciais e técnicos. Uma perspectiva computacional para a arquitetura altera consideravelmente a maneira como projetistas trabalham, permitindo explorar novas ideias e promover a inovação na indústria da construção.

\subsubsection{Rotinas para trabalhar com Python}

O Dynamo permite que se possa fazer programação através de códigos de texto usando dois tipos de "Nós": os nós do Python e nós de comando da linguagem Design Script. O Python é uma linguagem de programação largamente usada e um dos motivos para isso é a sua fácil sintaxe. Por ser um código mais análogo à escrita comum, seu aprendizado se torna mais fácil do que outras linguagens de programação (AUTODESK, 2018, p. 370).

As VPL's são linguagens intuitivas, porém em determinados casos podem ficar muito extensas e a criação de um número muito grande de nós e interconexões

\footnotetext{
${ }^{24}$ Suleiman Alhadidi é arquiteto, pesquisador e engenheiro. É o principal pesquisador do City Science Group (Changing Places) - MIT Media Lab. Sua pesquisa é focada no desenvolvimento da próxima geração de edificações acessíveis equipadas roboticamente para promover o empreendendorismo, aumentar a qualidade de vida e o desempenho no ambiente construído e nas cidades.
} 
termina por dificultar o seu entendimento. Algoritmos que poderiam ser resolvidos com pequenas linhas de código se tornam muito extensos e complexos. Na Figura 21 podemos verificar um exemplo da comparação dos dois tipos de código.

Figura 21 - Algoritmo escrito em uma VPL e a mesma codificação feita em Python

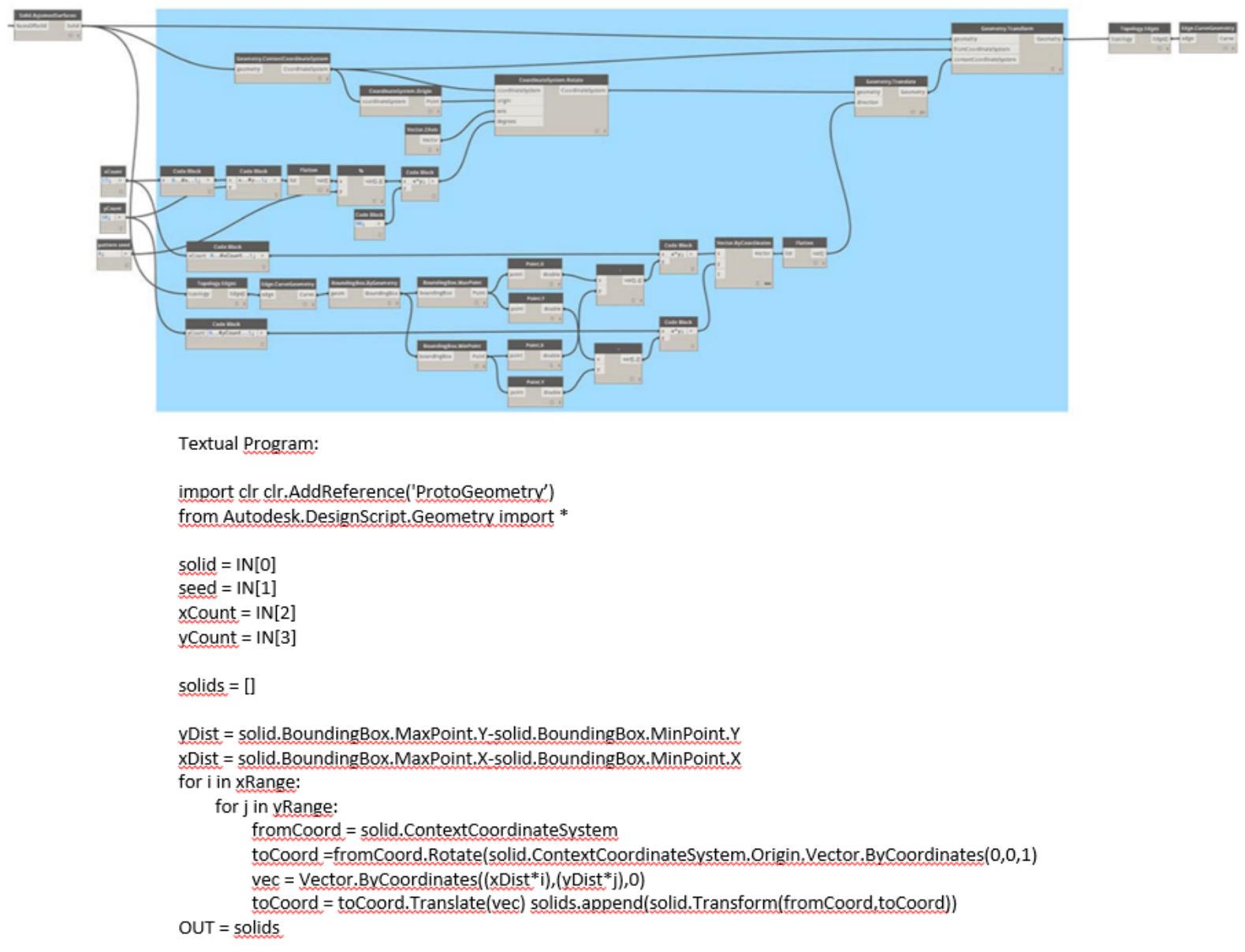

Fonte: (AUTODESK, 2018, p. 371)

Existem várias vantagens em se usar uma linguagem VPL, principalmente por usuários que não são programadores ou não entendem essa lógica. No entanto, alguns conceitos desta área se fazem necessários para superar limites das barreiras que a VPL's podem oferecer . O manual do Dynamo The Dynamo Primer aponta no seguinte sentido: "O Python é uma ferramenta poderosa que pode estender os recursos do Dynamo e permitir a substituição de muitos nós por algumas linhas de código concisas." (AUTODESK, 2018, p. 370) ${ }^{25}$ [tradução nossa].

25 Python is a powerful tool that can extend the capabilities of Dynamo and allow you to replace many nodes with a few concise lines of code. 
Não é raro em algoritmos mais extensos ou com tarefas mais complexas o uso de nós de Python (Figura 22). Para Ignatova, Zotkin e Zotkina (2018, p. 5), atribuir parâmetros às famílias de dutos somente usando os nós do Dynamo não atendeu a necessidade imposta pelo algoritmo, sendo necessário o uso da linguagem Python para a solução do problema.

Figura 22 - Nó em Python para input de parâmetros em todos os elementos de uma categoria

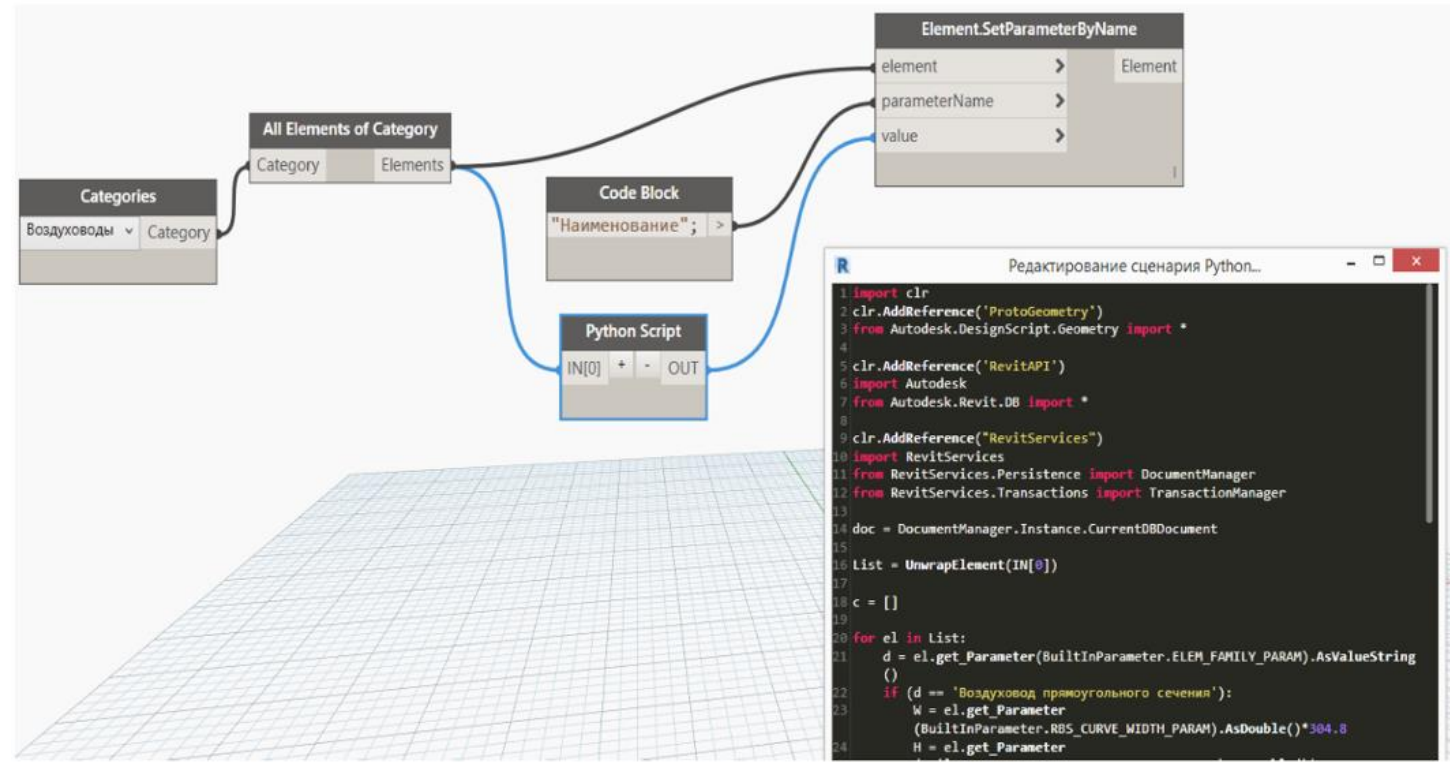

Fonte: (IGNATOVA; ZOTKIN; ZOTKINA, 2018, p. 6)

$\mathrm{Na}$ criação de nós customizados, nós de Python também são usados com frequência. Uma referência para o bom entendimento de como usar o Python com o Dynamo pode ser avaliada em uma conferência postada no Youtube por Danny Bentley e Dennis Eldridge (BENTLEY; ELDRIDGE, 2017).

\subsubsection{Uso de Design Script}

A linguagem de programação Design Script foi criada com um propósito diferente de outras linguagens como Python, C\#, dentre outras. Para que estas linguagens atinjam objetivos específicos de construções geométricas e algoritmos que manuseiem elementos de um edifício, um grande esforço de programação deve ser executado. Por outro lado, o Design Script tem seu viés direcionado para este fim. Através do uso da linguagem se manifestam intenções de design que, por sua vez, 
podem ser expressos de várias formas. As linguagens de programação demonstram uma lógica e estão atreladas a cálculos e não é diferente com o Design Script. Entretanto, a principal vertente da linguagem é lidar com geometria (TIERNEY, [s.d.], p. 5$)^{26}$.

O Design Script traz consigo uma maneira de escrever códigos que está ligada ao uso progressivo da linguagem na criação de um projeto. Isso significa que muitas vezes o programador não tem o resultado final construído e ele pode fazer alterações em função do experimento de design que a própria ferramenta permite experimentar (Figura 23).

\section{Figura 23 - Utiliza Design Script para criar um objeto a partir de pontos: Bezier e Surface} Revole
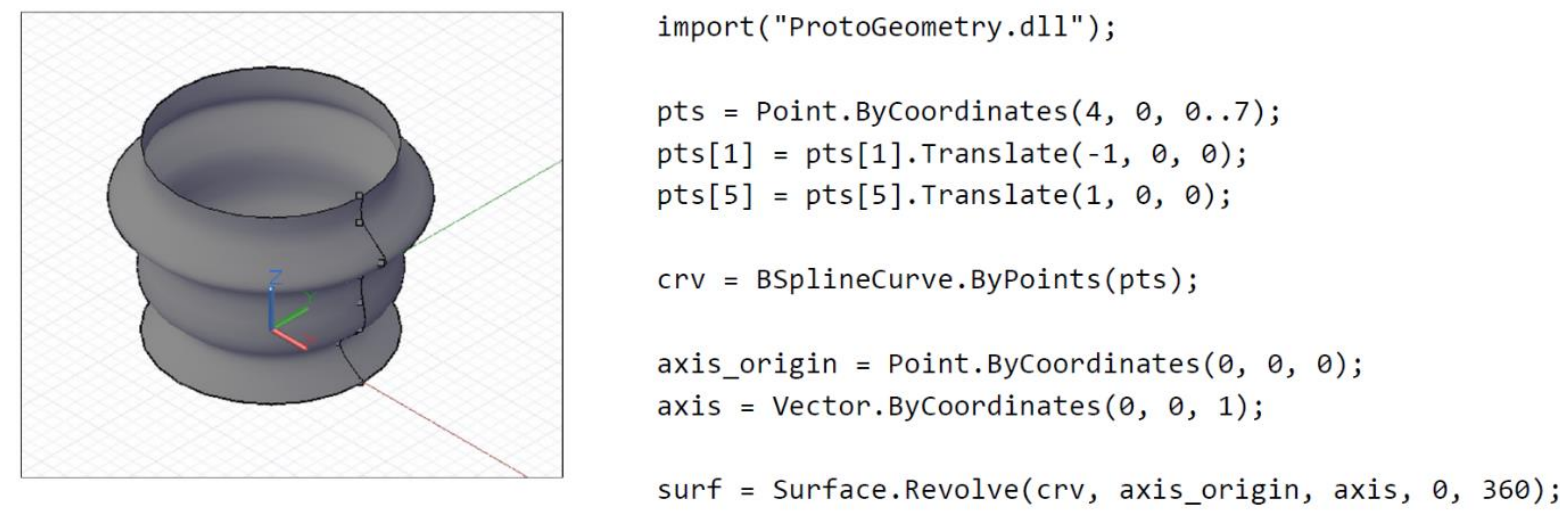

Fonte: (TIERNEY, [s.d.], p. 65)

A Programação Visual tem uma fácil interface de comunicação com o usuário: os nós e as conexões através de fios. Facilmente se pode ampliar o poder dos algoritmos acrescentando nós, muitos ainda não conhecidos ou nunca utilizados pelo programador. Essa interface intuitiva é entendida como uma vantagem, na medida em que permite que programadores com pouca experiência comecem fazendo códigos e usando ferramentas para automatizar processos.

Entretanto, quando rotinas se tornam muito extensas ou tem muitas recursividades o uso da programação visual através de nós pode não ser a melhor solução. O uso excessivo de nós pode deixar o código muito difícil de ser entendido.

\footnotetext{
${ }^{26}$ Patrick Tierney é graduado em Arquitetura pela UCLA e Mestre pela Princeton University; BA UCLA). Trabalha como engenheiro de software na Autodesk e seu trabalho é a síntese de projetar com o auxílio da programação. Tierney projeta em DesignScript e Dynamo e auxilia os profissionais da área de AECO a trabalhar de forma otimizada na tecnologia BIM.
} 
Nestes casos o uso de linguagem escrita é mais adequado. Por esse motivo, usar a forma correta de expressar a linguagem é importante.(AUTODESK, 2015, p. 1)

Figura 24 - Nó do Dynamo usando a linguagem DesignScript

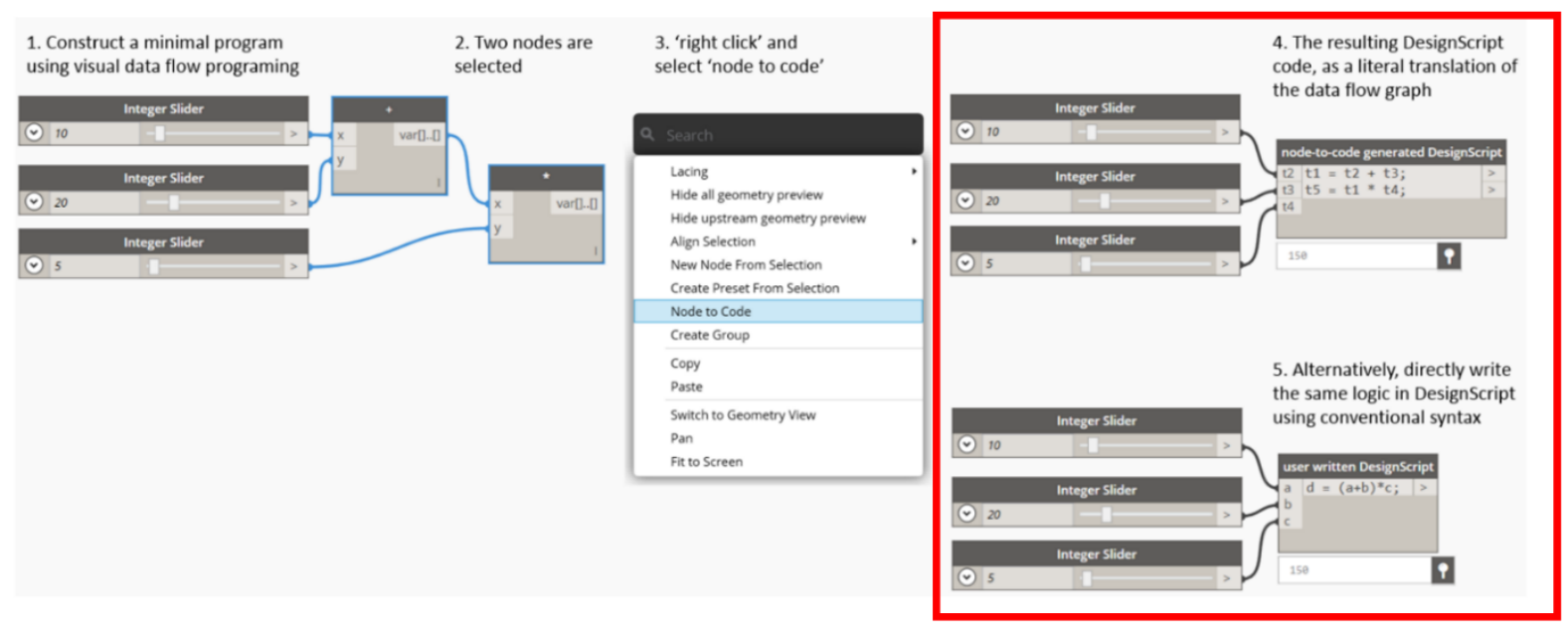

Fonte: (AUTODESK, 2015, p. 1)

O Dynamo usa o compilador do Design Script e seu motor de execução para rodar os nós. Portanto, cada nó do Dynamo é, na realidade, uma declaração em Design Script (Figura 24). Para escrever um código em Design Script, basta clicar duas vezes no canvas do Dynamo e o nó Code Block.

Figura 25 - Code Block nó para a escrita de código Design Script

1. The independent variables $(a, b, c)$ in the expression are assigned their respective values from the 'input' ports

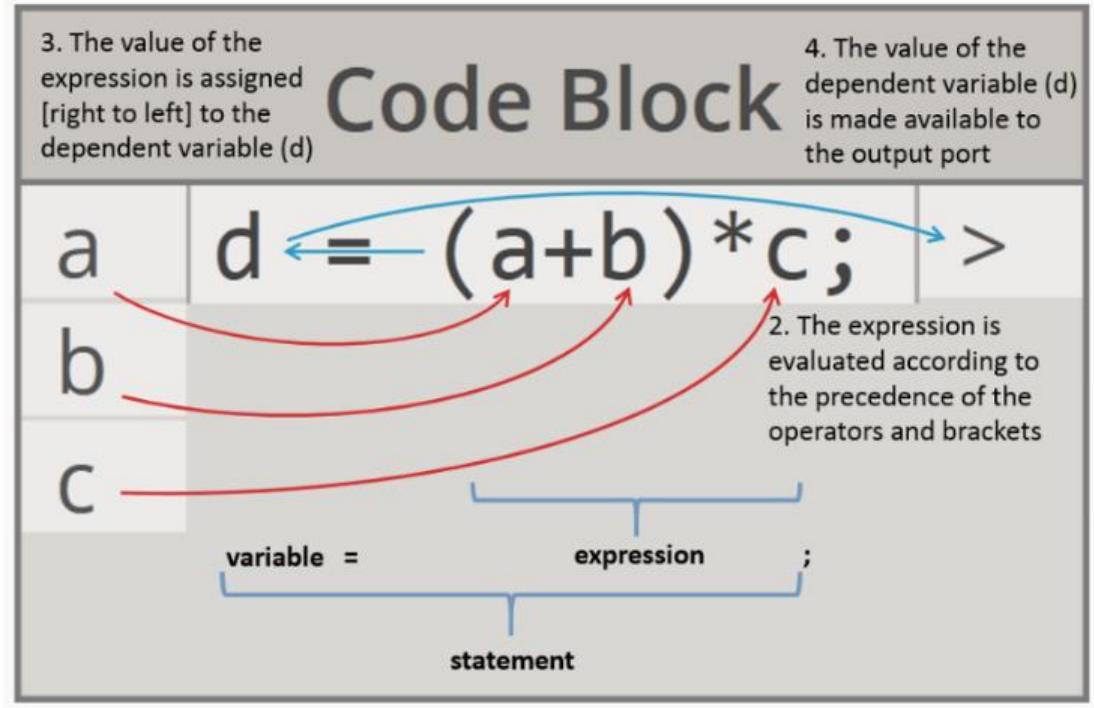

Fonte: (AUTODESK, 2015, p. 2) 
Este nó possui, do lado esquerdo (assim como outros nós do Dynamo), a entrada de dados e, do lado direito, a saída. À medida em que se digitam variáveis, internamente o código começa a criar suas variáveis de entrada e saída de maneira automática, aspecto muito funcional para o programador (Figura 25).

\subsubsection{Nós customizados}

Por ser uma linguagem de programação open source, é possível criar nós customizados no Dynamo, que podem ser compartilhados em seus próprios códigos ou com outros usuários. Algumas das vantagens de se fazer nós customizados estão escritas no próprio manual The Dynamo Primer Guide (AUTODESK, 2018, p. 356$363)$, como se segue: quando criamos nós customizados, podemos deixar nosso código mais claro e limpo; caso tenhamos que mudar alguma coisa na rotina, se temos um nó que se junta a vários, a mudança pode ser propagada sem maiores esforços; mas talvez a mais importante das características dos nós personalizados seja a possibilidade de distribuição deles para a comunidade. Se usuários experientes compartilham seus nós proprietários, contribuem com toda a comunidade que avança no uso de automação de processos, usando linguagem de programação acessível, sem necessidade de ter muito conhecimento de como programar.

Figura 26 - Descrição de como criar um nó personalizado no Dynamo

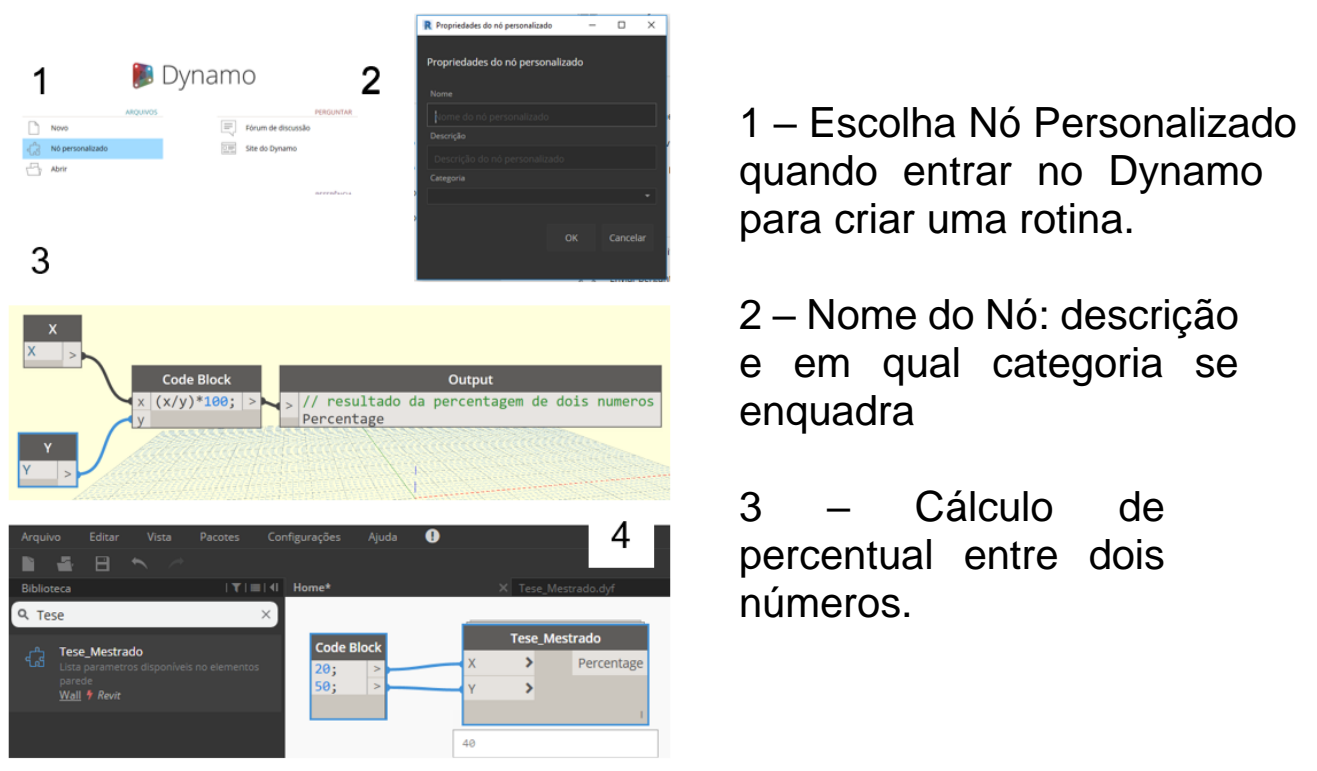

Fonte: Autor referência The Dynamo Primer Manual 
Por isso, criar um nó personalizado não é uma tarefa complicada; o Dynamo praticamente assume todo o gerenciamento do fluxo necessário para que isto aconteça. É imperioso usar nós de input e output (Figura 26); o procedimento é similar ao de criar um código na interface.

Uma vez criado, o nó pode ser publicado para que, sempre que se abra uma seção do Dynamo, ele esteja disponível. Isto é executado abrindo o nó customizado criado e apertando o mouse do lado direito; no canvas do Dynamo, a opção de publicar o Nó aparece e deve ser salva numa pasta desejada. O software lerá sempre os nós salvos neste local, deixando-os disponíveis. A dinâmica usada pelos desenvolvedores do software procura deixar as coisas o mais simples possível e, neste sentido, facilitar para aqueles usuários que não são programadores.

\subsubsection{Pacotes externos de dados}

Uma das grandes possibilidades que o Dynamo traz é sua capacidade de criar novas funções através da comunidade de usuários que podem trabalhar diretamente na linguagem do software, mas principalmente através de Pacotes. Resumidamente, pacotes são coleções de nós que acrescentam novas funções ao Dynamo e estão disponíveis na internet para serem instalados (DYNAMO, [s.d.]) via aba pacote na interface do usuário. Até a nossa última pesquisa, o LunchBox for Dynamo era um dos pacotes mais baixados, seguido de perto pelo archi-lab.net, ambos com aproximadamente 16.000 downloads. Depois de instalados no computador normalmente, os pacotes podem ser vistos e abertos através do seu acesso ao local onde foi armazenado.

O acesso à pasta onde os novos nós são armazenados é útil pois são códigos abertos e o usuário pode usar a lógica por trás dos nós publicados em seu favor para melhorá-los, usá-los como referência para criar novos algoritmos e tecer comentários a respeito de possíveis aperfeiçoamentos, podendo ser direcionados aos autores do pacote. A Figura 27 mostra o nó LunchBox Attractor e sua lógica. Para a criação deste nó customizado, foram usadas as funções out of the box, instaladas com o pacote original Dynamo, acrescentando uma outra rotina com o nó do Python para recursividade e tomada de decisão com o comando IF. 
Figura 27 - Nó customizado pacote do Lunchbox

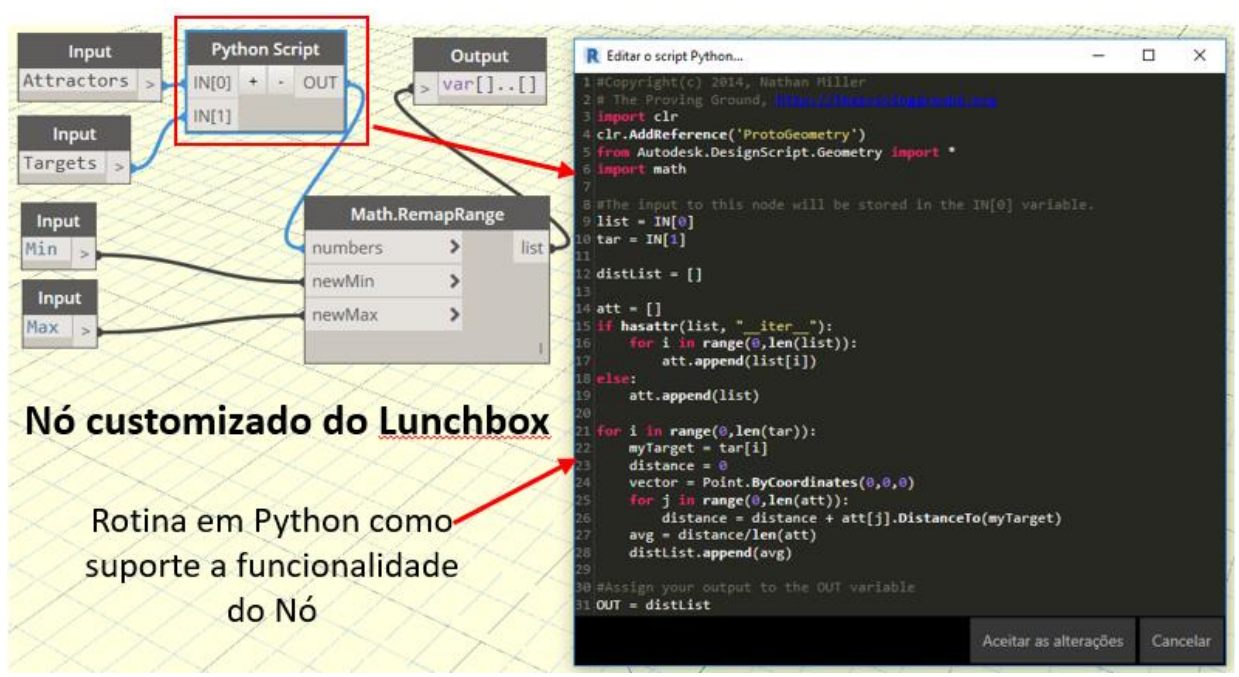

Fonte: Autor referência: Dynamo

A partir das últimas versões do Lunchbox, foram acrescentados nós referentes à Artificial Inteligence, algoritmos de Machine Learning, usando classificações, regressões e outros modelos de aprendizado de máquina. É uma nova porta que se abre na automação de projetos arquitetônicos, um avanço na linguagem. Apesar de existirem outras linguagens de programação textual que permitem o uso de algoritmos já pré-configurados, as VPL's são bem mais intuitivas (Figura 28).

Figura 28 - Pacote para o Dynamo LunchBox - Linguagem de Máquina

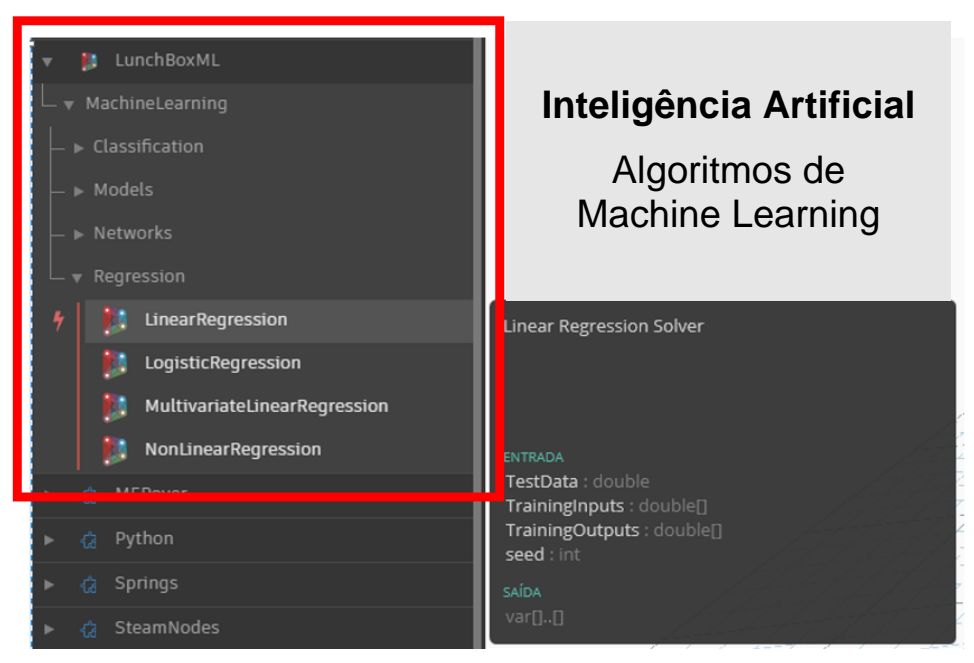

Fonte: (DYNAMO, [s.d.]) 


\subsubsection{Listas no Dynamo}

A estrutura de dados é fundamental para a programação, o armazenamento e a consulta desses: ela define como os dados são alocados na memória do computador e permite o processamento dos mesmos para que um determinado resultado seja alcançado. Entender a estrutura de dados de uma base de informações se torna chave para o manuseio destas.

Tendo sido formatada e criada, a base de dados pode ser acessada seguidamente sem preocupações de como é feito o gerenciamento desses dados na memória. As principais estruturas de dados são: Array (vetores e matrizes), Listas, Pilhas, Arvores As listas são uma das mais simples estruturas de dados, no entanto é possível manipulá-las de várias formas atribuindo funções e operações às mesmas. $A$ modelagem paramétrica usa as listas, formas rápidas e contingenciais de manipular os dados. Os programadores de modelagem paramétrica devem ter como prioridade aprender a manipular as listas (WOODBURY, 2010a, p. 58) ${ }^{27}$. As listas podem conter diversos valores para uma variável que podem ser acessados através seus index; uma lista pode ter sublistas e os tipos de variáveis podem ser numéricas ou alfanuméricas. A Figura 29 ilustra a estrutura de uma lista e o acesso aos dados através de chamada de seus indexs.

Figura 29 - Estrutura e acesso aos dados de uma lista

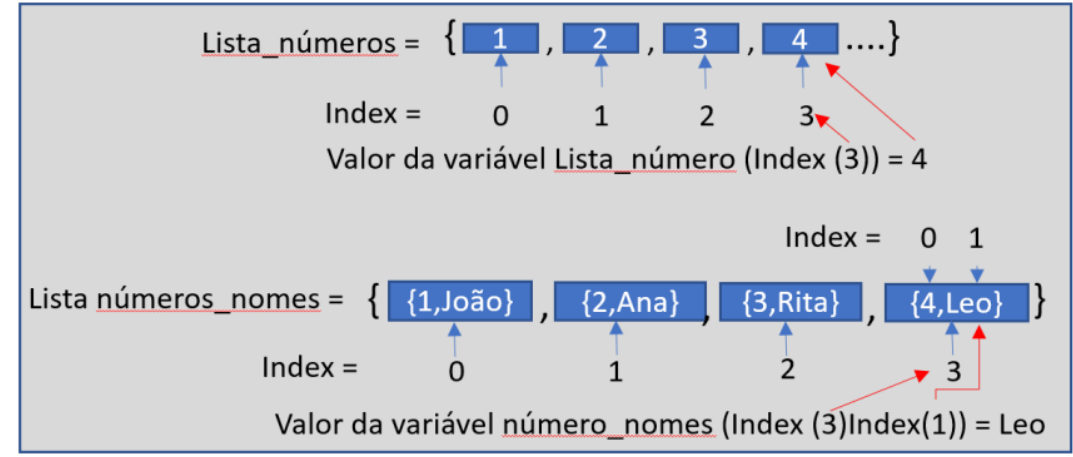

Fonte: Autor referência: Dynamo

\footnotetext{
${ }^{27}$ Robert Woodbury é Professor Universitário graduado pela Carleton University, Mestre e Pós Doutor pela Carnegie Mellon University. Atualmente trabalha na Simon Fraser University, no campus de Surrey, Canadá. Seus principais focos de interesse são o Design Computacional, Visual Analytics e Sustentabilidade. Tem mais de 150 publicações e prêmios relevantes.
} 
O uso e entendimento de listas também se faz necessário para o uso adequado de automação de processos usando a base de dados do Revit em conjunto com nós do Dynamo. The Dynamo Primer Guide (AUTODESK, 2018, p. 175) dedica uma seção específica para o entendimento de listas. Podemos encontrar vários exemplos do uso de listas nesta seção. Uma outra fonte para o acesso rápido e prático de como as listas podem ser usadas está no endereço eletrônico (KIM, 2018).

Figura 30 - Estrutura usada para extração de parâmetros de elementos no Revit

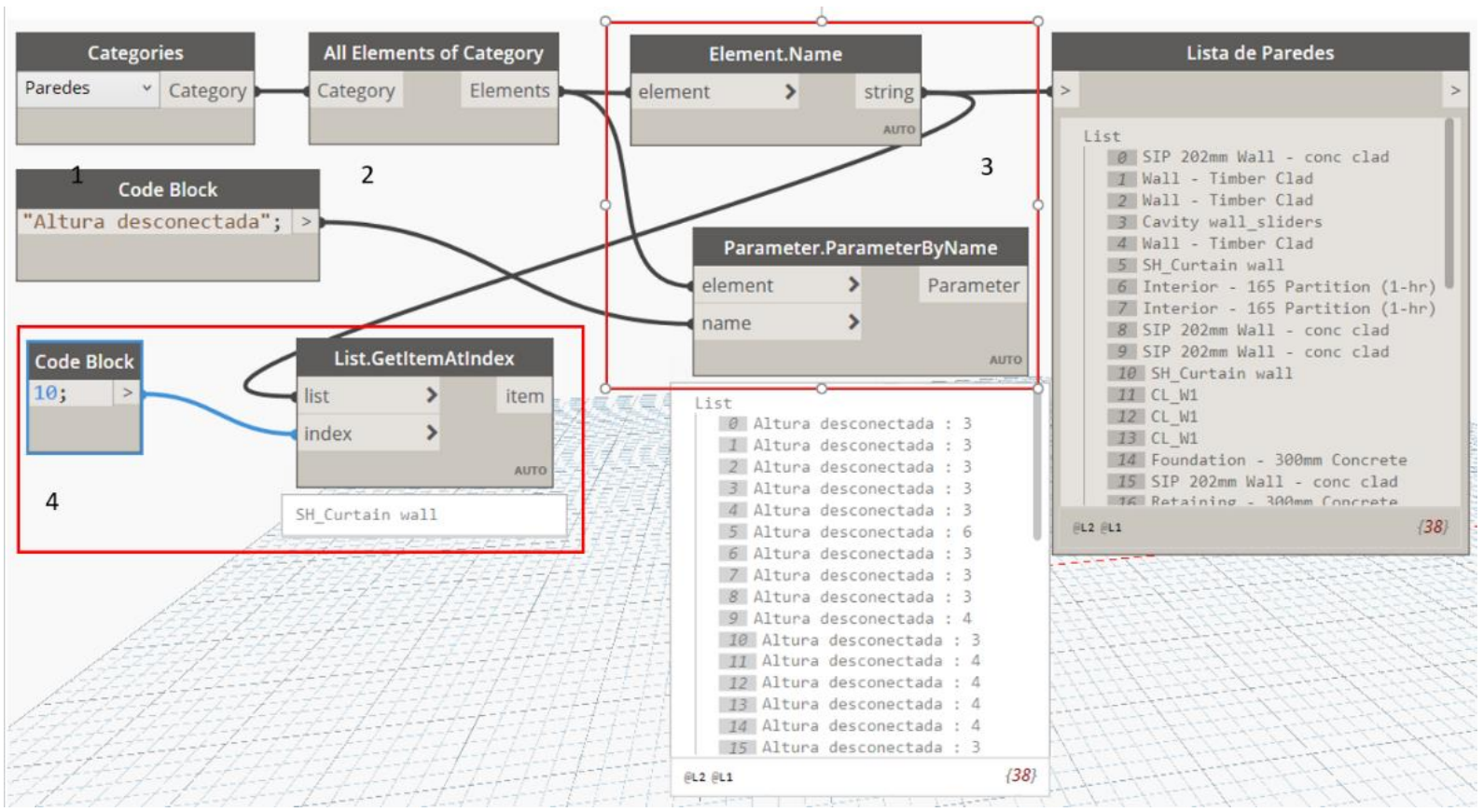

Fonte: Autor referência: Dynamo

A Figura 30 ilustra umas das formas muito usadas em algoritmos de consulta e manipulação de dados de elementos inseridos no projeto. O nó Categories (1) seleciona a categoria de elementos que se quer processar, em seguida o nó All.elementsOf.Categories (2) busca todos os elementos daquela categoria inseridas no projeto e o conjunto de nós Element.Name e Parameter.ParameterByName (3) pega os nomes dos tipos de famílias de paredes que foram inseridas no projeto $\mathrm{e}$ seleciona o parâmetro de Altura desconectada. Neste exemplo pode ser observado que os nós geram listas. Um item da lista pode ser acessado e o seu parâmetro de Altura desconectada mudado; os parâmetros podem mudar tanto a forma geométrica como os metadados atrelados aos elementos, criando possibilidades de manipulação destas informações através de algoritmos de automação. Para acessar 
um item da lista, o nó List.GetltemAtIndex (4) pode ser usado; ele tem como entrada a lista e um número inteiro. Um item da lista pode ser selecionado através do seu index (Figura 30).

\subsubsection{Dicionário}

A partir do Dynamo versão 2.x foi introduzido o conceito de dicionário. Esse é um tipo de dado composto por uma coleção feita por pares de valores-chave, onde cada chave é única para uma determinada coleção. Enquanto em uma lista acessase a um determinado item dela por meio de seu índice, em um dicionário acessa-se um item através do uso de chaves (AUTODESK, 2018, p. 335).

Figura 31 - Uso de nó de Dicionário - Dictionary.ValueAtKey

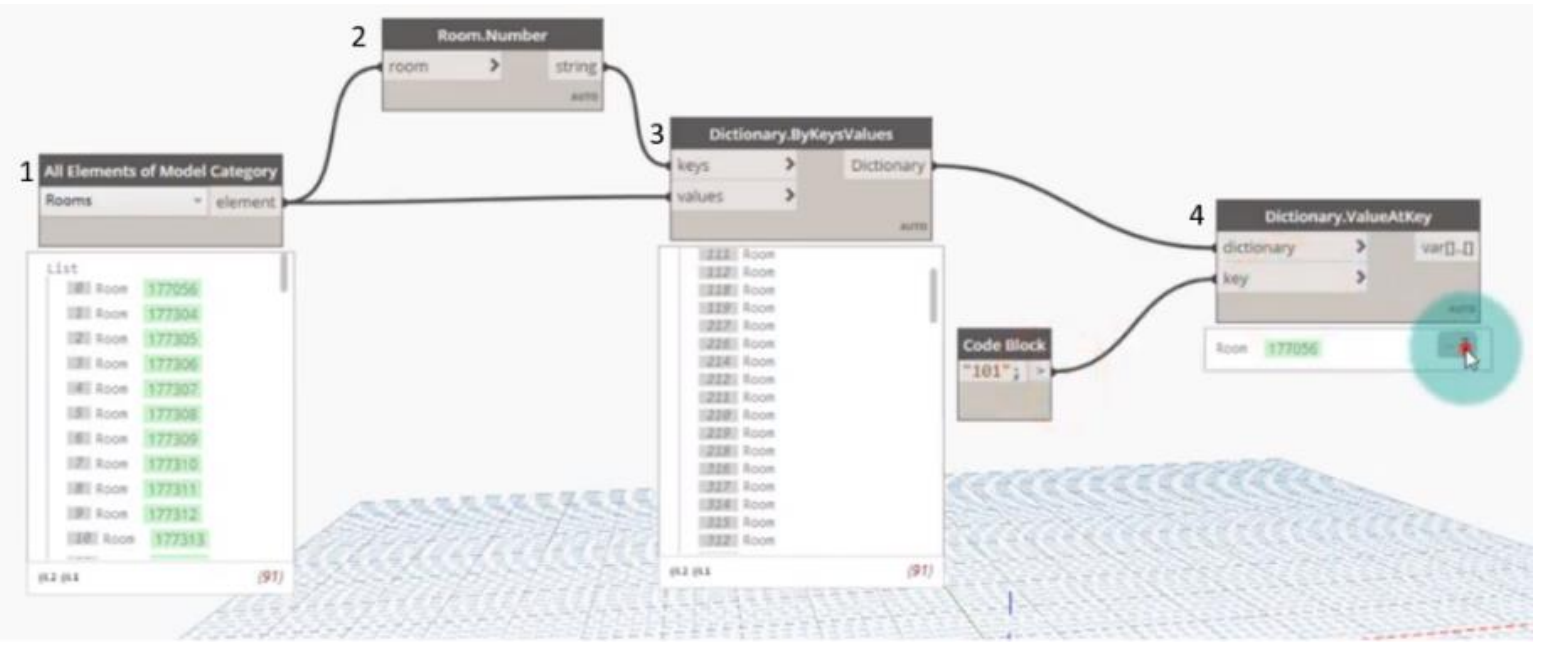

Fonte: (PIERSON, [s.d.])

A Figura 31 mostra como podemos associar o elemento ambiente (Room) ao seu número e ilustra também a estrutura do Dynamo no que diz respeito a novos nós publicados pela comunidade. O nó All elements of Model Category (1) economiza nós, deixando o programa mais claro e limpo fazendo a união de 3 outros nós. Este nó coleta todos os ambientes do projeto, Room.Number (2) pega os parâmetros de números dos ambientes, o nó Dictionary.ByKeyValues (3) associa a coleção de ambientes e números dos ambientes em pares de chaves. Com o nó Dictionay.ByValueKey (4), podemos inserir como entrada um número e ele diz qual o ambiente que está associado a este. Caso o número não esteja associado a nenhum elemento similar, ele retorna com um erro na rotina. 


\subsection{ESTUDOS EXPLORATÓRIOS E ROTINA EXPERIMENTAL EM DYNAMO}

Dois estudos exploratórios foram discutidos com base nas informações apresentadas sobre o Dynamo. Os dois primeiros estudos abordam casos identificados nas referências, isto é, foram programados por terceiros e acessados pelo pesquisador. Já o terceiro estudo corresponde a um script programado pelo pesquisador a fim de testar as características observadas na linguagem e apresentar uma perspectiva experimental das condições de programação.

\subsubsection{Criação automática de paredes a partir do elemento ambiente}

É comum que a modelagem de paredes seja inicialmente realizada "em osso" e a aplicação do revestimento ocorra em uma etapa posterior do projeto. Esse procedimento resulta em um tempo de modelagem maior pois as paredes são feitas três vezes: a primeira, em que se define o vão osso sem revestimento, e as outras duas, quando se criam os revestimentos nos dois lados da parede, podendo ser, por exemplo, de um lado cerâmica e do outro pintura. A rotina apresentada automatiza esse processo; uma explicação sobre o entendimento de parâmetros de tipo e de instância é dado antes de apresentar a rotina para que seu entendimento seja facilitado.

Como um software BIM, o Autodesk Revit possui uma estrutura de dados baseada em elementos paramétricos que podem ser geométricos ou não. Os parâmetros são a base de informações do modelo, atendendo a requisitos de representação, de conteúdo de projeto e de codificação dos elementos para a construção. Durante o processo do projeto, os parâmetros de elementos construtivos podem ser capturados e manipulados individualmente ou por categorias do tipo paredes, pisos, pilares, janelas, dentre outros. As categorias têm dois parâmetros predefinidos, que são os parâmetros de tipo e de instância (NGUYEN; KIM, 2011, p. $3403)^{28}$.

\footnotetext{
${ }^{28}$ Dr. Tang-Hung Nguyen é PHD em Engenharia pela Pennsylvania State University e professor licenciado da California State University, Long Beach. Seu foco de pesquisa é o avanço que as tecnologais emergentes podem gerar nos setores de projeto e construção. Um dos seus projetos de pesquisa é a utilização do 3D para aprimorar o processo de projeto e seu gerenciamento.
} 
Os parâmetros de tipo permitem alterar elementos típicos de um determinado elemento ou categoria de elementos. Assim, como pode haver vários elementos de um mesmo tipo, é possível alterar alguma propriedade comum a todos os elementos pertencentes ao tipo por meio de mudanças nos parâmetros gerais de tipo. A Figura 32 ilustra a mudança de valor do parâmetro Altura da janela PAC_JAN_Correr do tipo 1.2x1.2 m Vidro Liso. Neste caso, a determinação do tipo de elemento foi definida em razão das dimensões do elemento; no caso, a janela. Uma janela com outra dimensão é possível de ser criada facilmente, duplicando este tipo e ajustando nome e parâmetros de dimensões. Dessa forma, a família da janela passa a conter dois tipos de janela, diferenciados em razão do dimensionamento do vão, que estão prontos para ser utilizados no modelo.

Figura 32 - Parâmetros de Tipo - elemento janela Autodesk Revit

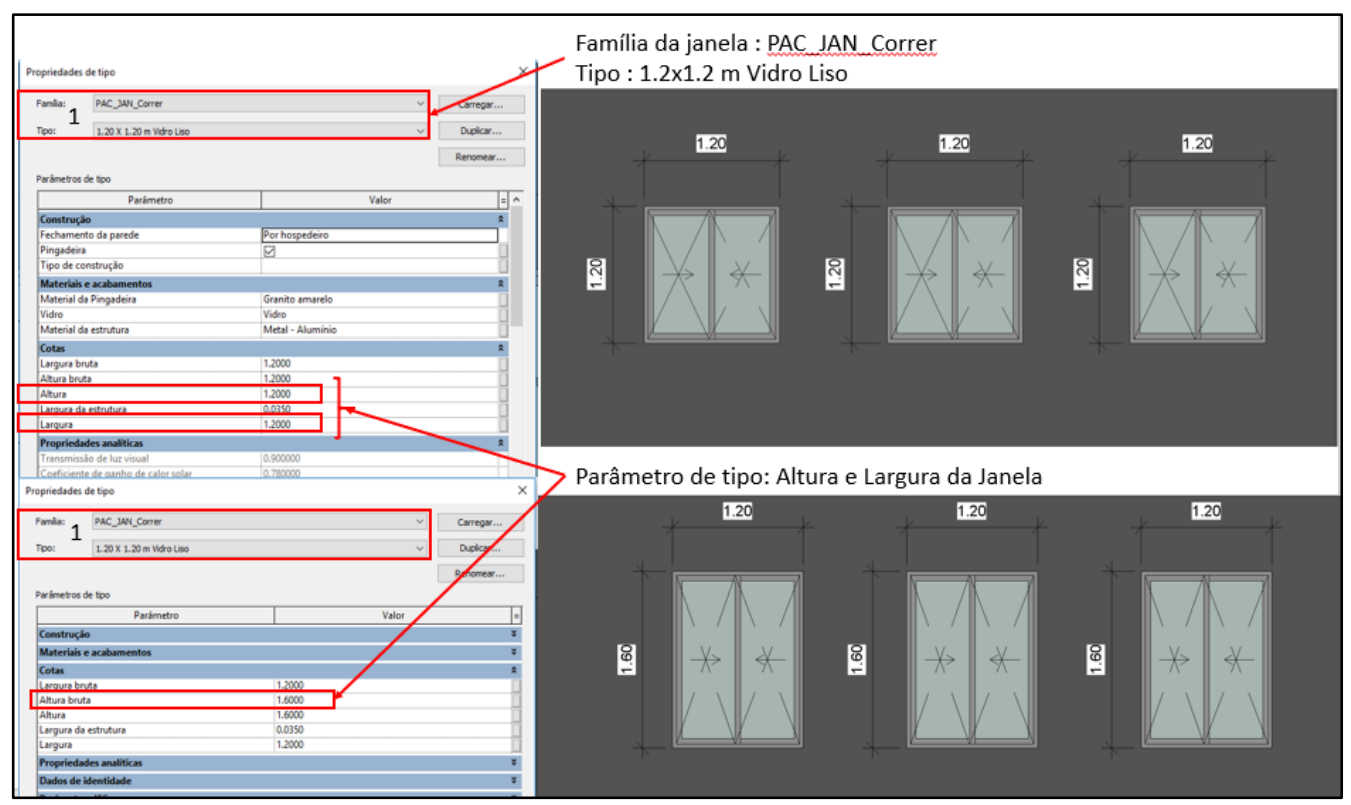

Fonte: Elaborado pelo autor

Já os parâmetros de instância permitem alterar os parâmetros de um determinado elemento sem influenciar outros elementos do mesmo tipo. Assim, ao alterar um valor de parâmetros de instância de um elemento inserido no modelo, como a janela, apenas a janela modificada apresentará a mudança registrada, mantendo inalterada as propriedades dos demais elementos de mesmo tipo que não tiveram diretamente modificado o mesmo parâmetro de instância (Figura 33). 
Figura 33 - Mudança de uma instância do tipo Janela PAC_JAN_Correr 1.2x1.2m Vidro Liso

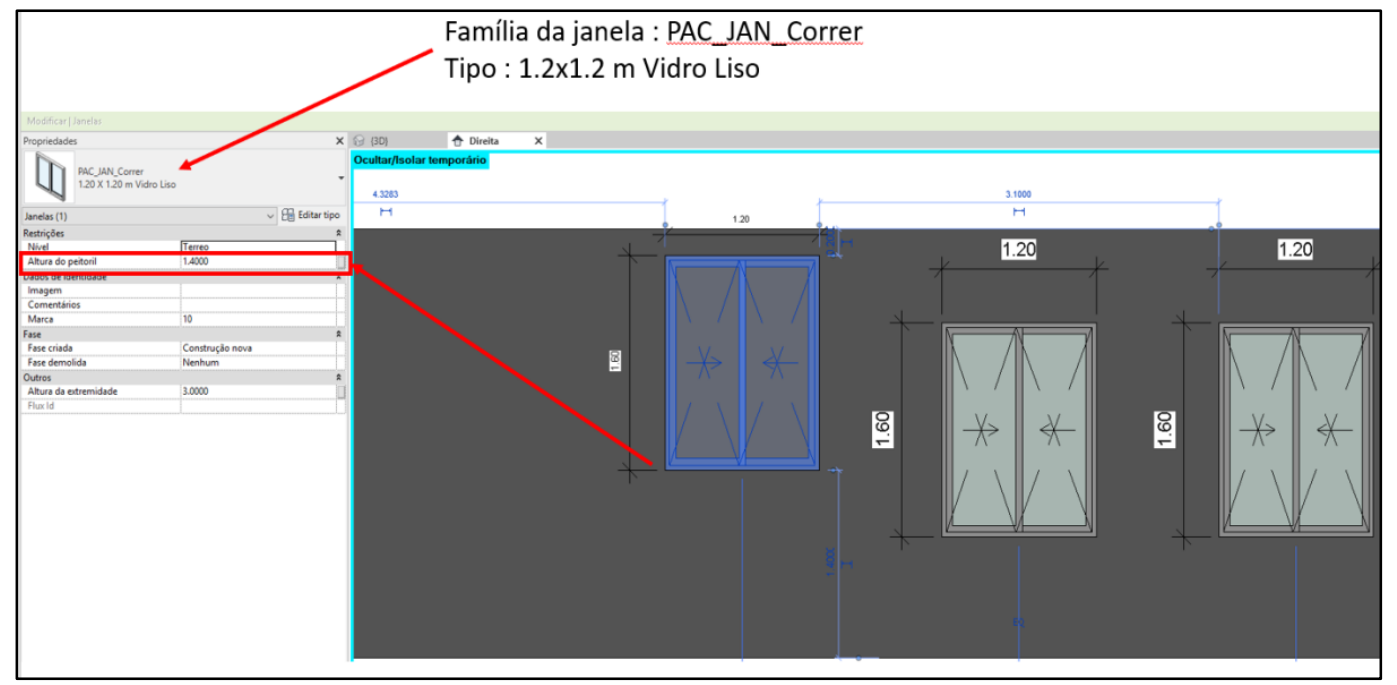

Fonte: Elaborado pelo autor

Cada parâmetro pode ser armazenado em diferentes formatos, tais como texto, número inteiro, comprimento, área, volume, ângulo, URL, material e sim/não. Parâmetros ainda podem ser atribuídos especificamente para um projeto, identificados como parâmetros de projeto, ou abranger vários projetos, apresentando assim parâmetros compartilhados (NGUYEN; KIM, 2011, p. 3403). Cabe observar que essa diversidade de parâmetros dos elementos são instrumentais para grande parte das possibilidades de automação dos processos de projeto. Assim, tais possibilidades são aumentadas empregando recursos de manipulação dos parâmetros por meio de linguagens de programação, permitindo a criação de funções customizadas.

Além dos parâmetros nativos que estão atrelados a cada elemento, no caso do Revit é possível associar novos parâmetros a elementos que podem ser manipulados por meio de algoritmos computacionais. Um exemplo de criação de novo comando em que se automatizou a aplicação de revestimento de paredes foi analisado para a ,pesquisa. Para tanto, foi utilizado um pacote de nós para o Dynamo, disponibilizado pela Modelical (MODELICAL, [s.d.]). Este nó economiza tempo de modelagem ao alterar o método de atribuição de revestimentos a paredes.

Existem diferentes maneiras de modelar uma parede: a depender da situação, pode-se especificar todas as camadas de uma parede ou separá-las em elementos 
distintos, de acordo com os diferentes serviços e materiais empregados na execução. Para utilizar o nó em questão, as paredes devem estar "em osso", isso é, sem a especificação de qualquer revestimento, uma vez que o revestimento será sobreposto posteriormente.

Nesta estratégia de modelagem os revestimentos são inseridos como um elemento sobreposto à parede em osso e pode ser realizado diretamente pelos comandos do Revit, desde que se tomem alguns cuidados durante a modelagem. No caso, antes de inserir as janelas e portas que automaticamente abrem um vão com as suas dimensões na parede, é preciso unir os elementos das paredes "em osso" e de revestimento para que o vão seja aberto por completo. Caso contrário, uma das paredes não reconhecerá o vão.

O nó WallFinishesByRoom do Dynamo, disponibilizado pela Modelical, automatiza este processo utilizando os parâmetros do ambiente que o Revit cria para delimitar a localização e limites de paredes que o contornam. Este nó possui três entradas de dados: ambientes (rooms); tipo de parede a ser usada para revestimento (Wall Finish param); e a altura do forro (Ceilling Height param). A Figura 34 mostra o resultado que o nó criado proporciona ao criar automaticamente, em segundos, todas as paredes de revestimento.

Para que o nó funcione, o usuário deve criar dois parâmetros de projeto: o Wall Name e Ceiling Height, associados à categoria Ambientes (rooms). É por meio deles que a rotina atribui valores para criação e modificação automática de revestimentos de paredes. O nó WallFinishesByRoom conta com uma rotina que utiliza algoritmos Python, já que promove a automação de maneira objetiva. Todavia, sua utilização mediada pelo Dynamo é acessível até mesmo a projetistas com pouca experiência em programação. 
Figura 34 - Exemplo de modelagem de revestimento de parede com Nó WallFinishesByRoom

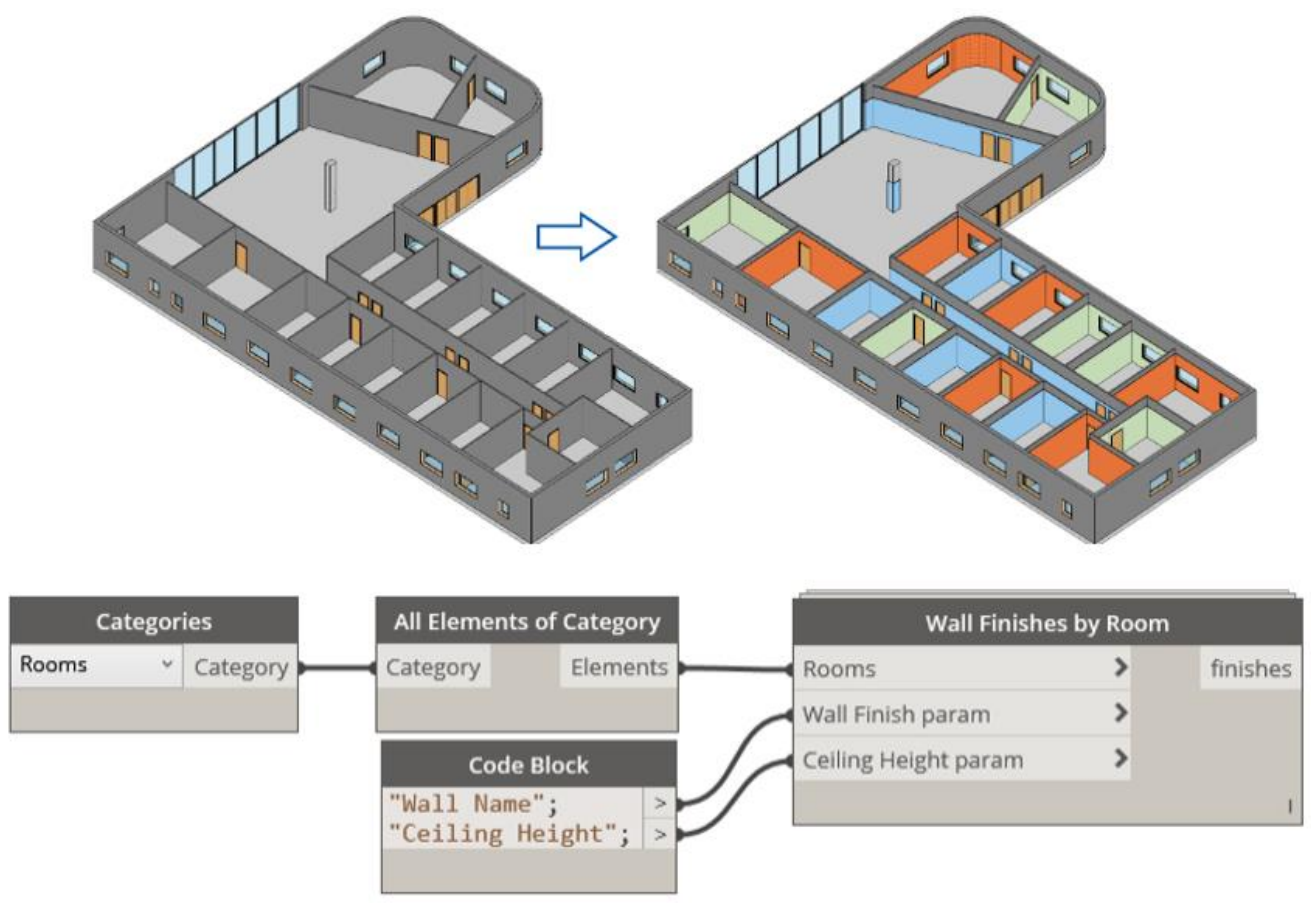

Fonte: (MODELICAL, acessado em 30-05-2019)

Assim como o exemplo, outras tarefas podem ser automatizadas, porém algumas exigem um grau mais alto de domínio de programação para criação ou mesmo entendimento do funcionamento dos comandos das rotinas disponíveis, que podem restringir a potencialidade de trabalhar com o Dynamo associado à modelagem em Revit.

\subsubsection{Automação da análise do ciclo de vida do edifício}

O segundo estudo que explora o Dynamo associado ao Revit aborda um processo de avaliação de desempenho do ciclo de vida do edifício para apoiar a decisão do projeto. Segundo Bueno, Pereira e Fabricio (2018, p. 332 ${ }^{29}$, dados sobre o ciclo de vida dos componentes do edifício disponibilizado por fabricantes, que permitem avaliar os impactos da construção sobre o meio ambiente, não são

\footnotetext{
${ }^{29}$ Cristiane Bueno é Professora Adjunta do Departamento de Engenharia Civil (Deciv), da Universidade Federal de São Carlos (UFSCar). Possui graduação em Arquitetura e Urbanismo pela Faculdade de Arquitetura e Urbanismo da Universidade de São Paulo - FAU USP (2006); Mestrado em Arquitetura, Urbanismo e Tecnologia pelo Departamento de Arquitetura e Urbanismo da Escola de Engenharia de São Carlos - Universidade de São Paulo - EESC USP (2010); e Doutorado em Arquitetura, Urbanismo e Tecnologia pelo Instituto de Arquitetura e Urbanismo da Universidade de São Paulo - IAU USP (2014). Desenvolveu pesquisa de Pós-Doutorado no Instituto de Arquitetura e Urbanismo da Universidade de São Paulo - IAU USP (2014-2017) tendo como tema central a utilização da plataforma Building Information Modelling para realização de estudos de Avaliação de Ciclo de Vida no processo de projeto de edifícios.
} 
considerados no início do processo do projeto, quando as principais decisões são tomadas.

Quando realizadas, estas análises ocorrem tardiamente e requerem o apoio de especialistas, tamanha complexidade e volume de trabalho. Para viabilizar uma análise do ciclo de vida a tempo de subsidiar os projetistas no processo decisório que ocorre nas fases iniciais do projeto, Bueno, Pereira e Fabricio, (2018, p. 332) desenvolveram experimentalmente uma rotina, assim descrita:

O principal objetivo desta pesquisa é o de desenvolver uma interface de integração entre os dados de LCA fornecidos pelos fabricantes e uma plataforma BIM através da combinação de aplicações consolidadas (nominalmente Autodesk Revit e Dynamo, e Microsoft Excel), a fim de criar perfis ambientais para a tomada de decisão nas fases iniciais do projeto, requerendo desta forma menos tempo, esforço e a ajuda de especialistas ${ }^{30}$.

O desenvolvimento da rotina de automação foi esquematizado pelos autores num diagrama de fluxo que facilita o entendimento de seu funcionamento (

Figura 35).

${ }^{30}$ Original: The main aim of this research is to develop an integration interface of manufacturer-based LCA data into a BIM platform by combining applications of existing and consolidated tools (namely, Autodesk Revit and Dynamo, and Microsoft Excel), in order to obtain environmental profiles for decision-making in the initial design stages, requiring less time, effort and ad hoc experts. 
Figura 35 - Diagrama de fluxo de desenvolvimento da pesquisa

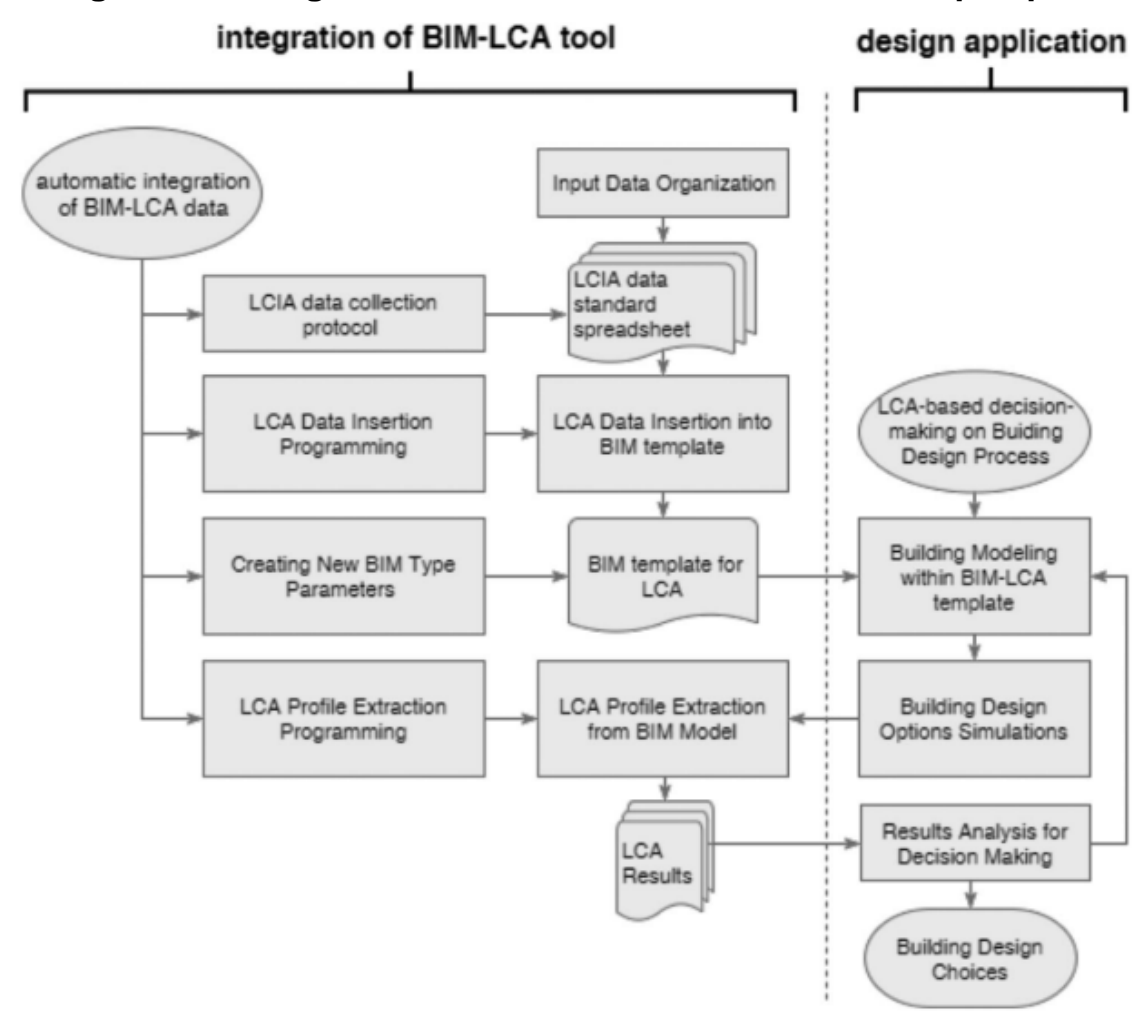

Fonte: (BUENO; PEREIRA; FABRICIO, 2018, p. 338)

Para que este algoritmo funcionasse corretamente foi preciso que três condições fossem atendidas. Primeiramente, foi preciso dar entrada com os dados no Revit; esta condição foi realizada por meio do uso de nós do Dynamo que se comunicam com o Excel. A segunda condição dependia de poder acessar os parâmetros do modelo e transferir as informações do Excel para cada elemento do modelo; para viabilizar essa condição, um template de Revit foi criado com novos parâmetros associados aos elementos do projeto que são compatíveis com as informações que estão contidas na planilha do Excel. A Figura 36 mostra uma tela do Revit onde o elemento Telha Canal da categoria telhado tem todos os parâmetros associados que fazem referência à tabela do Excel. 
Figura 36 - Novos parâmetros criados no Revit para associá-los às informações provindas do bando de dados em Excel

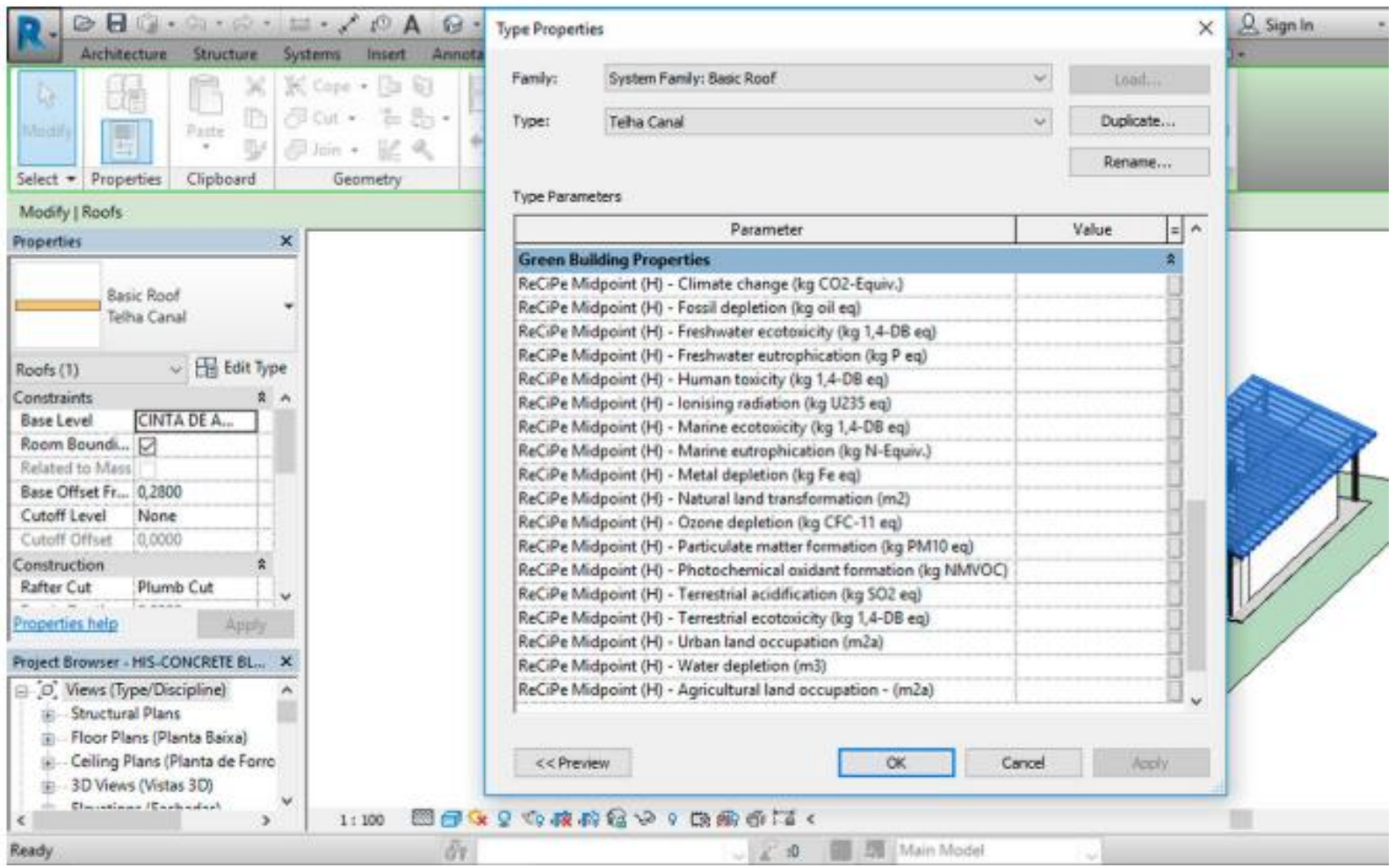

Fonte: (BUENO; PEREIRA; FABRICIO, 2018, p. 339)

A terceira condição estava vinculada à criação da rotina em Dynamo para a comunicação dos dados entre os aplicativos Revit e Excel usando a programação visual, como explicado:

Como uma planilha em Excel foi criada e configurada com as informações de LCA e um template BIM com os parâmetros ambientais correspondentes já estava desenvolvida e disponível, a próxima etapa consistiu em desenvolver a programação visual para automatizar o processo de inserção / extração de informações de/para o modelo. A programação visual foi organizada em duas fases principais: (a) fase de inserção de dados de LCV e (b) fase de extração de perfis de ACV. Para cada fase, um arquivo de programação individual foi preparado para evitar arquivos muito pesados. (BUENO; PEREIRA; FABRICIO, 2018, p. 439, tradução nossa) ${ }^{31}$

Para automatização do processo, as programações foram criadas no Dynamo separadamente. Como mostra a Figura 37, para inserção de dados LCA uma rotina

\footnotetext{
${ }^{31}$ Original: Since a spreadsheet set up with manufacturers-sourced LCA information and BIM template with the corresponding environmental parameters were already developed and available, the next step consisted of developing the visual programming to automate the process of information insertion/ extraction to/from the model. The visual programming was organized in two main phases: (a) LCA data insertion phase and (b) LCA profile extraction phase. For each phase, an individual programming file was prepared to avoid super-heavy files.
} 
foi criada onde parâmetros lidos da planilha em Excel referentes ao impacto de Ocupação de Terras Agrícolas são atribuídos aos elementos de parede. Este processo se repete para outros parâmetros de impacto e outras categorias de elemento do modelo.

Figura 37 - Rotina para inserção de dados LCA nos elementos paredes. Impacto sobre Ocupação de Terras Agricultáveis

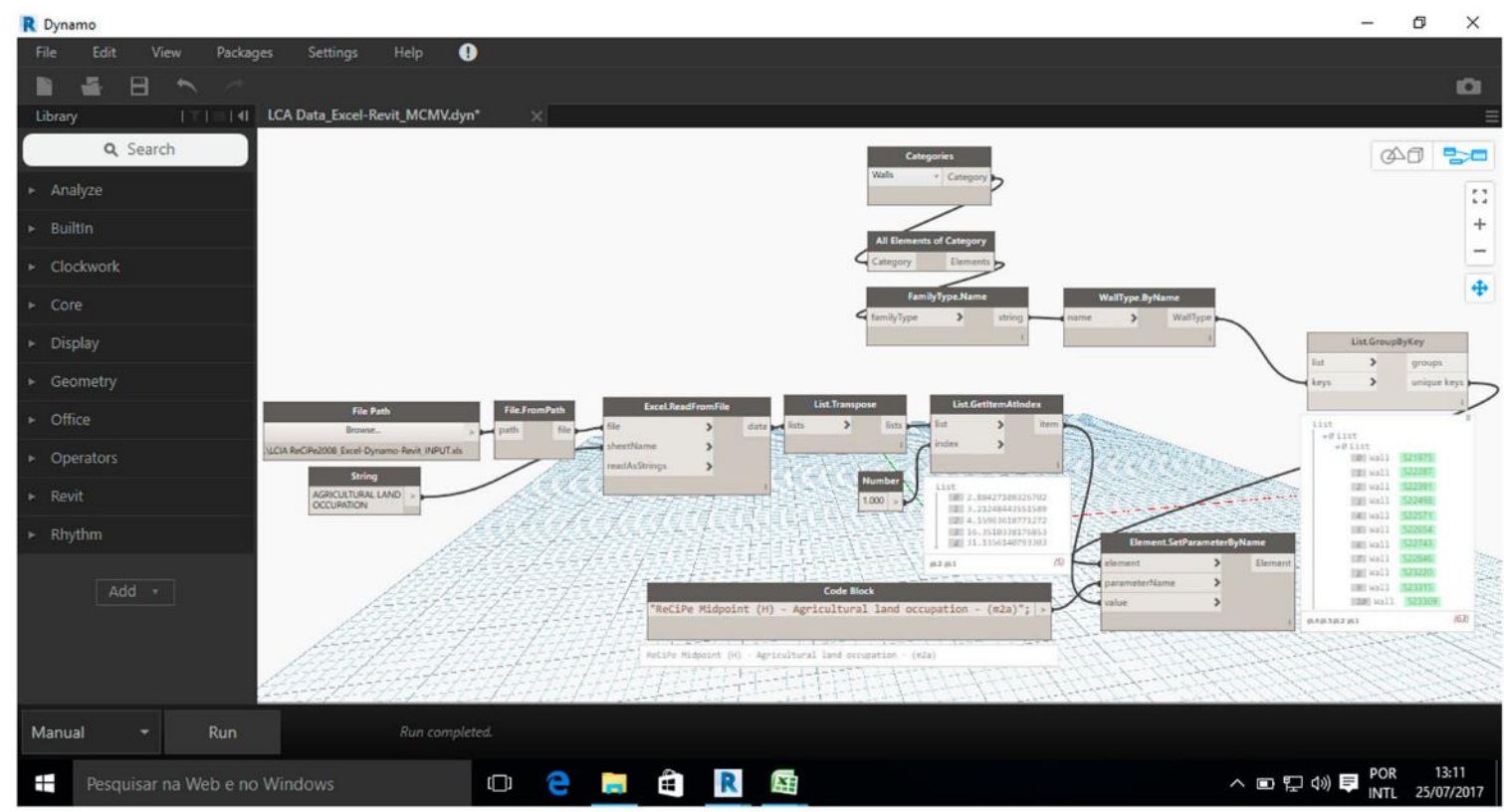

Fonte: (BUENO; PEREIRA; FABRICIO, 2018, p. 340)

Outra rotina é criada para extração dos totais referentes a todos os elementos propostos no modelo que estão associados ao LCA e que formarão o perfil ambiental do modelo de construção. Esses índices são somados e desta vez exportados para a planilha Excel. Da mesma forma que no processo anterior, estas rotinas são executadas separadamente em função de índices analisados.

A Figura 38 ilustra a execução em separado das rotinas em função de um índice. Neste caso, no entanto, a planilha de saída é a mesma pois nela o Dynamo é capaz de direcionar o local da coluna e linha que um determinado dado vai ser colocado. 
Figura 38 - Rotina de exportação de totais de LCA para o modelo em função do índice de Ocupação de Terras Agrícolas

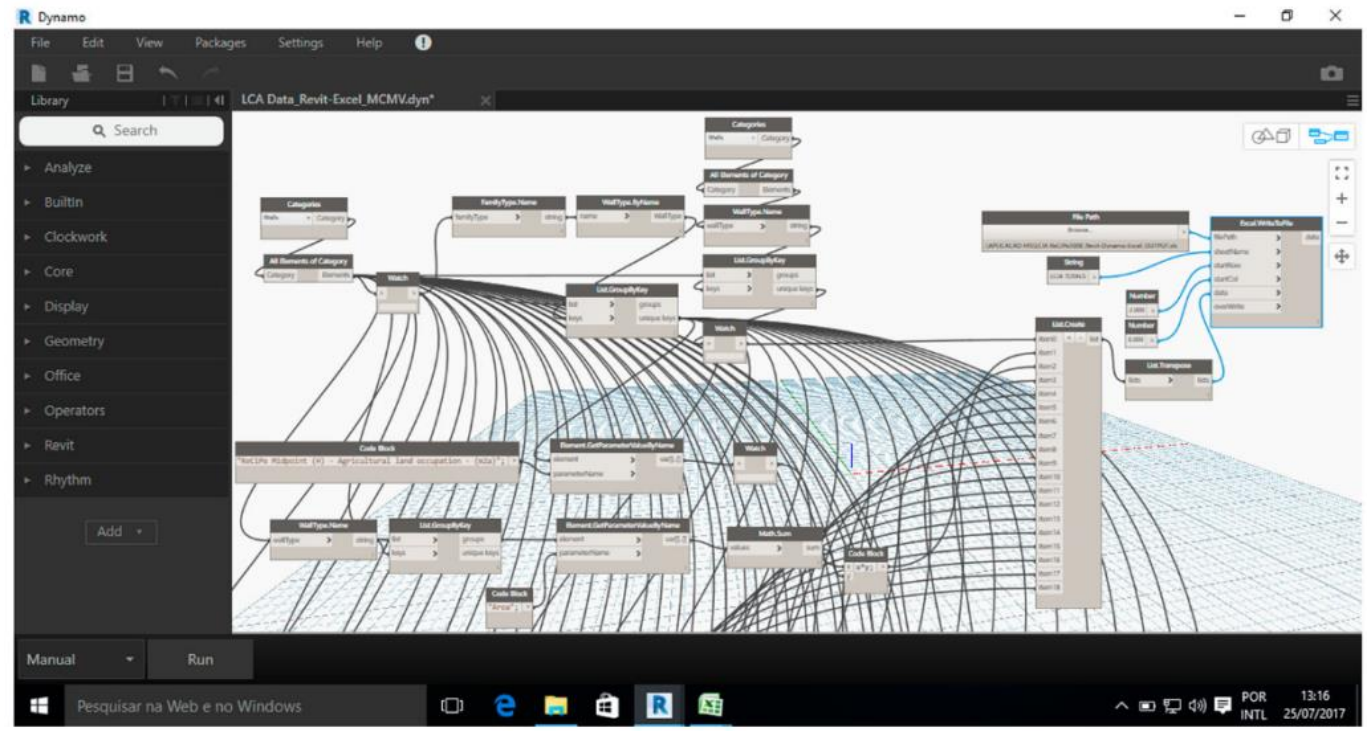

Fonte: (BUENO; PEREIRA; FABRICIO, 2018, p. 340)

Este processo de interação de dados pode ser de grande valia pois, por meio de uma única planilha várias informações que são extraídas em momentos diferentes com rotinas distintas feitas com Dynamo em programação visual podem analisar aspectos de um modelo em BIM e compilar estas informações em um único local.

A Figura 39 demonstra esta possibilidade quando apresenta, de três formas diferentes, os resultados da análise de modelo feito em BIM com relação aos índices de LCA usando automação de processos e extraindo os resultados para um único local. 
Figura 39 - Planilha Excel com informações compiladas de um modelo BIM com relação aos indicadores de LCA

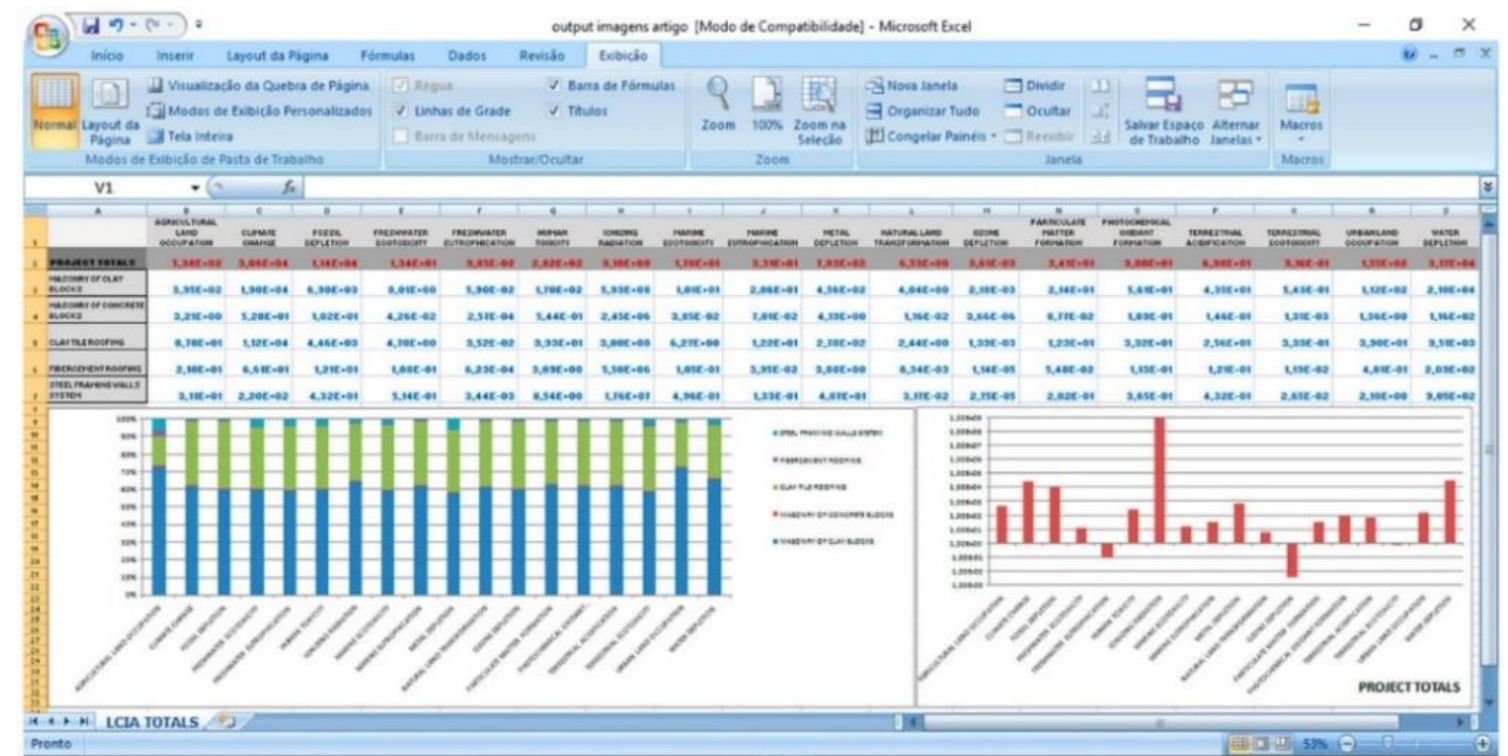

Fonte: (BUENO; PEREIRA; FABRICIO, 2018, p. 341)

Segundo Bueno, Pereira e Fabricio (2018, p. 344) a revisão literária sobre ferramentas robustas de análise de modelos BIM dentro do contexto de LCA não foram encontradas. Além dessa questão, as alternativas encontradas não permitem a contribuição dos projetistas para um melhor desempenho da edificação na fase inicial do processo. As ferramentas encontradas são ou muito simples ou então muito complexas para serem aplicadas na prática. O estudo exploratório demonstra de forma objetiva a possibilidade de automatizar tarefas, utilizando o Dynamo dentro do ambiente Revit, como será citado a seguir:

A meta foi alcançada uma vez que a ferramenta desenvolvida foi capaz de prover um resultado completamente automático sem que o projetista tivesse que mudar qualquer coisa no software ou na interface. Esta característica pode melhorar e simplificar o uso de dados ambientais para a tomada de decisão de projeto nas fases iniciais dos mesmos, já que permite a análise de vários cenários de materiais e opções de projeto para alcançar o potencial de ganho ambiental que pode surgir a partir de diferentes escolhas e alternativas apresentadas no processo.(BUENO; PEREIRA; FABRICIO, 2018, p. 243) ${ }^{32}$

\footnotetext{
${ }^{32}$ Original: This goal was achieved as the developed tool was able to provide complete results automatically, without the designer having to change the software or interfaces. Such features may improve and simplify the use of environmental data for decisionmaking during the early design stage, since it allows the consideration of various scenarios regarding design and materials options in order to evaluate the potential environmental gains arising from different choices.
} 
Analisando a rotina utilizada neste estudo através dos dados disponíveis, podese sugerir melhores alternativas para o desenvolvimento do algoritmo. Casos como os aqui apresentados podem ser aprimorados com o uso de outros recursos computacionais. Por exemplo, o uso do nó do Dynamo que dá acesso à linguagem Python pode ajudar em rotinas que requerem loop e tratam do acesso ao banco de dados do Revit através de classes e parâmetros que não são visíveis, mesmo quando usamos a linguagem Dynamo. É de igual relevância o fato de que profissionais com pouca experiência em programação podem tirar proveito da automação de processos com a utilização de linguagens visuais, como é o caso do Dynamo.

\subsubsection{Estudo experimental - Checagem de código de obras - Rotina em Dynamo}

A rotina experimental, aqui apresentada, mostra a análise de código de obras municipal para a verificação do atendimento às suas normas em relação ao projeto arquitetônico de forma automatizada.

Segundo Solihin e Eastman (2015, p. 69), o uso do BIM tem crescido e, após uma curva inicial de aprendizado, os usuários desta tecnologia vem aperfeiçoando cada vez mais os modelos, tornando-os mais complexos. Uma inspeção visual do modelo já não é mais suficiente para a acuidade das informações nele contidas. Os modelos já tratam de outras informações, que não são apenas geométricas. A aplicação automatizada de checagem de modelos com regras bem definidas e mínima intervenção dos usuários se torna cada vez mais necessária.

Para Nawari (2012, p. 315) ${ }^{33}$, os métodos de tentativa e erro foram usados ao longo de cem anos; hoje a indústria está concentrando esforços no sentido de evitar este tipo de prática. Um exemplo disso é o uso do SmartCode, de iniciativa do International Code Council (ICC). O uso desta abordagem permite a checagem de regras e regulações sem alteração do modelo criado, mas com o poder de acessar a base de dados das configurações paramétricas dos elementos, suas relações ou atributos. A partir disso, compreende-se que o uso deste sistema analisa o modelo

\footnotetext{
33 Dr. Nawari tem mais de vinte e cinco anos de experiência em design, ensino e especialização em Estruturas de Arquitetura
} e BIM. Atualmente é professor na Universidade da Florida. É autor e coautor de mais de 125 publicações e cinco livros. 
e fornece uma resposta ao projetista, apontando se um determinado elemento está com informações necessárias ou inexistentes em função de uma regra ou regulamentação. O sistema alerta se uma regra imposta ao parâmetro de elemento foi atendida, se falhou, se está inadequada ou simplesmente ausente.

O modelo BIM se torna muito propício para a abordagem através de um sistema de automatização de checagem de regras. A letra I do BIM, ou seja, informação, requer que qualquer objeto possua parâmetros ligados à sua geometria. Não obstante, outras informações podem ser atreladas ao objeto em forma de metadados.

Os estudos BIM tem se estendido para várias áreas da indústria $A E C$, incluindo não só arquitetura, mas engenharia, facilities management e construção. Isto se deve muito em parte à poderosa base de dados que estes sistemas possuem. A criação de um sistema computacional automatizado é capaz de analisar as informações contidas no modelo 3D do edifício, entendendo suas caraterísticas e dando a possibilidade para que este sistema faça checagem das regras e regulamentos que serão implementados através de algoritmos computacionais. A estrutura do banco de dados do modelo em BIM já é formatada nesse sentido (KIM et al., 2019, p. 143) ${ }^{34}$.

Vários países têm buscado o uso de sistemas computacionais para a automatização de checagem de regulamentação e leis usando como parâmetros modelos $3 \mathrm{D}$ elaborados com o emprego da tecnologia BIM. Sem estas regras, as informações contidas no modelo podem não oferecer aos projetos os dados adequados para o melhor andamento da construção (KIM et al., 2019, p. 143).

Um dos aspectos a serem levados em conta, com relação à automatização de regras e regulamentações, é que as leis diferem de país para país, gerando várias centenas de normas que não podem ser facilmente replicadas em um sistema computacional (KIM et al., 2019, p. 143). O governo de Singapura começou estudos para a realização de checagem de regulamentos e códigos em projetos desde 1995, ainda sobre a base 2D de desenhos. Na segunda fase da evolução do projeto, avançaram para um novo sistema, o CORENET, que tem sua base estruturada em

\footnotetext{
${ }^{34}$ Hayan Kim - Mestre em Ciências pela Yonsei University, Seul, Republica da Korea.
} 
arquivos IFC. O sistema prevê a análise de projetos através da checagem de códigos e propriedades dos elementos, que são analisados via online e aprovados ou não em função das leis e regulações de projetos para Singapura (EASTMAN et al., 2009, p. 1013). Hoje em dia formatos nativos já são aceitos dentro da plataforma como, por exemplo, os .RVT.

Outros países, como Estados Unidos e Austrália, são exemplos desta nova busca pela automação de análise de projeto via arquivos BIM. Nestes países, a maioria dos estudos tem se baseado numa linguagem de programação através de códigos escritos em linguagens de alto nível, o que culmina na demanda do recurso humano desta área de programação, já que não é comum profissionais da área de projetos entenderem de processos computacionais e linguagens de programação (KIM et al., 2019, p. 144).

O objetivo deste estudo experimental é mostrar a viabilidade de uso do Dynamo como ferramenta para a checagem da modelagem em BIM, no que se refere ao código de obras municipal de Ribeirão Preto. O exemplo tem como referência o sistema CORENET aplicando apenas o conceito de checagem de regras numa situação específica para o estudo aqui proposto. O código de obras (PREFEITURA DE RIBEIRÃO PRETO, 2019) dispõe em seu Capítulo IX sobre a classificação, dimensão, ventilação, iluminação e pé direito mínimo de compartimentos em uma edificação residencial. A Tabela 1 mostra as áreas mínimas exigidas para o cumprimento das exigências descritas na Lei Complementar Nº 2932.

O processo proposto, através da rotina, indica se o projeto atende ou não à norma nos quesitos áreas mínimas dos compartimentos. Para tanto, famílias específicas de objetos foram criadas a fim de sinalizar diretamente ao projetista se o modelo atende ou não à legislação. Rotinas como essa, tanto podem ser usadas para os projetistas ou em sistemas mais robustos, como os de prefeituras. 
Tabela 1 - As dimensões mínimas dos compartimentos em edificações residenciais

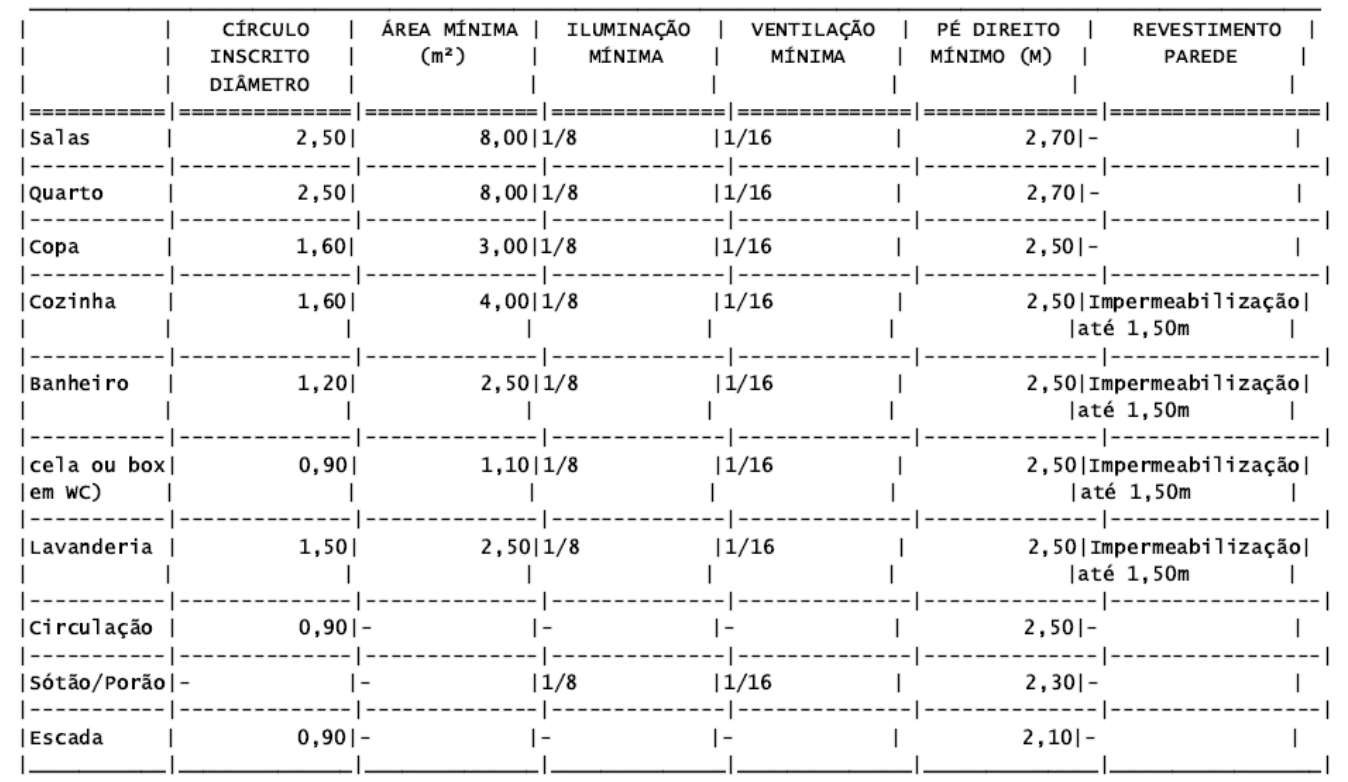

Obs.: Compartimentos não indicados serão analisados por similaridade ao uso.

Fonte: (PREFEITURA MUNICIPAL DE RIBEIRÃO PRETO, 2019), Tabela XI

O Dynamo possui um modo de execução automático de uma rotina que roda intermitentemente, possibilitando uma interação dinâmica com o modelo. Por exemplo, ao mudar uma parede de local a checagem da conformidade da regulamentação é automaticamente atualizada. Esta rotina culmina por permitir novos experimentos de projeto com a segurança de que a legislação será atendida. A planta proposta para ser analisada pela rotina é apresentada na Figura 40 
Figura 40 - Planta para análise do código de obras Ribeirão Preto

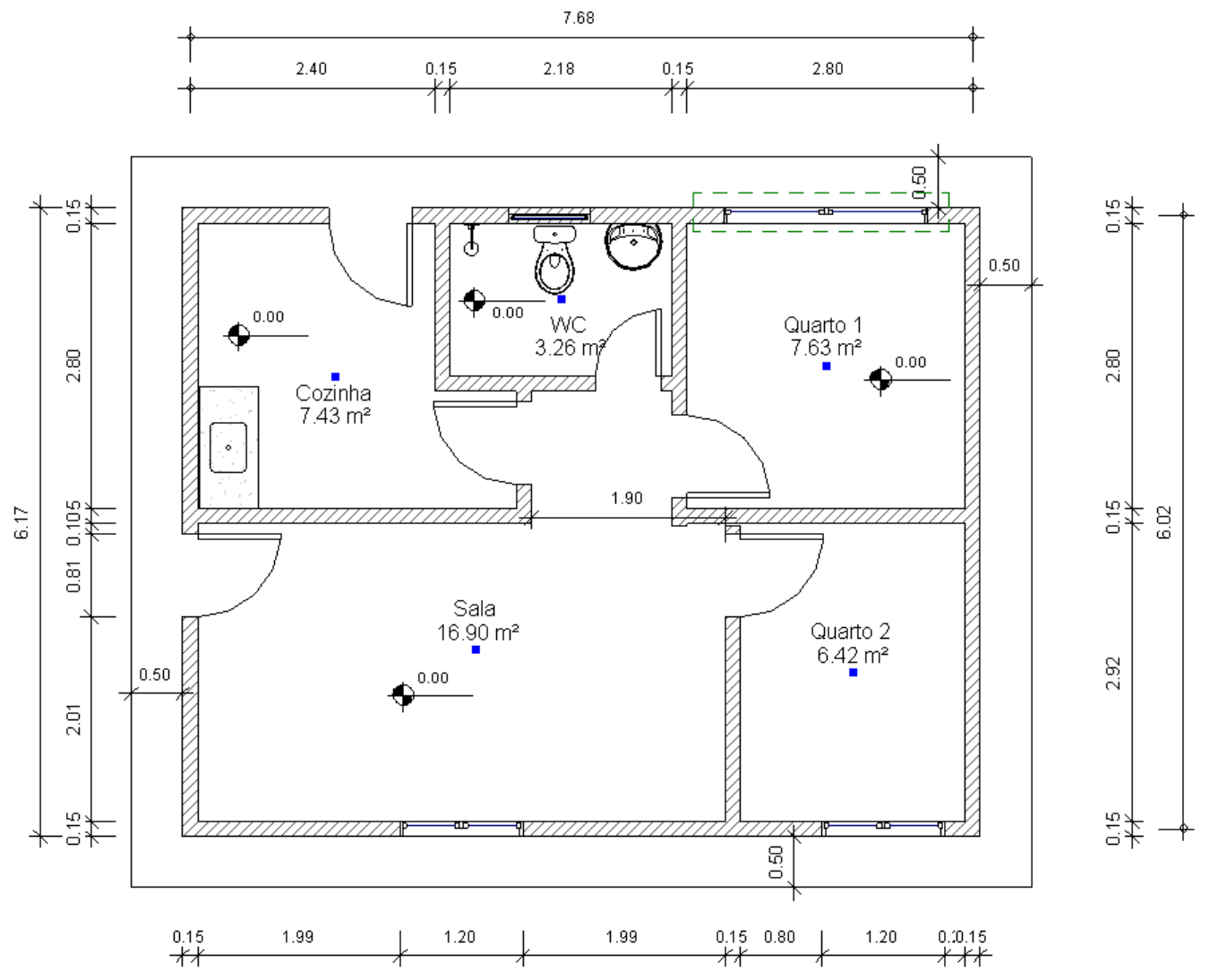

Fonte: Elaborado pelo autor

A rotina começa lendo informações do modelo do Revit referentes aos parâmetros do elemento ambiente: nome e metragem quadrada. $O$ nó Data.ExportExcel se comunica com o software externo, no caso o Excel, e busca o arquivo referência, criado previamente com os dados da Tabela 1. A rotina abre o Excel e escreve as informações retiradas do modelo, nas linhas e colunas determinadas. Através de fórmulas disponíveis no Excel, verificamos se os dados extraídos atendem ao código de obras nos requisitos mencionados na tabela 3.

Uma vez feita a consulta ao código, a planilha em Excel passa a conter informações sobre o projeto e quais itens foram atendidos segundo a norma. Estas informações podem ser disseminadas para outros departamentos da empresa, de forma que se possa fazer um pós-processamento. Isto mostra a possibilidade de extração de dados de um modelo BIM usando ferramentas disponíveis no mercado. Tendo o resultado da "consulta", o nó Data.ImportExcel lê os dados da planilha e aplica as informações recebidas no modelo, retroalimentando informações para o projetista. Para essa ação ocorrer, executa-se quatro procedimentos específicos: 
1 - Caso a área mínima do compartimento não seja atendida, uma mensagem de texto será inserida naquele compartimento com o texto "Área Insuficiente". A rotina permite experimentos dinâmicos de outras dimensões para os compartimentos. Assim que a área conveniente for alcançada, a expressão "Área Insuficiente" será apagada.

2 - Como temos acesso a centroide do elemento ambiente em função das paredes que o circundam, este ponto de inserção serve para criar um círculo com o diâmetro mínimo exigido pelo código e checar se as medidas de projeto atendem este critério. A programação foi realizada porem observou-se que alguns ajustes com relação a referência do nome do ambiente e o ponto de inserção do círculo são necessários.

3 - A altura do pé direito também pode ser verificada pelo elemento ambiente, checando a altura e comparando-a com o código de obras. Este procedimento foi realizado diretamente por meio da planilha do excel.

O fluxo da rotina apresentado na Figura 41 consta as principais etapas definidas para solução do problema, além dos nós usados na linguagem de programação visual. Este estudo exemplifica, através de um único elemento, diversas informações que podem ser extraídas do modelo. Novos elementos podem ser criados e a comunicação, com uma base externa de dados, pode ser feita. O estudo demonstra, ainda, como a automação de processos com o uso da linguagem Dynamo de programação pode abordar diferentes aspectos, no que se refere ao auxílio à tomada de decisão, para que projetistas possam usar ferramentas disponíveis para a melhoria da qualidade de projetos. 
Figura 41 - Fluxograma da rotina de isolamento e ventilação

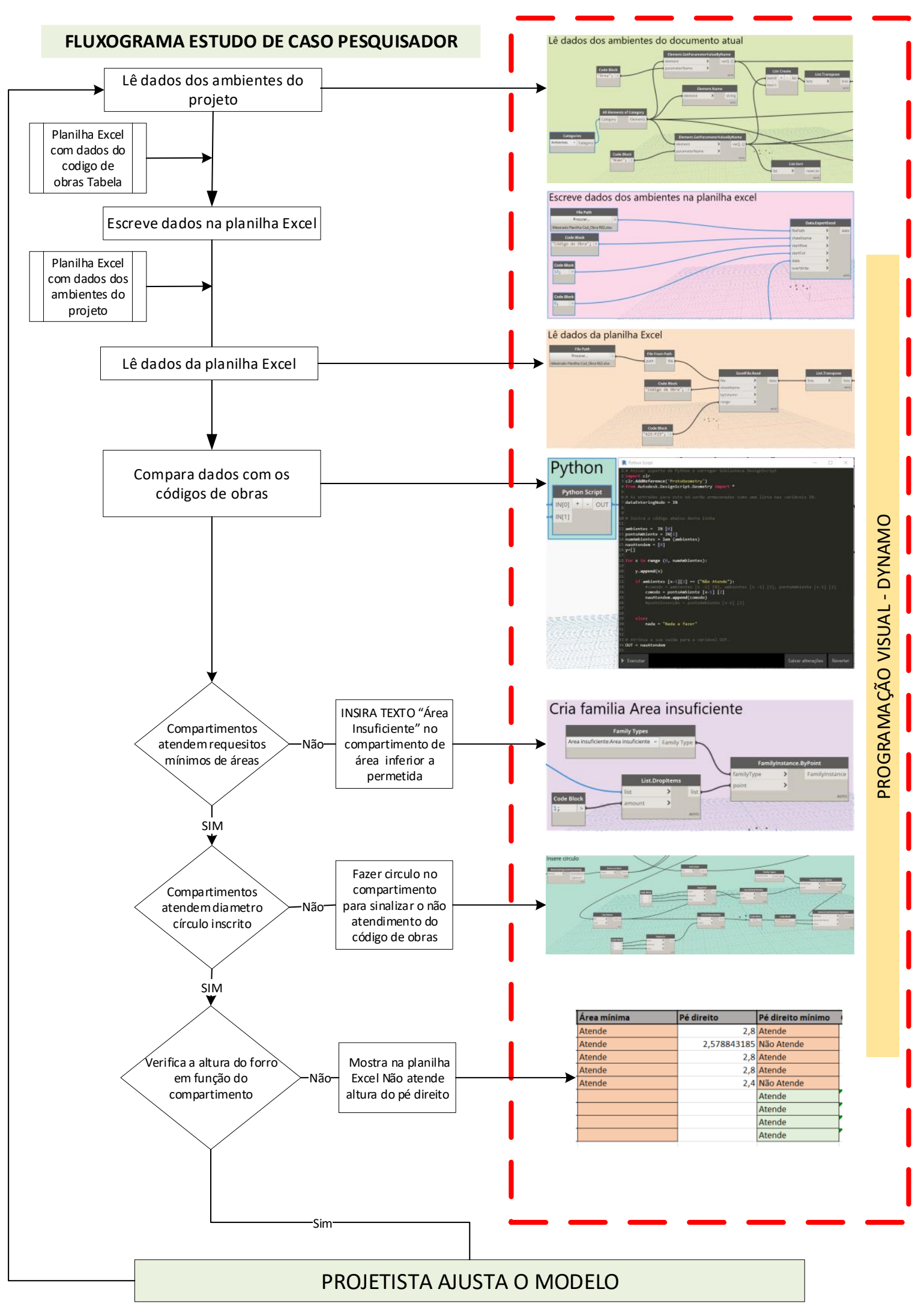

Fonte: Elaborado pelo autor 
As famílias, criadas e inseridas automaticamente no modelo, permitem a visualização das áreas que não atendem ao código de obras de forma muito direta, como demonstrado na Figura 42. Na planta a esquerda, após verificar que a área do quarto é insuficiente, o código insere um aviso no ambiente. Quando a parede é deslocada, aumentando a área do quarto, na planta a direita, o aviso é retirado automaticamente.

Figura 42 - Famílias criadas para alerta aos projetistas sobre o não atendimento ao código de obras
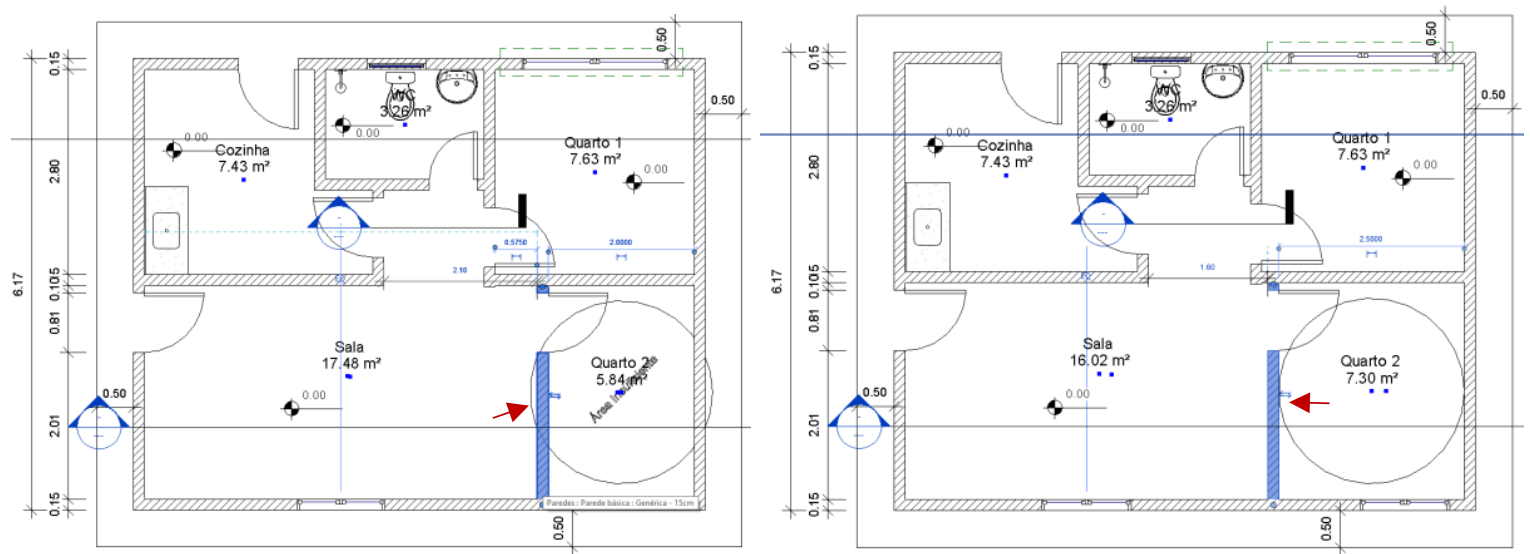

Fonte: Elaborado pelo autor

A proposta não faz a automação completa do processo, uma vez que os nomes dos compartimentos devem ser compatibilizados entre o elemento ambiente do Revit e o código de obras do município. Se um compartimento está configurado com o seu nome no código de obras como "Lavanderia", não se pode usar o nome "Área de serviço" dentro do Revit para determinar o nome do ambiente, uma vez que essa rotina não permite que isso seja feito automaticamente. A Tabela 2 mostra o resultado da rotina aplicada ao projeto mostrado como exemplo e a compatibilização que a coluna 1 tem que ter para que a rotina possa funcionar. 
Tabela 2 - Planilha Excel com código de obras e dados retirados do modelo BIM

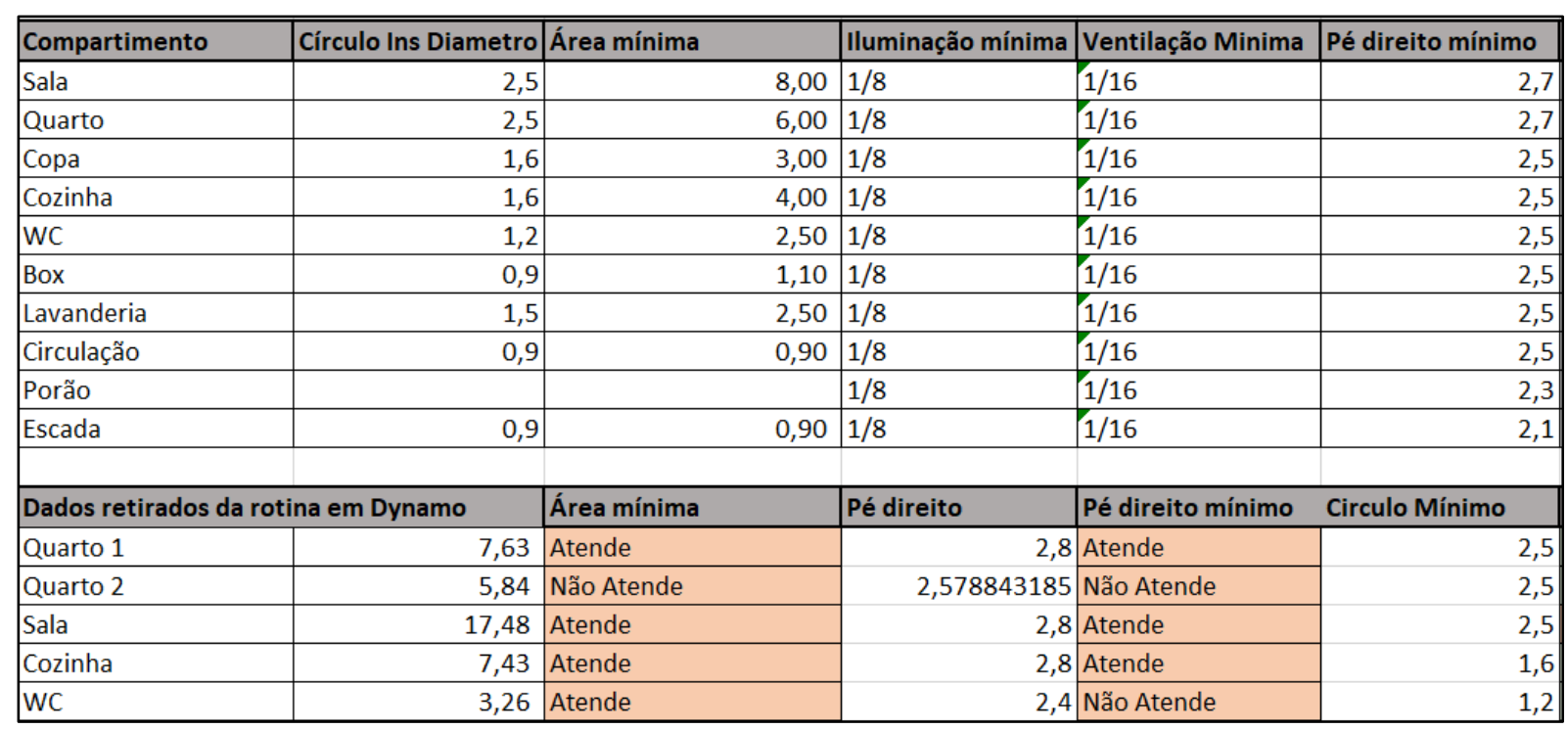

Fonte: Elaborado pelo autor

O caso apresentado pela pesquisa obteve êxito quando foi experimentado no cenário proposto e com a planta apresentada. Foi percebida a importância da compatibilização das informações entre o código de obras e os elementos criados no modelo. Novos experimentos devem ser feitos para testar a rotina com regras e plantas arquitetônicas mais complexas. A linguagem de programação VPL pode não ser a mais adequada para situações onde o entendimento de um texto sobre uma determinada lei tenha que ser aplicada. Não obstante a este fato, a criação da rotina envolveu conceitos sobre o que foi estudado no capítulo, contribuindo para o entendimento e a valorização do estudo de processos computacionais e de automatização de projetos arquitetônicos. 


\subsection{CONSIDERAÇÕES SOBRE O USO DE DYNAMO PARA AUTOMAÇÃO}

O uso de VPL's analisados nos dois estudos exploratório e na rotina experimental demonstraram as facilidades e limitações de sua utilização. Como se trata de uma linguagem visual, a introdução de profissionais e alunos à experiência de programação de códigos de rotinas são facilitadas. Além dos benefícios práticos de automação, quando essas práticas são utilizadas para programar ajudam a consolidar o raciocínio lógico necessário à elaboração de algoritmos, o que beneficia também o desenvolvimento de projetos.

O Dynamo tem sido um importante incentivador para que agentes ligados ao projeto de AEC compreendam a linguagem de códigos de comando e possam automatizar tarefas. A interface de comunicação é de fácil apreensão e o uso, graças a estrutura de nós e arames que se interligam, deixam um fluxo de pensamento muito intuitivo. As perspectivas de eliminação de tarefas repetitivas por meio da automação de processos com o uso do Dynamo é acessível mesmo para aqueles usuários que têm pouca ou nenhuma experiência no assunto, em razão das várias rotinas prontas e tutoriais que podem ser acessados na internet, corroborando para a facilidade de trabalho na linguagem.

Apesar de existirem outros softwares com mesmo conceito de programação visual destinados a trabalhar com o desenvolvimento de formas complexas e possuírem certa interatividade com o Revit, após a versão 2017 o Dynamo já está integrado ao pacote da Autodesk e se comunica com o banco de dados do software por meio da Application Programming Interface (API), o que confere ganhos operacionais e de compatibilidade significativos. Por ser um software open source, o Dynamo tem uma base colaborativa de desenvolvimento que sempre está em evolução, com acréscimo de novas funções.

Embora o Dynamo seja uma ferramenta muito adequada, principalmente para aqueles que querem começar a automatizar rotinas e dar seus primeiros passos no sentido de ter um raciocínío computacional para a criação de projetos, alguns 
aspectos devem ser considerados quando queremos fazer algoritmos de programação mais robustos:

- $\quad$ Constatou-se que rotinas recursivas não são as mais adequadas para serem usadas com o Dynamo, o que pode ser contornado com o uso de nós de Python, linguagem computacional textual. No primeiro estudo exploratório podemos observar este fato analisando o nó customizado;

- $\quad$ Outra característica do Dynamo que se pode perceber é a dificuldade na documentação do programa: muitas vezes, quando queremos voltar a ver uma rotina desenvolvida no pretérito, fica difícil de lembrar exatamente como ela foi feita;

- O Dynamo apresenta, também, um problema de consistência: muitas vezes não se consegue rodar o programa, havendo necessidade de fechálo para conseguir abrir novamente e trabalhar. Não é raro que isso aconteça, o que ocasiona perda de tempo até que o usuário se situe. Embora o Dynamo tenha o nó watch que permite a visualização dos valores de saída dos nós, isso por si só não constitui uma ferramenta de debug. Normalmente as linguagens de programação permitem que o usuário use a ferramenta de debug, o que possibilita o acompanhamento da execução do programa linha a linha. Esta operação é muito usada para detectar erros no código, é possível ver inclusive o valor das variáveis ao longo do processo.

Todos os estudos apresentados tiveram êxito na execução dos programas e serviram para constatar as potencialidades que o uso desta ferramenta pode trazer para a automação de processos de projetos arquitetônicos. O acesso a todos os elementos do Revit e seus parâmetros, a possibilidade de comunicação com bases externas de dados, o uso de programação em Design Script e Python e a possibilidade de criar formas complexas que podem ser incorporadas e transformadas em elementos do Revit, abrem novas perspectivas para uma arquitetura diferenciada. 
O BIM é uma poderosa ferramenta para melhorar a qualidade do processo projetual. No entanto, o seu uso inadequado pode acarretar grandes distorções no projeto e até mesmo ser prejudicial ao bom andamento da execução do próprio projeto no canteiro de obras. É importante que modelos possam ser checados para a elegibilidade dos elementos neles compostos e a documentação que deles será extraída seja confiável.

Constatou-se que o uso do Dynamo pode trazer grandes benefícios para aqueles que estiverem dispostos a investir no seu aprendizado e também ser um vetor para o pensamento sobre as competências que um arquiteto deve ter. Abrir o conhecimento destas possibilidades e implementá-las aos poucos irá gerar um conhecimento importante para as futuras gerações de arquitetos e o uso do Dynamo pode ser um player importante dentro deste contexto. 
CAPÍTULO 4 AUTOMAÇÃO COM O PYTHON 
Python foi a segunda linguagem de programação analisada para discutir as condições de automação em Revit. Diferente do Dynamo, trata-se de uma linguagem consolidada, com mais material didático e informativo disponíveis. Outra diferença considerável relaciona-se à característica de programação textual, o que impõe maior dificuldade de compreensão e aplicação por parte de profissionais de setores ligados à $A E C O$, quando comparado ao Dynamo. $O$ capítulo 4 está estruturado em três seções, apresentando uma estrutura equivalente ao capítulo anterior:

4.1 Linguagem Python: a presente seção abordou a importância do aprendizado da linguagem para o desenvolvimento de rotinas de automação avançadas, possíveis com o Python. No capítulo 3, já foi apresentada uma função do Dynamo que possibilita o uso de nós Python, o que permite explorar a potencialidade de algoritmos escritos, que apresentam um nível mais alto de complexidade. Os conceitos de programação escrita são abordados neste item, evidenciando quais são as condições particulares para sua adequada utilização;

4.2 Estudos exploratórios e rotina experimental sobre Python: esta seção apresenta dois estudos exploratórios sobre o uso da linguagem Python realizados por terceiros dentro do ambiente de programação do Revit. Em seguida apresentamos a rotina experimental, desenvolvida pelo pesquisador nessa linguagem. O primeiro estudo exploratório faz uso de um console de programação para rotinas em Python por meio de Interactive Python Shell. Este ADDIN 35 permite o acesso direto a funções e classes escritas na linguagem Python que fazem parte do SDK ${ }^{36}$ do Revit.

Esse tipo de console permite testar de forma direta e prática rotinas e comandos programados, o que reduz os esforços de compilação de códigos mais robustos usados em plugins, como de linguagem $\mathrm{C \#}$, por exemplo. $\mathrm{O}$ segundo estudo exploratório analisa a programação de um plugin desenvolvido com Python que automatiza um conjunto de rotinas repetitivas do Revit utilizadas durante o processo de projeto. Instalado, o plugin cria um novo ribbon com vários comandos e permite o

\footnotetext{
${ }^{35}$ Programa que roda externamente ao Revit e que faz a comunicação com a API do Revit (ADDIN)

${ }^{36}$ Software Developer Kit (SDK) - Programa distribuído pela Autodesk com a documentação das classes de objeto do Revit
} 
acesso aos seus códigos-fonte por meio de uma interface gráfica familiar aos usuários.

O terceiro tópico aborda o mesmo experimento apresentado na rotina desenvolvida para o Dynamo mas se restringe à apresentação das áreas e à checagem do atendimento aos requisitos da lei. Neste caso, foi empregada a linguagem Python, o que permitiu desenvolver uma análise comparativa entre as duas formas de programação, sintetizada na matriz comparativa entre as formas de programar, apresentada nas conclusões, que aborda aspectos como facilidades, dificuldades, dentre outros, para automatizar as novas funções do Revit.

4.3 Considerações sobre o uso do Python para automação: a última seção do capítulo 4 apresenta algumas considerações referentes às condições de utilização da linguagem de programação Python, elencando dificuldades e características particulares que não se relacionam diretamente à análise comparativa.

\subsection{LINGUAGEM PYTHON}

Deitel et al. (2002, p. 14) ${ }^{37}$ contextualizam a origem do Python remetendo-a até 1989, quando Guido van Rossum, pesquisador australiano da National Institute for Mathematics and Computer Science in Amsterdam (CWI), observou as limitações das linguagens existentes para a realização de tarefas administrativas distribuídas, o que demandava expansibilidade. Logo, decidiu criar uma nova linguagem scripting que combinasse os elementos já existentes de outras linguagens por meio de classes e interfaces de programação. Desde então, o Python tem sido desenvolvido por uma comunidade de desenvolvedores seguindo o caminho open source.

Python é uma linguagem de alto nível orientada a objetos, sendo distribuída gratuitamente através de seu site oficial (PYTHON, [s.d.]) e está disponível em várias plataformas: Windows, Linux/Unix and Mac OS X. No site oficial da linguagem, pode-

\footnotetext{
${ }^{37}$ Harvey M. Deitel, CEO da Deitel \& Associates, Inc., tem 40 anos de experiência no campo da computação incluindo os setores empresariais e acadêmicos. Dr. Deitel tem Bacharelado e Mestrado pela Massachusetts Institute of Technology e Ph.D. pela Boston University.
} 
se também encontrar outros documentos que auxiliam na sua aprendizagem como:

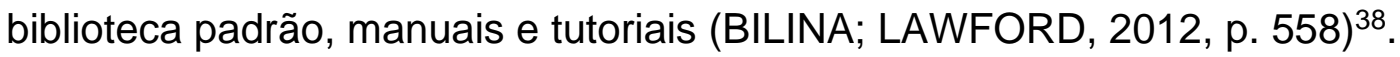

\section{Como descrevem Bilina e Lawford:}

Python é fácil de aprender e usar e é reconhecida por sua sintaxe clara, consistente e lógica. Este recurso, por si só, já a torna particularmente adequada para a rápida prototipagem de software e facilita a sua manutenção e depuração, além de permitir sua extensão pelo autor ou outro usuário (BILINA; LAWFORD, 2012, p. 559, tradução nossa) ${ }^{39}$.

\section{Para Swaroop (2019, p. 13) ${ }^{40}$ o Python pode surpreender positivamente o} usuário, deixando-o mais focado na solução do problema do que no entendimento da sintaxe e estrutura que fazem parte da linguagem que está sendo escrita. O site oficial do programa reforça o conceito de que esse meio linguístico computacional é eficaz, destacando que:

[...] Ela possui uma eficiente estrutura de dados de alto nível e abordagem simples mas eficaz, para programação orientada a objeto. Python tem uma sintaxe elegante e sua escrita é fácil. Aliado à sua natureza interpretada, ele se torna uma linguagem ideal para scripts e desenvolvimento rápido de aplicativos em muitas áreas e na maioria das plataformas e sistemas. (PYTHON, [s.d.]) tradução nossa) ${ }^{41}$.

Além disso, o Python apresenta uma significativa base de conteúdos de referência para o aprendizado online, com acesso fácil a tutoriais em inglês e português, blogs e fóruns da comunidade de usuários. Como exemplo dessa facilidade de acesso aos conteúdos sobre Python, pode-se observar numa pesquisa simples feita por meio do Google que ao digitar "looping Python" aparecem vários resultados pertinentes sobre comandos de loop, com exemplos de uso( Figura 43).

\footnotetext{
${ }^{38}$ Roseline Bilina - School of Operations Research and Information Engineering, Cornell University, Ithaca, NY, EUA.

${ }^{39}$ Original: Python is easy to learn and use, and is recognized for its very clear, concise, and logical syntax. This feature alone makes it particularly suitable for rapid software prototyping, and greatly eases subsequent program maintenance and debugging, and extension by the author or another user.

${ }^{40}$ Swaroop $\mathrm{C} \mathrm{H}$ é graduado em Engenharia, tem vasta experiência no desenvolvimento de startups de tecnologia, trabalhou e foi consultor de médias e grandes empresas e atualmente é diretor de engenharia da equipe de Machine Learning da Helpshift. Autor do livro A Byte of Python. Mora na California, EUA.

${ }^{41}$ Swaroop C H é graduado em Engenharia, tem vasta experiência no desenvolvimento de startups de tecnologia, trabalhou e foi consultor de médias e grandes empresas e atualmente é diretor de engenharia da equipe de Machine Learning da Helpshift. Autor do livro A Byte of Python. Mora na California, EUA.
} 
Figura 43 - Exemplo de resultado de uma pesquisa on line sobre loop na linguagem Python

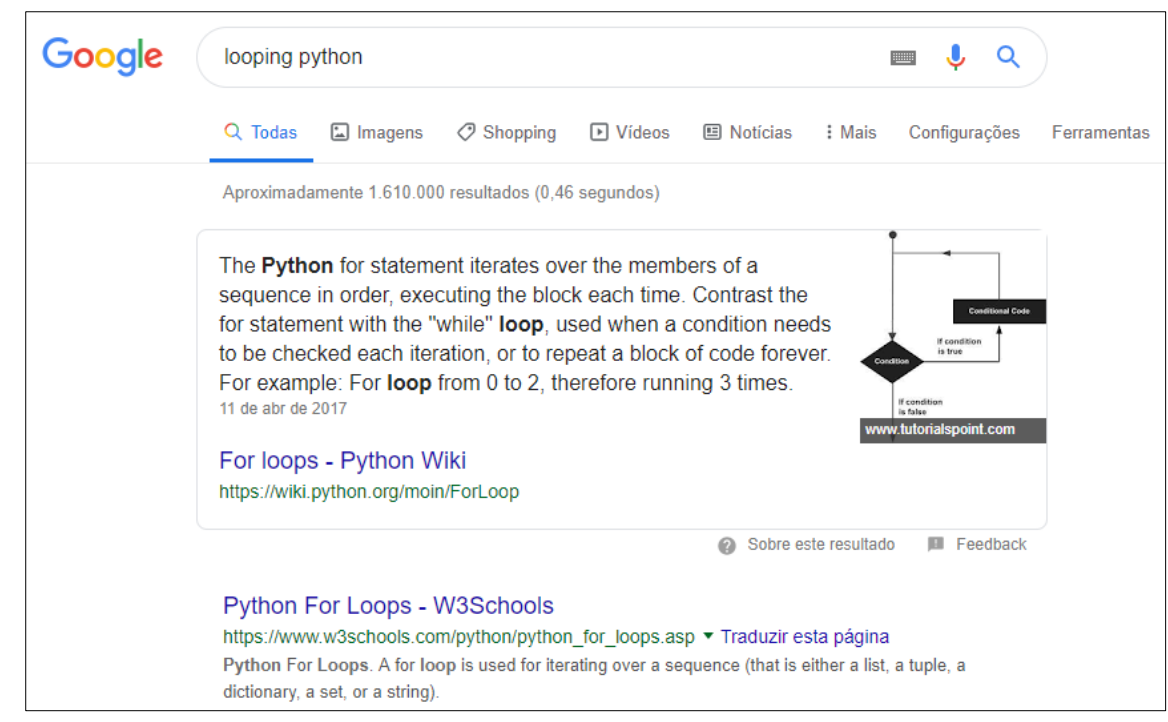

Fonte: Elaborado pelo autor

Uma pesquisa elaborada pela SlashData ${ }^{42}$ aponta que a linguagem Python superou a Java em popularidade, chegando a 8,2 milhões de desenvolvedores e é apontada como a segunda maior comunidade de usuários, com o crescimento de 2,2 milhões de novos adeptos em 2018. O crescimento de softwares voltados para o aprendizado de máquina é um dos fatores desta popularidade, uma vez que o Python apresenta rotinas voltadas para este nicho. Segundo a pesquisa, 69\% destes softwares e cientistas de dados usam o Python e $24 \%$ destes usam a linguagem $R^{43}$.

Ao se levar em consideração os dados apresentados na pesquisa da SlashData é possível traçar um paralelo entre usuários do Dynamo e a quantidade de rotinas que usam o nó da Python. Essa linguagem permite ampliar o potencial de uso do Dynamo para automação de processos de projeto com o Revit, como já visto anteriormente.

\subsubsection{Modelos paramétricos e a automatização dos processos projeto}

Segundo Davis (2013, p. 9) "um projeto paramétrico é um conjunto de equações que expressam um modelo geométrico através de funções explícitas de vários

\footnotetext{
${ }^{42}$ SlashData é uma empresa de pesquisa voltada à área de desenvolvedores de software

${ }^{43} \mathrm{R}$ é uma linguagem voltada para a área de manipulação a apresentação de dados gráficos e estatísticos (VENABLES; SMITH, 2019)
} 
parâmetros"44 . Assim, o BIM, enquanto sistema de suporte ao projeto paramétrico, estabelece um novo paradigma na indústria de AEC (LEE et al., 2013, apud ABRISHAMI et al., 2015; p. 351 ${ }^{45}$. Essa mudança na forma de projetar é possível devido a mecanismos automatizados de verificação e geração de alternativas de projetos controlados por regras de parâmetros pré-definidas.

Como Joklova e Budreyko (2019, p. 102) ${ }^{46}$ observam, o modelo BIM é composto por elementos orientados a objetos da construção que são gerados a partir de determinados tipos de parâmetros e podem ser manipulados ao longo do processo de projeto para realizar ajustes e testar alternativas. Tais recursos já são utilizados por projetistas da AEC para produzir múltiplas soluções com reduzidos esforços redundantes e paralelos (SUCCAR, 2011 apud SEPEHR ABRISHAMI et al., 2014, p. 351).

A manipulação desses parâmetros torna 0 processo de alteração mais eficiente, conferindo flexibilidade e integração por meio de um modelo geométrico gerado a partir de um banco de dados de parâmetros do projeto centralizado. Como os dados armazenados correspondem imediatamente à representação do modelo geométrico do projeto, qualquer nova entrada de dados ou mudanças feitas em um dado existente muda automaticamente os demais parâmetros associados àquele e ajusta o modelo (DAVIS, 2013, p. 8; EASTMAN et al., 2011, p. 15-26) ${ }^{47}$.

Todavia, alguns pesquisadores ressalvam que o nível de automatização por meio dos parâmetros apresenta limitações ligadas à falta de padronização de produtos da construção, que apresentam significativa variação de forma, de dimensões e de características materiais (SEPEHR ABRISHAMI et al., 2014, p. 351). As implicações de tais variabilidades não previsíveis demandam, por um lado, o desenvolvimento de

\footnotetext{
${ }^{44}$ Original: a parametric model is set of equations that express a geometric model as explicit functions of a number of parameters. 45 Sepehr Abrishami é pós-doutorando no Centre for Sustainable Development, The Grenfell-Baines School of Architecture, Construction and Environment, University of Central Lancashire, Preston, Reino Unido.

46 Viera Joklova é arquiteta e professora na Faculty of Architecture Slovak University of Technology, na República Eslovaca. Pesquisadora com foco em projeto urbano sob a influência de novas tecnologias. Participa de projetos de pesquisa internacionais, conferências, workshops e seminários.

47 Daniel Davis é arquiteto graduado na Nova Zelândia e Ph.D. em Design Computacional pela RMIT University Australia. É pesquisador interessado em dois temas principais: como a tecnologia influencia a arquitetura e como a arquitetura influencia as pessoas. Gerencia um grupo de pesquisa no WeWork.
} 
sistemas flexíveis e reconfiguráveis de manufatura e, por outro, que a modelagem apresente meios de interação intuitiva para auxiliar a experimentação e a tomada de decisão durante o processo de projeto e de gerenciamento da construção (FRUCHTER, 1998 apud SEPEHR ABRISHAMI et al., 2014, p. 351) ${ }^{48}$.

\subsubsection{Habilidades para projetar usando programação + BIM}

Parte do poder de atração que a programação aplicada ao processo de projeto exerce sobre arquitetos e engenheiros projetistas está vinculada à possibilidade de realizar tarefas de difícil execução por humanos, bem como à possibilidade de projetar soluções formais inviáveis de serem concebidas sem auxílio do processamento computacional.

Tal poder de atração logo enfrenta uma barreira ligada ao tipo de conhecimento exigido para empregar a programação no processo de projeto. O uso de uma linguagem como o Python requer o entendimento da lógica de programação, o que exige dos profissionais ligados ao projeto e seu gerenciamento o desenvolvimento de novas competências profissionais ligadas às ciências da computação. Segundo Downey (2012, p. 1), este tipo de competência leva o profissional a exercitar um raciocínio mais ligado à matemática, à engenharia e à ciência.

Por meio de um raciocínio matemático, um profissional usa a linguagem formal para apresentar ideias, principalmente as ligadas a cálculos. Pela engenharia, este profissional cria produtos por meio da combinação de elementos e partes, concebendo alternativas de projeto para esse fim. Com um pensamento cientifico, observa sistemas complexos, cria hipóteses e antecipa resultados. Essencialmente, Downey (2012, p. 1) reconhece tais qualidades no cientista da computação, apontando que este está focado na resolução de problemas, estudando as possíveis soluções e apresentando-as de forma precisa e clara.

\footnotetext{
${ }^{48}$ Dra. Renate Fruchter é engenheira graduada pelo Institute for Civil Engineering in Bucharest, Romênia, Mestre e Ph.D, pelo Technion - Israel Institute of Technology. É professora na Stanford University e líder do curso "Computer Integrated Architecture/Engineering/Construction Global Teamwork", que agrega universidades dos EUA, Japão e Europa.
} 
Para Woodbury (2010a, p. 7) os computadores apresentam recursos quase ilimitados ao processo de projeto por meio da criação de algoritmos e programas. Este potencial computacional para auxiliar arquitetos e engenheiros no desenvolvimento de projetos com novos conceitos e formas, no entanto, esbarra no tipo de formação que profissionais ligados a projetos em AECO recebem.

A automatização de processos de projeto por meio da parametrização e ciência da computação não é uma tarefa trivial. Woodbury (2010a, p. 7-8) salienta que, para aumentar o potencial de resolução de projeto por meios computacionais, os projetistas precisam combinar conceitos de sistemas paramétricos, entendimento de geometria e programação de computadores à sua atividade profissional:

\begin{abstract}
Acontece que absorver todas essas ideias não é fácil, pelo menos para aqueles com um background de arquitetura. Dominar estes conhecimentos requer que o indivíduo seja parte projetista, parte cientista da computação e parte matemático. Já é suficientemente difícil ser um especialista em uma destas áreas por si só. No entanto, alguns dos melhores e mais brilhantes (geralmente novos) arquitetos e projetistas estão fazendo justamente isso eles estão desenvolvendo habilidades impressionantes ao evocar o novo e surpreender (WOODBURY, 2010, p. 8, tradução nossa) ${ }^{49}$.
\end{abstract}

Criar um programa significa escrever algoritmos de forma precisa em uma determinada língua de programação. Assim, ao se aprender uma linguagem de programação o pensamento algorítmico também é absorvido em certa medida. Woodbury, (2010, p. 49) argumenta que, assim como a maneira mais efetiva de se aprender uma nova língua é conviver diariamente com indivíduos que têm esta como sua língua nativa, da mesma maneira a melhor forma de aprender uma linguagem de programação é usando-a intensivamente. Mesmo que arquitetos e projetistas assimilem uma determinada linguagem de programação, isso não significa que todos os conceitos ligados a um pensamento algorítmico tenham sido completamente assimilados.

Woodbury (2010a) explica que:

\footnotetext{
${ }^{49}$ Original: It turns out that these ideas are not easy, at least for those with typical design backgrounds. Mastering them requires be part designer, part computer scientist and part mathematician. It is hard enough to be an expert in one of these areas, yet alone all. Yet, some of the best and brightest (and mostly young) designers are doing just that - they are developing stunning skill in evoking the new a new and surprising.
} 
Isto acontece porque existem conceitos que devem ser dominados independentemente da linguagem em que se está programando. Cientistas de computação apreendem as combinações e descrições algorítmicas de forma mais abstrata programando em múltiplas linguagens de programação. $\mathrm{Na}$ realidade a maioria dos cientistas da computação afirmam que a ciência da computação é separada das habilidades para programação (Tradução nossa $)^{50}$.

Como BIM é um sistema que se baseia em softwares de modelagem paramétrica, o potencial de acrescentar e modificar parâmetros do projeto por meio de interfaces de programação oferece as condições tecnológicas para galgar patamares de qualidade projetual inalcançáveis sem a associação de projeto e programação (LABIB, 2017, p. 234) ${ }^{51}$. O domínio de linguagens de programação como Python desenvolve um raciocínio algoritmo que permite aos projetistas dominar os programas existentes, entender seus limites e, eventualmente, direcionar a discussão para adequar os programas existentes a diferentes necessidades de automação de processos.

Apesar do Python ser também uma linguagem orientada a objetos, na sua aplicação com o Dynamo através do nó Python normalmente se usa uma estrutura procedural. Neste capítulo serão explorados principalmente seus aspectos com essa estrutura de linguagem. Assim, para realizar essas programações, será necessário que o usuário esteja acostumado com as habilidades de pensamento algorítmico, computacional e matemático, como já apontado anteriormente.

Os detalhes podem ser diferentes, mas quase todas as linguagens de programação têm aspectos comuns que são: entrada de dados, saída de dados, cálculos matemáticos, repetições e execução condicional Figura 44 (DOWNEY, 2012, p. 3).

\footnotetext{
50 Original: This happens because there are general language-independent concepts to master. Computer scientists learn these through a combination more abstract algorithmic descriptions and programming in multiple languages. In fact, most computer scientists would assert that the science of computing is quite separate from programming skill.

51 Rania Labib é graduada em Arquitetura e pós-doutoranda da Texas A\&M University, onde leciona, e professora assistente da Prairie Vew A\&M University. Estudou ciência da computação na Suiça, Espanha e EUA. Seus principais focos de interesse em pesquisa são performance do edifício, desenvolvimento de ferramentas computacionais para análise de projetos e robótica.
} 
Figura 44 - Cinco aspectos comuns a diversas linguagens de computação

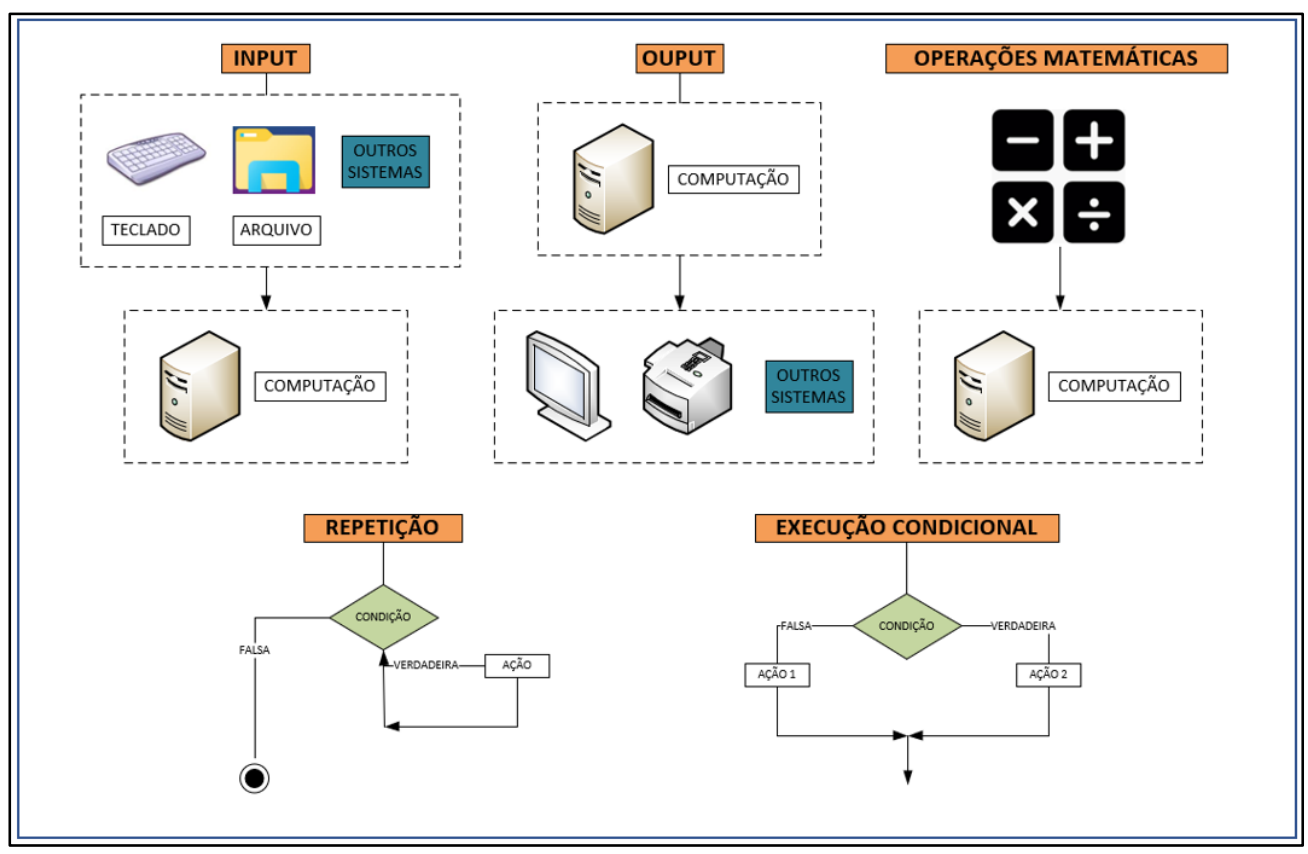

Fonte: Elaborado pelo autor

Apesar destes aspectos aparentarem ser uma descrição excessivamente simplificadora, Downey (2012, p. 3) observa que:

Acredite ou não, isto é praticamente tudo que eles fazem. Todo programa que você já usou, não importando o quanto complicado ele seja, é feito com instruções que se parecem com estas. Então você pode pensar em programação como um processo de dividir tarefas complexas em sub partes com tarefas menores e menores até que estas sejam simples o suficiente para que possam ser realizadas com algumas destas instruções (DOWNEY, 2012, tradução nossa) $)^{52}$.

As definições apresentadas no Quadro 3devem ser compreendidas como conceitos chave para o aprendizado de computação. Woodbury (2010 p, 49-58a) observa que 0 aprendizado destes conceitos chave pode abrir novas perspectivas para arquitetos e engenheiros projetistas dedicados a automatizar processos de projetos. De forma mais específica, este aprendizado é importante para criar automatização em sistemas BIM como a plataforma Revit, ao acessar e interagir com o banco de dados do modelo por meio de programação em linguagem Python.

\footnotetext{
52 Original: Believe it or not, that's pretty much all there is to it. Every program you've ever used, no matter how complicated, is made up of instructions that look pretty much like these. So, you can think of programming as the process of breaking a large, complex task into smaller and smaller subtasks until the subtasks are simple enough to be performed with one of these basic instructions
} 


\section{Quadro 3 - Conceitos de programação Woodbury}

\begin{tabular}{|l|l|l|}
\hline Conceito & \multicolumn{1}{|c|}{ Descrição } & \multicolumn{1}{|c|}{ Exemplos } \\
\hline \multirow{4}{*}{ Valores } & $\begin{array}{l}\text { Valor é um tipo de dado normalmente eles são } \\
\text { objetos onde o processamento ocorre }\end{array}$ & 5 é um numero inteiro \\
\cline { 3 - 3 } & & 2.13159 é um numero real \\
\cline { 3 - 3 } & & "f" um carater \\
\cline { 2 - 3 } & & "alternativa" é um texto \\
\hline
\end{tabular}

\begin{tabular}{|c|c|c|}
\hline \multirow{4}{*}{ Variáveis } & \multirow{4}{*}{$\begin{array}{l}\text { Variáveis são usada para quardar valores que podem } \\
\text { ser usados em outros lugares no programa. É } \\
\text { importante o nome da variável, ela deve ter um } \\
\text { significado adequado. }\end{array}$} & $\mathrm{b}=10$ (numero inteiro) \\
\hline & & larguraPorta = 1.2 (numero real) \\
\hline & & elementoTipo = "Janela" (texto) \\
\hline & & sitemaBasculante $=$ verdadeiro $($ Boolean $)$ \\
\hline
\end{tabular}

\begin{tabular}{|c|c|c|}
\hline \multirow{4}{*}{ Expressões } & \multirow{4}{*}{$\begin{array}{l}\text { Uma expressão combina valores, variáveis, } \\
\text { operações e chamadas a funções retornando valores. } \\
\text { Que por sua vez podem ser amazenadas em variaveis. } \\
\text { As variaveis para serem usadas em funções precisam } \\
\text { esta declaradas antecipadamente. }\end{array}$} & b uma variavel é um expressão simples \\
\hline & & $2+(5 * 8)$ retorna o valor de 42 \\
\hline & & $(1+$ sqrt(5)))/2) a expressão pode chamar também uma função \\
\hline & & $b+1$ a variavel $b$ tem que ser definida anteriormente \\
\hline
\end{tabular}

\begin{tabular}{|c|l|l|}
\hline Statements & $\begin{array}{l}\text { É uma unidade de codigo que uma linguagem } \\
\text { executa, numa determinada ordem. Uma declaração } \\
\text { (Statement) pode ser simples com apenas uma linha. } \\
\text { Ou composta de várias outras declarações. }\end{array}$ & $\begin{array}{l}\mathrm{a}=(1.0+\text { sqrt }(9)) / 2.0 ; \text { valor de } \mathrm{a}=2.0 \\
\mathrm{a}=3.144159 ; \text { o valor de a passa a ser } \\
\text { obs. A última linha de declaração é a que vale para uma declaração } \\
\text { portanto, o valor de a se altera }\end{array}$ \\
\hline
\end{tabular}

\begin{tabular}{|c|c|c|}
\hline \multirow{5}{*}{$\begin{array}{l}\text { Statements de } \\
\text { controle }\end{array}$} & \multirow{5}{*}{$\begin{array}{l}\text { A sequência de um programa são uma serie de } \\
\text { declarações em ordem seguindo um fluxo. Existe um } \\
\text { statement que muda este fluxo, e uma das mais } \\
\text { declarações sobre alteração de fluxo de program á o } \\
\text { if. }\end{array}$} & if $(a>5.0)$ \\
\hline & & \{ \\
\hline & & // uma sequência de declarações entra aqui \\
\hline & & 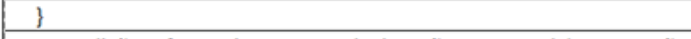 \\
\hline & & $\begin{array}{l}\text { se a condição a for aceita executa declaraçôes entre colchetes, senão } \\
\text { pula esta parte e segue para a linha seguinte. }\end{array}$ \\
\hline
\end{tabular}

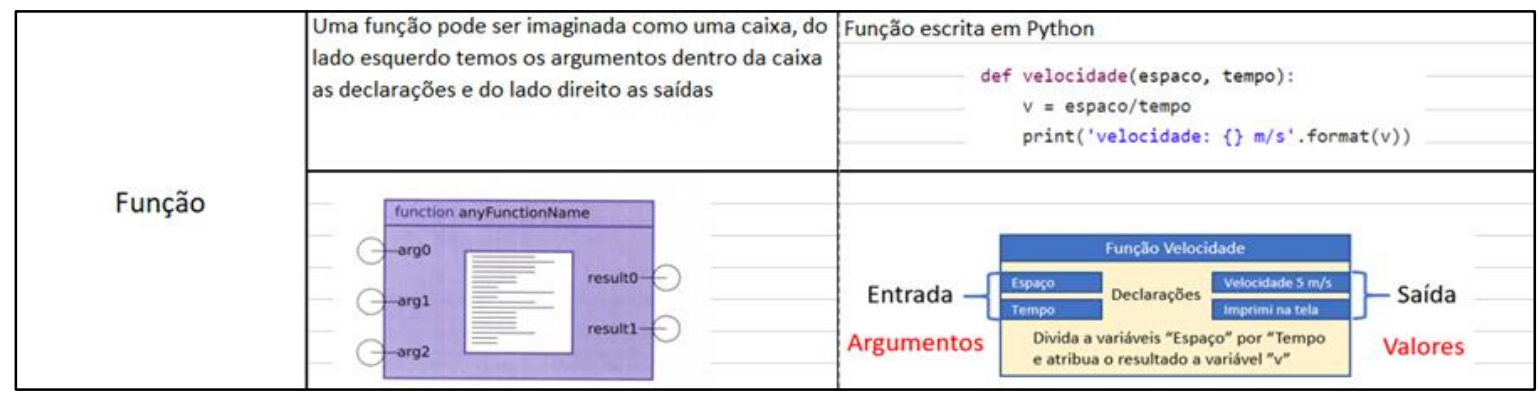

\section{Continua.}




\begin{tabular}{|c|c|c|}
\hline Conceito & Descrição & Exemplos \\
\hline Estruturas de dados & \begin{tabular}{|l|} 
Uma lista é usada para armazenar vários tipos de \\
variáveis em uma única classe. Dentro da estrutura \\
de dados ela armazena vários elementos em \\
sequência. Como uma lista tem uma serie de \\
elementos. Duas propriedades definem a estrutura da \\
lista, a primeira chamada de Head aponta o primeiro \\
item da lista. A segunda propriedade aponta para os \\
outros itens da lista. As intâncias podem ser \\
direrentes tipo de valores. O Símbolo 111 \\
normalmente representa um valor nulo. \\
A estrutura de dado é uma técnica abstrata porém \\
chave para a programação. Uma vez concebidas elas \\
vão fazer o trabalho sem termos que nos preocupar \\
mais com elas. Listas são estrutura de dado simples \\
embora tenham uma complexidade em determinada \\
operações. Listas e arrays são uma das primeiras \\
estruturas de dados que modeladres devem aprender \\
a usar.
\end{tabular} & 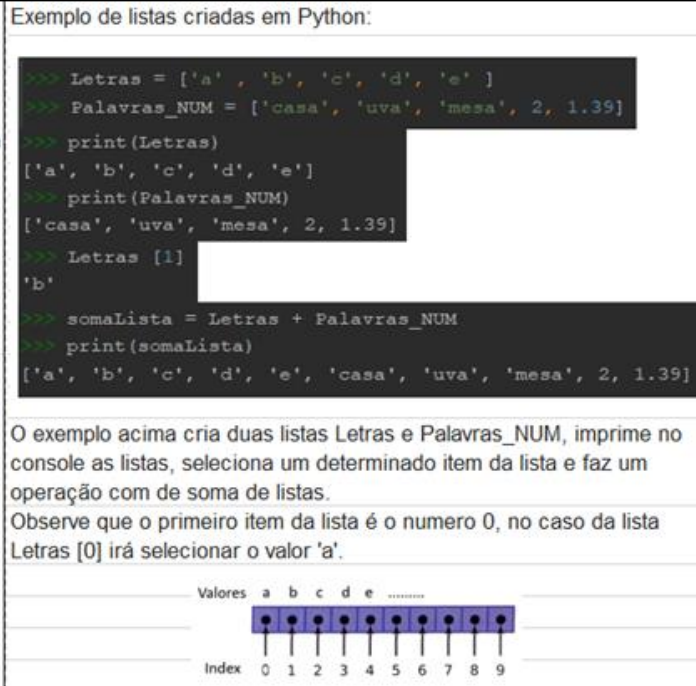 \\
\hline
\end{tabular}

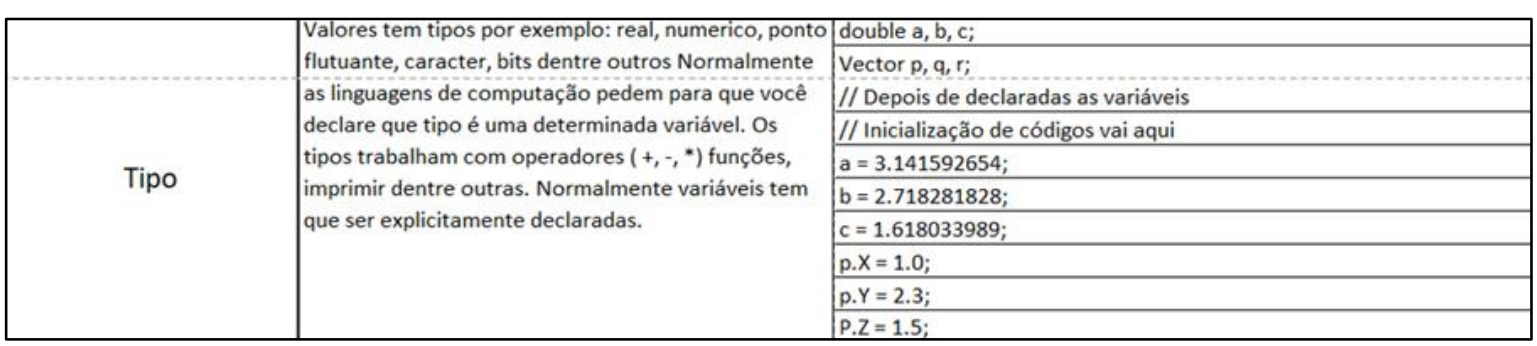

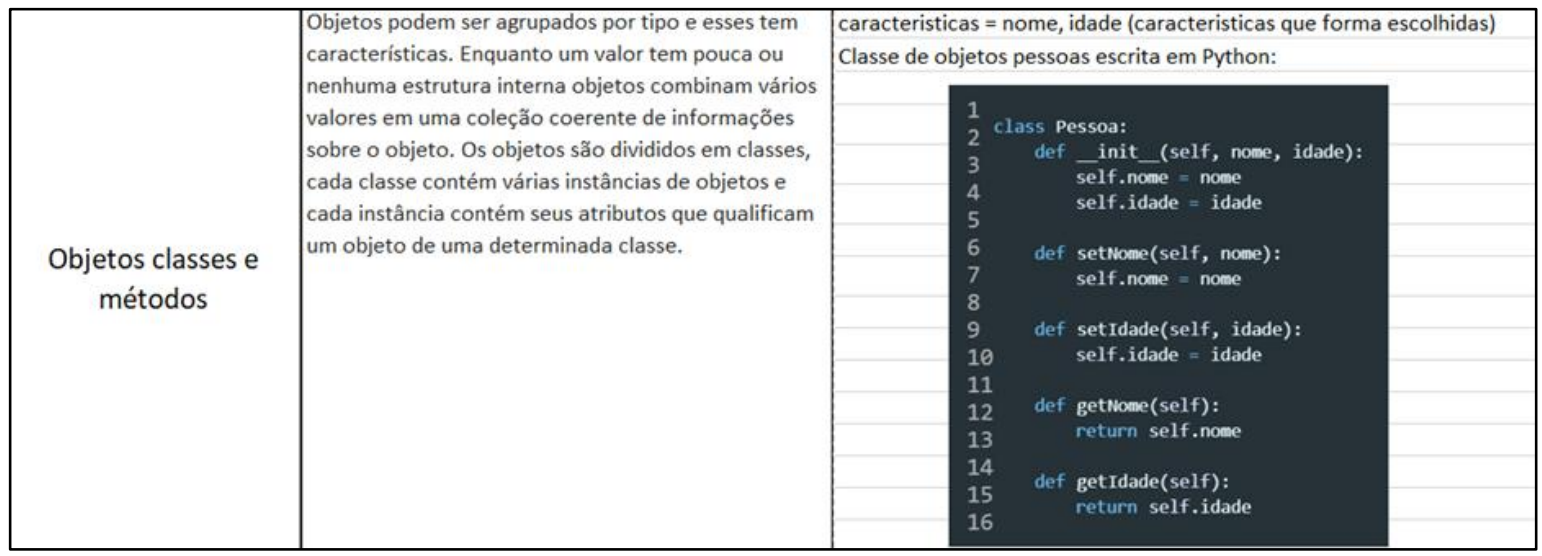

Fonte: Elaborado pelo autor 


\title{
4.2 ESTUDOS EXPLORATÓRIOS E ROTINA EXPERIMENTAL EM PYTHON
}

No Quadro 3 foram apresentados os conceitos de abordados por Woodbury (2010, p. 50-58). Estes conceitos de computação embasam os estudos realizados neste capítulo e também em toda pesquisa. Nas próximas seções são apresentados e discutidos os itens referentes aos dois estudos exploratórios e a rotina experimental que abordam linguagem Python script associados a um software BIM.

\subsubsection{Addin Console Revit Python Shell (RPS)}

Um plugin é um tipo de comando ou expansão de uso do software pelo qual os fabricantes de softwares permitem que desenvolvedores criem funções, originalmente, não disponibilizadas pelo software, por meio de uma interface de script, que conecta um programa externo ao software principal. No caso do Revit da Autodesk este acesso é feito por meio da (API) do Revit. Ou seja:

\begin{abstract}
Um plugin para um software (programa) é um tipo de módulo (ou arquivo) que adiciona funcionalidade para o produto, geralmente sob a forma de um comando para uma tarefa ou automatização personalizada do comportamento do produto. Um plug-in para o Revit® - ou Addin (suplementos) - significa um módulo que contém um código que faz uso do Revit $\AA^{\circledR}$ API. O Revit ${ }^{\circledR}$ carrega como plug-ins e os utiliza para customizar o seu comportamento sob determinadas condições (Autodesk, 2013; PEREIRA; AMORIM, 2014, p. 2958).
\end{abstract}

Entre as possibilidades de implementação de plugins baseados em Python, o Revit da Autodesk adota a implementação do tipo IronPython. Trata-se de um pacote de linguagem de programação Python escrito em C\#, que foi originalmente desenvolvido para a plataforma .NET da Microsoft, e que já vem instalado no Revit para apoiar a criação de macros, rotinas em Dynamo e scripts em Python.

O primeiro estudo exploratório que aborda as condições de programação em Python para automação em Revit, descreve e analisa um tipo de Addin de API para o Revit que consiste em um console para programação em Python (Figura 45) desenvolvido por meio do IronPython. O plugin Revit Python Shell (RPS) é um 
programa desenvolvido por Daren Thomas ${ }^{53}$ para testar comandos de análise energética para prédios em modelos do Revit (TAMMIK, 2009) ${ }^{54}$.

Figura 45 - Python Shell

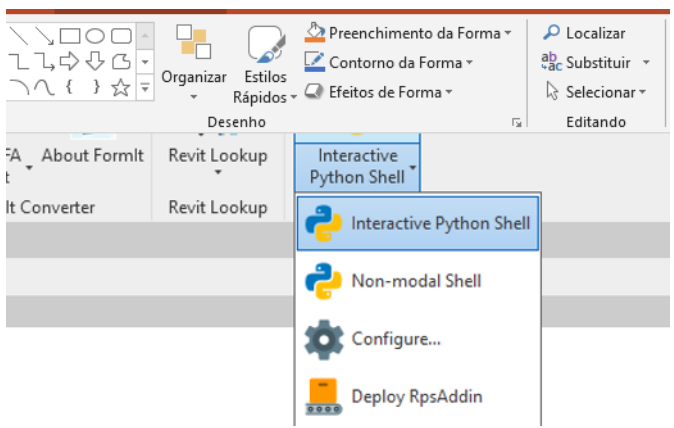

Fonte: Elaborado pelo autor

Miller et al. (2014) $)^{55}$ observam que normalmente a troca de dados entre um modelo BIM e programas externos para a análise de eficiência energética de edifícios tem sido feitas empregando arquivos IFC e gbXML. Contudo, este processo restringe o controle sobre a criação e o carregamento dos arquivos, limitando o acesso aos dados que podem ser extraídos do modelo e dificultando a interoperabilidade entre o modelo BIM e programas externos.

O RPS não enfrenta as mesmas dificuldades, pois acessa diretamente uma maior quantidade de dados do modelo BIM que uma API baseada em IronPython pode acessar sem a necessidade de adaptar as informações a um outro formato. O RPS se comunica diretamente com o banco de dados do Revit, o que permite uma maior flexibilidade para determinar que tipos de dados são extraídos. Nas palavras de seu desenvolvedor (THOMAS, [s.d.]):

\footnotetext{
${ }^{53}$ Daren Thomas é graduado em Engenharia de Software pela University of Applied Sciences ZHAW em Zurich. Trabalha em vários projetos, incluindo gerenciamento eletrônico de documentos, desenvolvimento de sites para web, otimização de processos de negócios. Atualmente está focado no BIM e sua aplicação na análise energética.

54 Jeremy Tammik é graduado em Matemática e Fisica pela Martburg University da Alemanha e trabalhou como professor de linguagens computacionais como o C\#. Trabalhou na Autdesk e atualmente dá treinamentos, conferencias, apresentações, juntamente com o Forge Partner Development team, nas APIs da Autodesk e tecnologias de nuvem.

${ }^{55}$ Clayton Miller é engenheiro civil graduado pela Universidade de Nebraska, EUA, Mestre em Edificações pela National University of Singapore e Doutor em Ciências pela ETH Zurich, na Suiça. Foco de interesse em ciência de dados para performance das edificações.
} 
O RevitPythonShell permite que se escreva plugins para o Revit em Python, (...) melhor ainda, por meio de uma janela interativa de programação, ele faculta que os resultados de seus códigos sejam vistos assim que você termina de digitá-los. Isso é muito bom para explorar a API do Revit enquanto escreve seus Addins - ao usar essa interface de programação junto com o RevitLookup para explorar o banco de dados do modelo vai fazer com que você se torne um expert (tradução nossa) ${ }^{56}$.

Tammik (2009) observa que o RPS permite que se mude o banco de dados de elementos explorando suas propriedades de forma direta e com grande liberdade. Além disso, destaca que é possível armazenar os dados e executar qualquer mudança aplicando novos valores aos parâmetros dos elementos e continuar a processá-los da maneira que o desenvolvedor considerar melhor. Tal forma de acesso aos dados do modelo Revit por meio do RPS apresenta maior facilidade para a automação de processos via API quando comparada aos métodos utilizados com base em consultas codificadas para acesso aos elementos da base de dados do modelo e suas propriedades.

O RPS abre a Application Programming Interface (API) do Revit e disponibiliza um campo (prompt) para inserir scripts em uma linguagem de programação escrita. Mais especificamente, o RPS disponibiliza uma interface com dois campos: o primeiro apresenta um prompt para comandos que podem ser executados imediatamente; 0 segundo corresponde a um campo para edição de texto, em que um conjunto indeterminado de linhas podem ser inseridas / digitadas, para, em seguida, serem executadas por meio da digitação do F5 ou de um clique no botão run (Figura 46).

\footnotetext{
${ }^{56}$ Original: The RevitPythonShell (RPS) lets you to write plugins for Revit in Python, my favourite scripting language! But even better, it provides you with an interactive shell that lets you see the results of your code as you type it. This is great for exploring the Revit API while writing your Revit Addins - use this in combination with the RevitLookup database exploration tool to become a Revit API Ninja :)
} 
Figura 46 - Console Python Shell - Linhas de comandos executados

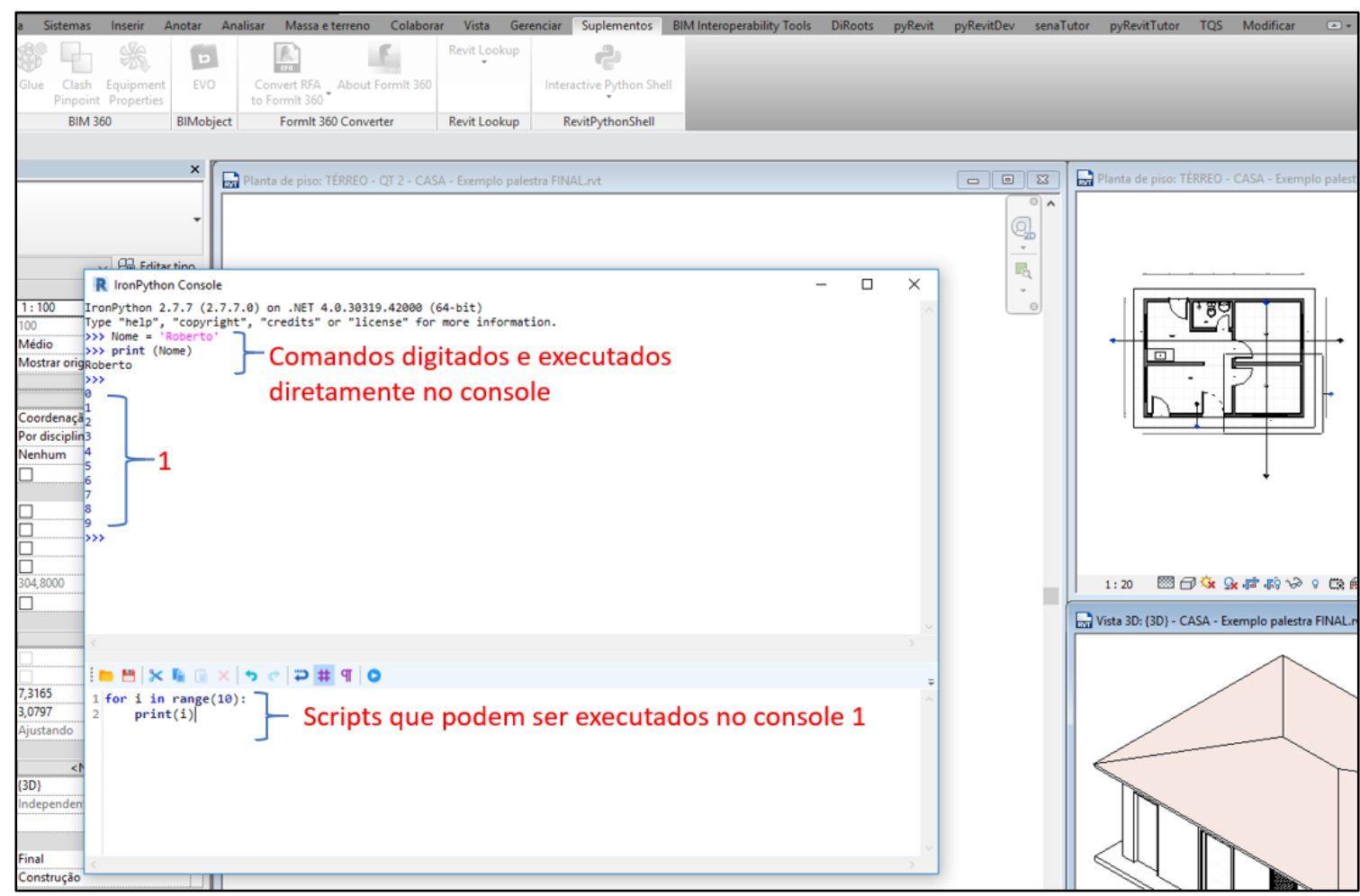

Fonte: Elaborado pelo autor

Dois códigos escritos em Python que são apresentados a seguir exemplificam a utilização do plugin RPS. Estes códigos são disponibilizados gratuitamente, podendo ser encontrados no repositório do GitHub (THOMAS, [s.d.] $)^{57}$.

A Figura 47 mostra a sequência de comandos executados em Python diretamente no console RPS que faz uma análise apresentando todos os tipos de parede existentes no modelo. São importadas as classes FilteredElementCollector, BuiltInCategory, BuiltInParameter do banco de dados do Revit. Em seguida, todos os dados são armazenados na variável cl através do comando FilteredElementCollector e uma instância de cl é criada para a categoria parede com o comando cl.OfCategory (BuiltInCategory.OST_Walls). O comando de "for" e "print" do Python mostram diretamente no console os elementos parede encontrados no documento ativo.

\footnotetext{
${ }^{57}$ GitHub é um repositório na web onde quarenta milhões de desenvolvedores trabalham juntos para depositar e revisar códigos, gerir projetos e desenvolver softwares juntos.
} 


\section{Figura 47 - Janela do RPS importação de classes carregamento dos elementos parede na} variável cl

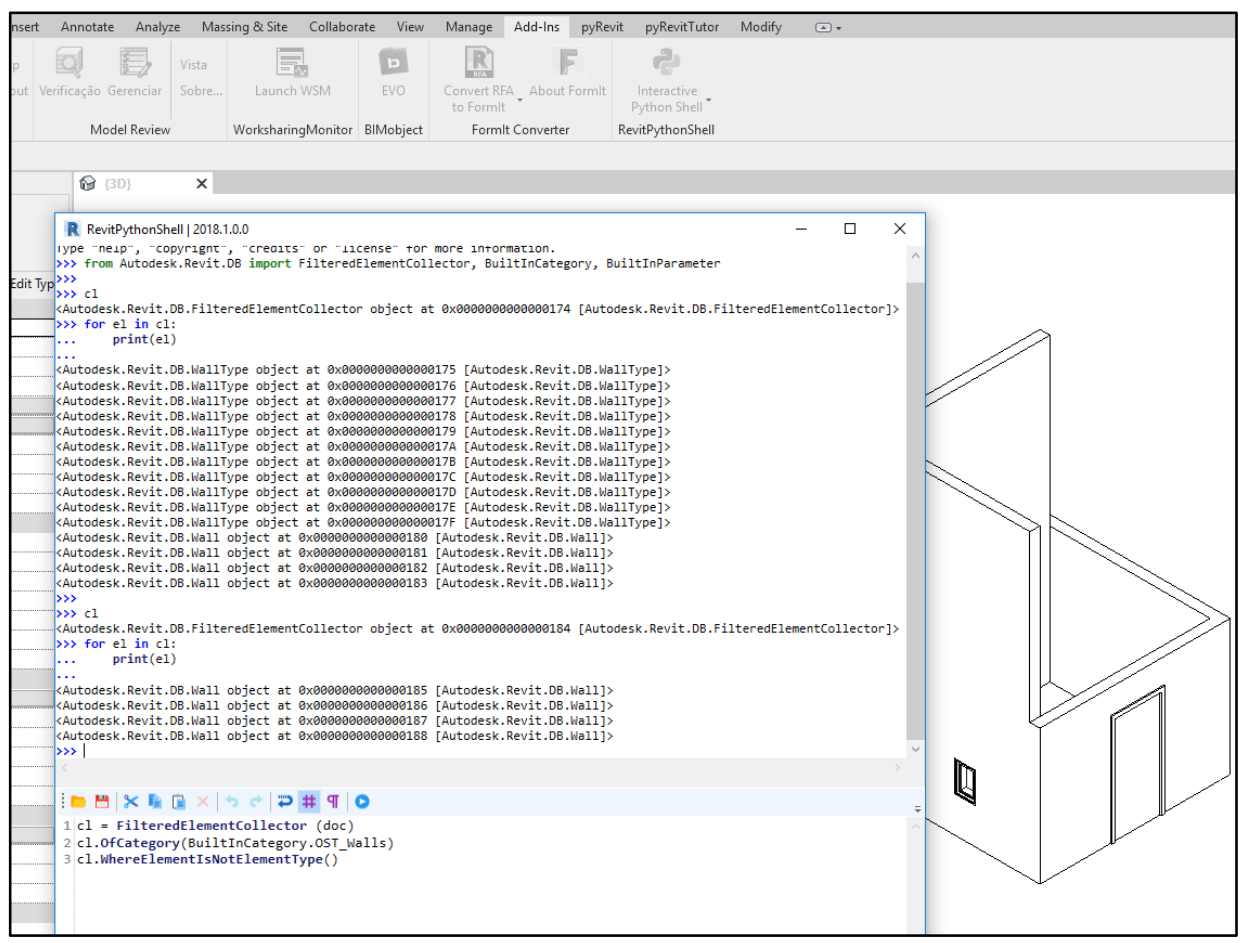

Fonte: Elaborado pelo autor

Com esse console de programação, os comandos podem ser testados um a um. Cada linha pode ser digitada no console, que devolve uma informação acessando diretamente o banco de dados do Revit.

No caso demonstrado na Figura 47, o primeiro comando recursivo "for" foi executado sem a inserção da linha 3, cl.WhereElementlsNotElementType(); na área de execução de várias linhas de comando, esse filtro seleciona as paredes do modelo que foram efetivamente inseridas mas não as disponíveis como famílias no projeto. Quando o segundo comando "for" é executado, apenas as paredes inseridas no modelo são selecionadas. Uma vez testados os comandos e os retornos que estes dão, scripts mais longos podem ser feitos usando, por exemplo, editores de texto como o bloco de notas do Windows ou o Notepad++ (NOTEPAD++, [s.d.]).

A Figura 48 mostra um exemplo de aplicação de programa utilizando RPS que calcula o volume das paredes inseridas no modelo. Por estar implementado na API do Revit, o script pode buscar diretamente as classes, objetos e métodos disponíveis no Software Development Kit (SDK) do Revit. Nesse caso foi aplicado o comando 
Parameter [BuiltInParameter.HOST_VOLUME_COMPUTED], que acessa o parâmetro de instância volume de cada parede.

Figura 48 - Script para determinar volume das paredes inseridas

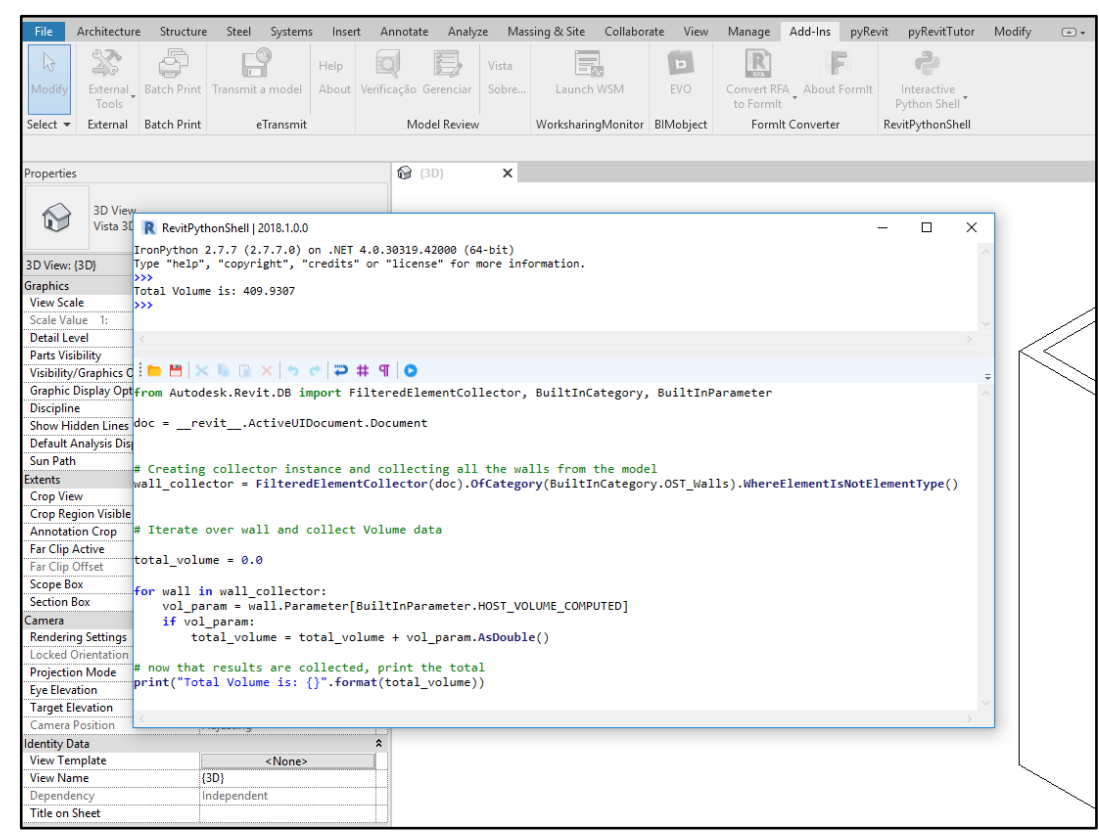

Fonte: Elaborado pelo autor

Com o conhecimento de conceitos sobre programação, domínio da linguagem Python, dos comandos do Revit e das classes e objetos disponíveis na API do Revit, vários processos como os exemplos apresentados podem ser automatizados com ganhos significativos para a execução de tarefas que, se fossem realizados manualmente, custariam tempo adicional, além de estarem sujeitos a erros humanos associados à repetitividade da tarefa.

\subsubsection{Addin PyRevit - Comandos acrescentados no Ribbon do Revit}

O segundo estudo exploratório analisado é o pyRevit (EHSAN IRAN-NEJAD, [s.d.] $)^{58}$. Essencialmente, este Addin é constituído por uma série de scripts escritos totalmente em IronPython, que são disponibilizados gratuitamente e apresentam um código fonte aberto a usuários. Em outros termos, trata-se de uma biblioteca de

\footnotetext{
${ }^{58}$ Ehsan Iran-Nejad é Mestre em Arquitetura pela Azad University of Mashhad, Iran. Especialista em BIM e desenvolvedor de
} software na TVA Architects em Portland, Oregon, EUA. Criador e mantenedor do pyRevit. 
comandos para Revit que podem ser utilizados diretamente por meio de ícones agrupados em uma Ribbon específica que é adicionada à interface do Revit quando a pyRevit é instalada (Figura 49).

Figura 49 - Ribbon do pyRevit com novos comandos para o Revit

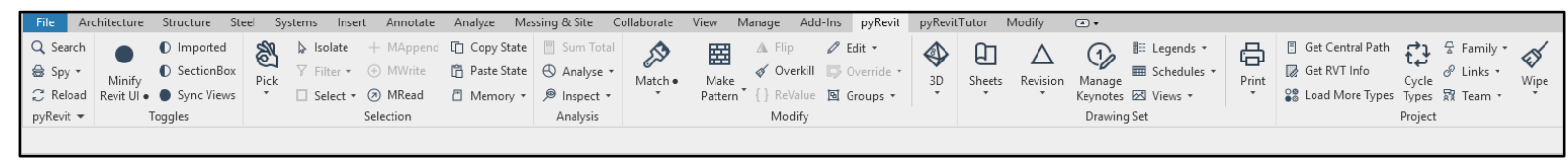

Fonte: Elaborado pelo autor

Embora os scripts do pyRevit possam ser rodados diretamente no Revit sem a necessidade de serem carregados em um console de programação (como ocorre com o RevitPythonShell), os códigos podem ser analisados e alterados pelo usuário. Durante a instalação, uma pasta chamada pyRevit / extensions é criada com todos os scripts cujos comandos estão relacionados na nova aba. Ao acessar esta pasta é possível analisar como cada script foi escrito, o que contribui para o aprendizado da linguagem IronPython e cria novos comandos que podem ser acrescentados ao ribbon do pyRevit.

As pesquisas feitas por meio de sites de pesquisas acadêmicas, como o Web of Science, ScienceDirect, ProQuest e o Google Scholar, não retornaram resultados que apoiassem a compreensão e discussão sobre o Addin pyRevit. No entanto, Bondarchuk sugere duas fontes online para suporte aos usuários do pacote pyRevit (PYREVIT, [s.d.]) em que são disponibilizadas informações sobre a instalação, configuração para inicialização (setting) e utilização.

Os exemplos utilizados para discutir o pyRevit foram disponibilizados por Ehsan (EHSAN IRAN-NEJAD, [s.d.]) e descrevem dois aspectos do pyRevit. O primeiro apresenta duas aplicações de comandos simples, acessados diretamente pela aba, 0 segundo introduz a estrutura do pyRevit de maneira a permitir operações mais complexas.

Um dos comandos disponibilizados pelo Addin permite que o usuário selecione objetos do modelo de maneira mais eficiente por meio de um comando similar à 
"máquina de somar", em que elementos podem ser identificados, acrescentados ou retirados da memória. Neste caso, um conceito semelhante foi adotado para selecionar elementos em múltiplas vistas. Este tipo de comando de seleção de objetos é realizado por meio do "painel de seleção" ao se clicar nos botões que representam as opções MAppend, MWrite e MRead (Figura 50).

Figura 50 - PyRevit botões para adição, subtração e limpeza de elementos selecionados em memória.

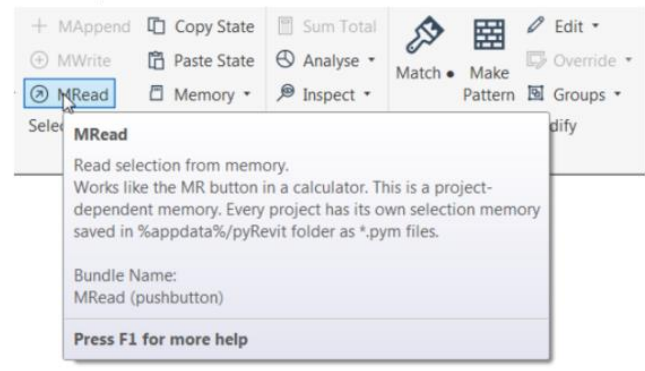

Fonte: Ehsan Iran-Nejad ( [s.d.])

O segundo comando destacado entre aqueles acessados por um botão do Ribbon do pyRevit automatiza a conversão e copia legendas para outros projetos. Encontrado no painel Drawing Set, o comando legends apresenta quatro opções de operação: a cópia de legendas para outros projetos abertos em uma sessão do Revit; a cópia de legendas de um projeto como desenhos; a conversão de legendas em desenho e a conversão de desenhos em legendas.

Os exemplos são acionados ao selecionar o comando por meio de um clique no botão. Além deste tipo de automação de tarefas de fácil acesso para qualquer usuário, existem outras formas de automatizar tarefas do processo de projeto que dependem do domínio sobre a estrutura do pyRevit.

De forma geral, o pyRevit é estruturado por dois componentes básicos relacionados ao funcionamento do Addin e as extensões que são acionadas por meio de seu funcionamento: pyRevit Core e pyRevit Extensions. O primeiro componente é responsável por analisar as extensões e criar os arquivos de montagem necessários para que a ferramenta se comunique com o usuário. Dentro do diretório do computador existem pastas que são acessadas e lidas pelo sistema pyRevit. Quando o comando é acionado, executa-se um script em IronPython que se comunica com o 
Revit através de sua API. O segundo componente acessa as extensões que operacionalizam de fato a automação das tarefas. Para ativá-las, é preciso selecionar os ícones de ferramentas que estão disponibilizados no Ribbon do Revit.

O componente elementar da interface do usuário (User Interface - UI) do pyRevit é o command bundle. Trata-se do acesso a uma pasta dentro do diretório do computador que é criada com a instalação do Addin, onde são encontrados ao menos dois arquivos, um com a extensão *.py, referente ao script de IronPython, e um outro arquivo de extensão *.png, que corresponde à imagem que compõe o ícone mostrado no ribbon do Revit. O command bundle é organizado em groups, panels e tabs que são lidos e interpretados pela aplicação para compor o UI do Revit.

Como já observado, uma das possibilidades que o pyRevit oferece é o acesso aberto a todos os seus códigos escritos em Python. Para facilitar o acesso aos códigos, existe uma forma mais fácil e rápida de acessar o script indicado por cada ícone da aba de comando. Basta, para isso, pressionar a tecla alt enquanto seleciona um ícone de ferramenta do pyRevit que revelará o local dentro do diretório onde o script foi gravado.

O código indicado no exemplo da Figura 51 corresponde ao script de execução do comando de acesso aos elementos selecionados e adicionados na memória com MRead. Embora seja relativamente simples, este script apresenta um caso de aplicação de conceitos de programação já abordados, que envolvem variáveis, loops, objetos, classes e outros. 
Figura 51 - Código em Python do comando MRead

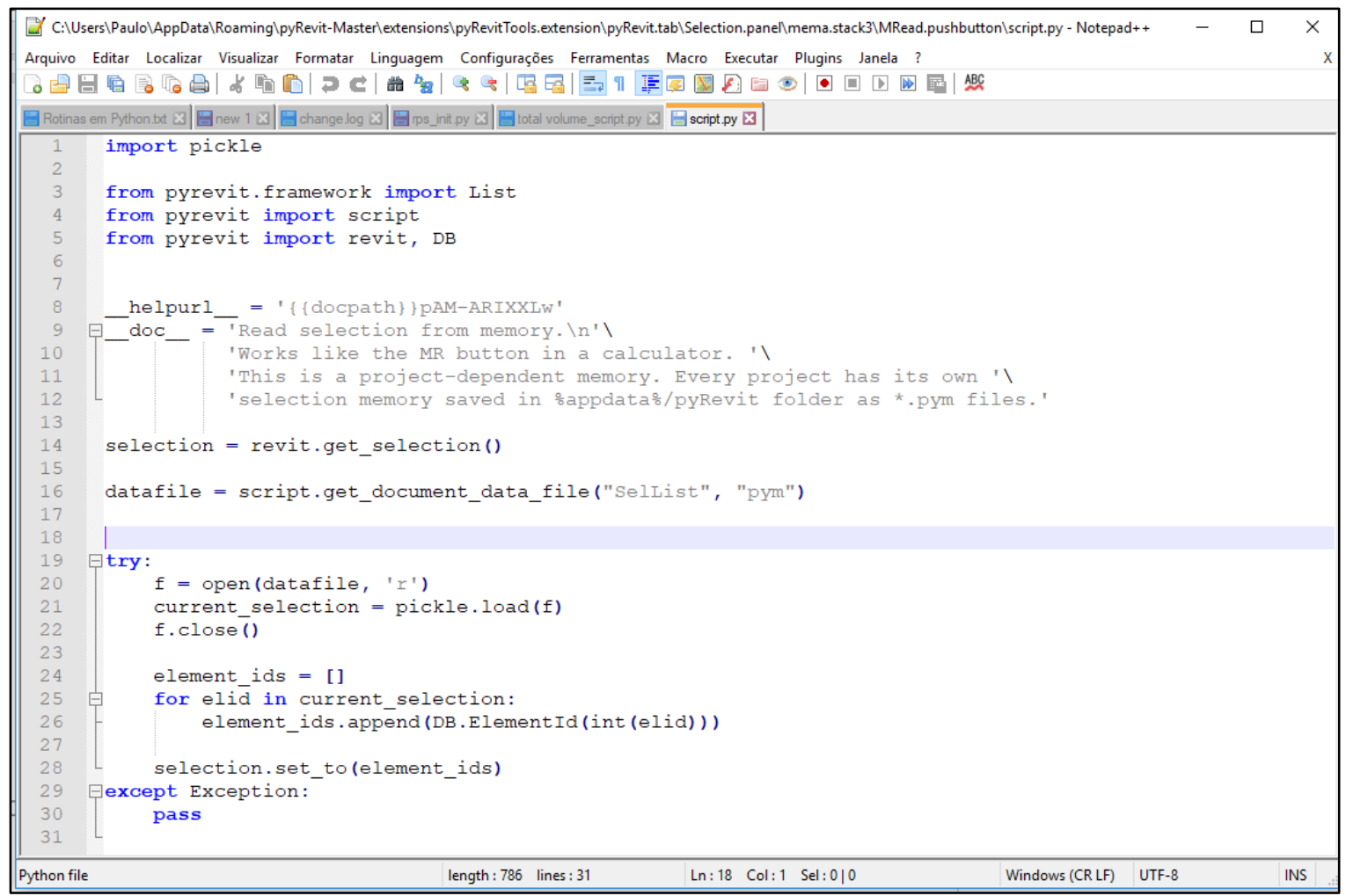

Fonte: Elaborado pelo autor

A escolha dos addins para o Revit apresentados nos dois estudos exploratórios deste capítulo foi orientada pelo objetivo de demonstrar as vantagens da utilização dos recursos disponíveis para auxiliar o aprendizado de programação de automação no Revit empregando linguagem Python. Todavia, cabe aqui diferenciar as vantagens de cada um. Por um lado, o RPS introduz flexibilidade e verificação em tempo real ao processo de programação durante o processo de projeto, permitindo digitar, testar comandos e verificar se a sintaxe está correta diretamente do console disponibilizado. Por outro, o pyRevit permite criar comandos diretos baseados em ícones em uma ribbon para tornar o processo mais ágil.

Assim, enquanto um script estiver inacabado ou durante a revisão da cópia de um script existente, feita para adaptar este comando a outro contexto de interesse, o RPS se mostra mais interessante. Quanto ao algoritmo, se for testado e validado, a utilização do pyRevit oferece ganhos significativos ao trabalho, uma vez que automatiza até mesmo a inserção dos códigos, muitas vezes longos, em Python na API do Revit. Assim, em vez de inserir toda vez os comandos, o pyRevit permite criar 
uma aba nova com vários ícones de comando permanentes, que serão executados diretamente no Revit com apenas um clique.

Na próxima seção é apresentado um estudo exploratório em que um script foi desenvolvido pelo pesquisador com base nos conhecimentos acumulados com 0 aprendizado obtido durante a pesquisa. O script tem como objetivo a checagem de restrições do código de obras da cidade de Ribeirão Preto.

\subsubsection{Experimento - Checagem de código de obras - Rotina em IronPython}

As últimas décadas têm apresentado novas formas de projetar, usando técnicas e ferramentas computacionais (LABIB, 2017, p. 234). Como exemplo, a modelagem paramétrica tem sido usada na criação de novos elementos que não são padrões na construção, requerendo outras formas de fabricação. O crescente uso deste tipo de ferramenta se dá ao fato dela ter uma interface visual de fácil uso, não requerendo que o arquiteto tenha habilidades com programação, como no caso de programas como o Dynamo.

Para Labib (2017, p. 234), a integração entre projetos arquitetônicos, computação e processos digitais se tornou uma necessidade, pois vários métodos computacionais têm sido adotados tanto na academia como em firmas de arquitetura. O uso da programação abrange a análise energética, cálculo da luz do dia em ambientes, análises de impacto ambiental, projetos paramétricos e cita:

A criação de códigos e scripts para computador pode ter contribuições inestimáveis ao endereçar esses desafios, personalizando as funções já existentes em várias ferramentas digitais e permitindo aos usuários executar tarefas difíceis que não eram possíveis antes. Além disso, a codificação de computador pode ser usada para automatizar tarefas repetitivas, reduzindo 0 tempo necessário para executar grandes e demorados processos. Ademais o script de computador pode ser usado para resolver problemas de design e analisar grandes bases de dados como os necessários na modelagem energética (LABIB, 2017, p. 234)(Tradução nossa) ${ }^{59}$.

\footnotetext{
${ }^{59}$ Original: Computer coding and scripting can be invaluable in addressing these challenges by customizing the built-in functions within various digital tools, thereby allowing users to perform difficult tasks that were not possible before. Additionally, computer coding can be used to automate repetitive tasks, reducing the time required to perform these large, time-consuming processes. Furthermore, computer scripting can be used to solve design problems and can even analyze and visualize huge datasets such as those data required in energy modeling.
} 
Educadores e pesquisadores estão identificando que rapidamente estudantes vão ter a necessidade de se familiarizar com métodos de projetos paramétricos, modelagem computacional ou programação de algoritmos, de forma a serem capazes de programar códigos de interesse particular a um escritório ou região. Assim, enquanto comandos de uso geral como os apresentados nos dois casos de estudos sobre a linguagem Python podem ser desenvolvidos por algum especialista em programação, compartilhados por uma comunidade de projetistas e utilizados nos mais diferentes contextos por usuários sem domínio de programação, outras necessidades podem ser específicas e requererem adequações locais.

Aplicações de automação por meio de programação para checar regras de construção utilizando-se de um código de lei de uma localidade, se mostram bastante específicas e complexas e nem sempre o uso de uma linguagem como a do Dynamo pode atender essas necessidades. Para Solihin e Eastman (2015, p. 69) a automatização de checagem de regras em modelos desenvolvidos para a indústria de AEC tem demonstrado ter um alto valor agregado. Porém, fatores como a complexidade de cada lei específica, bem como as suas abrangências são aspectos chave nos desafios da implementação desse tipo de procedimento. Para atender uma demanda tão expressiva de números de regras que podem ser aplicadas a um edifício se faz necessário uma sistematização, para que esse tipo aplicação possa ser viável.

Ao longo desta seção, questões relacionadas a importância de code checking serão exploradas no seu final, visto que na seção 1.2.3 já falamos deste contexto dentro de processos de automatização para a checagem de códigos de obras quando da criação da rotina em Dynamo, que exemplifica este uso. Para se ter um comparativo entre diferentes ferramentas para acessar e manipular o banco de dados do Revit através de sua API, a pesquisa vai utilizar o mesmo fluxograma da lógica de programação apresentado na Figura 41 (item 3.2.3)

Para a experimentação da criação de uma rotina em Python usando a implementação IronPython ,que se comunica com a API do Revit, foram usados como base o console Python Shell, o Addin instalado PyRevit e um editor de texto para a criação do script (no caso específico o Note ++). Uma nova aba de comando foi criada dentro do Revit e, dentro da aba, um comando que checa se as áreas dos cômodos 
atendem aos parâmetros de áreas mínimas estipulados pela lei municipal de Ribeirão Preto, como descrito no item 1.2.3 (Tabela 1).

O pyRevit foi estruturado de forma a facilitar a criação de abas e comandos dentro do Revit; para isto basta criar uma pasta específica seguindo a estrutura de árvore que é apresentada na Figura 52, que indica para o Revit em qual diretório buscar o arquivo de extensão *.py (extensão de execução de programas feitos em Python) deverá ser executado.

Figura 52 - Árvore do diretório para criação de nova aba no Revit

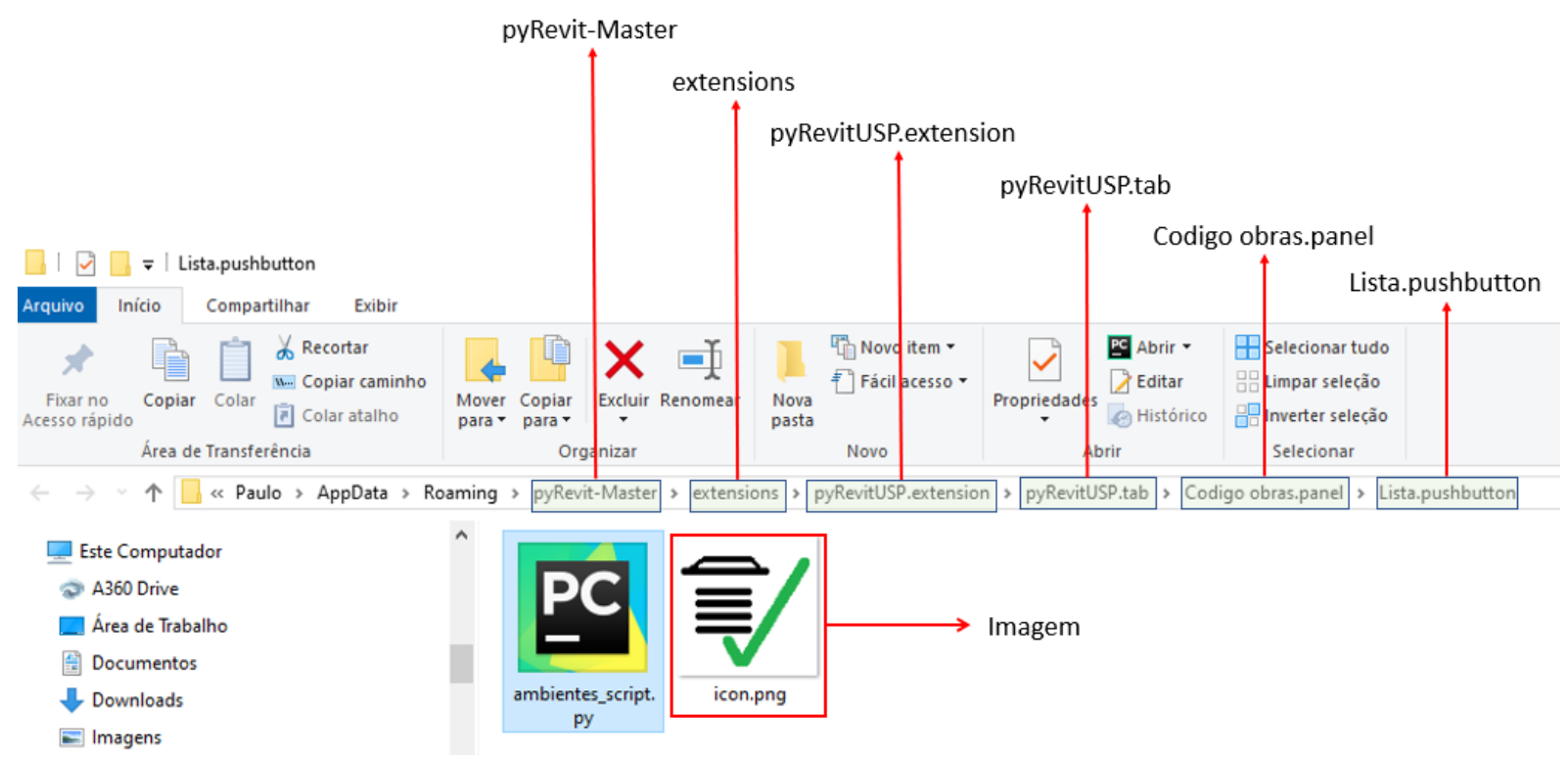

Fonte: Elaborado pelo autor

O código apresentado na Figura 53, escrito em Python, foi elaborado usando a forma linear de escrita de algoritmo, onde os passos descritos para execução do programa são feitos de forma consecutiva do começo ao fim (PUGA; RISSETI, 2004, p. 32). Essa abordagem permitiu que um código simples fosse construído para testar o uso da linguagem na verificação dos tamanhos mínimos dos ambientes. 
Figura 53 - Script de rotina em Python - Código de Obras

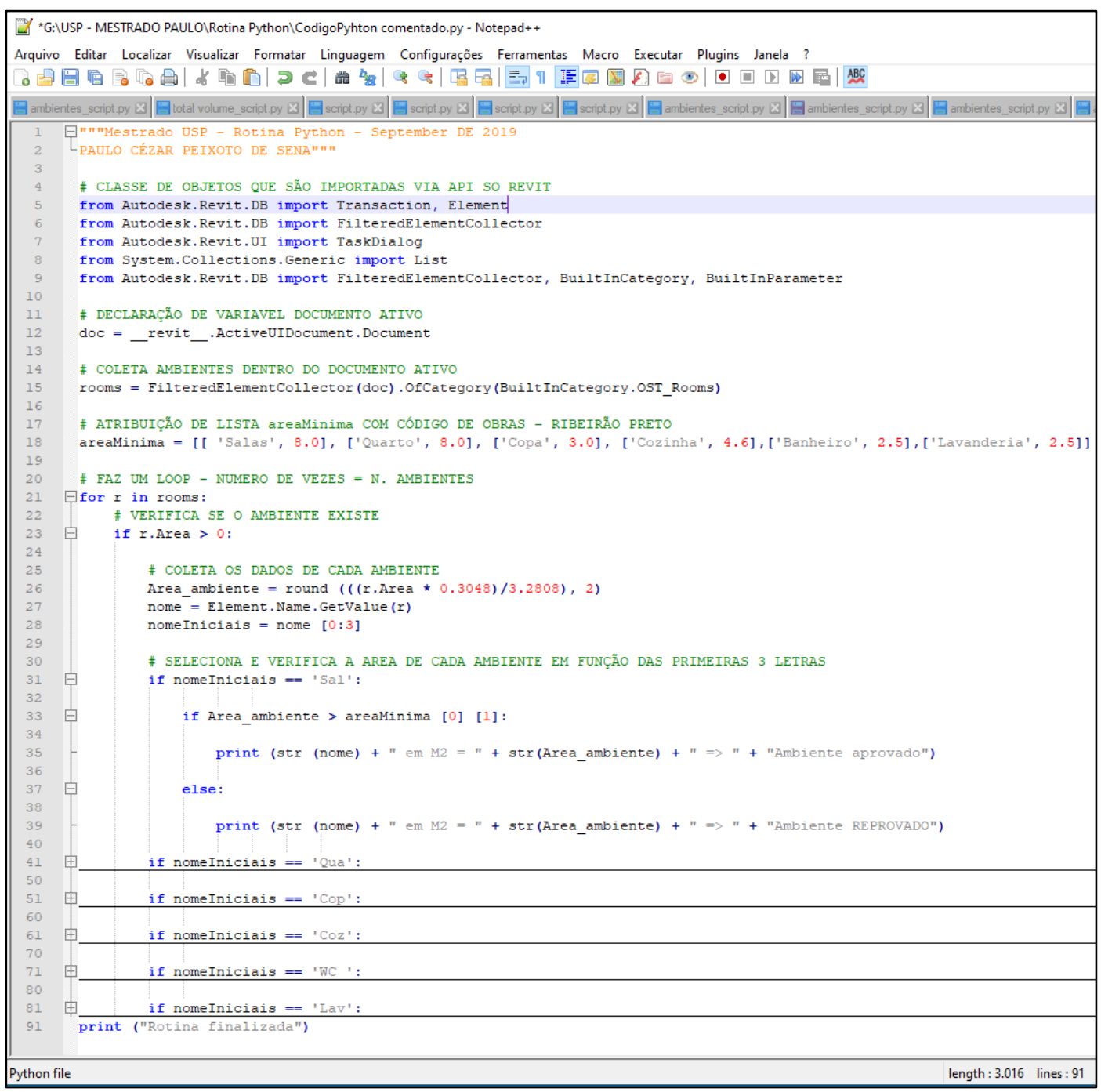

Fonte: Elaborado pelo autor

As primeiras linhas do código (5-10) acessam a base de dados de classes disponíveis através da API do Revi; uma vez carregadas é possível acessar o banco de dados do Revit do projeto que está ativo. A linha 12 coleta as informações específicas dos ambientes (rooms), carregando na variável "rooms" todos os dados disponíveis a respeito dos mesmos, que são os parâmetros de tipo e instância do Revit da categoria rooms. 
Em seguida, na linha 18, é atribuída à variável do tipo lista "areaMinima” as informações do código de Ribeirão Preto, com a relação aos cômodos e suas respectivas áreas mínimas. Uma vez coletadas as informações de restrições e as informações sobre cada ambiente do projeto, uma comparação entre esses dados pode ser feita.

Para isso é necessário selecionar que tipo de informação será coletada a fim de que a comparação possa ser efetivada. As linhas de 23 a 28 fazem essa tarefa: primeiro é definido que o ambiente não pode ser de valor igual a 0 , comando if linha 23; a linha 26 coleta a área do ambiente na variável "Area_ambiente", sendo necessária a transformação da unidade pés para metros pois o Revit trabalha em pés; a variável "nome", na linha 27, recebe o valor em forma de texto do nome do ambiente e, por último, uma função do Python quebra o texto selecionando pelas três primeiras letras do nome atribuído ao ambiente e permitindo que a comparação possa ser feita entre os ambientes dispostos no projeto e suas respectivas restrições.

Duas outras funções If encadeadas são declaradas nas linhas de 31 a 39 que comparam o nome do ambiente e fazem o teste do tamanho mínimo necessário, dando um resultado para cada ambiente encontrado dentro do projeto ativo. Esse processo é repetido para cada um dos cômodos previstos na legislação, apenas mudando as iniciais que vão ser comparadas, ex.: 'Sal', 'Qua', 'Cop', 'Coz', WC' e 'Lav'.

A Figura 54 apresenta os resultados do experimento quando o botão Lista, criado especificamente para esse experimento, é acionado. Uma janela tipo popup aparece na tela fazendo a indicação de quais ambientes se enquadram dentro das regras e normas específicas de áreas mínimas para o município. Esse comando fica disponível para o usuário e a qualquer hora pode ser acionado, permitindo que várias alterações sejam feitas no projeto até que sejam atendidas as normas da legislação. 
Figura 54 - Apresentação dos resultados da rotina experimental em Python

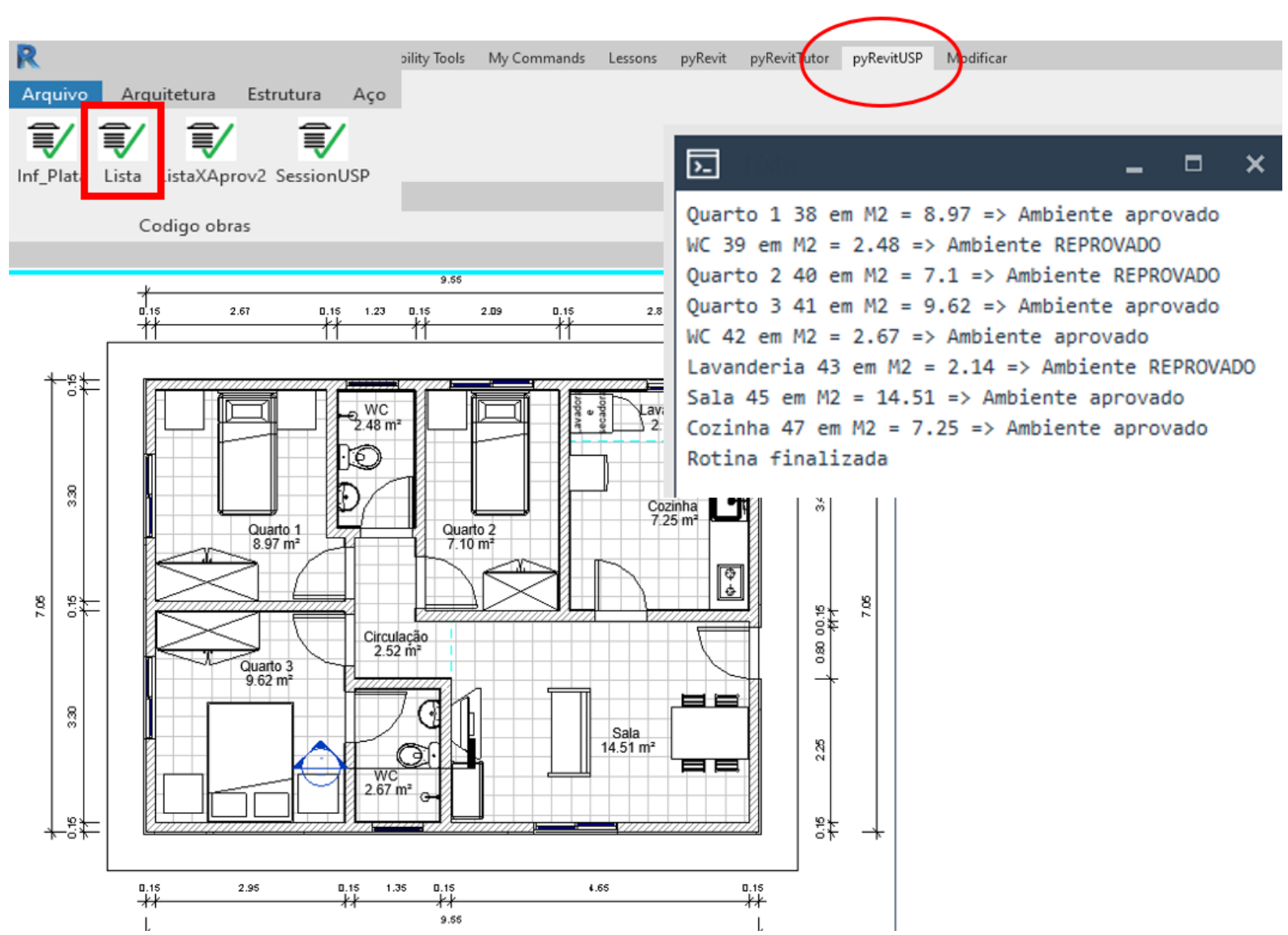

Fonte: Elaborado pelo autor

Levando-se em consideração os conceitos apresentados por Woodbury (2010b) no Quadro 3 dessa pesquisa, a rotina experimental feita nessa seção indica a necessidade de que o projetista tenha tais conhecimentos adquiridos, tendo uma visão mais avançada sobre a lógica de programação. O manuseio de listas, variáveis, loops em programação e testes de condição foram explorados no exemplo. Outras ferramentas poderiam ser usadas na criação desta rotina, como é o caso da criação de uma função que retornasse a impressão do resultado "ambiente aprovado ou reprovado".

Para a criação do plugin apresentado nessa seção foram usados o console de programação Python Shell e o pyRevit, que serviram como base para testes realizados durante o experimento. Com relação ao console Python Shell foi possível interagir diretamente com o banco de dados do Revit, permitindo que a sintaxe de uma frase pudesse ser checada. Por exemplo: 
A Figura 54 ilustra o tipo de retorno que é dado pela API do Revit quando a interação é feita. Isso permite que cada linha seja verificada de forma independente sem rodar o programa todo, facilitando a localização de algum erro. Esse procedimento também serve para que parâmetros dos objetos do Revit sejam checados e até mesmo substituídos usando as funções "Get" e "Set".

Figura 55 - Python Shell prompt de comandos - teste de sintaxe da escrita do código

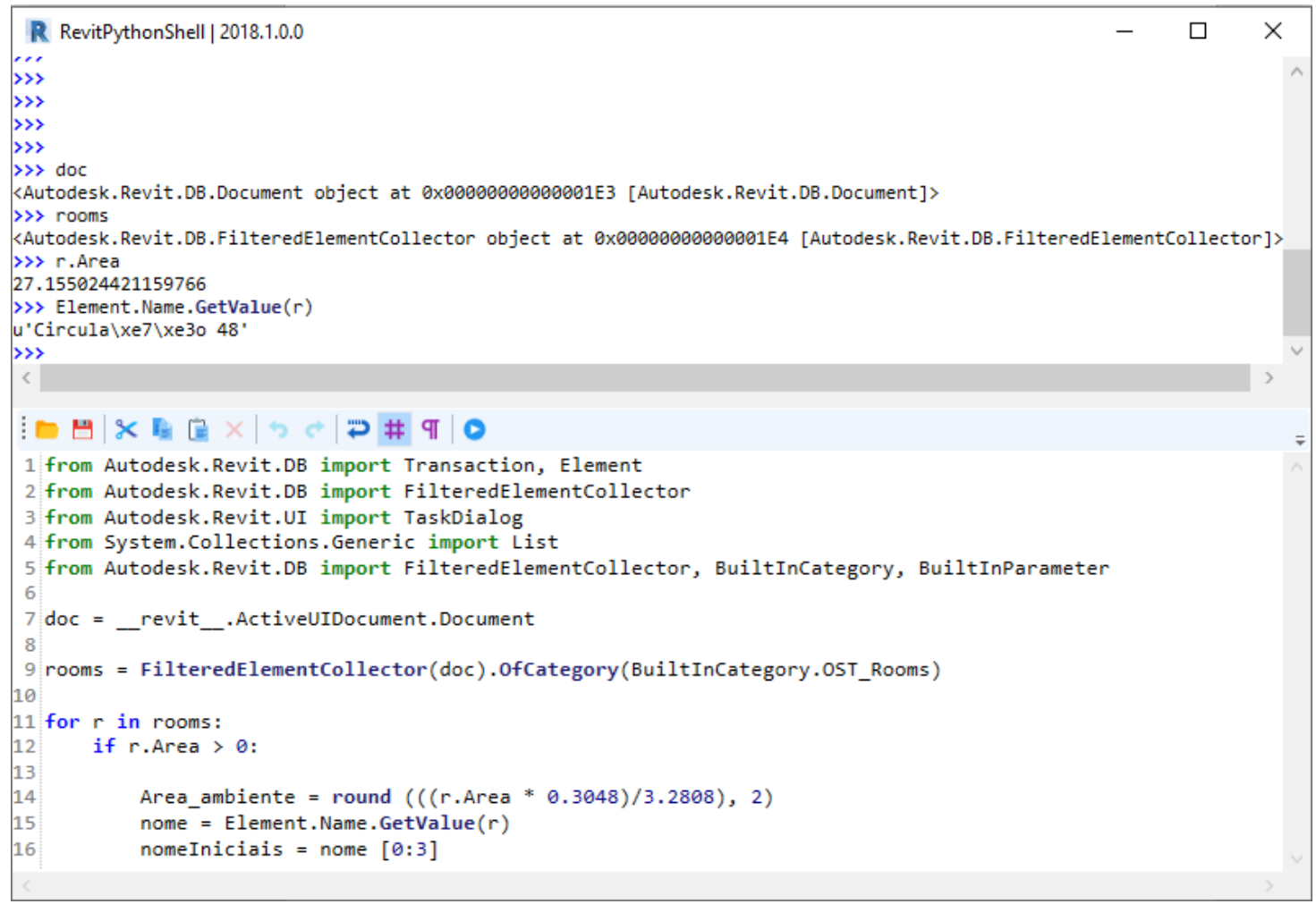

Fonte: Elaborado pelo autor

Depois de criar o comando "Lista" numa nova aba do Revit através do pyRevit (conforme apresentado na Figura 54), é possível acessar diretamente a rotina e fazer alterações no seu código. Para isso acontecer, a tecla "Alt" deve ser segurada e um clique deve ser dado em cima do comando lista. Uma vez feita e salva a alteração, pode-se retornar à interface do Revit e acessar a aba pyRevit e o comando "Reload": a rotina será automaticamente recarregada com as novas alterações. 
Outra ferramenta usada foi o plugin Revit Lookup, descrito com mais detalhes no capítulo seguinte, que permite a análise de cada objeto do Revit e suas referências em relação a nomes de classes e atributos que são usados através da API do software.

\subsubsection{Considerações sobre o uso do PYTHON para automação}

Conclui-se que o uso do Python para a criação da rotina testada se mostrou mais aderente a usuários com maiores conhecimentos de programação. Embora o Dynamo seja uma interface mais amigável, através do Python o programa ficou mais consistente e o acesso do usuário ao comando, mais transparente e direto.

Os estudos realizados em linguagem Python demonstraram que diferentes conceitos de programação se comparadas ao Dynamo podem ser usadas e estão disponíveis. Algumas funções não estão disponíveis no Dynamo ou então teriam que ser executadas através de um código muito complexo. Tais vantagens, todavia, estão condicionadas a um domínio de construção de scripts textuais, menos confortáveis e mais complexos que a linguagem visual disponibilizada pelo Dynamo.

As fontes existentes para aprendizado da linguagem são várias, tais como tutoriais e fóruns sobre a linguagem, que oferecem subsídio para se aprender a sintaxe da linguagem e aprofundar conhecimentos voltados ao raciocínio lógico e computacional. Em contrapartida, não são encontrados muitos trabalhos acadêmicos que abordem o desenvolvimento de plugins para o Revit usando somente o Python. Os estudos experimentais observados fazem referência à utilização condicionada aos nós do Dynamo, que permite utilizar scripts mais simples.

Como é possível acessar as classes e atributos por meio do SDK do Revit, o Python oferece possibilidade de automação mais avançada, o que the confere um nível de programação intermediário, adequado tanto ao desenvolvimento de aplicativos que são disponibilizados comercialmente como a soluções para serem utilizadas por empresas que necessitem de automatizações para melhoria de seus processos. Para este último estudo, o uso do Python Shell como ambiente de desenvolvimento para rotinas em Python oferece uma ferramenta poderosa de criação 
de pequenos códigos para validar comandos, testar o uso de classes e de pequenas lógicas de programação. Além de resolver rotinas mais simples, o Python Shell pode ser utilizado para testar partes de rotinas mais robustas, escritas em Python ou até mesmo em C\#.

Observou-se com os estudos que o uso do PyRevit associado ao Python Shell oferece um ambiente ainda mais amigável para o desenvolvimento de plugins para o Revit, pois os comandos podem ser criados e armazenados em novos Ribbons (abas), tornando prático o acesso às novas funções. Outro aspecto positivo acerca da combinação destes recursos está vinculado ao debugging do PyRevit, cuja tarefa de detecção dos erros de programa são facilitadas quando se usa o console de programação do Python Shell.

Outra vantagem da linguagem Python sobre uma VPL está vinculada à recursividade e organização do código. Como Labib observa:

Além de simplificar e organizar um script escrito através de código de computador pode também ser usado para executar tarefas que não seriam possíveis usando um ambiente de VPL. Um exemplo disso é o processo de modelagem recursividade. Recursividade em ciência da computação é "um processo onde o resultado final de uma solução depende da solução de pequenos problemas que são instanciados os quais estão dentro da própria solução. Uma função recursiva é uma função que pode chamar a ela mesma, esse tipo de função não é possível de ser chamada dentro de um ambiente de VPL, porque é impossível obter o resultado de uma função e retroalimentála através dela mesmo (LABIB, 2017, p. 235) ${ }^{60}$ [tradução nossa]

Por fim, como se trata de uma das linguagens mais usadas na área de análise de banco de dados e inteligência artificial, o uso do Python na indústria AECO abre novas possibilidades para a automação de processos que use algoritmos baseados em tais tecnologias. Embora o uso atual da linguagem Python por projetistas esteja bastante vinculada à automação de processos que podem ser realizados utilizando o

\footnotetext{
${ }^{60}$ Original: In addition to simplifying and organizing a visual script, computer coding can also be used to perform tasks that are otherwise impossible to do in a visual scripting environment. One example is the process of recursive modeling. Recursion in computer science is "a process where the final result of a solution to a specific problem depends on the solution of smaller instances of the same problem" [16]. A Recursive function is a function that can be used to call itself, this type of function is impossible to call within visual scripting software packages because it is impossible to get the result of the function and feed it back into the same function. By using a programming language, however, one can create such functions by having them define their output based on outputs from previous versions.
} 
Dynamo, a perspectiva de incorporar inteligência artificial, entre outros avanços de tecnologia da informação, deve ser considerada para pensar o desenvolvimento futuro de rotinas e plugins para a automação no Revit. 


\section{CAPÍTULO 5 AUTOMAÇÃO COM O C\#}


A terceira linguagem de programação analisada para discutir as condições de automação em Revit foi o C\#. Diferente do Python, cuja linguagem precisa ser interpretada para outra linguagem lida pela máquina, o C\# pertence ao grupo de linguagens compiladas diretamente pela máquina, o que reduz o custo de processamento em programações mais extensas e complexas.

Assim como os dois capítulos anteriores, o capítulo 3 está estruturado em três seções:

3.1 Linguagem C\#: os plugins profissionais disponíveis para utilização com Revit normalmente são escritos em C\#, uma linguagem bastante empregada em desenvolvimento de softwares para plataformas Windows. Esta seção aborda os principais aspectos da IDE do Visual Studio, apresentando sua interface de programação, os principais métodos para a criação de plugins para o Revit e a lógica de estruturação dos mesmos. Sugere ainda outras fontes de referência para maior conhecimento sobre a criação de algoritmos nesta linguagem.

3.2 Estudos exploratórios com linguagem C\#: são apresentados dois estudos exploratórios e uma rotina experimental. O primeiro plugin a ser analisado foi desenvolvido através da API do Revit para gerenciar a produção de modelos por meio de análises padronizadas de produtividade, com dados obtidos diretamente da utilização do software, de maneira automática. O segundo plugin é a ferramenta BIM Interoperability Tools, disponível no site da própria Autodesk, onde foram apresentadas as ferramentas relativas à classificação de elementos (Classification Manager) e à configuração e exportação de dados COBie (COBie Extension). No último experimento da dissertação foi desenvolvido em C\# um script de automação em Revit equivalente aos elaborados em Dynamo e Python. Isso é, apresenta o desenvolvimento de um script de checagem de critérios do código de obras.

3.3 Considerações sobre o uso desta linguagem de programação: nesta seção são apresentados os principais aspectos a serem considerados ao usar a linguagem de programação $\mathrm{C \#}$. 


\subsection{LINGUAGEM C\#}

\subsubsection{Histórico e vantagens de adoção do C\#}

A criação da linguagem de programação C\# remonta à década de 1990, quando a Microsoft buscava soluções para os diversos problemas de integração entre programas com linguagens distintas. Dessa forma, toda vez que fosse necessário migrar de uma linguagem para outra, os programadores necessitavam não só aprender a linguagem, bem como suas bibliotecas e o seu conceito (CAELUM, [s.d.], p. 4) ${ }^{61}$. Segundo Deitel et al., (2003b, p. 7) novos dispositivos eletrônicos como os telefones celulares, a internet e os computadores móveis levaram os desenvolvedores a perceber uma nova realidade.

A possibilidade de usar softwares que permitissem uma maior integração entre as diferentes plataformas teria também que resolver os problemas de instalação que eram comuns quando as linguagens eram diferentes. Além disso, deveriam permitir que os aplicativos fossem acessados via web:

Os desenvolvedores reconheceram a necessidade de software que fosse acessível para qualquer um e disponível por meio de praticamente qualquer tipo de dispositivo. Para tratar dessas necessidades, a Microsoft anunciou sua iniciativa .NET (pronuncia-se "dot-net", ou "ponto net") e a linguagem de programação C\# (pronuncia-se "ci-sharp", ou "cê-sharp") (DEITEL et al., 2003b).

Uma equipe de desenvolvedores da Microsoft lideradas por Anders Hejlsberg 62 e Scott Wiltamuth criou a linguagem de programação C\#, que foi concebida para atender a plataforma .NET. O C\# foi baseado nas linguagens C, $\mathrm{C}++$ e Java, que eram linguagens já bem conhecidas e consolidadas, o que facilitou a migração de desenvolvedores para a plataforma .NET. O desenvolvimento do C\# adaptou os melhores recursos das linguagens de referência para sua criação e desenvolveu características próprias.

\footnotetext{
${ }^{61}$ https://www.caelum.com.br/apostila-csharp-orientacao-objetos/

62 Anders Hejlsberg é um engenheiro de software dinamarquês que ganhou prestígio pelo desenvolvimento do Delphi e Turbo Pascal na Borland e a plataforma .NET. Após ter migrado para a Microsoft. Hejlsberg recebeu em 2001 o prêmio Dr. Dobb's de excelência pelo desenvolvimento das seguintes linguagens de programação: Turbo Pascal, Delphi, C\# e Microsoft .NET Framework.
} 
Programas em C\#, além disso, são feitos dentro de um ambiente de desenvolvimento integrado ou Integrated Development Environment (IDE) (DEITEL et al., 2003b). Trata-se de uma linguagem de programação de alto nível, que é orientada a objetos e com amplas aplicações em escritórios, aplicativos webs, programas para computadores desktop, web sites, telefones celulares, jogos, dentre tantas outras. Assim, a linguagem consiste numa série de classes que contém métodos específicos e, esses, por sua vez, contêm as lógicas de programação, que são as instruções que o computador executa.

Existem milhares de desenvolvedores que usam o $\mathrm{C \#}$, sendo que a maioria tem uma vertente direcionada aos produtos da Microsoft, sejam estes, no caso, empresas, organizações multiempresas ou desenvolvedores individuais. Diferentemente de outras linguagens como o PYTHON, o C\# não é uma linguagem aberta (open source). Assim com o .NET framework, a C\# é mantida exclusivamente pela Microsoft. Apesar de ser gratuita, ela não pode ser instalada independentemente pois faz parte do pacote .NET da Microsoft. Este pacote inclui um ambiente especial chamado de Common Language Runtime (CLR), que executa o código em linguagem de máquina depois que esse foi compilado. Em função dessa codificação os programas se tornam portáveis para outras plataformas de hardware e programas operacionais, incluindo aplicativos Mobile Windows. O C\# pode ainda rodar em outros sistemas operacionais como o Linux, iOS, Android e outros através da implementação .NET Mono, que não é suportada pela Microsoft (NAKOV et al., 2013, p. 18) ${ }^{63}$.

A Figura 56 apresenta um esquema das relações que permitem ao .NET trabalhar com diversas linguagens usando o CLR como um decodificador comum dessas para a linguagem de máquina. Quando foi lançado, o ambiente de programação .NET tinha por objetivo estabelecer "um novo olhar" sobre desenvolvimento de softwares para internet: a World Wide Web. Por meio de uma estrutura integrada, visava promover a independência de uma linguagem específica para atender a uma determinada aplicação.

\footnotetext{
${ }^{63}$ Svetlin Nakov é Ph.D. em informática e foi professor na Sofia University "St. Kliment Ohridski", Technical University - Sofia and New Bulgarian University. Escreveu 15 livros sobre programação por computador, tecnologias de software, criptografia, >NET, Java, C\#, JavaScript, Python e engenharia de software. Conferencista nos Estados Unidos, Singapura, Alemanha, Egito, Bulgaria e outros países.
} 
Figura 56 - Estrutura .Net para gerenciamento de diferentes tipos de linguagem

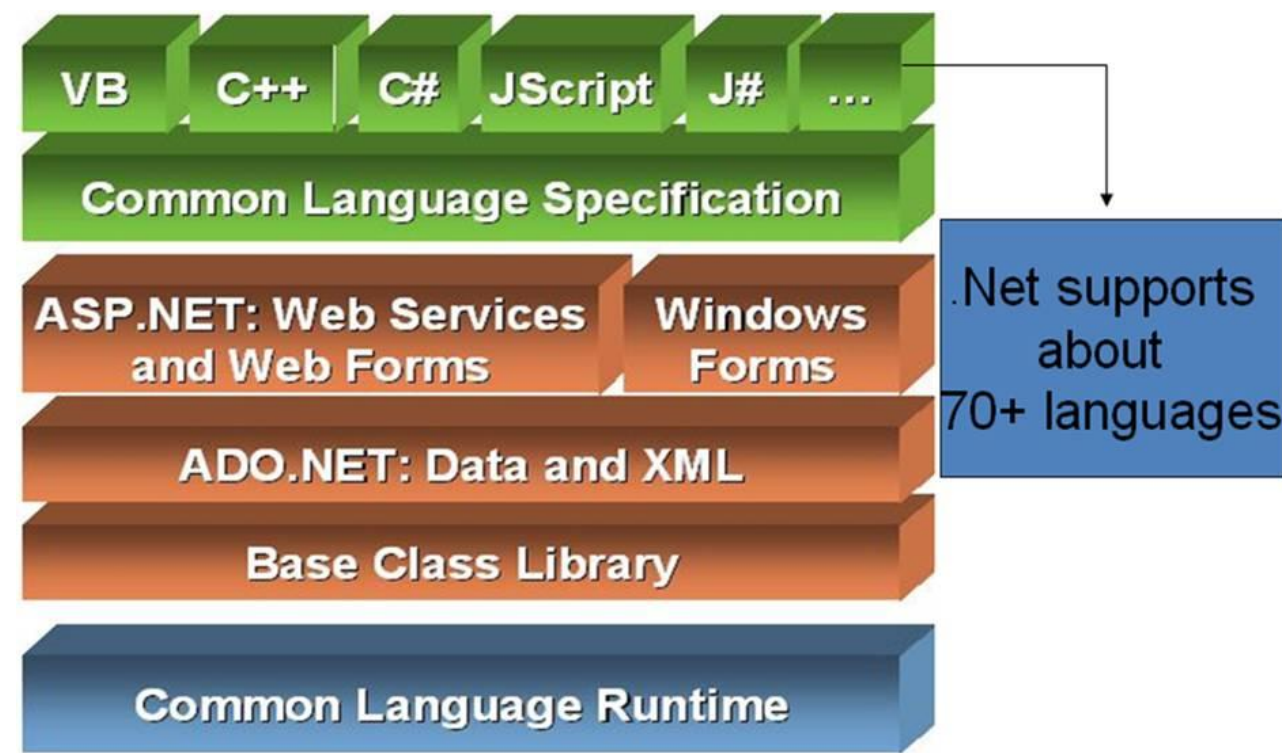

Fonte: (“Components of .Net Framework, CLR, CTS, CLS, Base Class Library”, [s.d.])

O programador pode escolher programar em qualquer uma das linguagens compatíveis, pois esta seria reconhecida pela máquina. O que permitiu que um mesmo sistema fosse programado parte em Python, parte C\#, e mesmo assim tivessem suas aplicações partilhadas, pois a interpolaridade é feita por meio da Microsoft Intermediate Language, que define posteriormente as instruções para compor a CLR.

Segundo Archer (ARCHER, 2002) ${ }^{64}$ a linguagem de programação em C\# apresenta características inovadoras, que foram acrescentadas em relação ao $\mathrm{C}, \mathrm{C}++$ e facilitam sua utilização. Algumas tarefas simplificaram e economizaram tempo de programação, como no caso do monitoramento e alocação de memória, que passaram a ser gerenciadas pela linguagem. Também foram incluídas outras características, tais como a definição de que todos elementos passam a ser objetos. Preenchendo uma lacuna entre tipos de valores e tipos de referência, a definição dos elementos como objetos faz com que a linguagem suporte atributos que permitem o uso de declaração de informação a respeito dos componentes e oferece uma

\footnotetext{
64 Tom Archer é desenvolvedor de softwares há 18 anos. Depois de trabalhar como um dos principais programadores da enciclopédia multimídia IBM World Book e no Peachtree Office Accounting, começou a escrever livros e é autor e co-autor de quatro livros sobre Microsoft Visual $\mathrm{C}_{++}$e tecnologias para a web.
} 
facilidade para as propriedades e métodos que no caso de incremento de um número fica bastante facilitado.

Diante das características mencionadas, Nakov et al. (2013) apontam o C\# como uma linguagem moderna e de simples aprendizado, que apresenta um arquitetura bem estruturada e poderosa, além de ser distribuída numa plataforma integrada como o Visual C\# Express Edition. No caso especifico do Revit, o C\# acessa e altera diretamente todas as classes e métodos disponíveis no programa tendo uma infinidade de recursos disponíveis aos usuários interessados em aprofundar a automação de processos através da criação de plugins.

\subsubsection{Linguagem orientada a objetos, classes, métodos}

A programação orientada a objetos ( $\mathrm{POO}$ ), em inglês object oriented program (OOP), estabeleceu um novo paradigma sobre como estruturar um sistema computacional. Até então, o conceito existente era o de dividir programas extensos em subprogramas chamados de blocos ou funções, como forma de permitir que o programador pudesse subdividir o trabalho em tarefas de programação menores, e, portanto, mais fáceis de serem escritas. Tal procedimento tinha como objetivo diminuir a complexidade das atividades, vinculando as partes programadas a um módulo central. Já na programação orientada a objetos, o raciocínio para reduzir a complexidade é outro. Em vez de subdividir a tarefa de programação em partes de um todo, a programação $\mathrm{POO}$ interpreta todos os elementos como se fossem objetos que podem compor um conjunto de objetos, uma vez que estes objetos se comportam e se relacionam de uma determinada forma, expressa por meio de seus atributos e suas operações (PUGA; RISSETI, 2004).

Uma maneira de entender a programação orientada a objetos está em considerar o programa como uma simulação do mundo real: um programa para jogar xadrez atua sobre um tabuleiro, onde dois exércitos atacam um ao outro; um programa gráfico simula uma geometria que será aplicada no mundo real; e um programa para operações contábeis simula as ações de contabilidade existentes no mundo real, tais como a emissão de notas promissórias e notas de recebimento, o agendamento e recebimento de contas a serem pagas, entre outras. Como o mundo é constituído por 
objetos que interagem, para que um programa possa simular adequadamente os eventos que ocorrem no mundo real, este deve também ser capaz de lidar com objetos computacionais equivalentes.

A Figura 57 faz alusão a alguns tipos de objetos que podem ser considerados para a elaboração de programas computacionais. Um objeto computacional corresponderia a uma extensão dos objetos existentes no mundo real, podendo ser tangíveis, incidentes ou objetos de interações. Um exemplo observado entre os objetos, dentro das atividades que estão ligadas a AECO, pode ser mencionado o de construção de uma parede, onde o objeto tangível corresponderia ao tijolo, o objeto incidente corresponderia ao local onde essa parede vai ser construída e o objeto de interação equivaleria à contratação da mão de obra ocorrida, de fato, em um determinado empreendimento..

Figura 57 - Tipos de Objeto

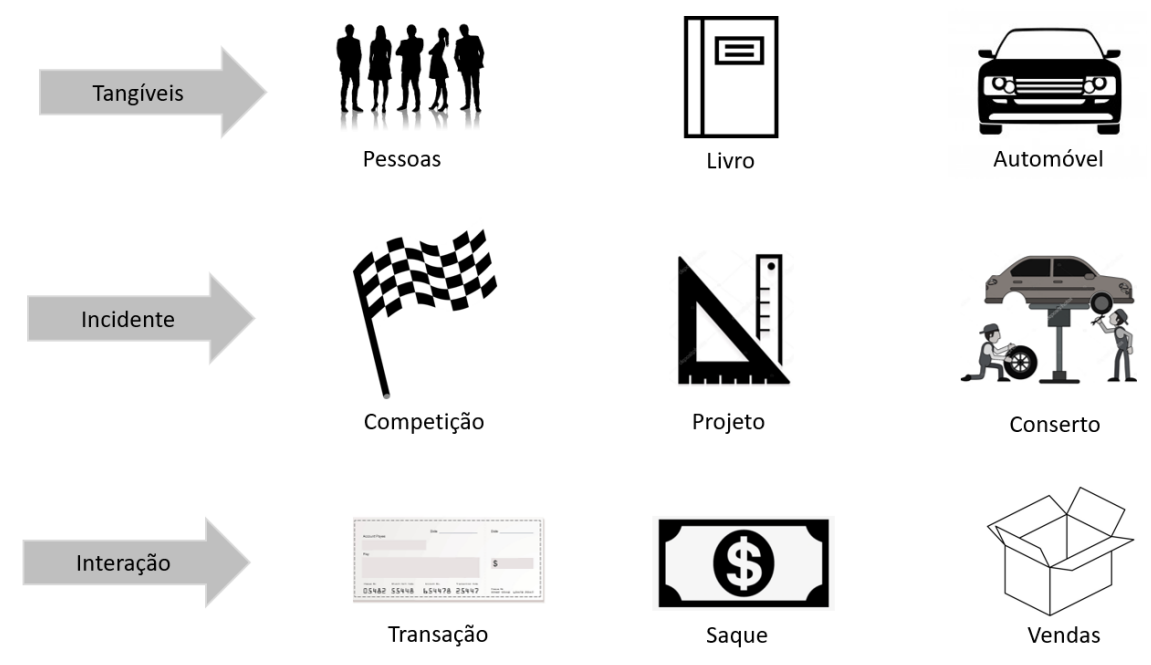

Fonte: (PUGA; RISSETI, 2004)

As classes correspondem a uma forma específica de agrupamento dos objetos, determinadas em função de atributos básicos que possuem operações classificadas como semelhantes. Por exemplo, uma referência para a criação de uma classe chamada bloco, agrupa objetos da construção que contem atributos de tipo, tais como o material de que é feito o bloco) e dimensões, indicados por valores como largura, altura e profundidade que representam suas dimensões. A Figura 58 mostra uma classe e as possíveis instâncias que podem apresentar. 
Figura 58 - Exemplo da criação de uma classe tijolos

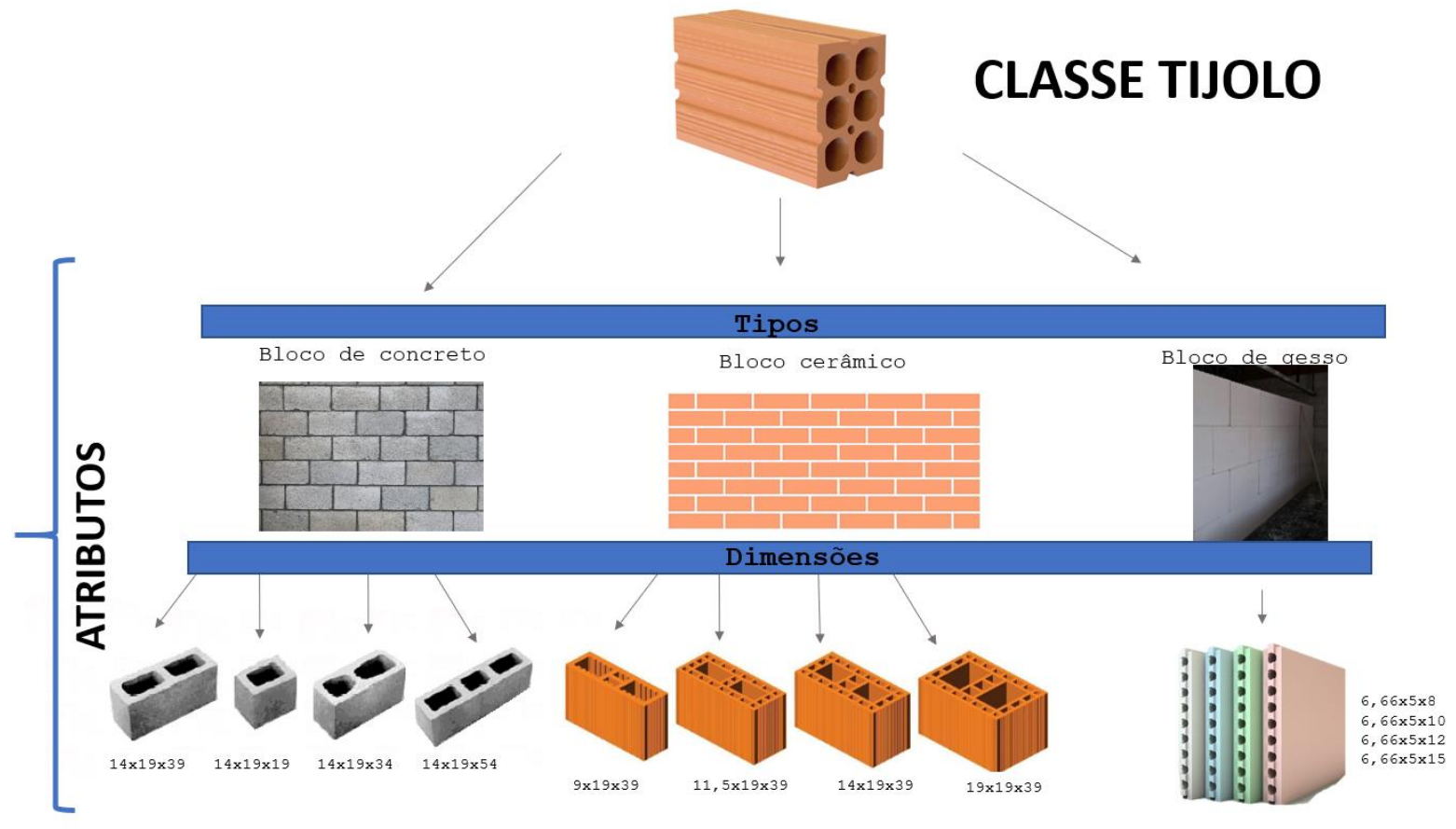

Fonte: Elaborado pelo autor

Conforme observam Eastman et al. (2012), as plataformas de sistemas BIM, tais como o Revit da Autodesk, o ArchiCAD da Graphisoft e o Bentley Architecture, são baseadas em uma estrutura computacional voltada à manipulação de objetos. Esta abordagem iniciou-se com softwares orientados a realização de projetos mecânicos e posteriormente foram desenvolvidos softwares para atender outras áreas de especialidade. Em comum, as estruturas de objetos e classes de objetos de todos estes softwares se organizam a partir de um controle hierárquico de instâncias de objetos por meio dos parâmetros deles. Essas instâncias, por sua vez, são definidas em conjuntos e subconjuntos:

No projeto paramétrico, em vez de projetar uma instância de um elemento de construção como uma parede ou porta, um projetista define uma família de modelos ou uma classe de elementos, que é um conjunto de relações e regras para controlar os parâmetros pelos quais as instâncias dos elementos podem ser geradas, mas cada uma irá variar conforme seu contexto. (EASTMAN et al., 2014).

A Figura 59 mostra algumas propriedades de instância do elemento paredes, conforme é ilustrado no guia do usuário do Revit 2011 (AUTODESK, 2010, p. 267). Por meio da programação orientada a objetos, no caso específico o C\#, é possível 
manipular as diversas classes de objetos de um determinado programa BIM, como o Revit. Como exemplo do que pode ser feito, a classe parede, definida por Wall Class, pode ser acessada e então, os membros, métodos e propriedades que contêm podem ser manipulados.

Figura 59 - Propriedades de instância de uma parede e do Revit

Propriedades de instância comuns para paredes são descritas abaixo.

\begin{tabular}{ll}
\hline Nome & Descrição \\
\hline Restrições & \\
\hline Linha de localização & $\begin{array}{l}\text { Uma linha de localização para a parede no plano especificado. A linha de localização } \\
\text { da parede permanece a mesma para aquela parede, mesmo se o tipo for alterado. }\end{array}$ \\
\hline Deslocamento da linha de localização & $\begin{array}{l}\text { Desloca o painel da parede na distância especificada em uma direção perpendicular } \\
\text { a face da parede cortina. }\end{array}$ \\
\hline Restrição base & O nível base da parede. Por exemplo Nível 1.. \\
\hline Deslocamento base & A altura da parede de sua restrição base. Esta propriedade somente está ativada \\
quando a Restrição base está definida para um nível.
\end{tabular}

Fonte: (AUTODESK, 2010, p. 267)

O código de programa escrito em $\mathrm{C \#}$ mostrado em seguida exemplifica a criação de um programa que usa a classe Tijolo para criar instâncias de tijolos nas variáveis x e y. Dentro do projeto Projeto_exem_classe, uma classe tijolos foi criada e seus parâmetros definidos em tipo; Larg; Alt; Prof. (Figura 60).

Figura 60 - Microsoft Visual Studio - Projeto_exem_classe

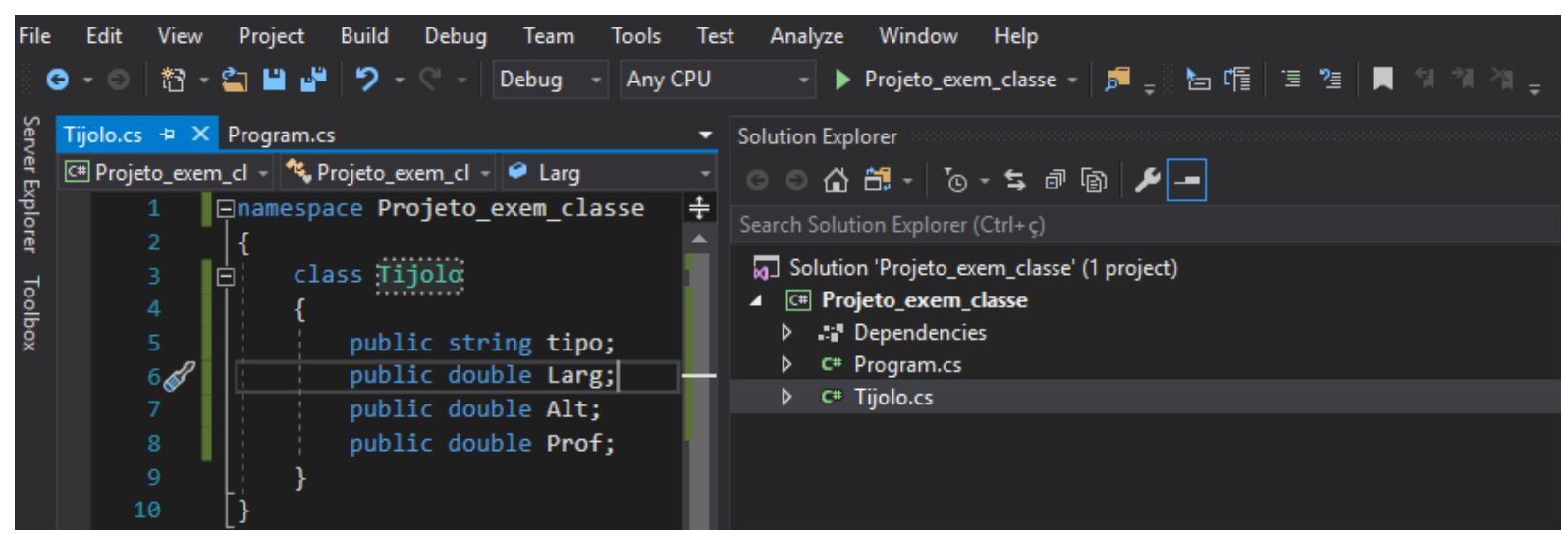

Fonte: Elaborado pelo autor 
Como esquematizado no Quadro 4 que descreve a estrutura de objetos para o C\#, a classe de um objeto contém métodos, que são funções que definem os comportamentos caraterísticos internos a uma classe de objeto, suas variáveis, que não são visíveis em outras partes do programa. Assim, a programação orientada a objetos permite a modularização dos programas, tornando mais simples ao programador reutilizar os códigos disponíveis (DEITEL et al., 2003b).

\section{Quadro 4 - Resumo dos conceitos de programação estruturada a objeto}

\begin{tabular}{|c|c|}
\hline objeto & $\begin{array}{l}\text { Elemento do mundo real: sinônimo de instancia de classe; } \\
\text { Ex: uma pessoa "Fulano de Tal". }\end{array}$ \\
\hline atributo & $\begin{array}{l}\text { Característica particular de uma ocorrência da classe; } \\
\text { Ex: dados do indivíduo (nome, sexo, data de nascimento) }\end{array}$ \\
\hline classe & $\begin{array}{l}\text { Agrupamento de objetos similares que apresentam os mesmos atributos e } \\
\text { métodos; } \\
\text { Ex: indivíduo, caracterizando as pessoas do mundo. }\end{array}$ \\
\hline método & $\begin{array}{l}\text { Lógica contida em uma classe para designar-lhe um comportamento; } \\
\text { Ex: cálculo da idade de uma pessoa em uma classe. }\end{array}$ \\
\hline mensagem & $\begin{array}{l}\text { Uma solicitação entre objetos para invocar certo método; } \\
\text { Ex: informar a idade da pessoa. }\end{array}$ \\
\hline evento & $\begin{array}{l}\text { Uma ocorrência significativa no mundo real que deve ser tratada; } \\
\text { Ex: idade informada, entrega efetuada etc. }\end{array}$ \\
\hline estado & $\begin{array}{l}\text { Situação de um objeto em um dado instante de tempo; } \\
\text { Ex: informando a idade da pessoa. }\end{array}$ \\
\hline generalização & $\begin{array}{l}\text { Atributo e operações comuns compartilhados por classes; } \\
\text { Ex: superclasse (parte) ou (pessoa) como generalização das subclasses } \\
\text { (organização) e indivíduo. }\end{array}$ \\
\hline
\end{tabular}

Fonte: Adaptado de (MONOLITO NIMBUS, 2014) 


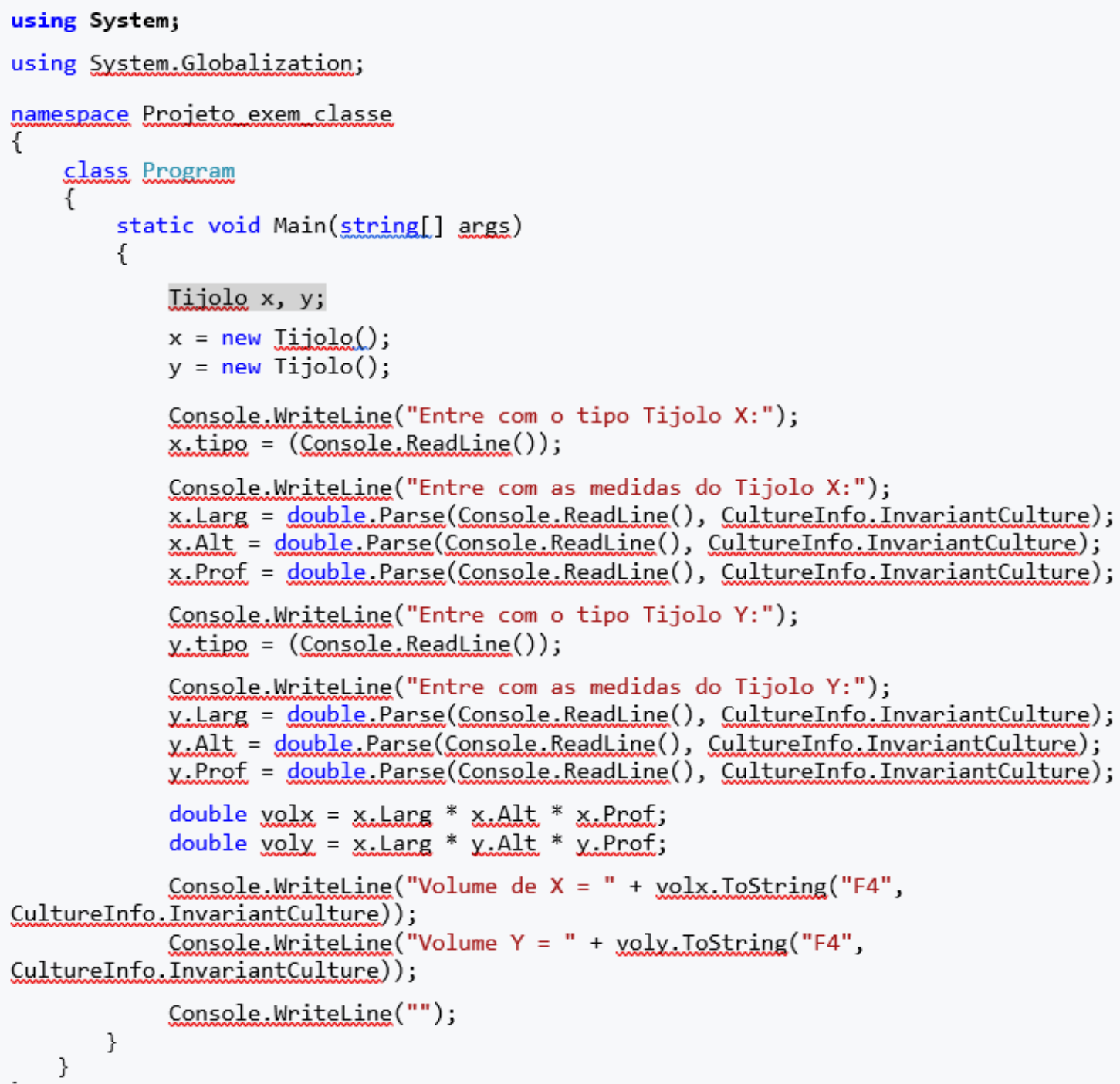

Fonte: Elaborado pelo autor

No exemplo de código de programa, escrito no Quadro 5, foi adicionada a classe Tijolo o método Volume, acrescentando as linhas destacadas em cinza do código descrito no Quadro 6. Esta alteração no código permite que o programa principal, além de usar uma classe para instanciar elementos com as mesmas características, ela retorne também aos cálculos que podem ser aplicados a cada instância, bastando para isso referenciar a classe. Por exemplo, quando a linha double volx $=\mathbf{x}$.Volule() substitui a linha double voly $=\mathbf{x}$.Larg * $\mathbf{y}$.Alt * $\mathbf{y}$.Prof, não apenas reduz o tamanho total do código como encapsula os dados em uma classe, organizando código para reduzir a dependência entre as partes. 
Quadro 6 - Exemplo de adição de método à classe: volume do tijolo

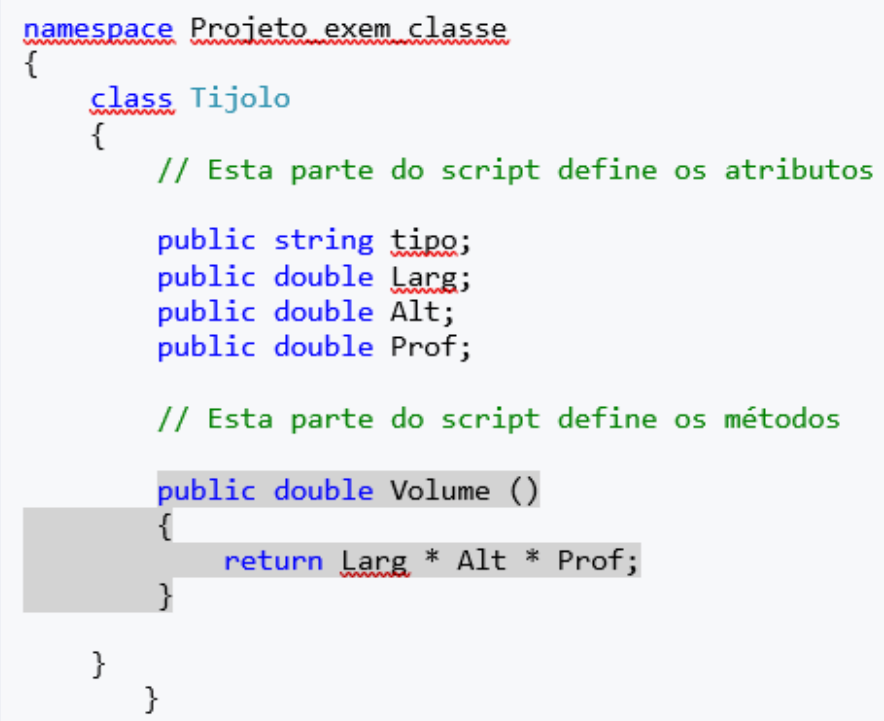

Fonte: Elaborado pelo autor

A programação voltada para objetos é um assunto extenso requerendo uma análise detalhada para o seu completo entendimento, mas o intuito da apresentação deste tema é ressaltar sua importância para o desenvolvimento de plugins em C\#, que irão requerer um conhecimento mais profundo sobre classes de objetos e métodos. Portanto, devido ao próprio escopo desta pesquisa, outras características que fazem parte da programação orientada a objetos não serão abordadas em maior profundidade, tais como os conceitos de: herança, que trata do compartilhamento de atributos e operações entre classes; polimorfismo, quando um objeto dentro do sistema assume uma forma diferente daquela em que ele foi criado; encapsulamento, quando os objetos e suas classes podem ocultar informações sobre eles que ficam apenas disponíveis dentro do próprio objeto, retornando apenas as informações necessárias.

\subsubsection{Revit API e o Software Developer Kit (SDK)}

Uma API corresponde a um conjunto de funções, métodos e ações que são programadas para que um software se comunique com outro. Comandos são enviados de ambos e a API recebe, traduz e envia requisições para que a comunicação possa ser feita. Um diagrama apresentado por Ignatova, Zotkin e Zotkina $(2018$, p.5) demonstra a forma como a estrutura da API funciona na criação 
de um plugin (Figura 61). O diagrama destaca dois arquivos que são importantes para a criação de um plugin do Revit: o arquivo de manifesto e o arquivo *.dll, que é um executável.

Figura 61 - Diagrama da estrutura tecnológica da criação de um Plugin

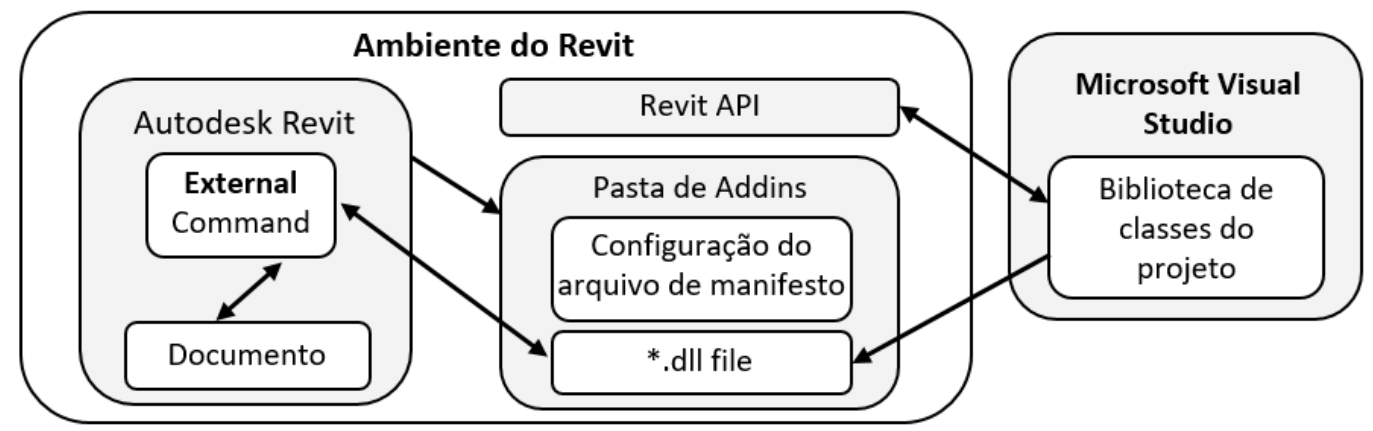

Fonte: (IGNATOVA; ZOTKIN; ZOTKINA, 2018, p.5)

O Kit de Desenvolvimento do Software (SDK) é uma ferramenta que vários fabricantes disponibilizam para que usuários externos acessem o banco de dados de seus aplicativos. A Autodesk também disponibiliza esta ferramenta, que pode ser instalada no primeiro momento da instalação do software ou posteriormente através do site (AUTODESK, [s.d.]). O SDK é um arquivo de instalação; após executado, irá conter algumas pastas com informações inerentes ao uso da API do Revit. Executando o arquivo RevitAPI.chm, o usuário tem acesso a um programa de ajuda para identificação das classes, métodos e propriedades disponíveis dentro do software Revit, podendo fazer uso dessas através de linguagens de programação compatíveis com o .NET da Microsoft' ${ }^{65}$.

Ao ser executado, o RevitAPI.chm abre uma tela de pesquisa similar a um browser, em que podemos pesquisar as classes desejadas e seus métodos, membros e subclasses. Através da busca em forma de árvore, podemos chegar à descrição sintática de como chamar uma determinada classe. Também é possível encontrar exemplos de códigos escritos que mostram como a classe pesquisada funciona. $A$ Figura 62 mostrará um esquema de busca para uma determinada classe.

\footnotetext{
${ }^{65} \mathrm{https}: / /$ knowledge.autodesk.com/pt-br/support/revit-products/learnxplore/caas/CloudHelp/cloudhelp/2020/PTB/Revit-Customize/files/GUID-D7E8694D-7DB3-41CA-A0F3AF64DC2DA015-htm.html
} 
Figura 62 - Esquema de árvore de como buscar informações na API do Revit

\section{Namespaces disponíveis}

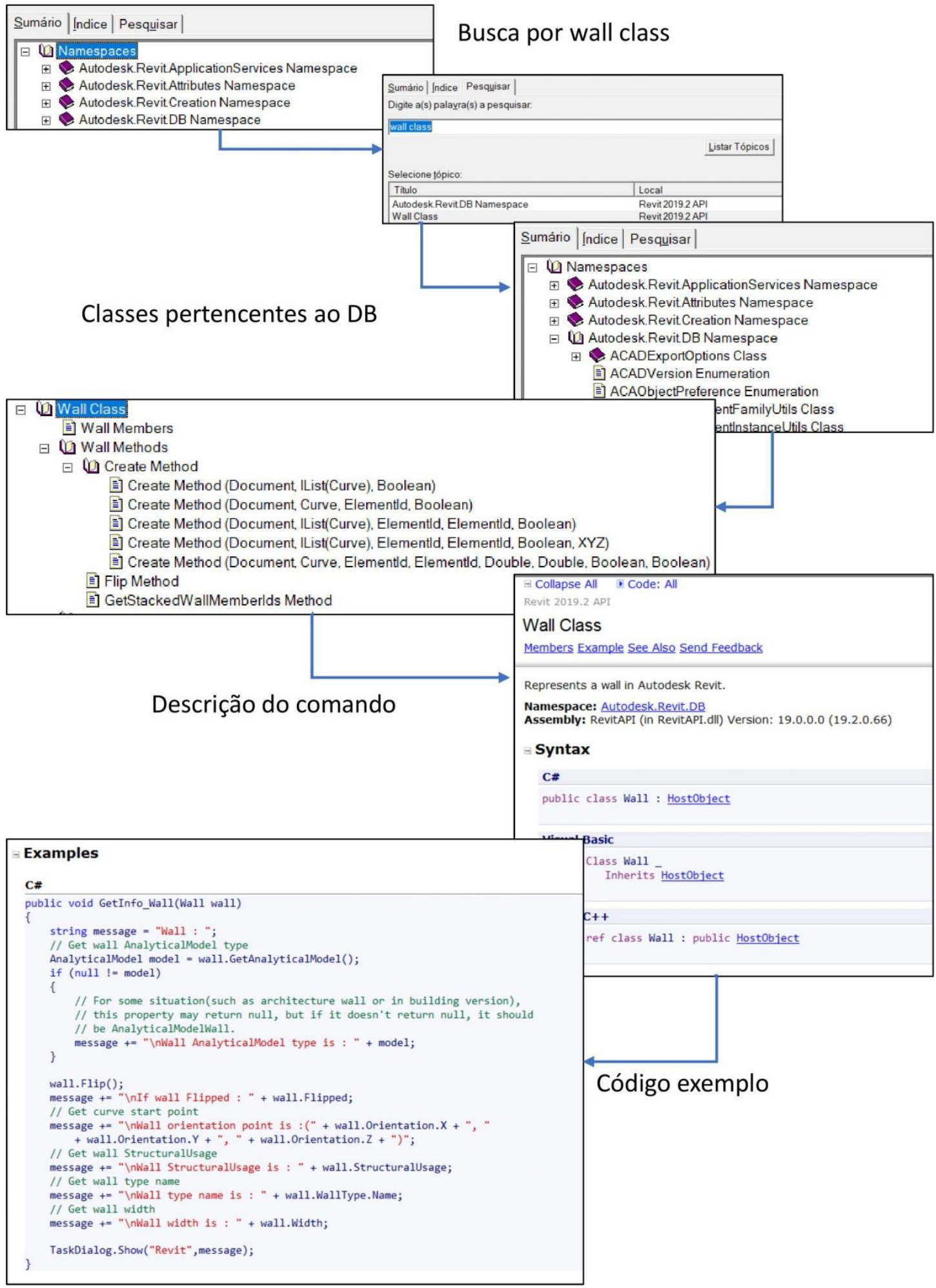

Fonte: Elaborado pelo autor 
Durante a instalação do SDK, uma pasta samples também é instalada contendo exemplos de códigos escritos em C\# e Visual Basic (VB). A Figura 63 mostra um destes códigos sample que, uma vez iniciado, oferece suporte à coleta de informações de ambientes.

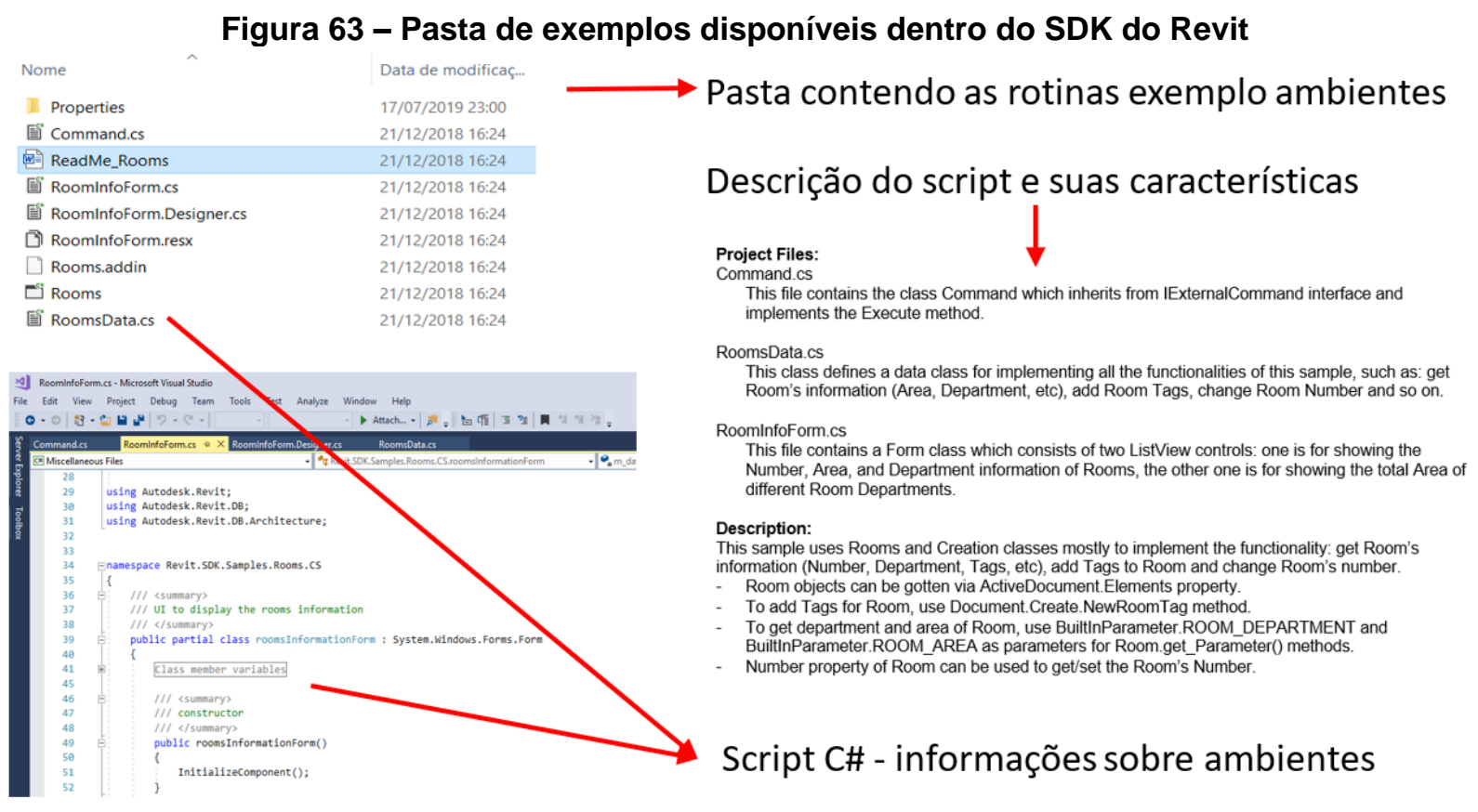

Fonte: Elaborado pelo autor

Outro recurso que está disponível para ser instalado gratuitamente (TAMMIK, [s.d.]) é o plugin Revit Lookup. Ele é capaz de analisar cada elemento dentro do banco de dados do Revit, mostrando o local e como são escritas as classes, métodos e os diversos parâmetros que estes possuem. A vantagem deste plugin é a identificação de cada elemento do Revit com todas as suas classes e membros e serve, portanto, para extrair todas as informações do banco de dados do modelo, representando uma valiosa ferramenta para escrita de código em C\# (Figura 64).

Tanto o SDK quanto o Revit Lookup são recursos para auxiliar a programação, que identificam os elementos, métodos e classes que estão contidos na base de dados do Revit. 
Figura 64 - Esquema de janelas e busca de informações do elemento através do plug-in

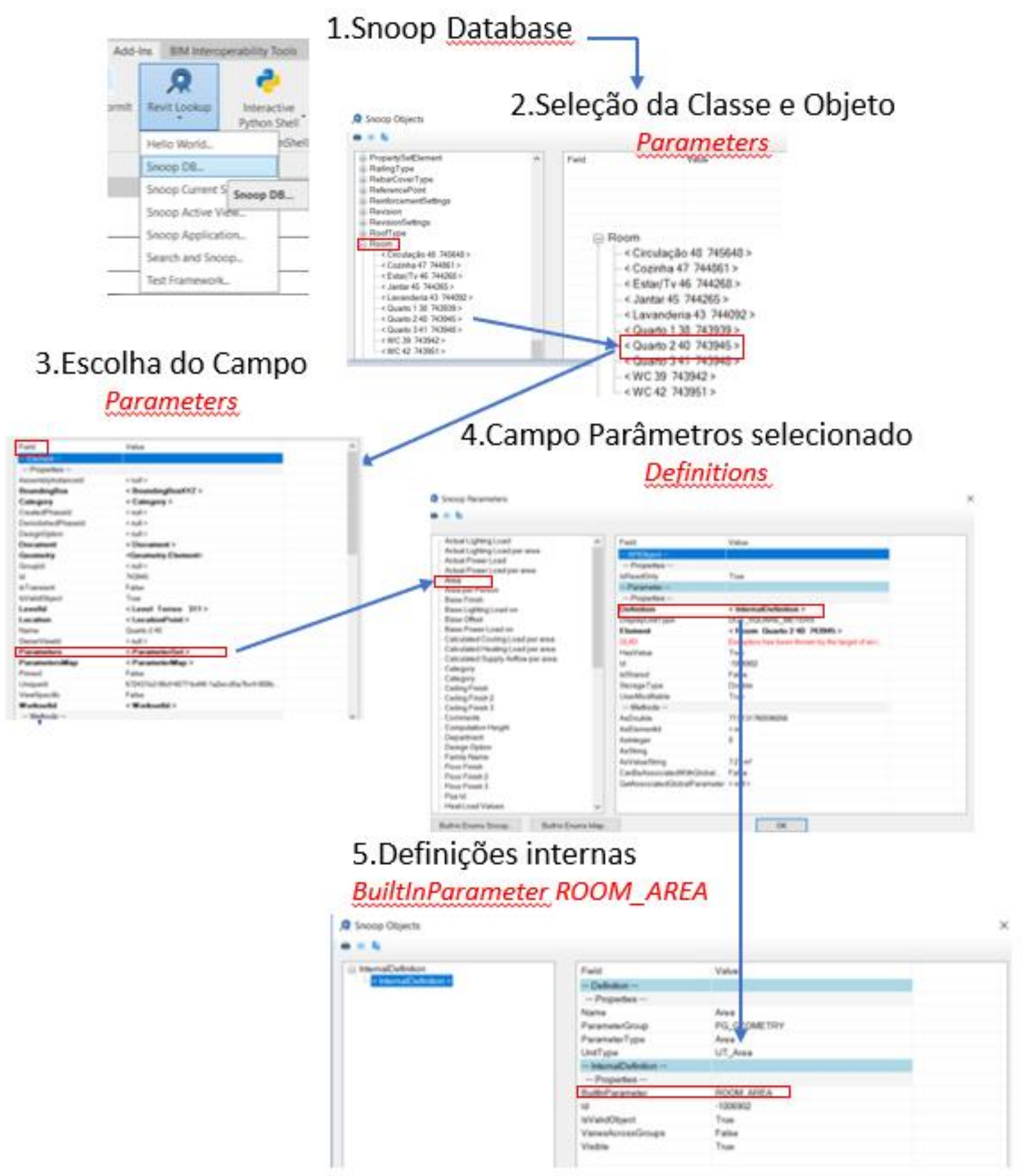

Fonte: Elaborado pelo autor

\subsubsection{Visual Studio}

O Visual Studio é um Ambiente de Desenvolvimento Integrado IDE. Estes ambientes de criação de sistemas de softwares são bastante difundidos entre desenvolvedores. Eles permitem que tarefas normalmente usadas por programadores tenham suporte do próprio ambiente. Dentre elas estão ferramentas de assistência 
como conclusão de código, depuradores e controles de versão integrados (AMANN et al., 2016, p. 124) ${ }^{66}$.

Fazem parte do IDE do Visual Studio o editor e o depurador de códigos que são comuns a estes tipos de sistema, mas, além disso, ele conta com ferramentas adicionais: preenchimento automático de códigos, intellisense, retofatoração, rabiscos, dentre outros. No site da Microsoft, "Documentos do Visual Studio", (MICROSOFT, 2019) pode-se encontrar a descrição mais detalhada destas e de outras características da IDE. A interface do programa é mostrada na Figura 65.

Figura 65 - Interface do usuário IDE Visual Studio

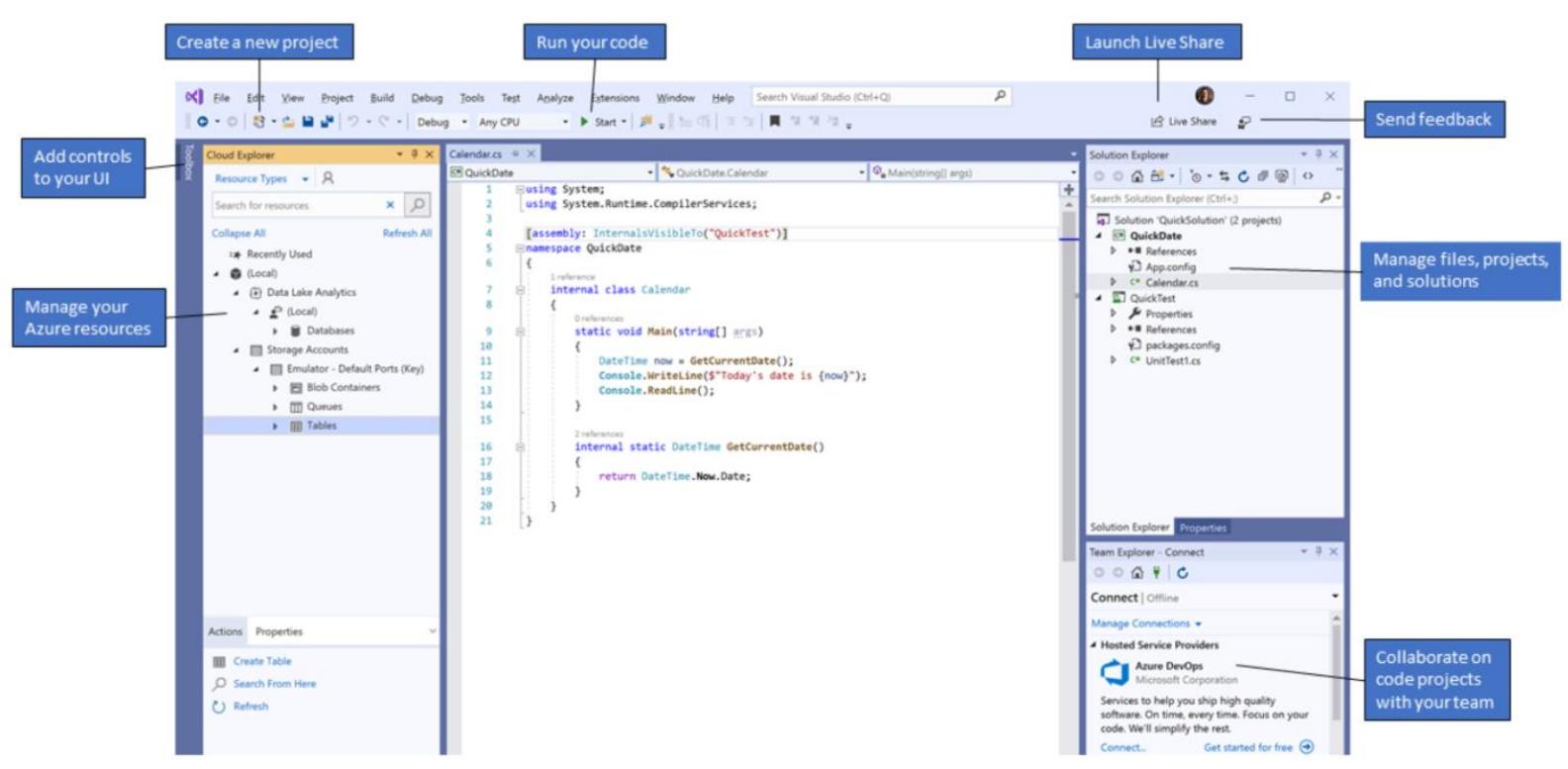

Fonte: Site Microsoft Documentos Visual Studio

Tutoriais existentes na internet que abordam o tema de criação de plugins para o Revit usando a linguagem de programação C\# explicam como fazer a instalação do Visual Studio. A versão normalmente demonstrada, é a Visual Studio Community, que é gratuita. (MICROSOFT, [s.d.])

\footnotetext{
66 Sven Amann é Ph.D em Engenharia de Software.pelo Software Technology Group at TU Darmstadt, Alemanha. Consultor, pesquisador e facilitador a desenvolvedores de tecnologias que garantam a qualidade dos softwares.
} 


\subsection{ESTUDOS EXPLORATÓRIOS E ROTINA EXPERIMENTAL EM C\#}

Os dois estudos exploratórios e a rotina experimental apresentados para 0 capítulo 5 buscam demonstrar na prática como se operam os elementos do $\mathrm{C \#}$ discutidos até aqui. Os dois primeiros estudos abordam scripts que estão disponíveis para utilização por profissionais em AEC que utilizam Revit. A rotina experimental, corresponde ao exercício de programação em que o pesquisador obteve as bases empíricas para discutir aspectos relacionados à prática de programação na linguagem.

\subsubsection{Monitoramento de modelagem 3D através de API do Revit}

O primeiro estudo proposto apresenta e discute um script de automação em C\# que realiza o monitoramento das ações de modelagem desenvolvidas no Revit. A perspectiva de monitoramento do desempenho da modelagem de um projeto de edifício que envolva vários projetistas de diferentes disciplinas é um apoio gerencial importante pois permite, por exemplo, acompanhar a ocorrência de conflitos entre especialidades nas definições de componentes da edificação e assim antecipar uma solução que seja adequada ao tempo de modelagem de cada disciplina.

Embora medições relativas à produtividade sejam usadas em todas as indústrias para acompanhar o atendimento de prazos definidos em cronograma, predomina a utilização de algumas métricas tradicionais de avaliação de desempenho: 1 - baseadas na medição dos documentos produzidos por hora de projetos; 2 - horas de projeto por volume de "área construída" ou de quantidade de elementos modelados; 3 - "horas normalizadas". Cada uma dessas métricas apresenta características específicas, destacadas a seguir (THOMAS; SANVIDO; PARFITT, 1999, p. 1).

O primeiro tipo de métrica citada, relacionada à contagem de documentos produzidos por hora de projetos, apresenta uma taxa de produção que normalmente é mensurada por uma relação das pranchas de projeto produzidas por hora de trabalho. Trata-se de um critério de medição de produtividade que não leva em conta 
aspectos como a dificuldade do projeto, ocasionando potencialmente uma distorção entre os resultados medidos e a qualidade obtida.

O segundo tipo de medição comum baseia-se na relação entre as horas de projeto e a quantidade de elementos, de volume ou de "área construída" que foram projetadas. O terceiro tipo, é uma variação desta métrica corresponde às horas normalizadas. Neste caso, é considerada uma base de dados de projetos que permite comparar as horas efetivamente gastas com uma previsão de tempo definida com base nas experiências anteriores adotadas como referência. Assim é possível normalizar eventuais distorções por meio de dados históricos consolidados.

O estudo de exploratório analisa uma proposta de plugin baseado em API do Revit, feita por Yarmohammadi e Castro-Lacouture (2019), que apresenta uma nova base para análise do desempenho, tanto individual como da equipe de projeto, que se baseia no monitoramento em tempo real de eventos de modelagem no Revit. Tal monitoramento é realizado automaticamente, por meio de recursos de captura de dados de modelagem que são utilizados como entradas para o processamento computacional de um diagnóstico que considere mais variáveis do que tempo e volume de produção (YARMOHAMMADI; CASTRO-LACOUTURE, 2019) ${ }^{67 .}$

O a rotina, proposto inicialmente por Yarmohammadi e Castro-Lacouture (2019) está dividido em duas fases, sendo que a primeira é relativa a coleta de informações que estão associadas à modelagem no exato momento em que está sendo executada e a segunda envolve um processamento dos dados extraídos no momento da modelagem.

\section{Coleta de informações do modelo}

Para que a checagem da qualidade do modelo seja realizada em tempo real, é preciso que os dados de modelagem sejam coletados e medidos enquanto são

\footnotetext{
${ }^{67}$ Saman Yarmohammadi é Ph.D. em Filosofia pelo Georgia Institute of Technology, onde obteve título de Mestre em Ciência da Computação. Mestre em Engenharia Civil pela University of Florida e engenheiro civil pelo Sharif University of Technology. Trabalhou como pesquisador na Universidade da Georgia e atualmente é consultor na Data Scientist at Reflexis Systems, Inc. Especialista em Machine Learning.
} 
realizados. Assim, quando um projetista realiza um comando do Revit, como mover, copiar ou apagar um objeto, os dados dessa ação são capturados, convertidos e processados pela rotina em métricas predefinidas (YARMOHAMMADI; CASTROLACOUTURE, 2019, p. 91). A captura de dados pode ser feita por meio do reconhecimento de eventos e gatilhos que são disparados quando uma determinada ação ocorre, permitindo assim, a automatização da coleta e do armazenamento em um banco de dados. Este controle é feito por meio de uma API criada para monitorar as entradas, processamentos e saídas, segundo a lógica computacional que os operadores do programa BIM, neste caso específico o Revit, efetuam durante a modelagem. A Figura 66 mostra como está configurada a estrutura de coleta de dados do plugin.

Figura 66 - Diagrama do Plugin para verificação de performance do modelo

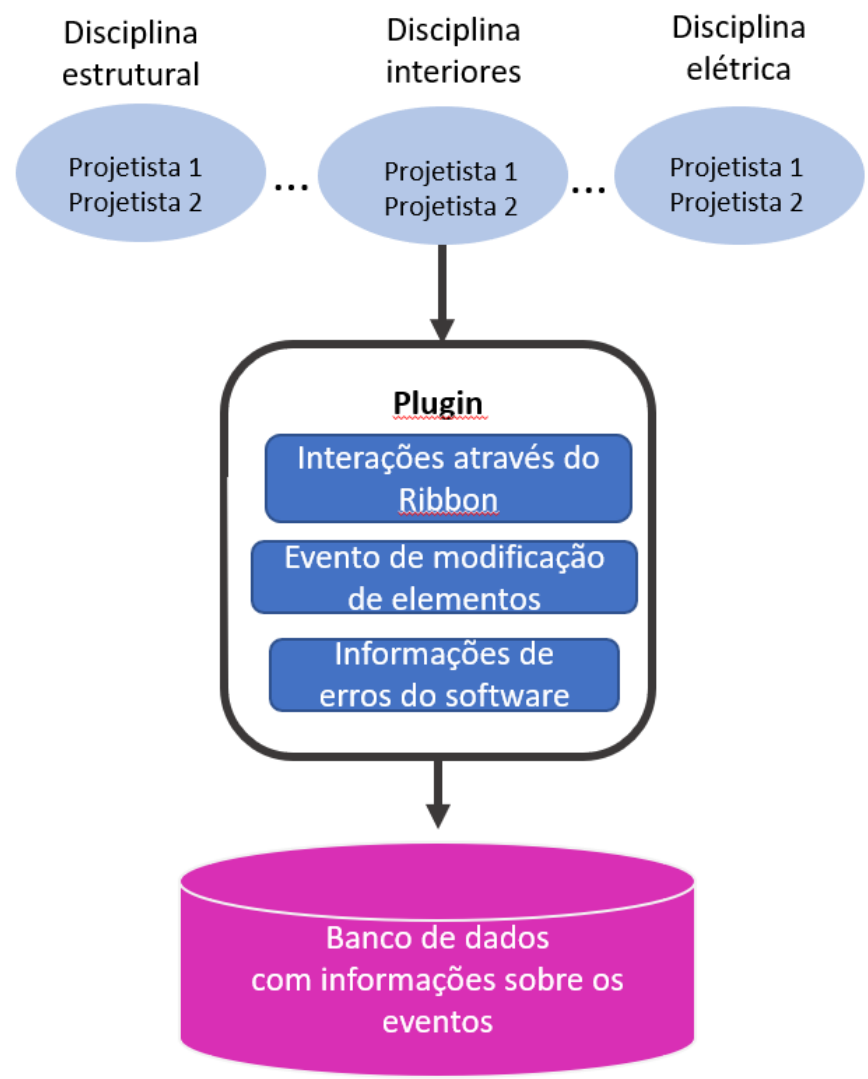

Fonte: baseado em Yarmohammadi e Castro-Lacouture (2019, p.94). Tradução nossa.

Para que o processo seja automático, o plugin utiliza o comando lexternalApplication do API do Revit, que, uma vez implementado, possui dois métodos de ativação: o Onstartup() e o OnShutdown(). Juntos, ambos os métodos 
possibilitam que o plugin inicie e encerre seu funcionamento junto o Revit. Com a inicialização automática, a coleta de dados ocorre concomitante a modelagem, por meio de uma API desenvolvida especificamente para que o armazenamento das informações seja realizado em tempo real.

Em contraposição aos métodos mais ortodoxos, cujas medições de produtividade só são possíveis de serem compiladas e analisadas depois da realização do projeto, a API de Yarmohammadi e Castro-Lacouture (2019) inicia a coleta e tratamento dos dados assim que o trabalho inicia. De fato, assim que o arquivo é aberto já são registrados a data e a hora. Após isso, os eventos que ocorrem durante a modelagem são coletados e empilhados no banco de dados criado especificamente para essa função. Por meio das classes e dos métodos disponíveis na API do Revit, o plugin analisa os dados relativos as atividades de modelagem executadas por cada projetista envolvido no projeto. Quando um usuário encerra a seção de trabalho no projeto, a coleta e armazenamento de dados são encerrados com a data e hora do encerramento.

Os principais tipos de monitoramento, assim como seus respectivos pontos de gatilho empregados no caso são relacionados a seguir:

RibbonltemExecutedEventArgs - esse evento fica engatilhado e é executado quando um comando do Ribbon é ativado ou uma tecla de atalho é acionada. ID_EDIT_MOVE e o ID_OBJECTS_WALL_RibbonListButton que são usados para mover elemento e criar paredes, respectivamente, que são instâncias destes eventos.

RibbonltemExecutedEventArgs - esse evento é executado quando um elemento sofre uma mudança, o que inclui qualquer tipo de modificação ou, também, quando o objeto é apagado.

FailuresProcessingEventArgs - esse evento é ativado quando um erro é induzido pelo usuário ou acontece uma falha de execução no software, isso inclui erros de memória e alertas sobre posição dos elementos em local errado (YARMOHAMMADI; CASTRO-LACOUTURE, 2019, p.94) (tradução nossa) ${ }^{68}$.

\footnotetext{
68 Original: RibbonltemExecutedEventArgs - this event handler is triggered when a ribbon button is clicked or a keyboard shortcut is used. ID.EDIT.MOVE and ID.OBJECTS.WALL.RibbonListButton, which can be used to move elements and create a wall respectively, are instances of such events.

DocumentChangedEventArgs - this event handler is executed when a model element is changed. These changes include addition, any type of modification, or deletion.

FailuresProcessingEventArgs - this event handler is activated when a user-induced error or software failure occurs, including memory errors and wrong element positioning warnings.
} 


\section{Tipos de eventos registrados pelo plugin}

Entre os tipos de eventos que o plugin registra para verificar o desempenho de modelagem, são destacados a seguir aqueles relacionados ao acionamento de ícones de Ribbon, de modificação dos elementos e de avisos de erros e outros alertas do Revit.

O registro de eventos relacionados ao acionamento de comandos textuais ou ícones de comando do Ribbon é possível por meio da classe Autodesk.Windows, disponibilizada pela Autodesk para permitir o rastreamento de tais atividades. Quando esse código de implementação dos registros de eventos é acionado (Figura 67), inicia o registro das informações associadas a palavra chave "Command", que é usada para especificar o tipo de informação a ser gravada, a hora e a data corrente, se o comando foi acionado via tecla de atalho ou por meio do Ribbon, o ID único especificado pela Autodesk e informações complementares a respeito do comando executado são também repassadas para o arquivo de texto.

Figura 67 - Código de implementação dos eventos relacionados ao Ribbon do Revit

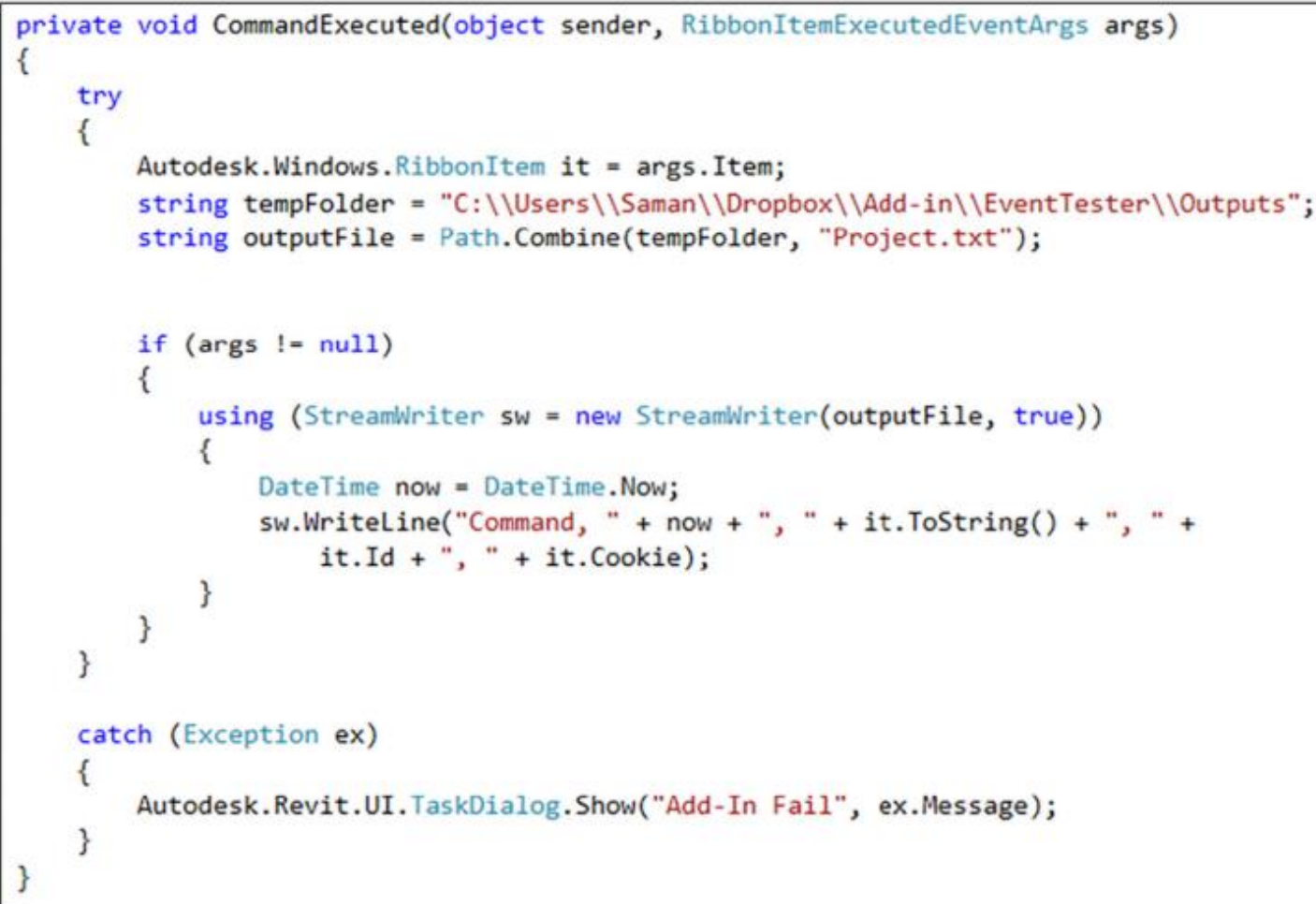

Fonte: (YARMOHAMMADI; CASTRO-LACOUTURE, 2019, p.96) 
Em alguns casos específicos determinados eventos de modificação dos elementos, tais como o comando mover, podem ser realizados sem interação do usuário com o Ribbon ou teclas de atalho. Nestes casos, o plugin desenvolvido endereça este problema com outra implementação, que capta eventos que não são ativados via comandos do Ribbon por meio da ação "DocumentChangeEventArgs", que é ativada quando qualquer mudança é feita no modelo. Todas as modificações são então registradas de acordo com uma das três seguintes variáveis: apagar elemento (Element deletion), elemento modificado (Element modified) e elemento adicionado (Element addition) (YARMOHAMMADI; CASTRO-LACOUTURE, 2019, p.97).

Assim como ocorre nos tipos de registro de eventos anteriores, quando ocorrem evento de erros e outros avisos do programa, tais como um problema de superposição de elementos relatado pelo Revit ao usuário, o plugin registra tal ocorrência no histórico de eventos, relacionando-o a outros parâmetros, como data e hora da ocorrência e o nome do usuário que está trabalhando. A Figura 68 mostra exemplos de entradas que são registradas para cada tipo de evento detectado enquanto 0 modelo está sendo processado.

Figura 68 - Plugin com eventos e saídas que são gravadas no arquivo texto.

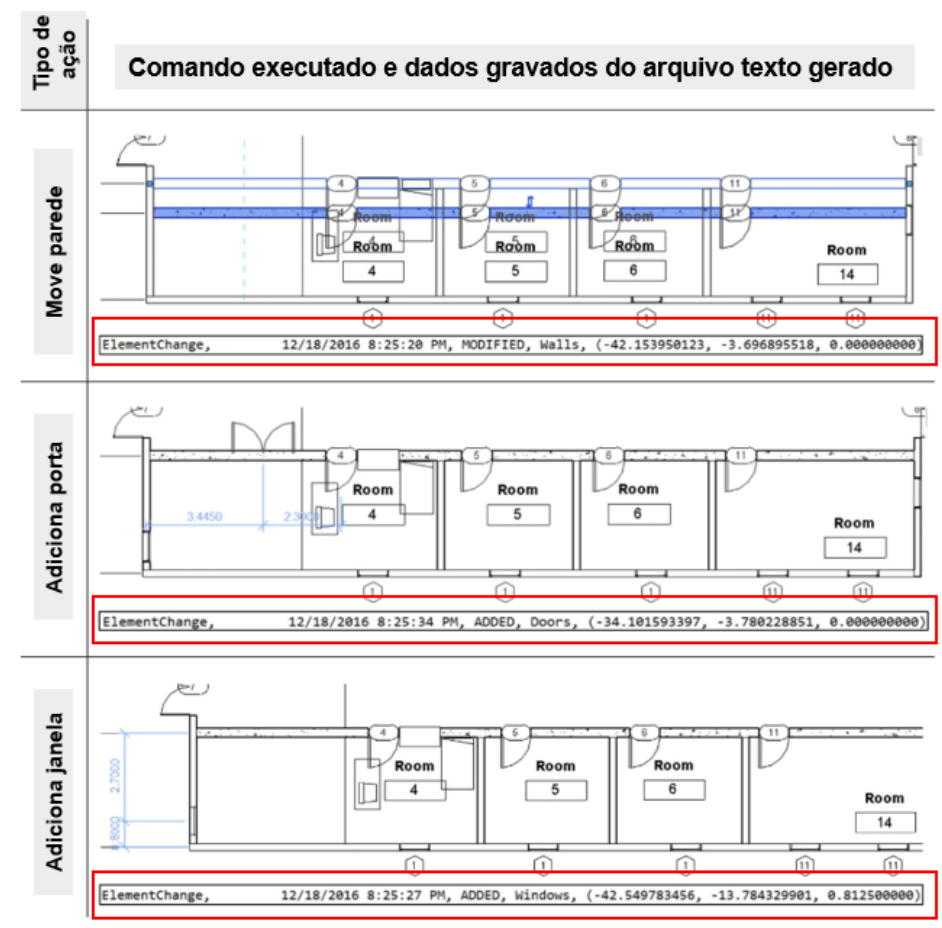

Fonte: (YARMOHAMMADI; CASTRO-LACOUTURE, 2019, p.99) (tradução nossa) 


\section{Teste do monitoramento e exemplo de processamento dos dados extraídos pelo plugin}

Para testar o funcionamento do plugin e suas saídas, um estudo foi realizado conforme indicado:

Cada comando executado por meio do Ribbon, de modificação direta no elemento (mouse drag), atalhos de teclado, e alertas de erros, foram manualmente anotadas e posteriormente comparadas com as anotações feitas automaticamente pelo plugin [...]...[...] A precisão da performance do plugin foi validada quando comparada com as medidas feitas manualmente (YARMOHAMMADI; CASTRO-LACOUTURE, 2019, p.101) ${ }^{69}$

O teste do plugin foi realizado por Yarmohammadi e Castro-Lacouture (2019) contando com a colaboração de cinco mestrandos do Instituto de Tecnologia da Georgia que foram selecionados entre dez candidatos em razão de sua capacidade de modelar em um nível de complexidade equivalentes ao definido para o LOD $200^{70}$. Após realizada a seleção, os cinco novos colaboradores modelaram o edifício mostrado na Figura 69, utilizando o plugin de monitoramento.

Figura 69 - Modelo para teste de performance de modelagem

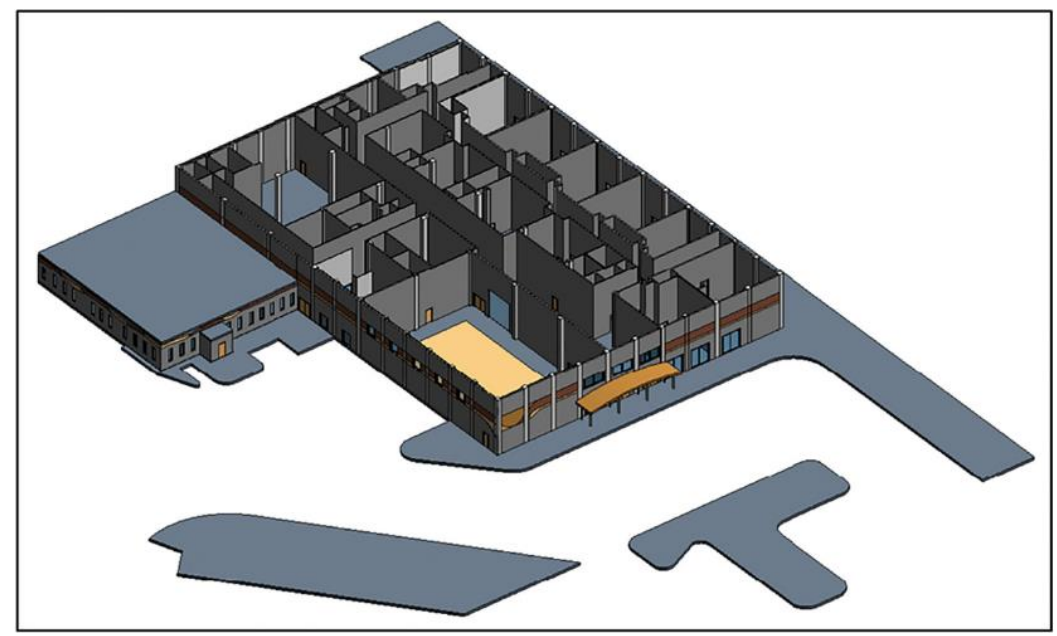

Fonte: (YARMOHAMMADI; CASTRO-LACOUTURE, 2019, p. 102)

\footnotetext{
${ }^{69}$ Original: Every ribbon command execution, direct element modification (mouse drag), keyboard shortcut, and error warning were manually recorded, and these recordings were then compared with the output produced by the plugin. Fig. 9 illustrates screenshots of some of the executed Revit commands and the corresponding outputs produced by the plugin. The accuracy of the plugin's performance was validated by comparing the output with the manually recorded information.

${ }^{70}$ LOD pode ser entendido como Level of Detail, que representa uma escala de detalhamento geométrico dos elementos BIM, ou Level of Development, que está mais relacionado à confiabilidade e detalhamento das informações de determinado objeto. Existem diversas definições e especificações de LOD atualmente disponíveis, mas o nível 200 geralmente prevê objetos genéricos sem detalhamento preciso de geometria ou informação.
} 
Os eventos que ocorreram durante as seções de modelagem realizadas por estes cinco colaboradores para projetar o edifício também foram manualmente anotados para comparar este levantamento manual com o resultado do monitoramento automatizado. Confirmada a eficácia do plugin, foi possível avaliar os resultados para verificar que tipo de análise poderia ser feita.

Após serem coletados pelo plugin, os dados foram exportados para serem analisados por meio de um programa de manipulação de dados baseado em Python, baseado na biblioteca Pandas ${ }^{71}$. O Quadro 7 mostra um exemplo do tipo de dados que foram coletados em cada seção de modelagem monitorada. Para que pudessem ser processados pelo programa de manipulação de dados, estes dados foram exportados em formato textual CSV, em que os valores dos parâmetros monitorados são separados por vírgula.

\section{Quadro 7 - Data frames}

\begin{tabular}{|c|c|c|c|}
\hline \multicolumn{4}{|c|}{ Dataframes } \\
\hline & $\begin{array}{c}\text { Mudanças em elementos } \\
\text { (deletados, modificados, } \\
\text { adicionados) }\end{array}$ & Comandos & Erros \\
\hline $\begin{array}{c}\text { Nomes das } \\
\text { colunas }\end{array}$ & $\begin{array}{l}\text { User: nome do } \\
\text { modelador } \\
\text { Time : data e horário } \\
\text { atual } \\
\text { Action : identificador } \\
\text { de mudança } \\
\text { Category: categoria do } \\
\text { elemento alterado } \\
\text { Min: faixa de limite } \\
\text { mínima do elemento } \\
\text { Max: faixa de limite } \\
\text { máxima do elemento } \\
\text { Center: centro da caixa } \\
\text { de limite do elemento } \\
\text { Type: tipo de elemento } \\
\text { Family : familia de } \\
\text { elemento } \\
\text { ID: ID do elemento } \\
\text { View : vista atual } \\
\text { Project : nome do projeto }\end{array}$ & $\begin{array}{l}\text { Time: data e horário atual } \\
\text { Exec_Pt : ponto de execução } \\
\text { do comando } \\
\text { Cmd_ID:ID do comando } \\
\text { Cmd_Info: informações } \\
\text { complementares de } \\
\text { comando para } \\
\text { informação }\end{array}$ & $\begin{array}{l}\text { User: nome do } \\
\text { modelador } \\
\text { Time: data e horário } \\
\text { atual } \\
\text { ErrorType: tipo de } \\
\text { falha }\end{array}$ \\
\hline
\end{tabular}

Fonte: (YARMOHAMMADI; CASTRO-LACOUTURE, 2019, p. 102)

\footnotetext{
${ }^{71}$ Panda é uma biblioteca de dados escrita para o Python que manipula os dados como uma matriz de linhas e colunas, ela traz consigo funções de análise de banco de dados que aumentam as potencialidade do Python em relação ciência de computação voltada para dados: (WILLEMS, 2019)
} 
O Quadro 8 mostra um resumo dos eventos coletados pelo plugin enquanto uma seção de modelagem do edifício estava sendo executada pelos cinco colaboradores. Pelos resultados obtidos, pode-se observar que dos cinco colaboradores selecionados dois modeladores executaram em torno de três vezes e meia a mais entradas que os outros três para realizar o mesmo trabalho, sugerindo graus de experiencia diferentes entre estes dois grupos de colaboradores.

No geral, os comandos mais executados foram para inserir elementos como paredes e janelas. Os modeladores identificados como menos experientes usaram com frequência o comando de concluir modo de edição de paredes, enquanto todos usaram preferencialmente $o$ acesso aos comandos por meio da seleção de ícones do Ribbon.

Quadro 8 - Resumo de ações coletadas pelo plugin por modelador

\begin{tabular}{|c|c|c|c|c|}
\hline & $\begin{array}{l}\text { Número de } \\
\text { entradas }\end{array}$ & $\begin{array}{l}\text { Número de } \\
\text { erros }\end{array}$ & $\begin{array}{l}\text { Tipos de erros } \\
\text { mais frequentes }\end{array}$ & Tipos de vista \\
\hline Modelador 1 & 17,318 & 162 & $\begin{array}{l}\text { Finish sketch } \\
\text { Structural column } \\
\text { Drag }\end{array}$ & $\begin{array}{l}\text { Level } 1 \\
\{3 D\} \\
\text { East }\end{array}$ \\
\hline Modelador 2 & 12,220 & 155 & $\begin{array}{l}\text { Drag Wall End } \\
\text { Finish sketch } \\
\text { Wall - Line }\end{array}$ & $\begin{array}{l}\text { Level } 1 \\
\{3 D\} \\
\text { East }\end{array}$ \\
\hline Modelador 3 & 4131 & 75 & $\begin{array}{l}\text { Join Walls to Roof } \\
\text { Wall Line } \\
\text { Drag }\end{array}$ & $\begin{array}{l}\text { Level } 1 \\
\{3 D\} \\
\text { North }\end{array}$ \\
\hline Modelador 4 & 4740 & 61 & $\begin{array}{l}\text { Trim/ Extend to } \\
\text { Corner } \\
\text { Wall - Line } \\
\text { Drag }\end{array}$ & $\begin{array}{l}\text { Level } 1 \\
\{3 D\} \\
\text { Roof }\end{array}$ \\
\hline \multirow[t]{2}{*}{ Modelador 5} & 4739 & 55 & $\begin{array}{l}\text { Wall - Line } \\
\text { Select the roof }\end{array}$ & $\begin{array}{l}\text { Level } 1 \\
\{3 D\}\end{array}$ \\
\hline & & & Finish sketch & East \\
\hline
\end{tabular}

Fonte: (YARMOHAMMADI; CASTRO-LACOUTURE, 2019, p. 106)

Além da identificação destes padrões de comportamento, outras análises puderam ser feitas a partir do processamento dos dados levantados pelo plugin, como por exemplo, comparar o tempo de inserção de paredes versus janelas. O conjunto de variáveis que foram consideradas definiu um determinado perfil de profissional que pode ser avaliado entre os colaboradores, permitindo destacar aqueles que apresentavam melhor desempenho segundo o perfil especificado para o caso. 
A perspectiva de construir perfis que considerassem outras variáveis de modelagem não foi analisado, mas entende-se que o experimento foi bem-sucedido, uma vez que estabeleceu novas métricas e forma de medição da produtividade em projetos modelados em Revit. Tal execução só foi possível graças a possibilidade de ampla interação entre a linguagem C\# e a API do Revit.

\subsubsection{Plugin BIM Interoperability Tools - Revit}

O segundo plugin C\# analisado para a dissertação é o BIM Interoperability Tools, um plugin desenvolvido pela Autodesk. Embora esse plugin não seja analisado através da sua estrutura de programação, mesmo porque esse é um código compilado que não dá acesso ao seu código fonte, a sua escolha se deve por apresentar aspectos importantes para o contexto da pesquisa: o programa demonstra a ampla possibilidade de utilização da API na criação de novos comandos para o Revit; é uma ferramenta com larga utilização pelo mercado; demonstra a interação de um aplicativo externo com o banco de dados do Revit permitindo a alteração e criação de parâmetros para vários elementos.

Além destes, outro fator que contribuiu para a escolha deste plugin foi devido a reforçar a importância da padronização necessária para que uma abordagem de relação a análise de códigos de obras seja bem-sucedida, com classificações definidas para os elementos analisados. Este plugin cria um novo Ribbon com vários comandos divididos em quatro seções, como resumidamente explicado no Quadro 9.

A análise que ora é apresentada se limita aos painéis de comandos A e $\mathbf{D}$, relacionados respectivamente ao gerenciamento da classificação (Classification Manager) e a extensão COBie (COBie Extension). Os estudos desenvolvidos para a dissertação discutem como a aplicação das ferramentas contidas nestes painéis ajudam a atender as necessidades de classificação de elementos e integração das informações COBie. 
Quadro 9 - Resumo de conceitos atribuídos aos painéis do plugin

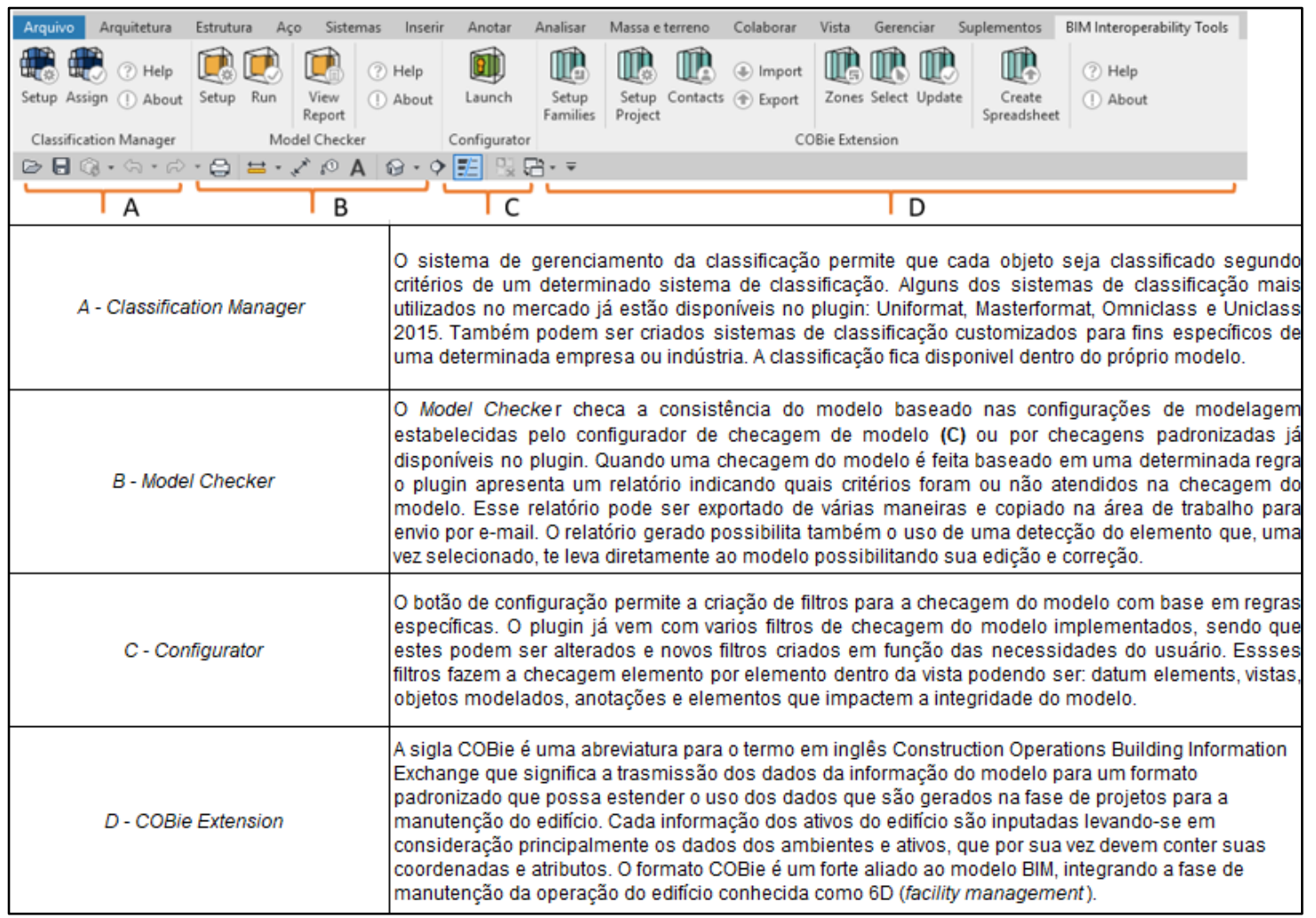

Fonte: Elaborado pelo autor

\section{Painel de comandos A: Gerenciamento da Classificação}

Os setores ligados a AEC apresentam como uma de suas principais características uma cadeia de suprimentos fragmentada que demanda de intensa troca de informação. Para mediar essas trocas de informação são elaborados sistemas de classificação que permitem estabelecer regras de comunicação e uma linguagem padronizada, reduzindo problemas de entendimentos divergentes acerca da caracterização de materiais, localizações, componentes etc.

No caso do Brasil a situação é agravada por causa das diferenças regionais. Diante da falta de um padrão nacional, atualmente em desenvolvimento, são recorrentes a discordância entre termos, tais como ladrilho e azulejo, tijolos e blocos, algeroz e rufos, que tornam a simples tarefa de trocar informações de projeto um problema para o desenvolvimento de empreendimentos imobiliários (ABDI, 2017, p.10). Para mitigar tal problema: 
Um sistema de classificação visa evitar ou minorar as inevitáveis perdas decorrentes dessas trocas, evitar interpretações dúbias e facilitar a interoperabilidade entre diferentes sistemas informatizados. Para isso, os sistemas propõem "classes" que agrupam objetos físicos ou virtuais que apresentem características semelhantes a partir de uma abordagem lógica definida (ABDI, 2017, p.10)..

A aba de gerenciamento da classificação ajuda na tarefa de classificar as informações relacionadas a cada objeto da construção segundo um determinado sistema de regras, tais como o Omniclass, o Uniformat, o Masterformat e o Uniclass 2015. Além dos sistemas de setor mais difundidos é possível criar e acessar sistemas de classificação proprietários, específicos de uma determinada empresa ou rede, utilizando o comando do Setup deste painel.

Acessando o ícone que habilita o Setup, é possível selecionar um arquivo Excel com uma base de dados customizada ou uma base de dados pré-definida como o IFC (Figura 70).

Figura 70 - Janela de configuração do Classification Manager

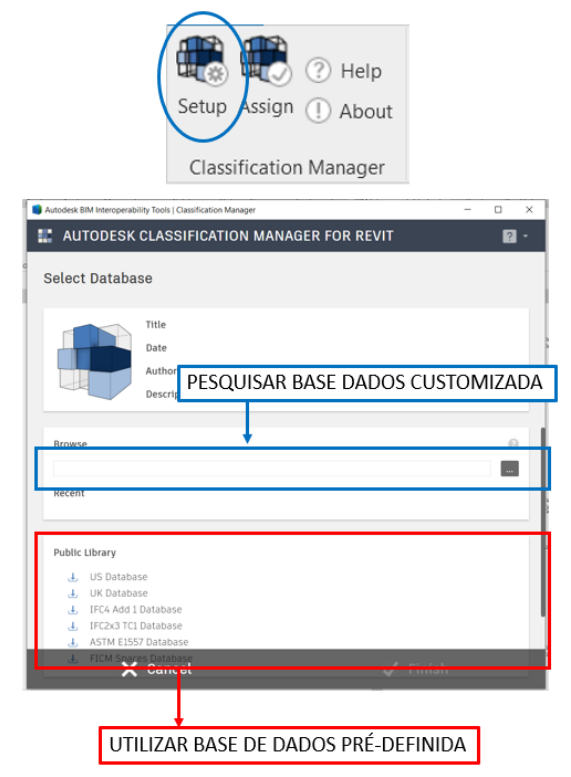

Fonte: Elaborado pelo autor

No caso da elaboração de um sistema de classificação proprietário, uma planilha Excel customizada pode ser criada a partir de arquivos pré-definidos do plugin. Os parâmetros de classificação podem ser aplicados tanto a espaços e ambientes como a elementos por tipo e elementos por instância ou categorias que são nativas do Revit (Figura 71). 


\section{Figura 71 - Tabela Excel com Classificação Customizada}

\begin{tabular}{|c|c|c|c|c|c|c|}
\hline \multirow{2}{*}{\multicolumn{2}{|c|}{$\begin{array}{l}\text { TITLE } \\
\text { DESCRIPTION } \\
\text { VERSION } \\
\text { FUNCTION } \\
\text { NUMBER PARAMETER } \\
\text { DESCRIPTION PARAMET }\end{array}$}} & \multicolumn{3}{|c|}{$\begin{array}{l}\text { Classificaçăo Mestrado } \\
\text { Classifica elementos conforme códigos customizadongl } \\
\text { R00 }\end{array}$} & \multicolumn{2}{|c|}{$\begin{array}{l}\text { Parâmetro para Número da } \\
\text { Classificação }\end{array}$} \\
\hline & & \multicolumn{3}{|c|}{$\begin{array}{l}\text { Classificacao.Mestrado.Numero } \\
\text { Classificacao.Mestrado.Descricao }\end{array}$} & \multicolumn{2}{|c|}{$\begin{array}{l}\text { Parâmetro para Nome/ } \\
\text { Descrição da Classificação }\end{array}$} \\
\hline NTMBER & & \multicolumn{3}{|l|}{ DESCRIPTION } & IEVI & 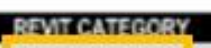 \\
\hline Classificaçăo & Mestrads & Classifica elementos confo $n$ & me códigos customiza & dos $(R 0$ & 0 & \\
\hline 10 & & Janelas & & & 2 & -2000014 \\
\hline 10.10 & & Janelas de Alumínio & & & 3 & -2000014 \\
\hline 10.10 .10 & & Correr Duas Folhas & & & 4 & -2000014 \\
\hline 10.10 .20 & & Maxim-Ar & & & 4 & -2000014 \\
\hline 20 & & Portas & & & 2 & -2000023 \\
\hline 20.10 & & Portas de Madeira & & & 3 & -2000023 \\
\hline 20.10 .10 & & Abrir Uma Folha & & & 4 & -2000023 \\
\hline 20.20 & & Portas de Aluminio & Nível dentro da & & 3 & -2000023 \\
\hline 20.20 .10 & & Abrir Uma Folha & hierarquia de & & 4 & -2000023 \\
\hline 30 & & Paredes & cação & & 2 & -2000011 \\
\hline 30.10 & & Alvenaria & & & 3 & -2000011 \\
\hline 30.20 & & Drywall & & & 3 & -2000011 \\
\hline 40 & & Equipamentos Hidráulicos & & & 2 & -2001160 \\
\hline 40.10 & & Bacia Sanitária & & & 3 & -2001160 \\
\hline 40.20 & & Lavatório & & & 3 & -2001160 \\
\hline 40.30 & & Chuveiro & & & 3 & -2001160 \\
\hline 40.40 & & Bancada Cozinha & & & 3 & -2001160 \\
\hline 50 & & Pisos & & & 2 & -2000032 \\
\hline 50.10 & & Lajes & & & 3 & -2000032 \\
\hline 50.20 & & Pisos Acabados & & & 3 & -2000032 \\
\hline 50.20 .10 & & Contrapiso e Cerâmica & & & 4 & -2000032 \\
\hline 50.20 .20 & & Cimentados & & & 4 & -2000032 \\
\hline 60 & & Forro & & & 2 & -2000038 \\
\hline 60.10 & & Forro Gesso Acartonado & & & 3 & $\cdot 2000038$ \\
\hline 70 & & Revestimento de Paredes & & & 2 & -2000011 \\
\hline 70.10 & & Pintura & Nome/Descrição & & 3 & -2000011 \\
\hline 70.20 & & Azulejo & do elemento & & 3 & -2000011 \\
\hline 80 & & Mobiliário & & & 2 & -2000080 \\
\hline 80.10 & & Camas & & & 3 & -2000080 \\
\hline 80.20 & & Mesas & & & 3 & -2000080 \\
\hline 80.30 & & Sofás & & & 3 & -2000080 \\
\hline 80.40 & & Armários & & & 3 & -2000080 \\
\hline 90 & & Eletrodomésticos & & & 2 & -2000080 \\
\hline 90.10 & & Fogāo & & & 3 & -2000080 \\
\hline 90.20 & & Geladeira & & & 3 & -2000080 \\
\hline 90.30 & & Lavadora & & & 3 & -2000080 \\
\hline $\begin{array}{l}\text { Código da } \\
\text { classificação }\end{array}$ & & & & $\begin{array}{l}\text { Código } \\
\text { da cate }\end{array}$ & $\begin{array}{l}\text { o do Revi } \\
\text { egoria do }\end{array}$ & $\begin{array}{l}\text { ra identificação } \\
\text { mento }\end{array}$ \\
\hline
\end{tabular}

Fonte: Elaborado pelo autor 
Para que o sistema de classificação customizado funcione adequadamente é preciso criar parâmetros do Revit com os mesmos códigos de identificação e nome que os especificados nos campos de Number Parameter e Description Parameter da tabela do Excel com a classificação customizada. A inserção dos códigos de classificação ao modelo pode ser feita por meio da adição dos valores em uma tabela de quantitativos do Revit ou adicionada diretamente com a seleção dos elementos no modelo.

Na segunda opção de inserção do código de classificação, após selecionar o elemento, os códigos de classificação disponíveis para o objeto selecionado são apresentado na aba Classification Manager seguindo a categoria definida pelo sistema de classificação ativo na configuração (Figura 72).

Figura 72 - Classificação de elementos pelo Classification Manager

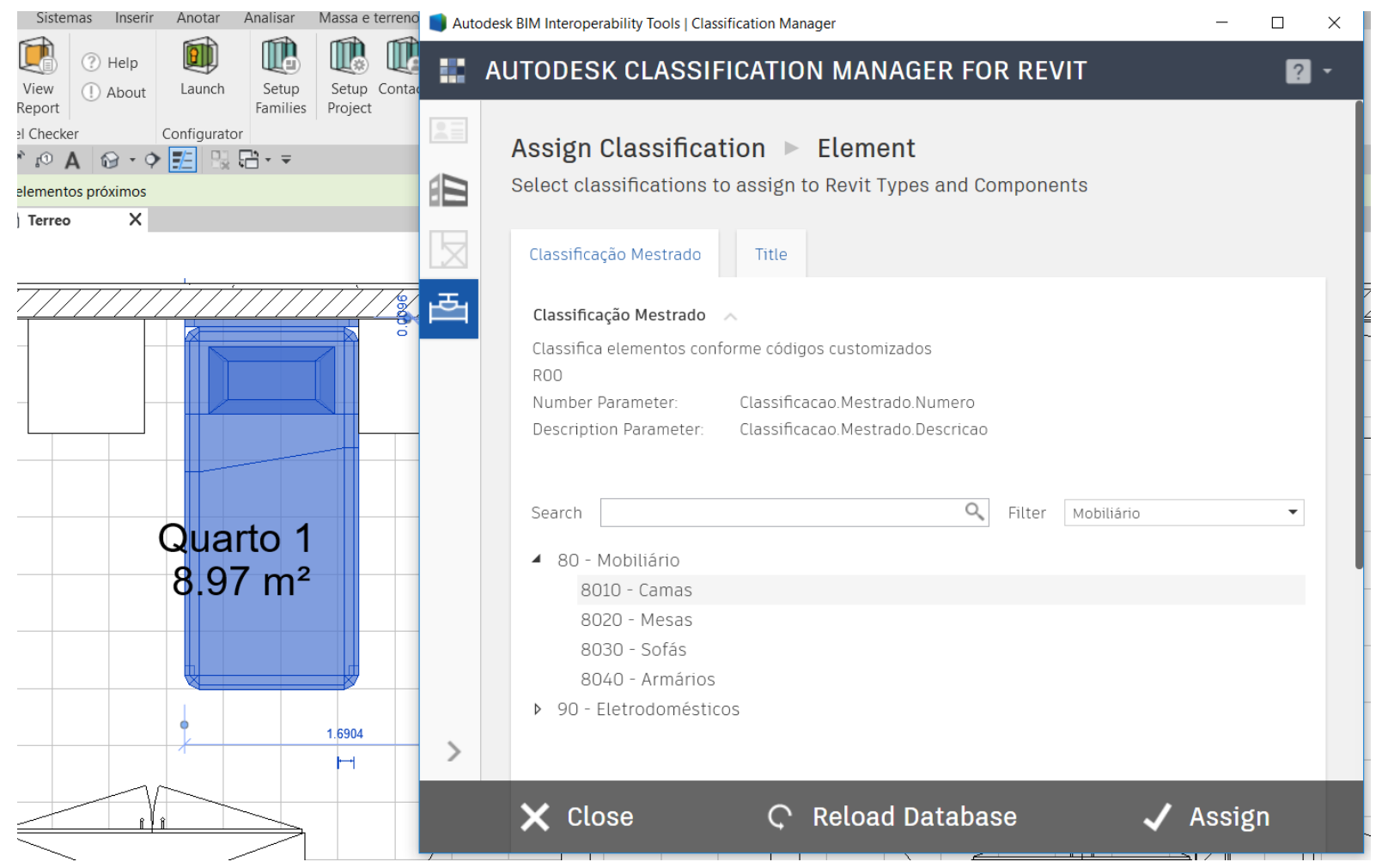

Fonte: Elaborado pelo autor

Para que o processo seja completo, o código e a descrição indicados pela interface do plugin devem, então, serem inseridos nos campos de parâmetros das propriedades de tipo de elementos, conforme especificado no exemplo da Figura 73. 
Figura 73 - Parâmetro de classificação aplicado ao elemento

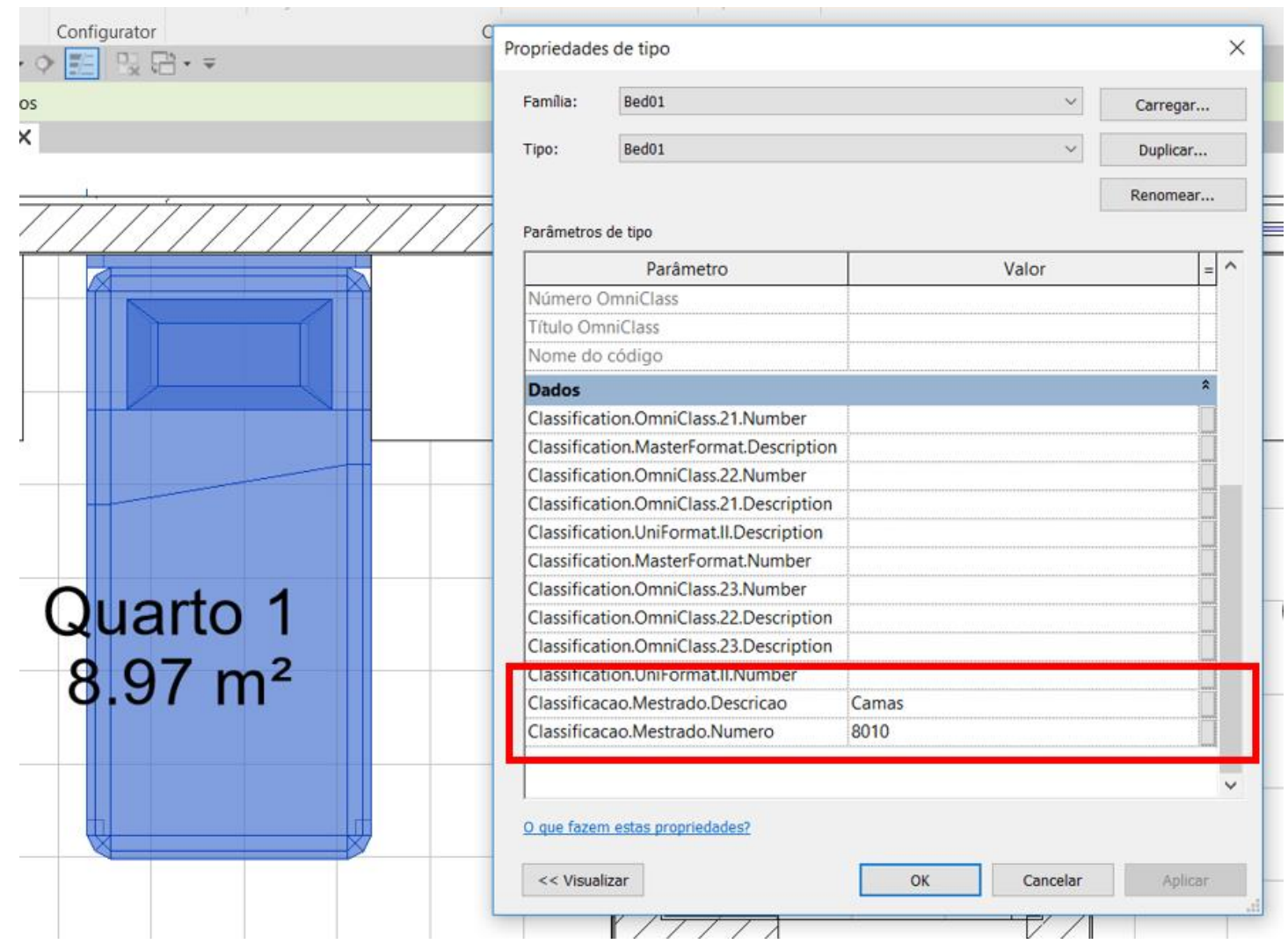

Fonte: Elaborado pelo autor

A utilização do recurso de classificação do plugin permite maior facilidade em estabelecer uma base de dados coesa para a categorização e inserção de informações nos elementos construtivos do modelo. A padronização destes dados permite que a programação de outras aplicações e plugins possa ser desenvolvida onde as funções do código escrito, como comandos do tipo “If”, por exemplo, tenham uma base de dados consistente como suporte para a tomada de decisões durante a programação.

Neste caso, tal banco de dados pode ser proveniente de modelos já classificados e/ou analisados pelas ferramentas de classificação do plugin (Classification Manager). Como o sistema de classificação proprietário também pode ser relacionado à informações específicas para exportação COBie, tais como contatos e procedimentos para o gerenciamento da construção (facility management), o plugin permite integrar os sistemas de classificação proprietários e os sistemas de classificação setoriais ao modelo, utilizando tais informações também para uso, operação e/ou criação de novos plugins. 


\section{Painel de comandos D: Construction-Operations Building information exchange (COBie)}

Figura 74 - Configurações para exportação das planilhas COBie

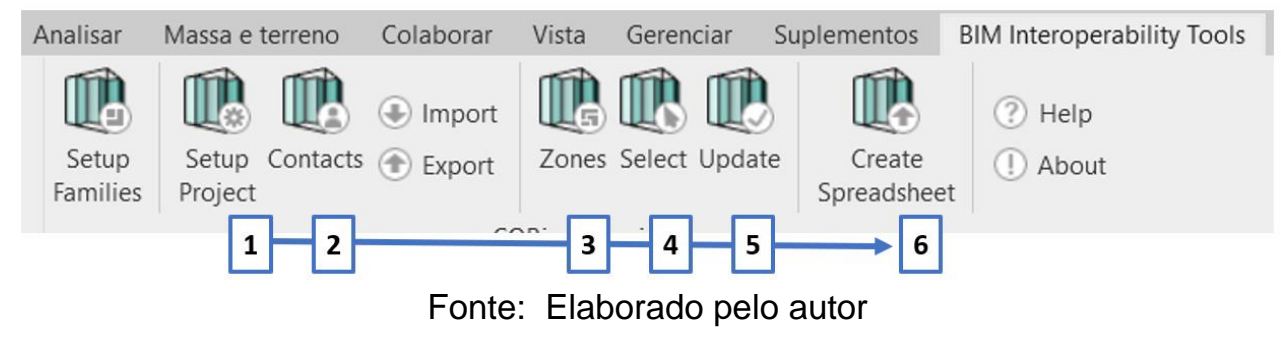

O comando Setup Project (1, Figura 74) define a configuração geral de exportação das informações do projeto, especificando informações tais como os tipos de objetos que são vinculados às zonas do COBie; as configurações dos nomes de tipos de elementos e de nomes de instância; a classificação dos sistemas; a determinação de parâmetros que serão exportados para a tabela COBie Attributes; se serão criadas tabelas dentro do Revit com o padrão COBie ou não; dentre outras configurações (Figura 75).

Figura 75 - Configuração de projeto no COBie Extension

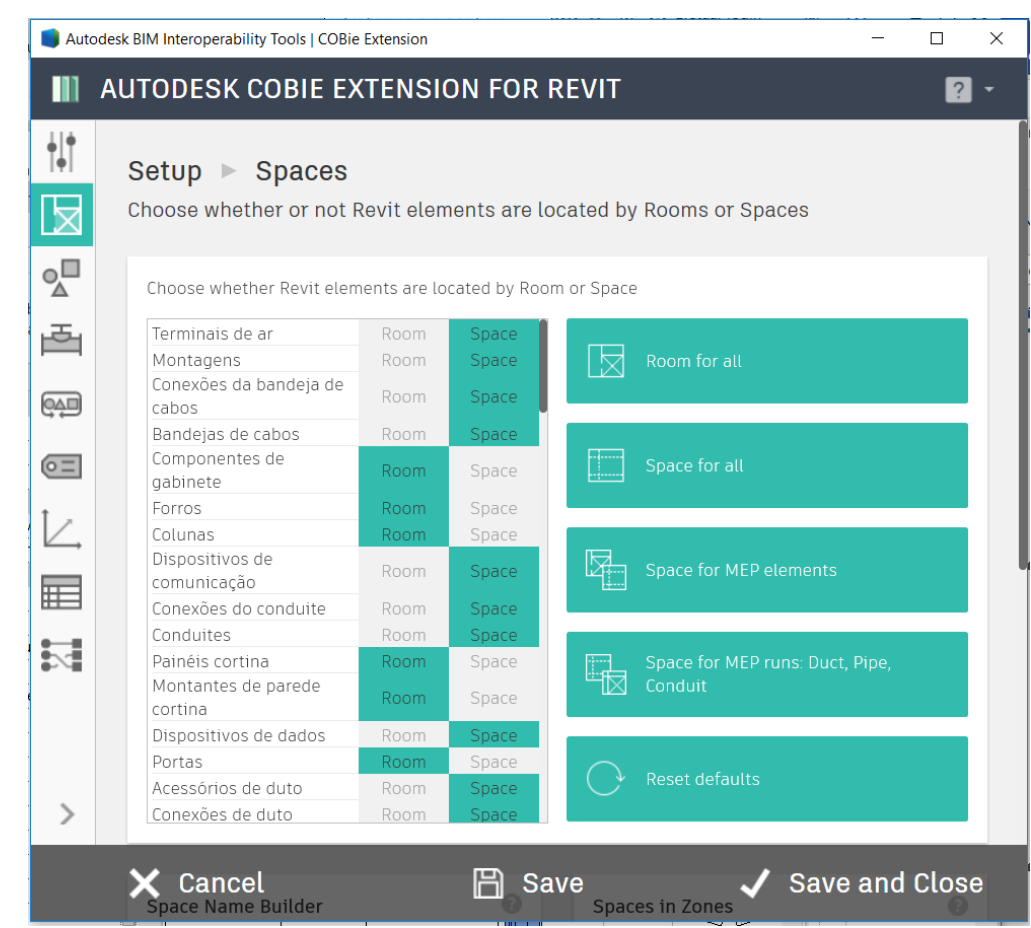

Fonte: Captura de tela de Autodesk COBie Extension for Revit 
O comando Contacts (2, Figura 74) permite relacionar a lista dos contatos que serão exportados para o COBie. Os contatos definidos nesta opção também podem ser utilizados para definir propriedade ou autoria tanto do projeto quanto de elementos específicos (Figura 76). Tanto as configurações de contato quanto as configurações gerais do projeto podem ser importadas de um arquivo existente ou exportadas para determinar um padrão para uso futuro.

Figura 76 - Configuração de contatos no COBie Extension

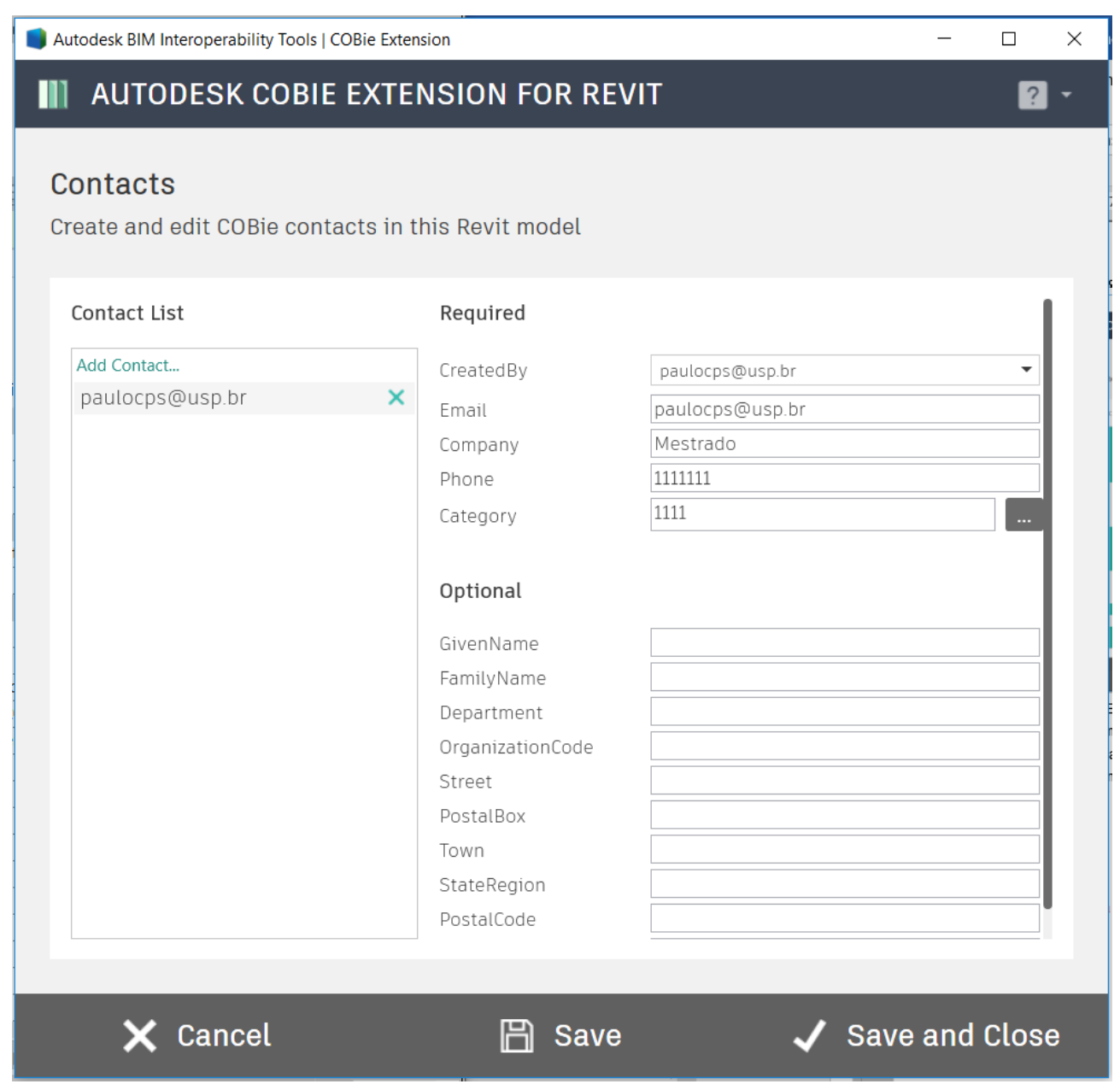

Fonte: Captura de tela de Autodesk COBie Extension for Revit

Com a ferramenta acessível por meio do comando zones (3, Figura 74) podese configurar as zonas padrão do COBie com base nas categorias de ambientes (rooms) e espaços (spaces) padrão do Revit. As zonas podem ser configuradas conforme o critério desejado. 
O comando Select (4, Figura 74) determina quais serão as famílias, tipos e elementos do Revit que serão exportados para as planilhas padrão e o comando Update (5) alimenta os parâmetros que são criados no Revit para exportação dos dados no padrão COBie. Estes parâmetros são tanto de tipo quanto de instância (Figura 77).

Figura 77 - Parâmetros gerados no Revit para exportação dados COBie

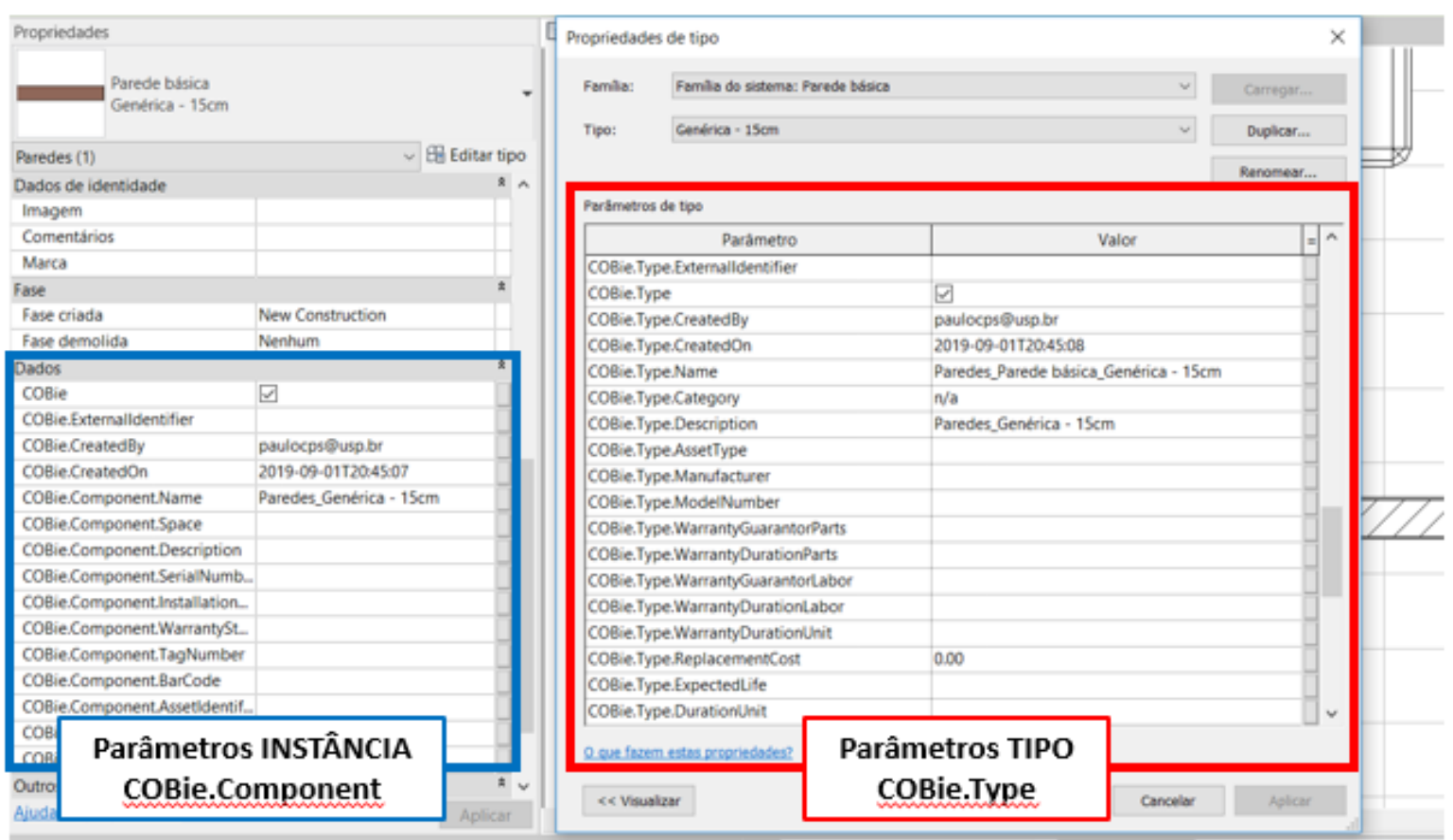

Fonte: Elaborado pelo autor

A ferramenta Select ainda permite que sejam exportados para as planilhas apenas componentes ou tipos que estejam habilitados para a exportação para o COBie, com base nos parâmetros gerados. Isto permite maior controle sobre quais elementos deverão constar na exportação. Para avaliar as informações que vão preencher nas planilhas do COBie no momento da exportação, são criadas tabelas dentro do Revit que a serem alimentadas com os parâmetros determinados nas configurações do plugin (Figura 78). 
Figura 78 - Tabela COBie gerada no Revit

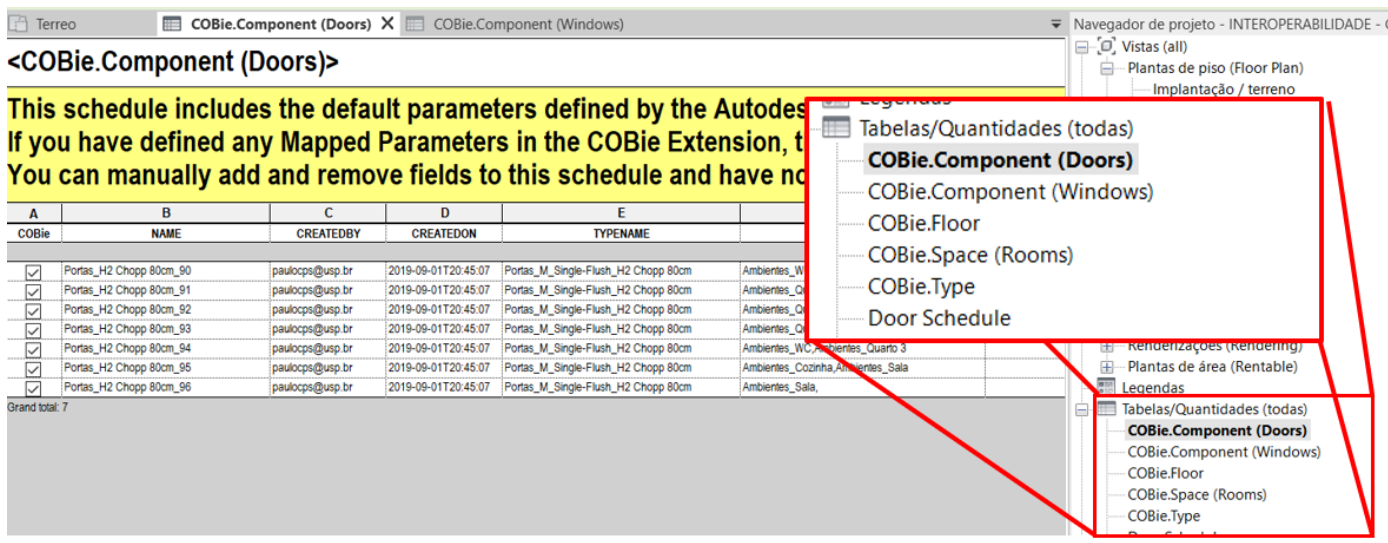

Fonte: Elaborado pelo autor

Com a definição de todas as informações e configuração das opções de exportação pode ser gerada a planilha COBie padronizada pelo comando Create spreadsheet (6, Figura 74). Nesta opção são determinadas todas as folhas da planilha que serão exportadas e o local a ser exportado. A planilha gerada será no formato padrão do COBie, com as informações necessárias para gestão dos ativos e operação da construção (Figura 79).

Figura 79 - Planilha Excel exportada conforme padrão COBie

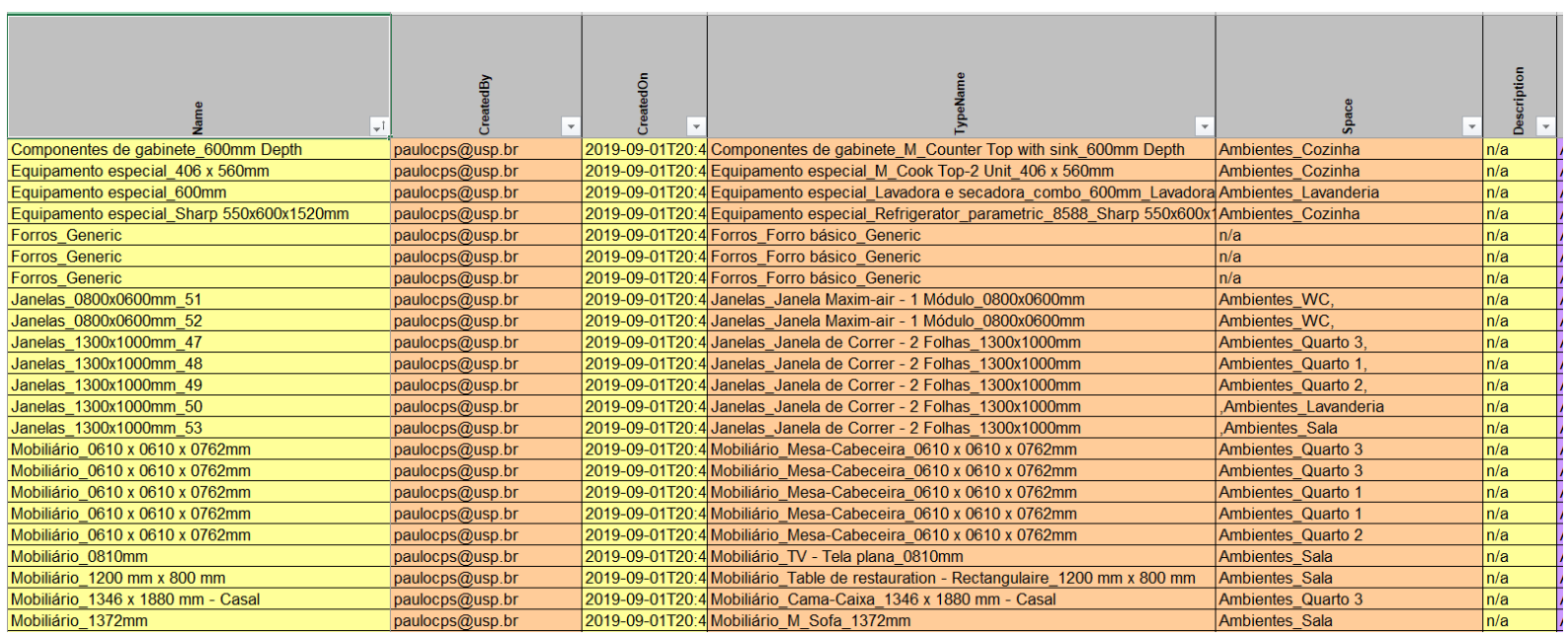

Fonte: Elaborado pelo autor.

As funções da extensão de COBie para o Revit demonstram o potencial da configuração das informações do modelo, que podem ser adaptadas para um padrão de mercado que possibilite para gestão do edifício em seu uso e operação. Por meio do uso dos metadados dos elementos e informações de localização em relação à espaços, se cria um poderoso banco de dados para utilização após a construção. 
O desenvolvimento de API's para o Revit com o uso da linguagem de programação C\#, como aqui apresentado, requer conhecimentos voltados a área de ciência da computação além do uso adequado das interações com a API do Revit. Diferente dos recursos analisados nos estudos anteriores, este plugin apresenta característica que enquadram seu desenvolvimento como um sistema comercial oferecido pela Autodesk que não demanda do usuário domínio de programação. Entretanto, trata-se de um exemplo de uso profissional de programação para automação que oferece recursos que não seriam facilmente conseguidos utilizando Dynamo.

A importância deste plugin está relacionada intimamente a oferecer condições de manipular dados do modelo de forma padronizada. Esta condição é importante para permitir a execução dos estudos experimentais realizados para a dissertação, como o caso a seguir.

\subsubsection{Experimento - Checagem de código de obras - Rotina C\#}

Para Eastman (2009, p. 1012) a verificação de códigos e de checklist de entregas de documentos de projeto de um edifício é uma tarefa dispendiosa que requer considerável esforço e tempo. Nesse sentido abre-se uma janela de oportunidade para o desenvolvimento de sistemas informatizados de checagem de regras e código de obras que atendam a três à diferentes demandas:

1 - Para todos edifícios - condições gerais para a legislação de códigos do edifício nos âmbitos nacionais, regionais e municipais;

2 - Para edifícios particulares - guias de projetos das melhores práticas para um tipo de edifício; esse tipo de base de regra pode ser definido pelo cliente por uma organização alternativamente, como melhores práticas dentro de uma firma de projeto ou engenharia;

3 - Para um edifício em particular: programa requerido para o edifício, como os seus espaços requeridos, aspectos sobre circulação, layout ergonômico e considerações especiais sobre sua área externa, e regras especificas como parte do programa e critérios de revisão durante as fases de projetos e construção. (EASTMAN et al., 2009, p. 1023, tradução nossa) ${ }^{72}$.

\footnotetext{
72 Original: 1. For all buildings-general conditions such as building codes, at the national, regional or municipality level of organization.

2. For particular building types-design guides of best practices for a building type; this type of rule-base may be defined by the client organization, or alternatively, as best practices within a design or engineering firm.

3. For a specific building project: programmatic requirements for a building instance, such as its space requirements, circulation issues, ergonomic layout and special site considerations; these may be developed by the client or design firm, and the specific rules defined as part ofthe program and review criteria during project design and construction
} 
Assim como ocorreu com os experimentos realizados com o Dynamo e Python, o estudo experimental em C\# aborda um caso de criação de uma rotina de checagem da adequação de projetos às regras estipuladas por um código de obras. Como já discutido anteriormente nas seções que abordam a programação de rotinas de checagem de regras, trata-se de um tipo de automação que demanda pragmatismo e uma compreensão adequada sobre as variáveis do código de obra e de programação, de forma a garantir a consistência do código de programação escrito e os dados extraídos do modelo. Tal intrincado conjunto de relações caracterizam a este processo de automação por meio de programação como sendo de realização difícil e complexa (SOLIHIN; EASTMAN, 2015, p. 69).

Um exemplo de como algumas variações triviais da modelagem podem impactar sobre o resultado da verificação automática, dependendo de como o código da rotina é escrito, está relacionado a ocorrência de mudança do nome de algum ambiente do edifício. Dependendo de como é programado, se o nome de um ambiente de banheiro está especificado como "WC" no modelo e como "Banheiro" no código, haverá incompatibilidade de informações.

Para Navari (2012, p. 316) um dos principais requerimentos de programação para que um modelo BIM possa ser analisado adequadamente por um programa de checagem de códigos automática é que este modelo apresente um conjunto de informações sobre os objetos necessárias para sua correta identificação. A base de dados de um software BIM apresenta especificações de família/categoria, tipo/instancia e propriedades/parâmetros de cada objeto do modelo, que podem ser analisados por um programa externo ao se definir e seguir um determinado esquema de configuração das informações compatível com as especificações do software.

A automação de processos de checagem de obras, ora apresentado, possui uma versão equivalente em Dynamo e Python. Outras experiências nesse sentido já foram realizadas anteriormente, como observado em Singapura com a implantação do CORENET ePlanCheck (SOLIHIN; EASTMAN, 2015, p. 70), que trata-se de uma implementação de automação de code checking robusta, realizada em nível nacional. Comercialmente, pode-se destacar iniciativas como as apresentadas pela SOLIBRI 
(SOLIBRI, [s.d.]), que atualiza continuamente seu software com novas funções para a checagem (SOLIHIN; EASTMAN, 2015, p. 70).

A observação destes casos e outras fontes da revisão permitiu determinar uma sequência de passos que são necessárias à criação de um plugin para o Revit usando a linguagem C\#. A Figura 80 ilustra como ocorre o fluxo de informações entre linguagens de programação, a Application Programming Interface (API) e o Revit. Duas referências são usadas para o desenvolvimento e criação de plugins que estão localizadas na pasta de instalação do Revit. São elas: a RevitAPI.dll, que utiliza métodos usados para acessar aplicações, documentos, elementos e parâmetros que estão disponíveis no banco de dados do Revit; e a RevitAPIUI.dll, que oferece permissão para acessar e manipular a interface do usuário, podendo-se criar e modificar as abas e comandos (AUTODESK, 2014, p. 8).

Figura 80 - Fluxo de informações entre API do Revit e linguagens de programação

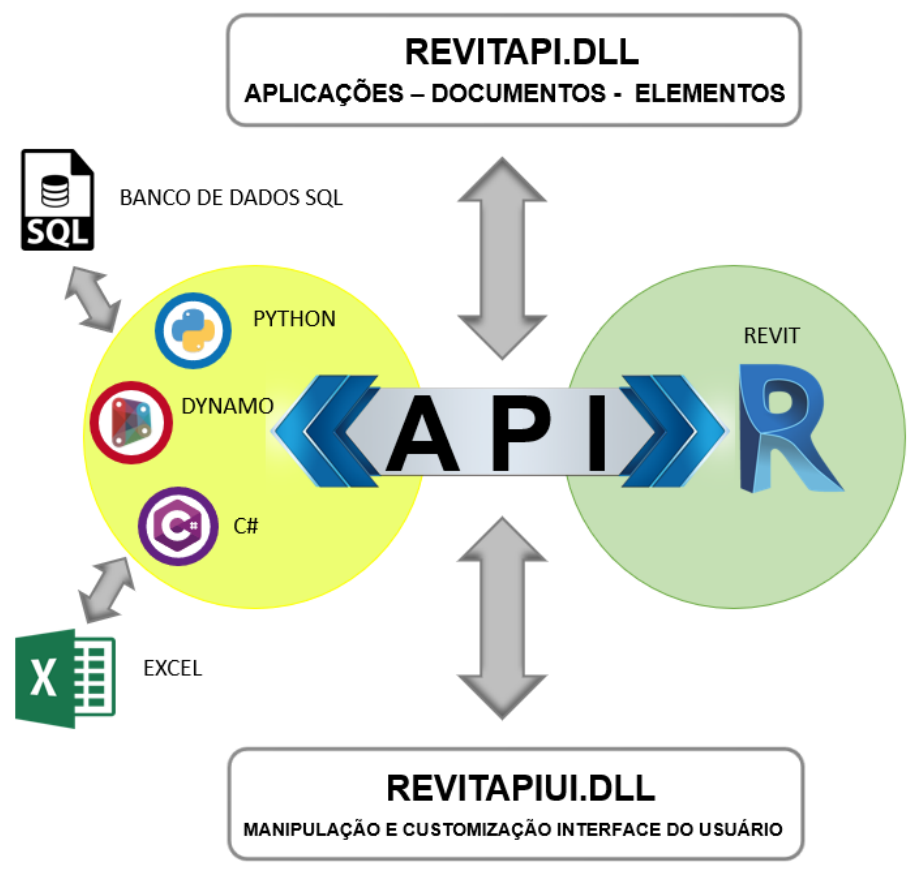

Fonte: Elaborado pelo autor

Embora outras IDE's possam ser utilizadas na criação de plugins para o Revit, - Visual Studio é o ambiente de programação comumente adotado, pois a configuração desse ambiente oferece melhor suporte ao desenvolvimento dos plugins para o Revit escritos em C\#. 
Entre as práticas boas práticas de programação em C\# utilizando o Visual Studio adotadas para o experimento, destacam-se (GRAHAM, [s.d.]) $)^{73}$ :

- Configurar o Visual Studio para que abra o Revit, permitindo a depuração do código;

- Carregar as referências RevitAPI.dll e RevitAPUI.dll para o browser do Visual Studio, onde será possível a pesquisa por uma determinada classe dentro do próprio Visual Studio;

- Acrescentar um item de arquivo de manifesto, que permita que o arquivo manifesto seja editado dentro do próprio Visual Studio;

- Direcionar a gravação do arquivo de manifesto na hora de compilar o código para que o mesmo possa ser armazenado no local determinado para ser lido toda vez que o Revit for aberto.

Dois arquivos são necessários para que um plugin seja executado, conforme detalhadas a seguir. O primeiro é o próprio código que deve ser escrito levando-se em consideração as classes e métodos necessários para que o programa possa ter acesso ao banco de dados do Revit. As classes são carregadas nas primeiras linhas do código, logo em seguida, é acionado o comando externo, correspondente a classe que está associada ao arquivo de manifesto e, então, o código que executa o script acessa as classes que foram carregadas nas primeiras linhas, conforme ilustra Figura 81. Para que o código seja executado, esta precisa ser compilado de forma gerar um arquivo de extensão .dll. Um arquivo de extensão .dll possui comportamento semelhante a um arquivo executável do tipo exe.

73 Jeremy Graham é Diretor de Computational Design na HDR, Australia. Desenvolve modelos e ferramentas para auxiliar desenvolvedores e clientes na utilização de softwares. É especialista em BIM e produziu cursos online de Python e C\#, que ensinam arquitetos e engenheiros a programar nestas linguagens. 
Figura 81 - Rotina de inserção de círculo de área mínima em função das regras municipais de Ribeirão Preto

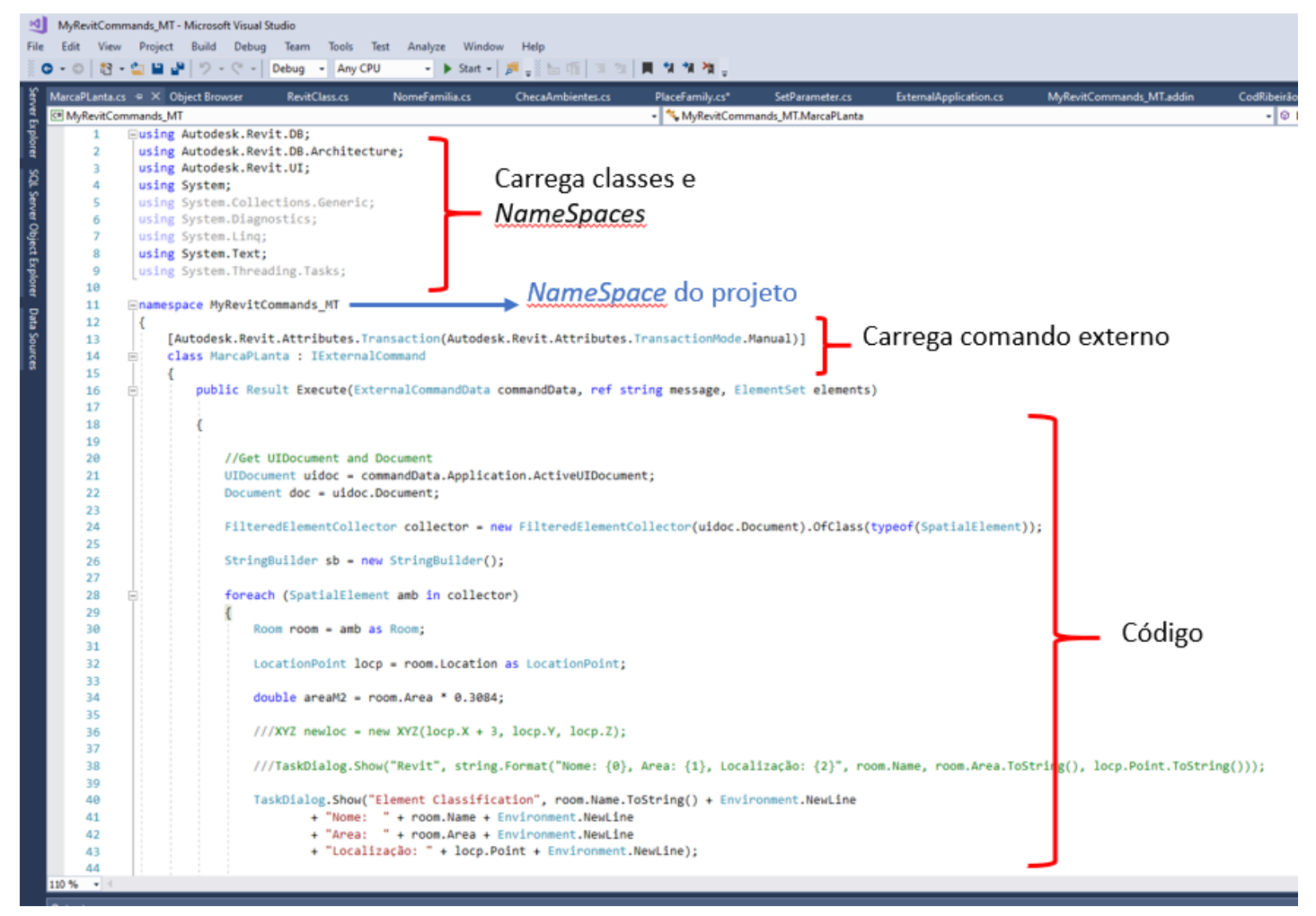

Fonte: Elaborado pelo autor

O segundo arquivo necessário para que a rotina seja executada é o arquivo de manifesto. Trata-se de um apontador do local onde o arquivo .dll do código correlato foi armazenado. Para que realize adequadamente esta função, o manifesto só pode ser salvo em um local específico que é lido pelo Revit toda vez que é iniciado (Figura 82).

Figura 82 - Exemplo de arquivo manifesto

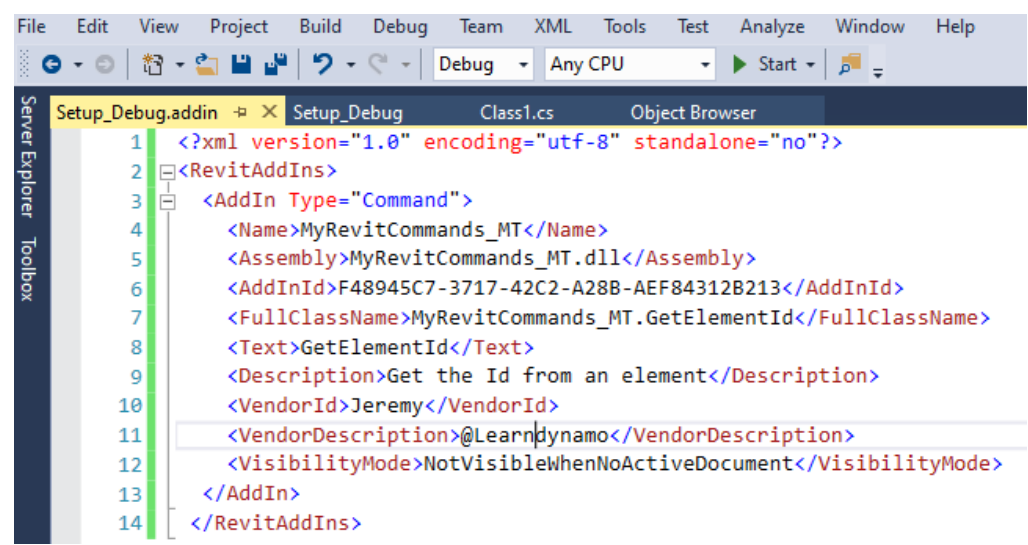

Fonte: Elaborado pelo autor 
Os dois lugares possíveis para armazenar o arquivo de manifesto são:

- C:IProgramData\Autodesk\Revit\Addins\(ano da versão do Revit);

- C:IUsers\Paulo\AppDatalRoaming\Autodesk|Revit|Addins\(ano da versão do Revit).

Uma pesquisa feita sobre a IDE do Visual Studio demonstrou que, entre as facilidades para o desenvolvimento de softwares disponibilizadas, a conclusão de código é a ferramenta mais usada, pois evita a digitação dos comandos uma vez que esses são sugeridos dentro do ambiente de programação. Além desta, as ferramentas mais utilizadas são as ferramentas de compilação e de depuração, de busca por funções do código, de conserto rápido no código e de controle sobre a versão do programa (AMANN et al., 2016, p. 124). Em português, a palavra depurar significa purificar, limpar, desembaraçar; já na informática o termo depurar (Debbuging) possui um significado mais específico, de encontrar e resolver erros de um código de programa. Tal tarefa geralmente é realizada enquanto o programa é executado (Figura 83). 


\section{Figura 83 - Janelas capturadas da IDE do Visual Studio enquanto um código está sendo depurado}

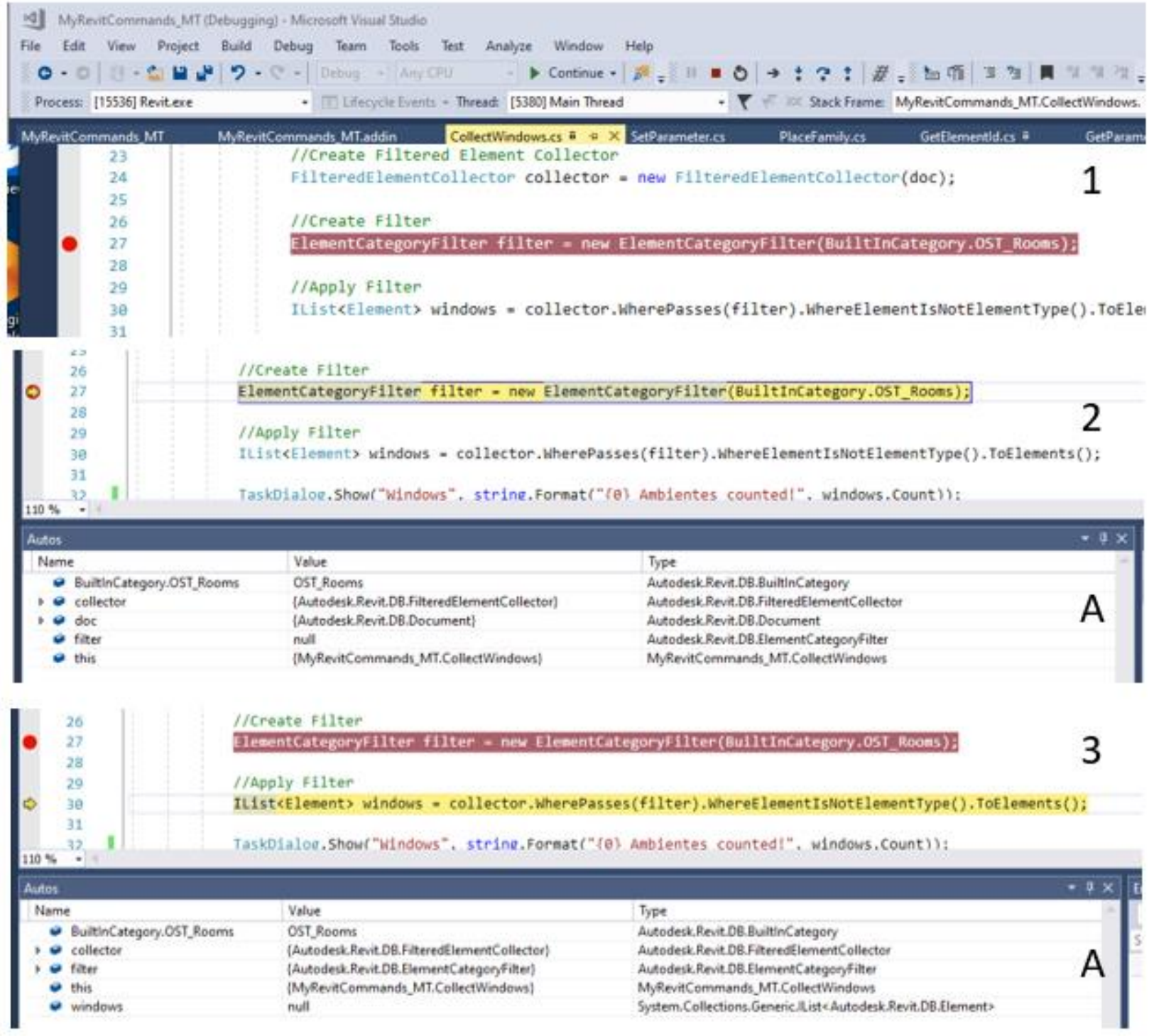

Fonte: Elaborado pelo autor

Quando é configurada corretamente, a IDE do Visual Studio apresenta um comando que permite que se defina um trecho do código para ser externamente executado. A parte 1 da Figura 83 apresenta na linha 27 um exemplo de como este comando de execução no Revit para teste se processa. O comando é executado experimentalmente dentro do Revit e retorna para o Visual Studio conforme indicado na parte 2 da Figura 83. A linha testada é marcada de amarelo e logo abaixo a janela A, abaixo da parte 2, indica as variáveis que são atribuídas ao código, facilitando a identificação de possíveis erros. 
Cada linha do código pode ser executada individualmente, exibindo passo a passo as informações sobre seu funcionamento em interação com o Revit. Esta ação é muito comum na programação tradicional, utilizada por programadores pois facilita a depuração do código. Todavia, como o Revit é um software pesado, seu carregamento demanda algum tempo toda vez que a depuração é feita.

A rotina em questão busca todos os objetos de ambientes (rooms) existentes no projeto e coleta seus parâmetros de ponto de inserção. Em seguida, para cada ambiente encontrado, cria um novo objeto em forma de círculo com o diâmetro equivalente às dimensões exigidas pelo código de obras municipal de Ribeirão Preto. Esses objetos são inseridos no centro dos respectivos ambientes, permitindo observar se os ambientes projetados atendem a regras de dimensões mínimas previstas para cada tipo de cômodo (Figura 84).

Figura 84 - Rotina que desenha um círculo na planta com diâmetro mínimo do código permitido pela legislação

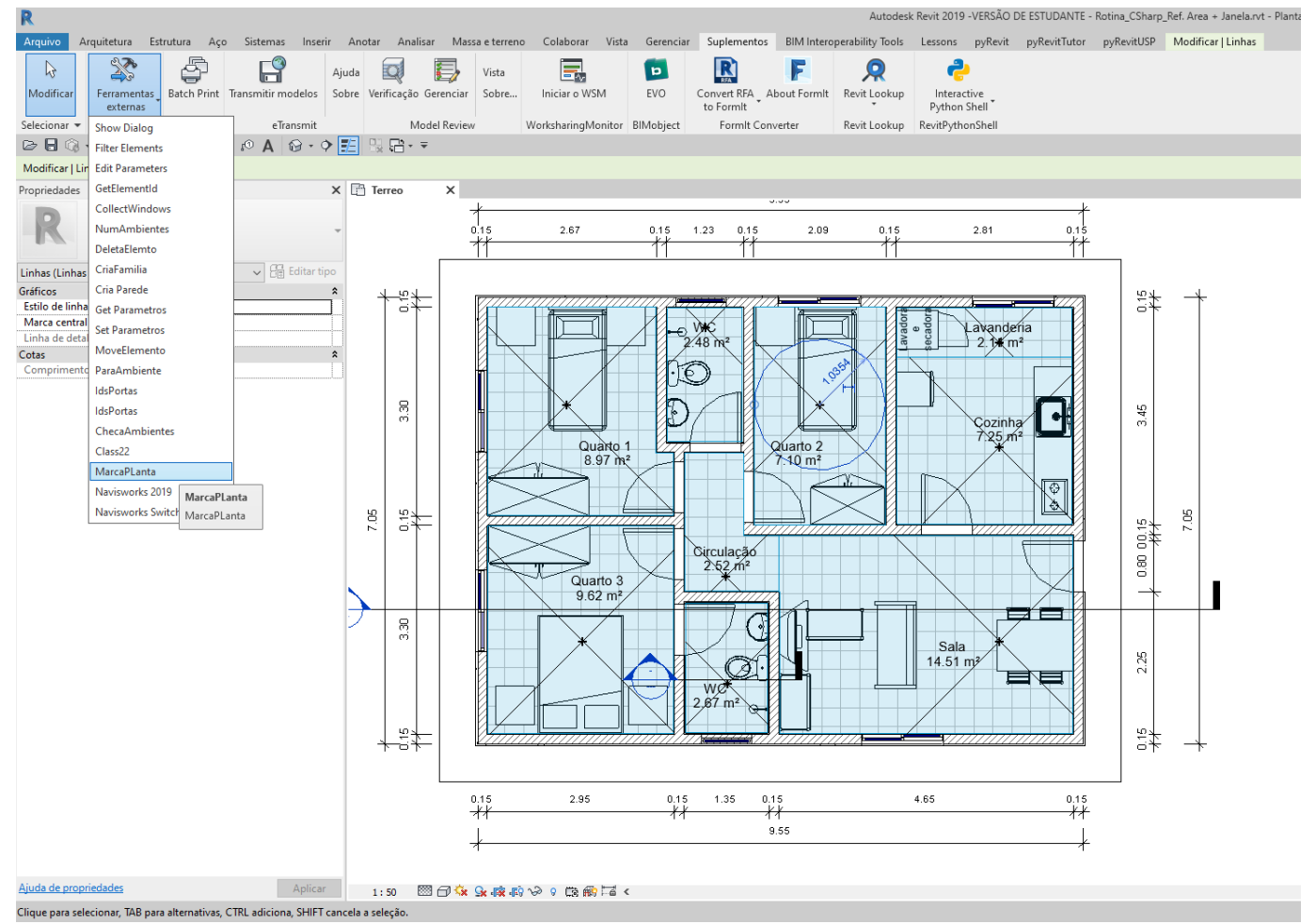

Fonte: Elaborado pelo autor

Por ser um ambiente voltado para a programação orientada a objetos, o Visual Studio permite que um projeto apresente várias classes, agrupadas em um mainspace. $\mathrm{O}$ agrupamento de classes em um único mainspace permite que a troca 
de informação seja feita entre as classes, por meio de instâncias de objetos criadas com métodos e atributos específicos. As instâncias de objetos de uma classe podem ser acessadas e processadas por métodos de outras classes de objetos.

Todo um sistema pode então ser criado baseado neste intercâmbio de dados de instâncias. Por exemplo, todos os dados dos ambientes podem estar instanciados em uma ou duas classes, ou ainda, os dados da legislação de um município também podem ser instanciados em outra classe. Como ambas as classes fazem parte de uma mesma solução, as informações podem ser trocadas criando sistemas para a verificação de projetos de AECO (Figura 85).

Figura 85 - Projeto criado no Visual Studio contendo várias classes

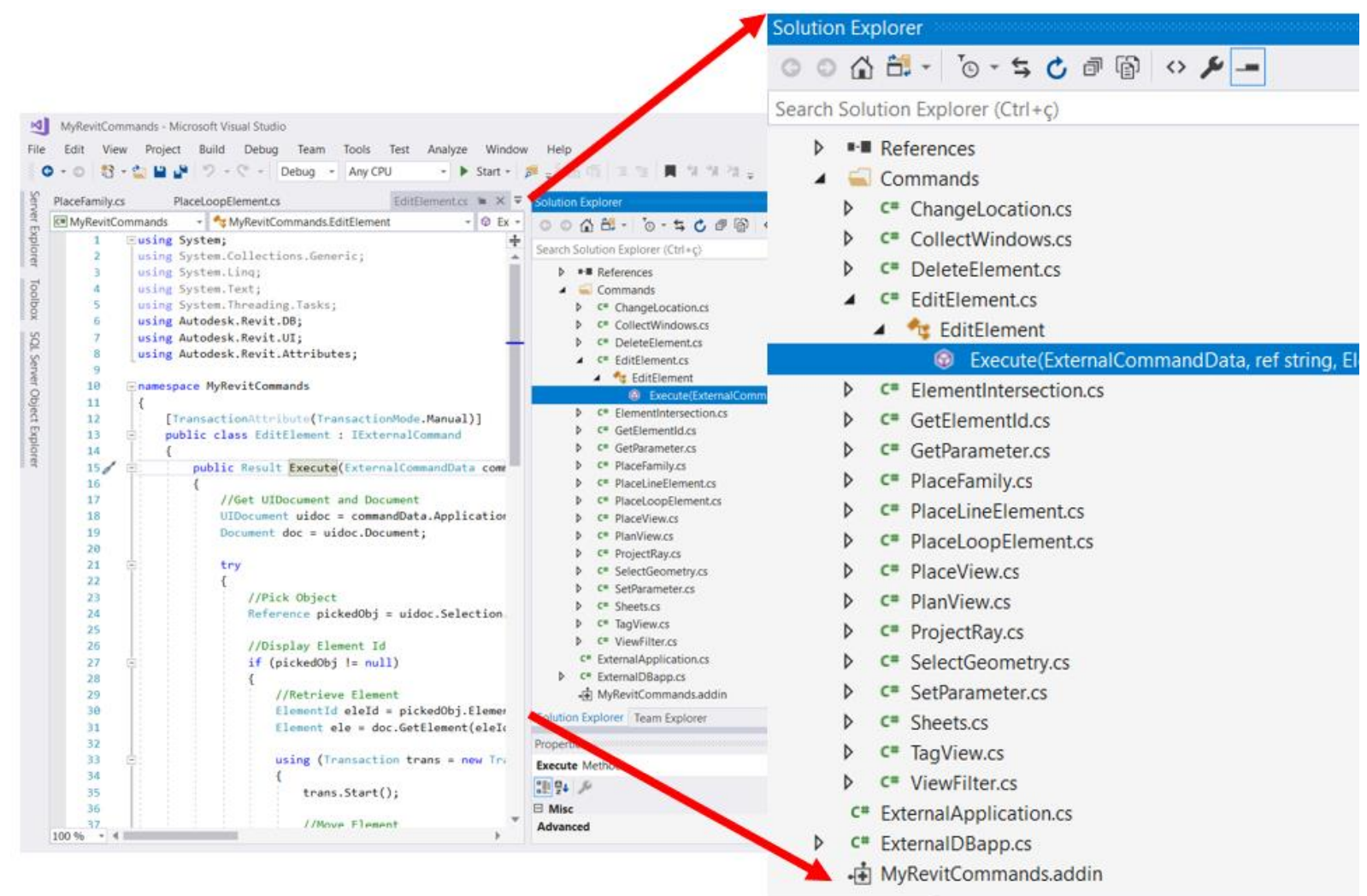

Fonte: Elaborado pelo autor

A criação de um projeto de software que contém várias classes pode ser mais simples porque os códigos criados para cada classe podem ser pequenos como o apresentado na Figura 86, que coleta na variável ambiente uma lista com todos os ambientes (rooms) de um projeto. Esse dado pode então ser referenciado em outra parte do programa dentro da mesma classe ou de outra. 
Figura 86 - Rotina para coletar numa variável todos dados dos ambientes do projeto

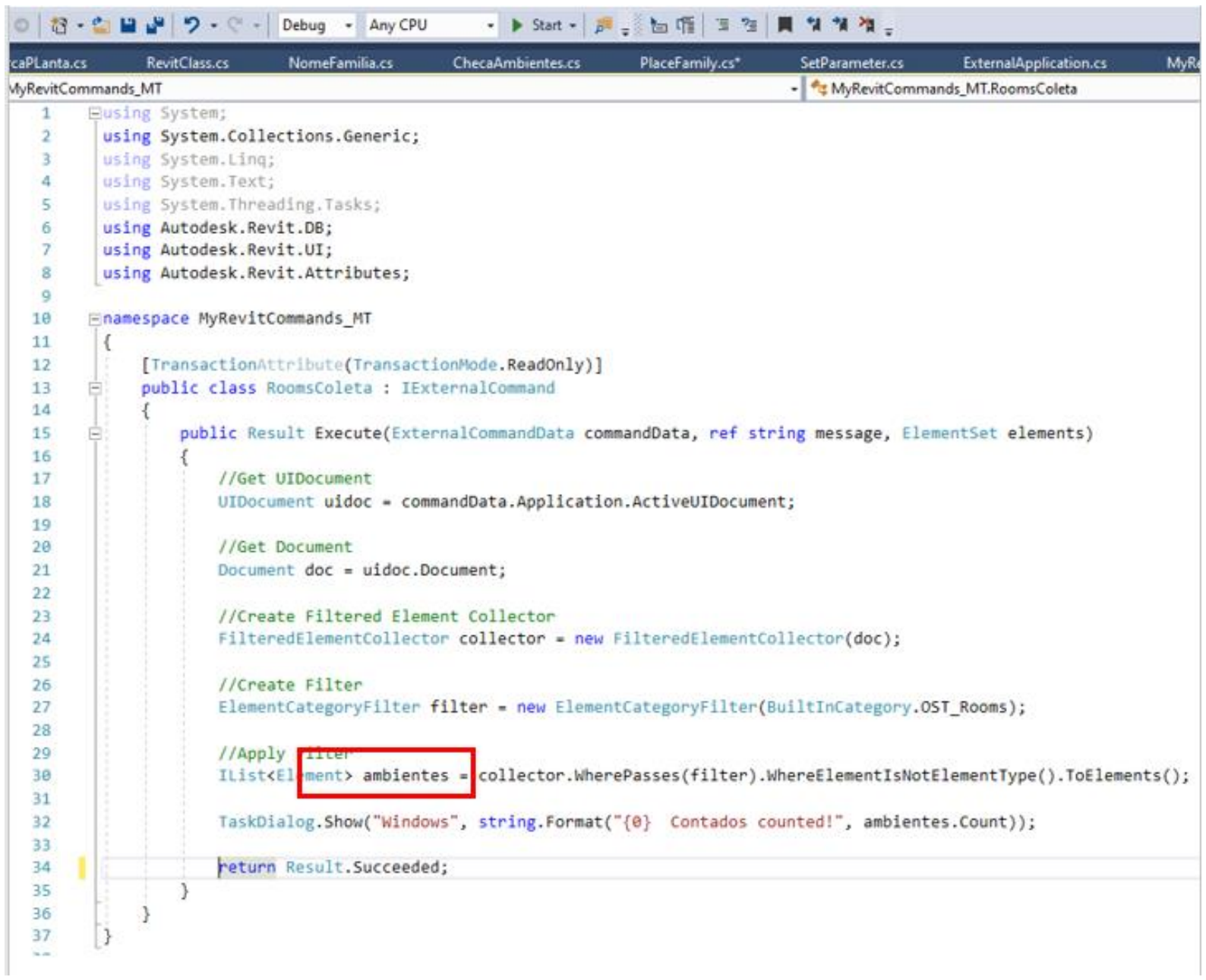

Fonte: Elaborado pelo autor

Para ampliar as funções de verificação e tornar o sistema mais robusto e adequável a diferentes contextos, explorou-se a possibilidade de conexão com uma base de dados SQL para inserir dados restritivos ao banco de dados. Neste caso, o Visual Studio fez a interface com a base de dados de forma a adicionar e gerir regras que não se aplicam exclusivamente a um município. Foram criadas janelas para a entrada de dados de mais de um município de forma a permitir que opções de restrições especificadas em uma base de dados sejam inseridas, selecionadas e imputadas (Figura 87). Assim o usuário pode selecionar as regras de qual o município que a conformidade do projeto será avaliada. Essa base também permite que diferentes projetos sejam analisados e que as informações que faltam a respeito dos ambientes daquele projeto sejam automaticamente completadas. 
Figura 87 - Base de dados SQL - Janela de entrada de dados

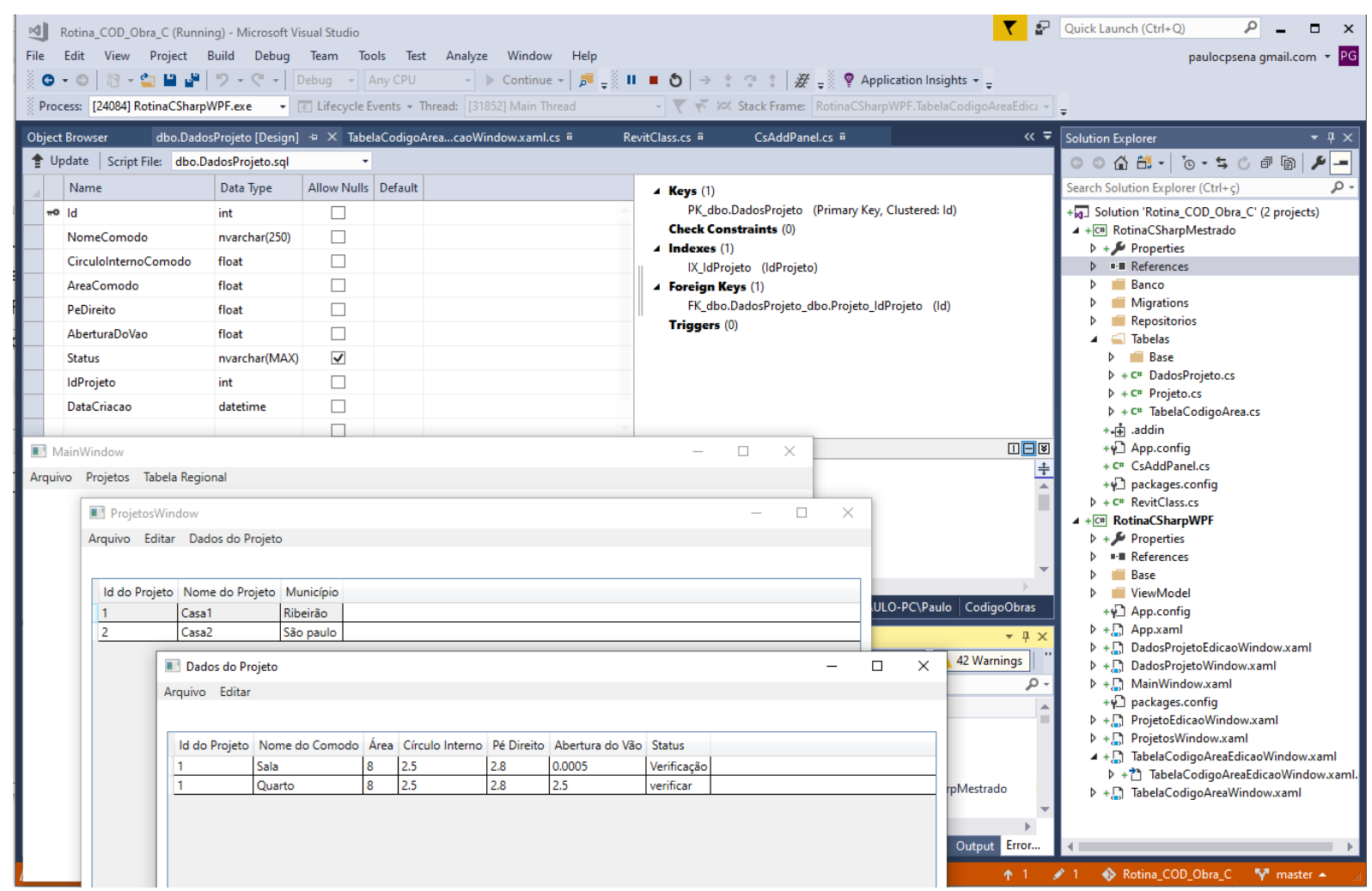

Fonte: Elaborado pelo autor

Cabe observar que, no caso específico da ampliação de funções de verificação realizadas complementarmente, não foi possível concluir a comunicação do plugin com o Revit. Por se tratar de um programa mais complexo, a conclusão de um arquivo executável não é uma tarefa trivial, tornando-se inviável no tempo e escopo desta pesquisa. Todavia, o intuito de experimentar as possibilidades de expansão que o ambiente de programação mais robusto associado a linguagem orientada ao objeto, como é o C\#, foi realizado com sucesso.

Durante o experimento foram observadas dificuldades associadas à curva de aprendizado do pesquisador em escrever um plugin em C\# usando a API do Revit, muitas das quais ligadas a lógica da programação orientada a objetos, a sintaxe de escrita dos códigos, bem como a grande quantidade de comandos disponíveis através de suas classes, métodos e propriedades, que são disponibilizadas para que o programador possa acessar os exatos elementos do Revit e seus parâmetros.

Por fim, cabe observar que, embora os plugins feitos para o Revit em linguagem C\# possam alcançar níveis de sofisticação e robustez maior, é preciso ficar atento a 
necessidade de atualização do plugin em função de mudanças de versão do software e Framework da IDE ou de outras alterações de propriedades que a desenvolvedora do software possa eventualmente implementar. Este alerta é importante tanto para os plugins desenvolvidos com o objetivo de serem comercializados ou disponibilizados na loja virtual da Autodesk, como plugins desenvolvidos internamente, para atender as necessidades de uma determinada empresa, pois implicam em um serviço complementar à criação do plugin, de gerenciamento de atualizações.

\subsection{CONSIDERAÇÕES SOBRE O USO DO C\# PARA AUTOMAÇÃO}

Levando em consideração os aspectos abordados nos dois estudos de exploratórios e a rotina experimental feito para analisar as possibilidades de automação com a programação em C\#, pôde-se observar que a linguagem apresenta características a serem explorada além daquelas definidas nos objetivos do trabalho, isso é, de entender o potencial de uso de programação para a automação em Revit por parte de profissionais de AEC. Como é uma linguagem orientada ao objeto, o C\# apresenta uma forma específica de pensar a programação que demanda um conhecimento profissional e especializado em ciência da computação. Certamente, este é um desafio para o setor, o de preparar profissionais que dominem suficientemente tanto as habilidades esperadas para o trabalho em AEC quanto em computação orientada a objetos.

No decorrer da pesquisa foram contatados profissionais com experiência em desenvolvimento de sistemas, mas estes apresentaram dificuldades para desenvolver rotinas em C\# aplicadas a área de AEC, para responder às demandas de automação de projetos modelados no Revit. Estes profissionais, embora dominassem a programação em C\# para criar executáveis, não tinham familiaridade com a API da Autodesk, nem com muitas das especificidades ligadas à $A E C$ que o Revit apresenta. Em razão desta lacuna de conhecimento, o entendimento sobre o problema e a comunicação com os profissionais a quem o software se destina são consideravelmente limitados.

No caso da rotina experimental, a programação foi realizada por um profissional de AEC, o pesquisador, que ao longo de sua carreira profissional desenvolveu suas 
habilidades como programador para atender a demandas de trabalho ligadas ao projeto. Desta forma, o conhecimento sobre ciência da computação foi apreendido de forma empírica, e não sistemática, como um profissional de programação apresentaria. Todavia, embora as dificuldades desse campo que foram observadas durante o estudo tenham sido superadas, alguns aspectos da criação da rotina não puderam ser analisados adequadamente. Por exemplo, um problema de erro na execução da rotina de checagem do código de obras observado em um computador específico não ocorreu quando testado em outras máquinas. O problema poderia ter relação com uma falha de instalação ou de atualização do SDK do Revit, porém o não funcionamento não pode ser devidamente esclarecido.

Existem, ainda, problemas de interoperabilidade entre os nomes de parâmetro encontrados no C\# e no Revit. Por exemplo: numa parede a altura superior é chamada de Top Constraint, quando acessamos suas propriedades via interface do usuário. Mas para acessar esse parâmetro via programação em C\# devemos usar WALL_HEIGHT_TYPE. Esta diferença dificulta a construção da lógica de programação, uma vez que exige um esforço adicional para correlacionar adequadamente os nomes de classes durante a escrita da rotina. O problema é agravado frente ao volume de parâmetros a serem considerados. $O$ arquivo RevitAPI.chm do SDK do Revit abre um browser onde vinte e nove mainspaces estão listados, cada um contendo dezenas de classes que, por sua vez, possuem seus atributos e métodos típicos do C\#. O Revit, por sua vez é um poderoso programa de gerenciamento de banco de dados que apresenta muitos comandos específicos, necessários para interagir com esses dados, o que torna a busca por uma determinada função, por meio de comandos com C\#, mais complicada que a interface gráfica do Revit sugere.

Um outro aspecto que foi levantado sobre a questão da programação orientada a objetos é que, apesar de ser um conceito muito poderoso, pode se tornar demasiadamente abstrato e de difícil leitura do código. Por exemplo, na programação de uma linha de comando em C\# que atribui à variável symbol uma determinada condição, temos várias classes encadeadas, que por sua vez evocam diferentes métodos. Neste exemplo, este código ainda utiliza uma função lambda para atingir o fim proposto, o que acaba por elevar o grau de complexidade da linha de código, 
dificultando seu entendimento. O resultado da linha de código finalizada para este exemplo é demonstrado abaixo. Para profissionais com experiência em ciência da computação este método apresenta vantagens e pode ser entendido com maior clareza, mas profissionais iniciantes na programação terão maiores dificuldades na compreensão da linguagem.

FamilySymbol. symbol=collector. OfClass (typeof(FamilySymbol)). WhereElementIsElemen tType().Cast<FamilySymbol>().First $(x=x$. Name $==$ "Area insuficiente");

Percebe-se que a linguagem C\# é a mais aderente à API do Revit, no sentido de fazer uma comunicação direta com o software tornando o plugin mais rápido do que se for usada uma linguagem como o Python e, muitas vezes, mais rápido do que se for usado o Dynamo. Isso pode não apresentar problemas em rotinas que envolvem um modelo pequeno, mas é um importante diferencial quando lidamos com milhares de elementos em um único modelo. É possível também constatar que a criação de plugins complexos com o uso da linguagem $\mathrm{C \#}$ é mais eficiente, pois o acesso às inúmeras classes e métodos que estão disponíveis para os usuários fazem com que se consiga ter uma interação com o banco de dados do Revit de forma quase nativa. Esta pode ser a melhor opção para aqueles que querem desenvolver plugins profissionais e com alta confiabilidade de funcionamento depois dos devidos testes e a dll disposta para ser usada.

Concluímos ressaltando que o aprendizado do uso da linguagem C\# para desenvolvimento de API's no Revit pode requerer um tempo considerável. Apesar das dificuldades encontradas ao longo do processo de estudos a linguagem $\mathrm{C \#}$ é moderna, totalmente voltada a orientação a objetos, pode ser facilmente documentada, códigos podem ser reutilizados, tem facilidade com relação a digitação, além de ser uma linguagem inteligente a qual propõe soluções para o usuário à medida que o código vai sendo escrito. Depois de um esforço inicial de aprendizado pode trazer um grande benefício para aqueles que querem desenvolver plugins profissionais. 


\section{CAPÍTULO 6 CONCLUSÃO}


O potencial identificado na revisão da literatura de aplicação da programação para promover a automação em processos de projeto de AEC baseados em BIM, pôde ser constatado a partir dos seis estudos exploratórios analisados e das três rotinas experimentais realizados para a dissertação em linguagens Dynamo, Python e C\#.

As premissas que subsidiaram o desenvolvimento dos estudos empíricos abrangeram conceitos ligados à automação, projetos auxiliados por computação, BIM, modelos paramétricos, algoritmos e pensamento computacional, características da linguagem de programação visual, características de programação orientada a objetos, fontes de referência para estudos e aprendizado das linguagens Dynamo, Python e C\#. Com este arcabouço teórico, pretendeu-se delimitar um referencial suficiente para orientar projetistas e colaboradores a adotarem boas práticas de automação no processo de projeto, evitando tarefas repetitivas e onerosas.

Além de uma descrição dos principais blocos de comando do Dynamo, os conceitos básicos para a escrita de códigos e uso de programação Python, descritos por Woodbury (2010a), foram sintetizados para orientar a programação visando extrair informações úteis do banco de dados de um projeto BIM para alcançar um determinado propósito, como automatizar processos ou checar premissas de projetos que deveriam ser cumpridas. Também foram explicados os princípios da linguagem orientada a objeto e, mais especificamente, o C\#, bem como os meios de utilização desta linguagem para programar por meio de IDE. Todos os textos introdutórios a cada linguagem, apresentados na seção inicial de cada capítulo, foram apresentados de modo a subsidiar a compreensão dos estudos exploratórios e das rotinas experimentais para exemplificar na prática quais são os pontos fortes e fracos de cada linguagem e qual é a dificuldade de execução por um usuário de AEC.

As conclusões apresentam uma análise comparativa das experiências com cada linguagem, sintetizando os achados apresentados em cada capítulo. As informações sobre cada linguagem de programação estudada foram compiladas em duas matrizes, apresentadas no Quadro 10 e Quadro 11, que ao todo consideram vinte e nove critérios inter-relacionados, porém com focos específicos ligados à linguagem e a seu usuário. 
A matriz que compara especificamente as características das linguagens de programação analisadas é apresentada no Quadro 10, empregando uma métrica relacional, arbitrada pelo pesquisador, que estabelece se a linguagem testada apresenta um nível de adequação baixo, médio ou alto para determinadas atribuições de automação em Revit. Já a matriz de comparação entre as características das linguagens de programação com relação ao usuário, apresentada no Quadro 11, mostra as habilidades que devem ser apresentadas (ou aprendidas) pelo projetista para que possa realizar determinadas tarefas centrais da automação, por meio de programação, bem como seus atributos e níveis de entendimento. Nesse caso, as métricas adotadas fazem referência ao nível de programação que o profissional de AEC deve apresentar, em uma escala entre básico, intermediário, avançado e nível de desenvolvedor de software, quando se sugere uma dupla formação profissional, ligada à AEC e à alguma formação da ciência da computação.

\subsection{Considerações sobre a análise comparativa entre as linguagens de programação}

A comparação realizada das características observadas entre as linguagens de programação que foram analisadas a partir dos estudos feitos nessa pesquisa considerou dezesseis itens que expressam a adequação de cada linguagem à automação de operações do Revit por meio de programação. Entre os itens apresentados no Quadro 10 foram relacionados aspectos ligados às linguagens analisadas e o software, ao perfil da organização de projeto e a ao desempenho na realização de scripts para usos específicos, relevantes para a automação, tais como debugging, manipulação de listas, adequação à automação de formas complexas, dentre outras.

A partir dos resultados, pode-se orientar o uso da programação em Dynamo para aqueles que não apresentam um alto nível de entendimento de programação e pensamento voltado à computação, nem pretendem desenvolver tal competência. Esta linguagem é adequada para introduzir a automação ao processo de projeto, uma vez que oferece uma forma mais rápida e menos complexa de aplicação das rotinas quando comparada às duas outras linguagens, uma vez que os processos no Dynamo são basicamente lineares. 
Quadro 10 - Comparação entre características das linguagens de programação analisadas

\begin{tabular}{|c|c|c|c|}
\hline Critérios de avaliação & Dynamo & Python & C\# \\
\hline \multicolumn{4}{|c|}{ Aderência da linguagem a grade curricular de matérias no ensino de arquitetura } \\
\hline \multicolumn{4}{|l|}{ Facilidade de uso } \\
\hline \multicolumn{4}{|l|}{ Confiabilidade } \\
\hline \multicolumn{4}{|l|}{ Simplicidade para definir tipos de variáveis } \\
\hline \multicolumn{4}{|l|}{ Uso por empresas de pequeno e médio porte } \\
\hline \multicolumn{4}{|l|}{ Uso por empresas de grande porte } \\
\hline Recursividade & $\mathrm{x}$ & & \\
\hline Tipo de estrutura da linguagem é visual & & $\mathrm{x}$ & $\mathrm{x}$ \\
\hline \multicolumn{4}{|c|}{ Tipo de estrutura da linguagem é orientada a objeto } \\
\hline \multicolumn{4}{|l|}{ Manipulação de listas } \\
\hline Recursos de debugging & $\mathrm{x}$ & & \\
\hline \multicolumn{4}{|l|}{ Facilidade para manutenção do código } \\
\hline \multicolumn{4}{|l|}{ Facilidade para a documentação do código } \\
\hline \multicolumn{4}{|l|}{ Interação com a API do Revit } \\
\hline \multicolumn{4}{|l|}{ Automatizar formas complexas } \\
\hline Artigos científicos que abordam a linguagem & $\mathrm{x}$ & & \\
\hline
\end{tabular}

\begin{tabular}{|l|c|}
\hline Nível de adequação & Legenda \\
\hline Baixa & \\
\hline Moderada & \\
\hline Alta & \\
\hline Não verificada & $\times$ \\
\hline
\end{tabular}

Fonte: Elaborado pelo autor

Outra característica relacionada a esta linguagem visual é o grande número de tutoriais que podem ser utilizados para aumentar os conhecimentos de programação com Dynamo. Eles permitem que o usuário aprenda sozinho a melhorar as rotinas de automação existentes, adequando-as às suas necessidades sem deter um conhecimento mais profundo de programação.

Dentre as características da linguagem Python, destaca-se o nível de recursividade que apresenta. Este recurso pode ser explorado com economia considerável de trabalho de programação e projeto. Embora a linguagem seja de fácil aprendizado, sua utilização demanda o domínio de conceitos de pensamento algorítmico. Por ocasião do trabalho de revisão bibliográfica, observou-se o uso cada vez mais recorrente de pequenos scripts, usando a linguagem Python por meio de um nó Dynamo específico que permite esta inserção. Outra característica observada e destacada no Quadro 10, a respeito da linguagem Python é que esta apresenta capacidade de interação com o Revit superior a do Dynamo. Esta capacidade de comunicação ampliada é possível por meio de um ambiente de programação voltado à escrita de scripts de códigos, apresentada nos estudos 2.2.1 e 2.2.2. 
O C\# é uma linguagem poderosa e tem uma forte aderência à API do Revit sendo que, para o uso desta, são necessários pré-requisitos para dominar os conceitos sobre orientação a objetos, lógica de programação, entendimento de classes, métodos e consoles de programação, como o IDE do Visual Studio. Por esta razão, o Quadro 10 sugere que a linguagem C\# pode ser utilizada por grandes empresas, que possuem condições de arcar com uma maior curva de aprendizagem para se beneficiar dos níveis de confiabilidade mais alta de funcionamento da programação.

Por ser uma linguagem robusta, o C\# é uma linguagem apropriada para o desenvolvimento e disponibilização de plugins comerciais do Revit. Entre os fatores que reforçam esta característica, destaca-se a possibilidade de dividir uma programação C\# em pastas e subpastas que são compreendidas pelo IDE do visual Studio como abas de comandos de um Ribbon específico, adicionado ao Revit. É fato que tal organização de comandos também pode ser feita no Python mas a interação entre as classes e métodos no C\# são otimizadas, já que se pode utilizar simultaneamente várias classes, que passam a ser disponibilizadas em uma única solução.

\subsection{Considerações sobre a análise comparativa sobre as habilidades de programação}

O Quadro 11 apresenta um conjunto de itens para avaliação das condições de automação por meio das linguagens estudadas, tendo como foco a habilidade de programação que o profissional de AEC deve apresentar. Para cada critério analisado sobre as três linguagens foi atribuído um nível de domínio, que pode ser básico, intermediário, avançado ou mesmo equivalente ao nível de um desenvolvedor de software. Alguns itens avaliados fazem referência à capacidade de utilizar, criar e atualizar scripts, outros abordam aspectos não operacionais, mas igualmente relevantes, para determinar o aproveitamento dos recursos disponíveis para automatização de processos em cada uma das linguagens, identificado por meio do nível de entendimento do raciocínio de programação que o profissional de AEC deve possuir ou aprender. 
Quadro 11 - Comparação entre as características das linguagens de programação com relação ao usuário

\begin{tabular}{|l|l|l|l|}
\hline Critérios de avaliação & Dynamo & Python & C\# \\
\hline Usar código existente para automatizar projeto & & & \\
\hline Criar código para automatizar projeto & & & \\
\hline Disponibilizar comercialmente código para automatizar projeto & & & $\mathrm{x}$ \\
\hline Raciocínio em computaç̃o & & & $\mathrm{x}$ \\
\hline Compreender linguagem orientada a objeto & & & $\mathrm{x}$ \\
\hline Explorar recursos de recursividade & & & \\
\hline Manipular as variáveis de modelos no Revit & & & \\
\hline Dominar manipulação de listas & & & \\
\hline Entender o processo de Debugging de um código & & & \\
\hline Interação com a API do Revit & & & $\mathrm{x}$ \\
\hline Formas complexas & & & $\mathrm{x}$ \\
\hline Gerar documentação do código desenvolvido & & & $\mathrm{x}$ \\
\hline Atualizar código desenvolvido & & & $\mathrm{x}$ \\
\hline
\end{tabular}

\begin{tabular}{|l|c|}
\hline Nível de programação & Legenda \\
\hline Básica & \\
\hline Intermediário & \\
\hline Avançado & $\times$ \\
\hline Desenvolvedor de software & \\
\hline
\end{tabular}

Fonte: Elaborado pelo autor

Com base nos dados levantados, conclui-se que a programação em Dynamo é a opção mais adequada para profissionais que não possuem um nível de entendimento de programação intermediário ou avançado (Quadro 11). De fato, o Dynamo é uma opção mais adequada para começar a trabalhar com a automação de forma rápida e menor complexidade para a aplicação de rotinas. Essa adequação à utilização "de entrada" está vinculada ao fato desta linguagem de programação ser orientada para VPL, o que oferece um entendimento rápido e fácil, mesmo para quem possui pouca experiência com programação.

Por causa da maior facilidade de aprendizado, observa-se uma difusão maior da linguagem entre profissionais de AEC e, principalmente, no ambiente acadêmico. Outra razão para esta predileção decorre do fato de o Dynamo oferecer bons recursos para a criação de formas complexas, sendo possível utilizá-lo para o trabalho com arquitetura generativa, inclusive, com vantagem frente às demais linguagens. Devese ter cuidado com as formas de documentar rotinas feitas em Dynamo pois, como a programação não é escrita linearmente mas desenvolvida por meio da conexão de 
nós, depois de programada pode ser difícil encontrar o raciocínio feito para a elaboração da rotina. Mesmo durante a programação, caso não haja disciplina para a organização de programação muito extensa, pode ser difícil compreender e editar as relações existentes na rotina.

Em relação à linguagem Python, pode-se observar que o nível de domínio de programação esperado do profissional é maior, predominantemente intermediário ou avançado (Quadro 11). Isso se deve à dificuldade da linguagem, usada profissionalmente para o desenvolvimento de aplicativos e soluções baseadas em inteligência artificial. Estas características a aproximam menos à linguagem Dynamo e mais à C\#. Quando comparado ao C\#, o Python apresenta uma interface mais amigável, principalmente se for utilizada com o Python Shell e o PyRevit como console e base de desenvolvimento para novas rotinas. Outro aspecto que caracteriza a linguagem Python como sendo intermediária está vinculado à familiaridade que o usuário de Dynamo mais experiente já detém em decorrência do nó Python, que permite embutir pequenos scripts na programação em Dynamo. Esta condição coloca a linguagem como a segunda mais utilizada por profissionais e acadêmicos de AEC.

A C\# é uma linguagem que requer conhecimento avançado sobre programação orientada a objetos. Trata-se de uma forma de estruturar o código, que exige grande capacidade de abstração, tornando-se pouco acessível ao uso por profissionais pouco familiarizados a esta lógica de programação. Por esta razão, a maioria de seus usuários tem nível equivalente ao de um "desenvolvedor de software" e, em menor número, são programadores de nível avançado ou intermediário (Quadro 11).

A partir desse grau de profissionalismo, ele sugere a colaboração entre profissionais de AEC e profissionais especialistas em computação para desenvolver procedimentos mais sofisticados de automação em Revit. A necessidade de colaboração decorre do fato de que, se por um lado profissionais de AEC dificilmente apresentarão competências avançadas para explorar os recursos mais avançados do C\#, por outro lado os programadores profissionais possuem pouca familiaridade com modelagem e parâmetros do Revit. 


\subsection{Considerações gerais}

Percebe-se que todas as linguagens abordadas nesta pesquisa possuem relevância no cenário da automação, uma vez que são demandados diferentes níveis de complexidade de programação para casos específicos nos projetos de AEC. Os diferentes objetivos para tanto abrangem a perspectiva de promover a otimização de determinados arranjos, a obtenção de formas complexas, a redução de trabalhos repetitivos operados pelos profissionais envolvidos, dentre outros.

Para o aprendizado, grande parte das possibilidades de automatização de processos pode ser realizada apenas com o uso de Dynamo. Como é uma linguagem mais acessível, com uma interface visual mais amigável, o uso por projetistas que desejem aprender a programar é recomendado, cabendo mesmo iniciar o domínio do Python para programar pequenos scripts por meio do nó Python. Esta abordagem prepara o projetista para explorar níveis mais avançados de programação. A partir do conhecimento obtido com o nó Python, o profissional de AEC estará apto a utilizar classes de objetos com scripts executados diretamente em Python, disponíveis por meio da API do Revit e com a instalação do SDK da Autodesk.

A linguagem C\# não é exatamente uma abordagem concorrente para a linguagem Python, ambas podem ser consideradas como linguagens alternativas $e$ complementares, adequadas a diferentes cenários. A experiência de desenvolvimento dos estudos mostrou, por exemplo, a possibilidade de desenvolver e testar as premissas de um determinado algoritmo em linguagem Python para, em seguida, implementá-lo, utilizando os recursos de integração mais robustos que o Revit disponibiliza para a C\#.

A disponibilidade de recursos de automação por meio das três linguagens oferecidas pela Autodesk no Revit indica um reconhecimento por parte da empresa de software da necessidade de oferecer maior autonomia para que usuários possam desenvolver soluções adequadas a situações particulares de seu trabalho. Os estudo sugerem que tais recursos oferecem um meio poderoso de promover níveis de maior eficiência e eficácia no setor. 


\subsection{Sugestões para futuras pesquisas}

Embora tenha-se reconhecido na presente pesquisa que a possibilidade de utilizar as linguagens apresentadas seja uma oportunidade valiosa para automação de projetos, cabe observar que a realização deste intento envolve outras questões que não foram foco desta dissertação, mas merecem uma maior reflexão.

São pontos de convergência a serem explorados que envolvem questões, tais como: Quanto um projetista de AEC deve saber sobre programação? É preciso preparar arquitetos para a indústria 4.0? Se sim, como? O currículo de graduação e pós-graduação deve conter matérias sobre lógica de programação ou esta é uma formação a ser adquirida fora das universidades? Qual métrica podemos usar ao medir os esforços para a criação de rotinas e plugins que automatizem processos? Como podemos medir exatamente os benefícios de um determinado plugin para avaliarmos em que medida a automação de processo compensa o esforço aplicado à sua elaboração?

Outro campo a ser observado é a Inteligência Artificial, que já é utilizada em várias aplicações do nosso cotidiano. Recentemente tem sido discutida em AEC, por exemplo, com o uso de algoritmos generativos que trabalham com formas geométricas. O uso de machine learning e internet das coisas oferece perspectivas ainda pouco exploradas, que potencialmente podem causar um grande impacto na indústria da construção a partir da possibilidade de interação de informações que estarão disponíveis em bancos de dados e as soluções baseadas em otimização de projetos que já são executadas. 


\section{REFERÊNCIAS}

ABDI. Classificação da Informação no BIMColetânea Guias BIM ABDI-

MDICBrasíliaABDI, , 2017.

ABNT. NBR 15.575-1: Edifícios habitacionais: Desempenho. Parte 1: Requisitos

Gerais. Rio de Janeiro: ABNT, 2013.

ABNT. NBR 9050: acessibilidade a edificações, mobiliário, espaços e equipamentos urbanos. 3. ed. Rio de Janeiro: ABNT, 2015.

ABRISHAMI, S. et al. Virtual generative BIM workspace for maximising AEC conceptual design innovation. Construction Innovation, v. 15, n. 1, p. 24-41, 2015.

ALHADIDI, S.; KIMM, G. Computation Design in Revit : Build Complex Forms Using Dyanamo. Revit Techology Conference Australasia. Anais...Sydney: RTC, 2014

AMANN, S. et al. A Study of Visual Studio Usage in Practice. 2016 IEEE 23rd International Conference on Software Analysis, Evolution, and Reengineering (SANER). Anais...Suita: IEEE, 2016Disponível em: <https://ieeexplore.ieee.org/document/7476636>

ARCHER, T. Inside C \#. 2. ed. Washington: Microsoft Press, 2002.

ASCENCIO, A. F. G.; CAMPOS, E. A. V. DE. Fundamentos da Programação de Computadores.pdf. São Paulo: Pearson Education do Brasil, 2006.

AUTODESK. Help: Get Started. Disponível em:

<http://help.autodesk.com/view/RVT/2018/ENU/?guid=GUID-C3DEF8F6-A9C0-496E-A5548147B12A4EDA>. Acesso em: 11 set. 2019a.

AUTODESK. Componentes adaptativos | Produtos Revit 2019 | Autodesk Knowledge Network. Disponível em: <https://knowledge.autodesk.com/pt-br/support/revitproducts/learn-explore/caas/CloudHelp/cloudhelp/2019/PTB/Revit-Model/files/GUID6E0ECA27-AF40-4B1D-9E0B-1DE5FBBD45F2-htm.html>. Acesso em: 11 set. 2019b.

AUTODESK. Revit Developer Center. Disponível em:

<https://www.autodesk.com/developer-network/platform-technologies/revit>. Acesso em: 12 set. 2019c. 
AUTODESK. Guia do Usuário: Revit Architecture 2011, 2010.

AUTODESK. Revit 2014 Platform API Developers Guidelines. 2014.

AUTODESK. DesignScript Language Summary. Disponível em:

<http://designscript.io/DesignScript_user_manual_0.1.pdf>. Acesso em: 5 jun. 2019.

AUTODESK. The Dynamo Primer - Guide. Disponível em:

$<$ https://primer.dynamobim.org/en/Appendix/DynamoPrimer-Print.pdf>. Acesso em: 12 jul. 2019.

BENTLEY, D.; ELDRIDGE, D. SFDUG Sept 2017 | Beginner's Guide to Python for Dynamo Users - YouTube. Disponível em:

<https://www.youtube.com/watch?v=2e6tKofKsSo>. Acesso em: 22 maio. 2019.

BILINA, R.; LAWFORD, S. Python for Unified Research in Econometrics and Statistics.

Econometric Reviews, v. 31, n. 5, p. 558-591, 2012.

BIM SERVICES INDIA. BIM Coordination Services. Disponível em:

<https://www.bimservicesindia.com/bim-coordination-services.php>. Acesso em: 12 set. 2019.

BUENO, C.; PEREIRA, L. M.; FABRICIO, M. M. Life cycle assessment and environmentalbased choices at the early design stages: an application using building information modelling. Architectural Engineering and Design Management, v. 14, n. 5, p. 332-346, 2018.

CAELUM. C\# e Orientação a Objetos. Disponível em: <www.caelum.com.br/apostilas>. Acesso em: 3 ago. 2019.

CELANI, M. G.; VAZ, C. E. Scripts em CAD e ambientes de programação visual para modelagem paramétrica: uma comparação do ponto de vista pedagógico. Proarq, v. 18, p. 177-194, 2011.

CHALINE, E. 50 Máquinas que Mudaram o Rumo da História. Rio de Janeiro: [s.n.].

COELHO, P. M. N. Rumo à Indústria 4.0. [s.I.] Universidade de Coimbra, 2016.

Components of .Net Framework, CLR, CTS, CLS, Base Class Library. Disponível em: <http://www.developerin.net/a/39-Intro-to-.Net-FrameWork/23-Components-of-.NetFramework>. Acesso em: 28 jul. 2019. 
DAVIS, D. Modelled on Software Engineering: Flexible Parametric Models in the Practice of Architecture. RMIT University, n. February, p. 243, 2013.

DEITEL, H. M. et al. Python How to Program. Book, p. 1103, 2002.

DEITEL, H. M. et al. C\# Como Programa. São Paulo: Pearson Education do Brasil, 2003a. V. ثقنق

DEITEL, H. M. et al. C\# como programar. São paulo: Pearson education do Brasil Ltda, 2003b.

DOWNEY, A. Think Python. Needham: Green Tea Press, 2012.

DYNAMO. Download | Dynamo BIM. Disponível em: <https://dynamobim.org/download/>. Acesso em: 11 set. 2019a.

DYNAMO. Fórum Dynamo. Disponível em: <https://forum.dynamobim.com/>. Acesso em: 11 set. $2019 b$.

DYNAMO. About | The Dynamo Primer. Disponível em: <https://primer.dynamobim.org/>. Acesso em: 11 set. $2019 \mathrm{c}$.

DYNAMO. Dynamo Packages. Disponível em: <https://dynamopackages.com/>. Acesso em: 12 set. $2019 d$.

EASTMAN, C. et al. Automatic rule-based checking of building designs. Automation in Construction, v. 18, n. 8, p. 1011-1033, 2009.

EASTMAN, C. et al. BIM Handbook: A guide to Building Information Modeling for owners, managers, designers, engineers and contractors. [s.l: s.n.]. v. 12

EASTMAN, C. et al. Manual de BIM - Um Guia de Modelagem da Informação da construção para arquitetos, engenheiros, gerentes, construtores e incorporadores. $1^{\mathrm{a}}$ ed. Porto Alegre: Bookman, 2014.

EASTMAN, P. C. M. et al. 2011 Charles M . Eastman Top Phd Paper Award Information Delivery Manuals To Integrate Building. 2011.

EHSAN IRAN-NEJAD. What's pyRevit. Disponível em: $<$ https://ein.sh/pyRevit/whatspyrevit/>. Acesso em: 20 jul. 2019.

FERREIRA, R. C.; SANTOS, E. T. Características Da Representação 2D E Suas Limitações 
Na Etapa De Compatibilização Espacial Do Projeto. Gestão \& Tecnologia de Projetos, v. 2, n. n. 2, p. 36-52, 2007.

FURNEAUX, C.; KIVVITS., R. BIM - Implications for Government. Construction Innovation, n. 5, p. 1-43, 2008.

GRAHAM, J. Pushing Revit to the Next Level: An Intro to Revit Plugins with C\# | Autodesk University. Disponível em: <https://www.autodesk.com/autodeskuniversity/class/Pushing-Revit-Next-Level-Intro-Revit-Plugins-C2018?linkld=70539564\#video>. Acesso em: 19 ago. 2019.

GSA. GSA Building Information Modeling Guide Overview - Series 01. Disponível em: <http://www.gsa.gov/graphics/pbs/GSA_BIM_Guide_v0_60_Series01_Overview_05_14_07. pdf>. Acesso em: 19 ago. 2019.

IGNATOVA, E.; ZOTKIN, S.; ZOTKINA, I. The extraction and processing of BIM data. IOP Conference Series: Materials Science and Engineering, v. 365, n. 6, 2018.

JOKLOVA, V.; BUDREYKO, E. Digital Technologies in Architectural Design, Verification and Representation. 2019 International Conference on Engineering Technologies and Computer Science (EnT). Anais...Moscow: IEEE, 2019

$\mathrm{KIM}, \mathrm{H}$. et al. Visual language approach to representing KBimCode-based Korea building code sentences for automated rule checking. Journal of Computational Design and Engineering, v. 6, n. 2, p. 143-148, 2019.

KIM, H. W. Enjoy Revit: Examples for All List Actions in DYNAMO. Disponível em: <http://plevit1.blogspot.com/2015/01/examples-for-all-list-actions-in-dynamo.html>. Acesso em: 25 maio. 2019.

KLEINSMANN, M.; VALKENBURG, R. Barriers and enablers for creating shared understanding in co-design projects. Design Studies, v. 29, n. 4, p. 369-386, 2008.

KOWALTOWSKI, D. C. C. K. et al. O processo de projeto em arquitetura da teoria a tecnologia. $2^{\circ}$ Reimpre ed. São Paulo: Editora Oficina de Textos, 2011.

$L A B I B, R$. Is computer programming beneficial to architects and architecture students for complex modeling and informed performative design decisions? Proceedings of the 12th Advanced Building Skins. Anais...Lucerne: Advanced Building Skins, 2017

LI, X. AT AL. 2017. Mapping the knowledge domains of Building Information Modeling (BIM): 
A bibliometric approach. Automation in Construction, v. 84, n. September, p. 195-206, 2017.

MICROSOFT. Free IDE and Developer Tools | Visual Studio Community. Disponível em: $<$ https://visualstudio.microsoft.com/vs/community/>. Acesso em: 12 set. 2019.

MICROSOFT. Visão geral do Visual Studio. Disponível em: <https://docs.microsoft.com/ptbr/visualstudio/get-started/visual-studio-ide?view=vs-2019>. Acesso em: 31 jul. 2019.

MILLER, C. et al. BIM-extracted EnergyPlus Model Calibration for Retrofit Analysis of a Historically Listed Building in Switzerland. ASHRAE/IBPSA-USA Building Simulation Conference. Anais...Atlanta, GA: 2014

MODELICAL. WallFinishesByRoom - Automatic modeling of finishes - Modelical.

Disponível em: <https://www.modelical.com/en/node/wall-finishes-by-room/>. Acesso em: 30 maio. 2019.

MONOLITO NIMBUS. Orientação a objeto no python e IDL. Disponível em:

<https://www.monolitonimbus.com.br/orientacao-a-objeto-no-idl/>. Acesso em: 12 set. 2019.

MORAIS, M. DE; GRANJA, A. D.; RUSCHEL, R. C. Restrições Orçamentárias e Entrega de Valor: Sinergias entre BIM e custeio-meta. Gestão \& Tecnologia de Projetos, v. 10, n. 1, p. 7-27, ago. 2015.

NAKOV, S. et al. Fundamentals of Computer Programming with C\# (The Bulgarian C\# Programming Book). Sofia: Telerik Software Academy, 2013.

NAWARI, N. O. Automating Codes Conformance. Journal of Architectural Engineering, v. 18, n. 4, p. 315-323, 2012.

NGUYEN, T. H.; KIM, J. L. Building Code Compliance Checking Using BIM Technology. Winter Simulation Conference. Anais...Phoenix: IEEE, 2011

NOTEPAD++. Notepad++ v7.7.1 - Current Version. Disponível em: <https://notepad-plusplus.org/download/v7.7.1.html>. Acesso em: 12 set. 2019.

OLOFSSON, T.; LEE, G.; EASTMAN, C. Editorial - Case studies of BIM in use. ITcon: Journal of Information Technology in Construction, v. 13, n. June, p. 244-245, 2008.

PEREIRA, L. M. et al. Estudo Exploratório Comparativo Da Eficácia Entre Protótipos Físico, Analítico 2D E 3D Na Identificação De Inconsistências De Projetos. Gestão \& Tecnologia 
de Projetos, v. 10, n. 1, p. 29-47, ago. 2015.

PEREIRA, L. M. et al. Aplicação do TVD assistido por BIM na fase inicial de um projeto colaborativo. ENTAC 2018 - XVII Encontro Nacional de Tecnologia do Ambiente Construído. Anais...Foz do Iguaçu: ANTAC, 2018

PEREIRA, L. M.; HIROTA, E.; FABRICIO, M. M. Implicações organizacionais da colaboração em BIM para integração do processo de projeto Design to Production Complex Shapes View projectSimpósio Brasileiro de Qualidade de Projeto no Ambiente Construído - SBQP . [s.I: s.n.].

PEREIRA, S. M. S. A.; AMORIM, S. R. L. O desenvolvimento de ferramenta de verificação de requisitos de projeto para o Revit, através de API. n. November 2014, p. 2954-2963, 2014.

PIERSON, J. New Dynamo Dictionary Nodes - YouTube. Disponível em: <https://www.youtube.com/watch?v=wSR-6nDymu0>. Acesso em: 26 maio. 2019.

PRETO, P. DE R. LEI COMPLEMENTAR Nº 2932 - DISPÕE SOBRE CÓDIGO DE OBRAS DO MUNICÍPIO, 2019.

PUGA, S.; RISSETI, G. Lógica de programação e estrutura de dados. São Paulo: Pearson Education do Brasil, 2004.

PYREVIT. pyRevit Home Page. Disponível em: <https://www.notion.so/pyRevitbd907d6292ed4ce997c46e84b6ef67a0>. Acesso em: 12 set. 2019.

PYTHON. Python.org Home Page. Disponível em: <https://www.python.org/>. Acesso em: 15 jun. 2019.

RODRIGUES, L. F.; JESUS, R. A.; SCHÜTZER, K. Indústria 4.0 - Uma Revisão da Literatura. Revista de Ciência \& Tecnologia - V.19, p. 33-45, 2016.

SCHWAB, K. The Fourth Industrial Revolution. Cologny/Geneva: World Economic Forum, 2016.

SEPEHR ABRISHAMI, L. H. et al. INTEGRATION OF BIM AND GENERATIVE DESIGN TO EXPLOIT AEC CONCEPTUAL DESIGN INNOVATION. Journal of Information Technology in Construction, v. 19, p. 351, 2014.

SGAMBELLURI, M. Practically Dynamo: Practical Uses for Dynamo within Revit. 
Disponível em: <https://www.autodesk.com/autodesk-university/class/More-PracticalDynamo-Practical-Uses-Dynamo-Within-Revit-2015>.

SÓ HISTÓRIA. Resumo - Revolução Industrial. Disponível em:

<https://www.sohistoria.com.br/resumos/revolucaoindustrial.php>. Acesso em: 12 set. 2019.

SOLIBRI. Solibri Office. Disponível em: <https://www.solibri.com/solibri-office>. Acesso em: 15 set. 2019.

SOLIHIN, W.; EASTMAN, C. Classification of rules for automated BIM rule checking development. Automation in Construction, v. 53, p. 69-82, 2015.

STORMS, C. Dynamo - Everyone's Doing It - V1 . 1 Your AU Expert : p. 1-64, 2016.

SWAROOP, C. H. A Byte of Python. Disponível em: <https://python.swaroopch.com/>. Acesso em: 5 jul. 2019.

TAMMIK, J. RevitLookup: Interactive Revit BIM database exploration tool to view and navigate element properties and relationships. Disponível em:

<https://github.com/jeremytammik/RevitLookup>. Acesso em: 12 set. 2019.

TAMMIK, J. The Building Coder: Revit Python Shell. Disponível em:

$<$ https://thebuildingcoder.typepad.com/blog/2009/12/revit-python-shell.html>. Acesso em: 14 jul. 2019.

THOMAS, D. Revit Python Shell: An IronPython scripting environment for Autodesk

Revit and Vasari. Disponível em: <https://github.com/architecture-building-

systems/revitpythonshell>. Acesso em: 14 jul. 2019.

THOMAS, H. R.; SANVIDO, V. E.; PARFITT, M. K. Conceptual Model for Measuring Productivity of Design and Engineering. Journal of Architectural Engineering, v. 1, n. 5, p. $1-7,1999$.

TIERNEY, P. DesignScript Language Manual. Disponível em:

<https://www.academia.edu/19943057/design_script_tutorials>. Acesso em: 23 jul. 2019.

VALKENBURG, A. C. The reflective practice in product design teams, 2000.

VENABLES, W. N.; SMITH, D. M. An Introduction to R. v. 1, 2019.

WILLEMS, K. Pandas Tutorial: DataFrames in Python (article) - DataCamp. Disponível em: <https://www.datacamp.com/community/tutorials/pandas-tutorial-dataframe- 
python?utm_source=adwords_ppc\&utm_campaignid=1455363063\&utm_adgroupid=650836 31748\&utm_device=c\&utm_keyword=\&utm_matchtype=b\&utm_network=g\&utm_adpostion= 1t1\&utm_creative=278443377086\&ut>. Acesso em: 27 ago. 2019.

WOODBURY, R. Elements of parametric design. Nova lorque: Routledge Taylor and Francis Group, 2010a. v. 1

WOODBURY, R. Elements of parametric design. [s.l: s.n.]. v. 1

YANG, X.; KOEHL, M.; GRUSSENMEYER, P. Mesh-to-bim: From segmented mesh elements to bim model with limited parameters. International Archives of the Photogrammetry, Remote Sensing and Spatial Information Sciences - ISPRS Archives. Anais...Riva del Garda, Itália: ISPRS, 2018a

YANG, X.; KOEHL, M.; GRUSSENMEYER, P. MESH-TO-BIM : FROM SEGMENTED MESH ELEMENTS TO BIM MODEL WITH LIMITED PARAMETERS Documentation \& Ruin Representation BIM platform Semantic model. ISPRS Annals of Photogrammetry, Remote Sensing and Spatial Information Sciences. Anais...Riva del Garda, Itália: 2018b YARMOHAMMADI, S.; CASTRO-LACOUTURE, D. Automated performance measurement for 3D building modeling decisions. Automation in Construction, v. 93, p. 91-111, 2019. 